\title{
Development of Performance Warranties for Performance Based Road Maintenance Contracts
}

\author{
by
}

\section{Mehmet Egemen Ozbek}

\author{
Thesis Submitted to the Faculty of the \\ Virginia Polytechnic Institute and State University \\ in partial fulfillment of the requirements for the degree of
}

Master of Science

in

Civil Engineering

\author{
Submitted to: \\ Dr. Jesus M. de la Garza, Chair \\ Dr. Michael C. Vorster \\ Mr. James K. Lowe, JR., P.E., ESQ.
}

April 23, 2004

Blacksburg, Virginia

Keywords: Performance Warranties, Performance Based Contracts, Road Maintenance, Highway Maintenance, Asset Management, Long Term Performance 


\title{
Development of Performance Warranties for Performance Based Road Maintenance Contracts
}

\author{
by
}

Mehmet Egemen Ozbek

Advisor: Dr. Jesus M. de la Garza

\begin{abstract}
Performance based contracting in the transportation arena is a rather recently implemented concept which has a few number of applications in the United States up to date. Nonetheless, the US Department of Transportation has vigorously promoted (by issuing memorandums to be distributed to the Highway Agencies and State Departments of Transportation) the conversion of traditional contracts to performance based contracts to reach a goal of $\mathbf{8 0} \%$ of the service contracts and actions being performance based by the end of fiscal year 2004 (Tomanelli 2003.) Virginia Department of Transportation (VDOT) has been one of the first state agencies that took the initiative of using a performance based contract for the maintenance of a portion of its interstate highway system. This initiative resulted in the establishment of the "Comprehensive Agreement for Interstate Highway Asset Management Services” between VDOT and a private contractor in 1996 which resulted in the privatization of highway maintenance services.
\end{abstract}

One of the important aspects of this contract related to this research is that it does not encompass any warranty clauses. In other words, the contractor does not provide any warranty to the VDOT for the services it is obligated to undertake. The contract is mute in this subject, making the contractor incur no liability for the underperformance of the maintenance activities. According to this research, this might lead to some cases which VDOT would not be willing to encounter. 
Just like performance based contracting, the use of warranties in highway contracts in the United States is a quite new concept which mainly dates back to 1995. There are different views possessed by different parties about the possible outcomes of implementing warranties in highway contracts. Nonetheless, this research proposes that the incorporation of warranty clauses into the VDOT issued performance based road maintenance contracts is vital to ensure the quality and durability of the work after the project completion. According to this research, warranty clauses, if developed carefully, give the contractor the motivation to implement superior maintenance practices to improve the overall conditions of the assets during the contract period. This is done in order to lengthen the life of each asset item and achieve the long term performance. Ultimately, the incorporation of warranty clauses is believed to reduce the risk imposed upon VDOT.

Within the context of the discussion presented above, this research first illustrates that the complete satisfaction of one of the parties (VDOT) may be in question due to the absence of the warranty clauses within the contract, then lists and explores the benefits that would/may be gained by the incorporation of warranty clauses into the contract, and finally develops a warranty clause template and proposes it to be used in the future performance based road maintenance contracts issued by VDOT. At the bottom line, this study aspires to help the party in question (VDOT) to reduce the risk imposed upon it and to improve the future performance based road maintenance contracts it will issue. This research uses the VDOT contract as a baseline to define the problem and to propose a solution (i.e. the developed warranty clause template) for that. Nonetheless, some of the principles and approaches used during the development of the warranty clause template can also be referred to for the development of warranty clauses for the performance based road maintenance contracts issued by the other state DOTs. 


\section{DEDICATION}

To my mom, Tulay Ozbek, and dad, Ahmet Ozbek...Without you, I would not be here. And to my grandma, Guzin Ertekin... I know that your prayers helped me a lot. 


\section{ACKNOWLEDGMENTS}

Now that I am at the point of stating my gratitude to the individuals who have contributed to this research by any means, I should spend a fair amount of time not to skip anybody. Of course, I need to start with Dr. Jesus M. de la Garza, the chairman of my advisory committee. He has been, if I may say, the true North for me throughout my studies for this research. He has guided me from the conception till the finalization of this research. I am confident that, he will also be guiding me in carrying this research to the next step in my further academic endeavors. I really appreciated our (at least) weekly meetings (in which I have gathered the notes and diagrams he had put on those "yellow paper"s) that directed me towards my goal at the times I was lost. His brilliant ideas appeared during the times I needed them most. As I told him earlier, it was truly an "honor" to be a graduate student of him.

Then come my other advisory committee members: I would like to state my sincere appreciation for Mr. James Lowe and Dr. Michael Vorster. Mr. Lowe has made some very critical suggestions and alterations that affected the final product of this research. I especially want to thank him for going through my write-up word by word in an effort to edit it. I also would like to thank him for supplying me with many references and also creating the opportunity for me to meet Nancy Gunderson, the Contracting Officer of the Pentagon Renovation Project (PENREN) Project. He was like a co-advisor to me throughout this research. I would like to extend my gratitude to Dr. Vorster for bringing up the issues that I have missed and for giving a whole new direction to my research at the proposal stage. I also would like to thank him for providing some real life examples which helped me understand the issues that I was struggling.

I would like to sincerely thank the following individuals whose ideas at certain stages of this research were indispensable: Ms. Nancy Gunderson, Mr. Vernon Edwards, Mr. Robert Bowes, Mr. Michael Hall, Mr. Mike Branch, Mr. Stan Lanford, Dr. Jeffrey Russell, Mr. Byron Blaschke, Ms. Emily Lewis, and Mr. Tony Porter.

A set of "special thanks" goes to Juan Pinero (PhD, P.E, and I guess more to come), who was my mentor in many ways. I feel myself really lucky for coming across to you at the very beginning of my graduate experience. I believe that you have changed a lot in me and taught me 
how to search for and achieve the best in everything. In fact you taught me how to be a researcher. Thanks for being my friend and for doing all the things that you have done for me.

Aysen and Emre, there is no way to state my appreciation to you. Thank you for being with me during my toughest times. Your advice and your invaluable help will never be forgotten.

I would like to acknowledge the Virginia Department of Transportation (VDOT) for providing the financial support to make this research possible

Of course, the family is above all. "Thanks for everything" goes to my mom, Tulay Ozbek, my dad, Ahmet Ozbek, my sister, Burcu Akinci, my grandma, Guzin Ertekin, and my “Nana”, Naciye Dagci.

Finally, thank you more than you can guess Pinar. Thanks for being with me all the time. Your unconditional support is truly appreciated... 


\section{TABLE OF CONTENTS}

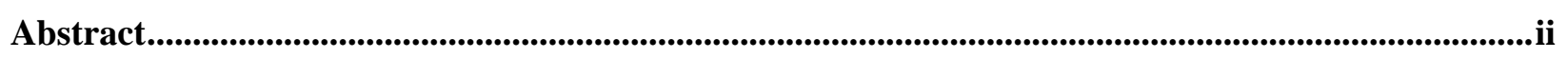

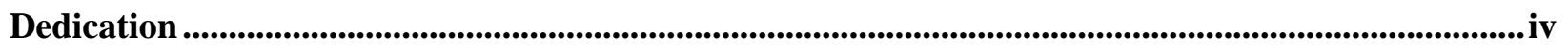

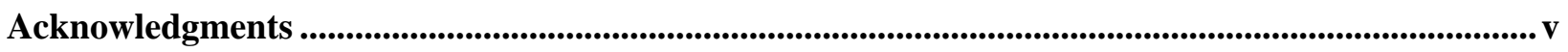

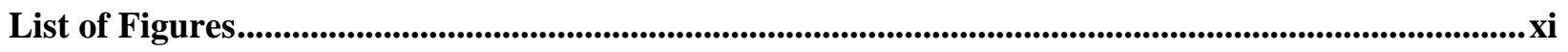

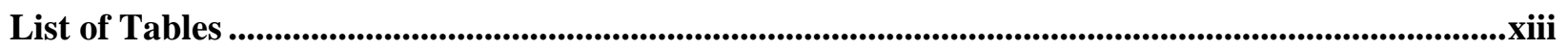

List of Appendices .........................................................................................................................................................

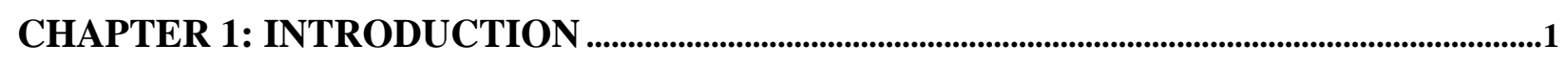

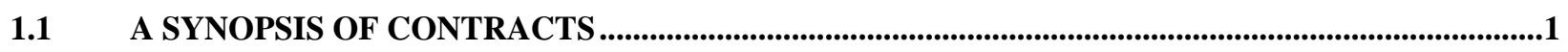

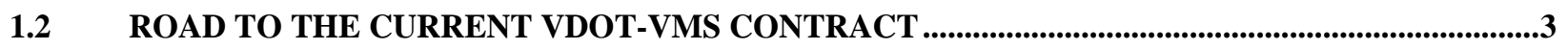

1.3 ADVENT AND DEVELOPMENT OF PERFORMANCE BASED CONTRACTING ...........................4

1.3.1 INTRODUCTION AND DEVELOPMENT OF PERFORMANCE BASED CONTRACTING IN THE USA ..................4

1.3.2 PERFORMANCE BASED CONTRACTING IN THE TRANSPORTATION ARENA ................................................6

1.3.3 ASPECTS AND BENEFITS OF PERFORMANCE BASED CONTRACTING ...................................................

1.3.4 PERFORMANCE BASED CONTRACTING IN HIGHWAY MAINTENANCE- VDOT'S CASE ..............................10

1.4 INTRODUCTION AND STATEMENT OF THE PROBLEM ......................................................11

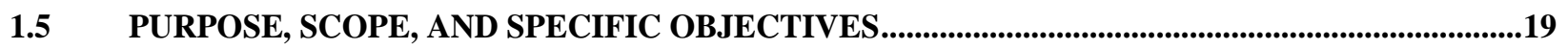

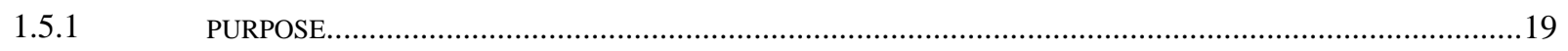

SCOPE

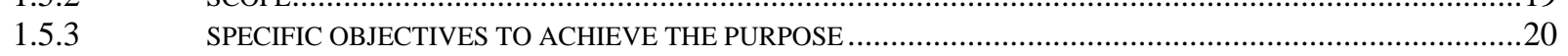

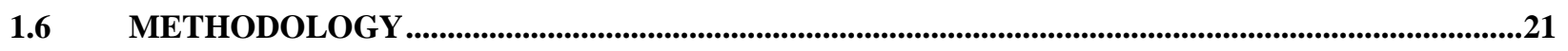

1.6.1 OVERVIEW OF UNIVERSALLY ACCEPTED RESEARCH METHODOLOGIES …........................................21

1.6.2 RESEARCH'S METHODOLOGY, RESEARCH'S PHASES, AND THE CORRESPONDING THESIS OUTLINE .......22

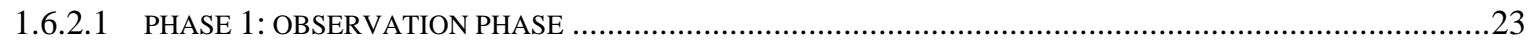

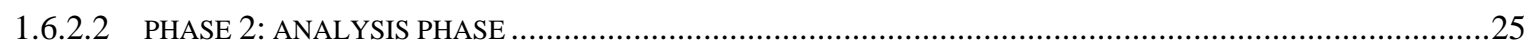

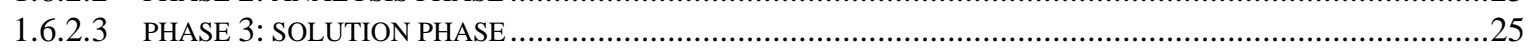

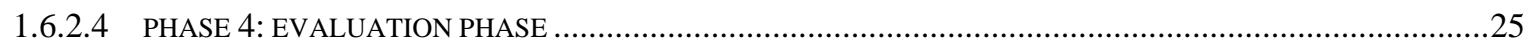

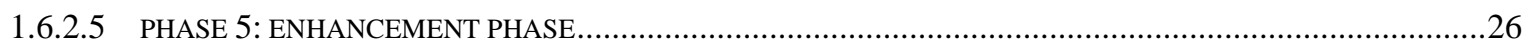

CHAPTER 2: PHASE 1- OBSERVATION PHASE ..................................................................27

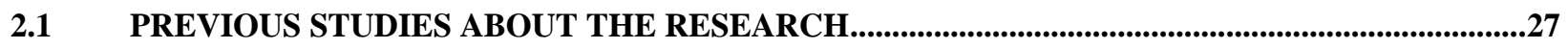

2.2 LEGAL DEFINITIONS OF RELATED TERMS..............................................................................28 
2.3 INTRODUCTION AND DEVELOPMENT OF HIGHWAY WARRANTIES IN THE USA ..............30

2.4 EXAMINATION OF HIGHWAY WARRANTIES IN THE USA ......................................................35

2.4.1 GENERAL REMARKS ABOUT THE HIGHWAY WARRANTY CONCEPT ……….......................................36

2.4.2 ISSUES TO BE TAKEN INTO CONSIDERATION FOR THE HIGHWAY WARRANTY CONCEPT ........................37

2.4.2.1 TYPE OF PROJECTS APPROPRIATE FOR WARRANTY IMPLEMENTATION ...............................................38

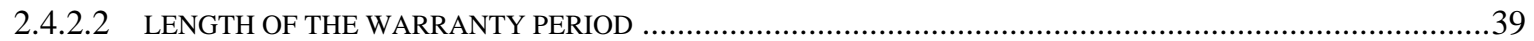

2.4.2.3 CRITERIA TO BE USED IN EVALUATING WARRANTY COMPLIANCE ...................................................42

2.4.2.4 EVALUATION AND AWARD OF THE CONTRACT...................................................................................4

2.4.2.5 EVALUATING WARRANTY COMPLIANCE AND IMPLEMENTATION OF REMEDIES ................................45

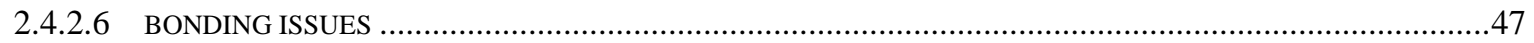

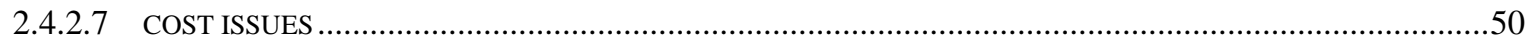

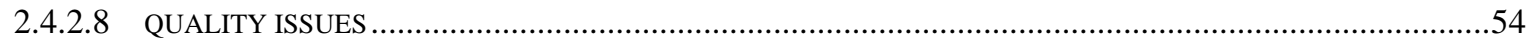

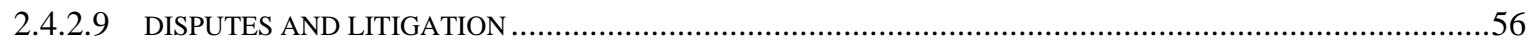

2.4.2.10 QUALITY ASSURANCE/QUALITY CONTROL AND INSPECTION BY THE STATE DOT ................................57

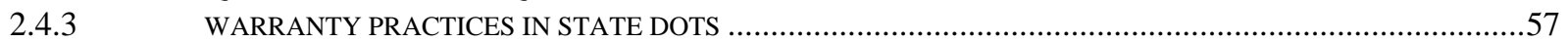

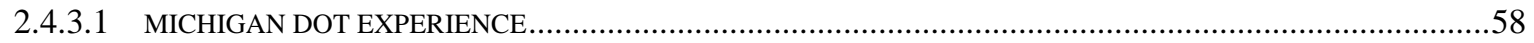

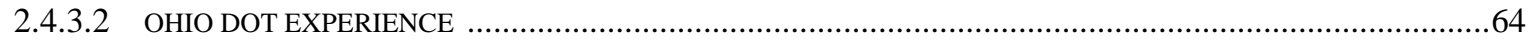

2.4.3.3 WISCONSIN DOT EXPERIENCE ……………................................................................................68

2.4.3.4 HIGHLIGHTS FROM THE WARRANTY EXPERIENCES OF SOME OTHER STATES ….................................76

2.4.4 FEDERAL HIGHWAY ADMINISTRATION'S PERSPECTIVE ON HIGHWAY WARRANTIES ...........................81

2.4.5 ADVANTAGES AND DISADVANTAGES OF HIGHWAY WARRANTIES AS DEEMED BY THE STATE DOTS,

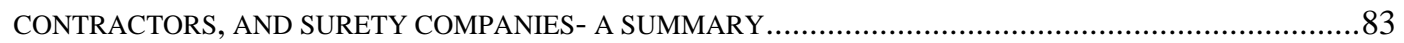

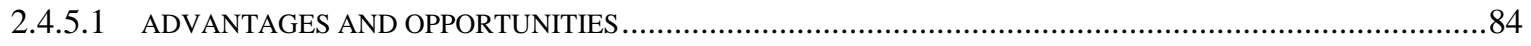

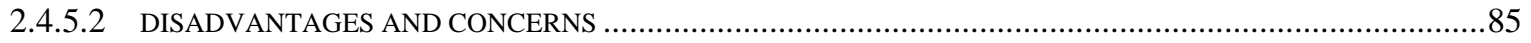

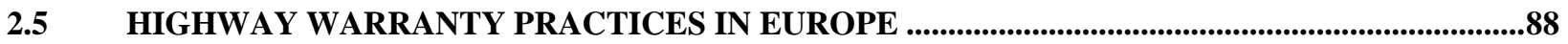

2.6 EXAMPLES OF PERFORMANCE BASED ROAD MAINTENANCE CONTRACTS WITH

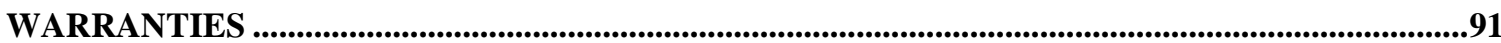

2.7 EXAMPLES OF PERFORMANCE BASED ROAD MAINTENANCE CONTRACTS ISSUED IN

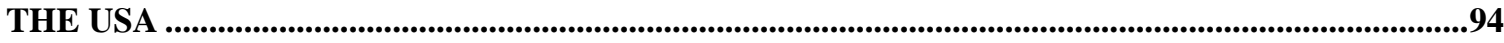

2.8 STANDARD FORMS OF TRADITIONAL DESIGN-BID-BUILD CONTRACTS .............................94

2.9 HIGHWAY AND BRIDGE SPECIFICATIONS PREPARED BY STATE DOTS .............................95

2.10 SOME OTHER EXAMPLES OF PERFORMANCE BASED CONTRACTS ISSUED IN THE

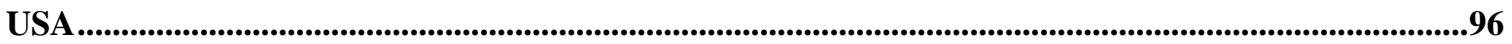

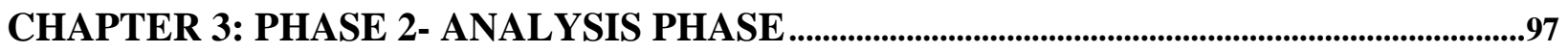

3.1 THE RATIONALE BEHIND DEVELOPING THE WARRANTY CLAUSES ......................................97

FIRST OBJECTIVE: DEFINING DEFECT ...........................................................................................103

3.2.1 GENERAL DISCUSSIONS ABOUT "DEFECTS" IN THE CONSTRUCTION INDUSTRY ................................103

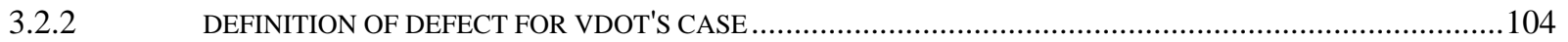

3.3 SECOND OBJECTIVE: IDENTIFYING THE LENGTH OF THE WARRANTY PERIOD.............107

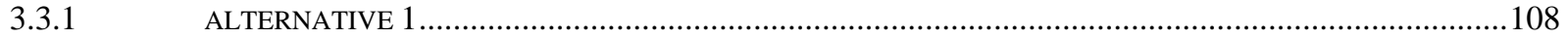

ALTERNATIVE 2 2....................................................................................................114

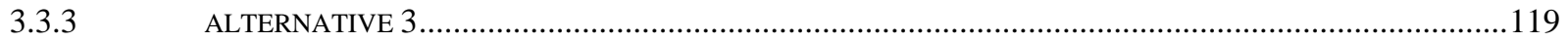

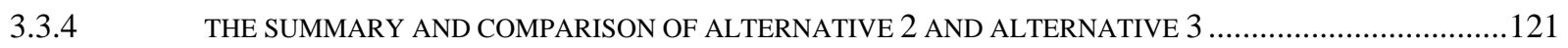


3.4 THIRD OBJECTIVE:IDENTIFYING OTHER COMPONENTS THAT SHOULD BE PRESENT IN

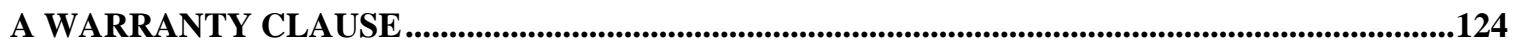

3.4.1 COMPONENTS THAT SHOULD BE PRESENT IN A WARRANTY CLAUSE AS IDENTIFIED THROUGH THE

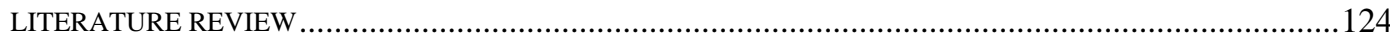

3.4.2 EXCLUSIONS AND WAIVERS WITHIN THE WARRANTY PERIOD ………..............................................125

3.4.3 WARRANTY COMPLIANCE EVALUATIONS (INSPECTIONS) ..............................................................127

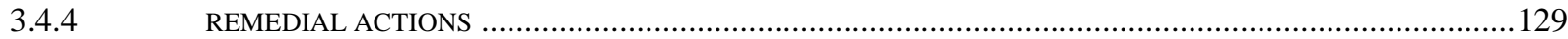

3.4.5 CONFLICT RESOLUTION PROCEDURES FOR THE WARRANTY PERIOD ...............................................131

3.4.6 ACTIONS TO BE TAKEN IN THE CASE OF THE CONTRACTOR'S DEFAULT WITHIN THE WARRANTY PERIOD

3.4.7 BONDING REQUIREMENTS FOR THE WARRANTY PERIOD ……………...........................................135

3.4.8 THE OPTION OF PREVENTIVE (ROUTINE) MAINTENANCE DURING THE WARRANTY PERIOD.................137

3.4.9 THE RESPONSIBILITIES OF VDOT DURING THE WARRANTY PERIOD ...................................................139

3.4.10 OTHER RESPONSIBILITIES OF VDOT DURING THE WARRANTY PERIOD ................................................141

3.5 FOURTH OBJECTIVE: MAKING DISTINCTIONS BETWEEN THE ASSET ITEMS...................142

3.5.1 DEFINITION OF DEFECT AND ESTABLISHMENT OF THE WARRANTY CRITERION..................................143

3.5.2 IDENTIFICATION OF THE LENGTH OF THE WARRANTY PERIOD.........................................................144

EXCLUSIONS AND WAIVERS WITHIN THE WARRANTY PERIOD ……................................................146

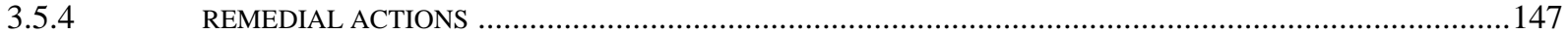

3.5.5 BONDING REQUIREMENTS FOR THE WARRANTY PERIOD .................................................................

CHAPTER 4: PHASE 3- SOLUTION PHASE.

4.1 FIFTH OBJECTIVE: DEVELOPING THE COMPREHENSIVE WARRANTY CLAUSE TEMPLATE AND AN EXAMPLE WARRANTY CLAUSE FOR THE "PAVED DITCHES"

ASSET ITEM..

4.1.1 THE WARRANTY CLAUSE TEMPLATE FOR THE VDOT ISSUED PERFORMANCE BASED ROAD

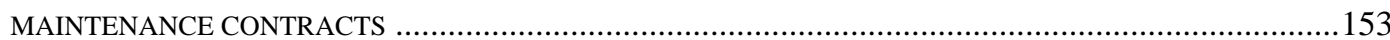

4.1.2 AN EXAMPLE WARRANTY CLAUSE FOR THE "PAVED DITCHES" ASSET ITEM ...................................166

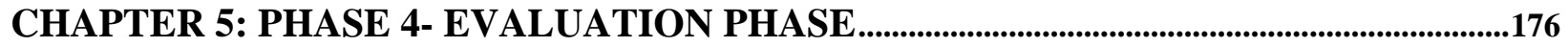

5.1 THE NEED FOR AND THE COMPOSITION OF THE PANEL OF EXPERTS ..............................176

5.2 THE METHODOLOGY USED IN PERFORMING THE EVALUATION PHASE ...........................178

5.3 FEEDBACK OBTAINED FROM THE PANEL OF EXPERTS............................................................178

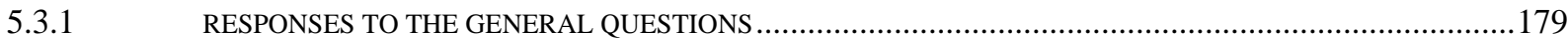

5.3.1.1 COMPLETENESS OF THE WARRANTY CLAUSE TEMPLATE ………...................................................179

5.3.1.2 VALIDITY OF THE LANGUAGE USED WITHIN THE WARRANTY CLAUSE TEMPLATE .............................179

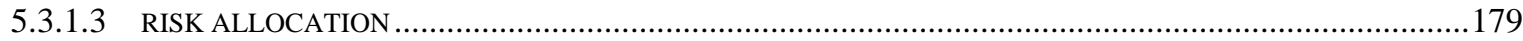

5.3.1.4 DIFFERENT WARRANTY CLAUSE FOR EACH ASSET ITEM ................................................................. 180

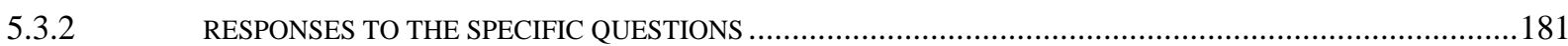

5.3.2.1 DEFINITION OF DEFECT AND ESTABLISHMENT OF THE WARRANTY CRITERION FOR EACH ASSET

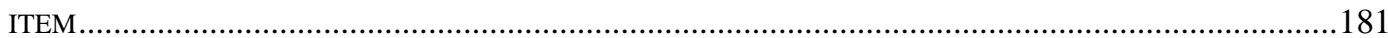

5.3.2.2 EVALUATION OF ALTERNATIVES USED IN ESTABLISHING THE LENGTH OF THE WARRANTY

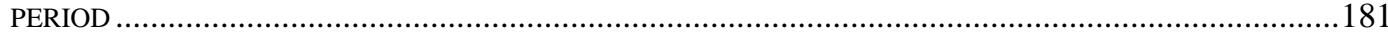

5.3.2.3 APPROACHES IN DETERMINING THE VALUE OF "A" AND THE VALUE OF " $\mathrm{W} "$....................................182

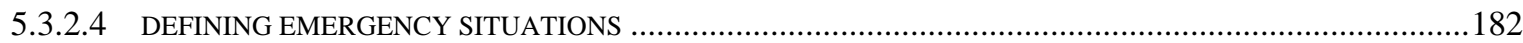


5.3.2.5 TIME TO COMPLETE REMEDIAL ACTIONS AND EMERGENCY REMEDIAL ACTIONS .............................183

5.3.2.6 TIME FRAMES FOR CONFLICT RESOLUTION PROCEDURES .................................................................184

5.3.2.7 ESTABLISHING BOND AMOUNT USING THE "MOST EXPENSIVE REASONABLE REMEDY" APPROACH ..184

5.3.2.8 OPTION OF THE CONTRACTOR TO IMPLEMENT MAINTENANCE ACTIVITIES DURING THE WARRANTY

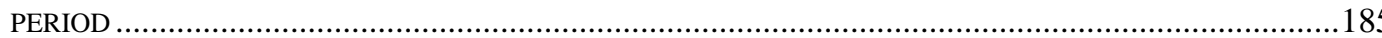

5.3.3 EXTRA COMMENTS AND SUGGESTIONS MADE BY THE PANEL OF EXPERTS ………...........................185

5.4 SUGGESTIONS FOR CHANGES IN THE LANGUAGE OF THE DEVELOPED WARRANTY

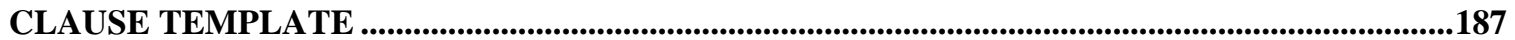

5.5 OTHER CHANGES INTRODUCED TO THE WARRANTY CLAUSE TEMPLATE ......................188

CHAPTER 6: PHASE 5- ENHANCEMENT PHASE ....................................................................189

6.1 THE FINAL FORM OF THE WARRANTY CLAUSE TEMPLATE ....................................................189

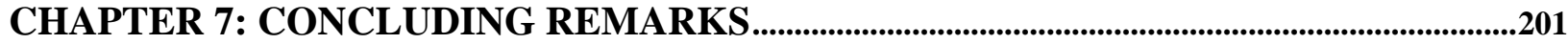

7.1 SUMMARY ..............................................................................................................................................201

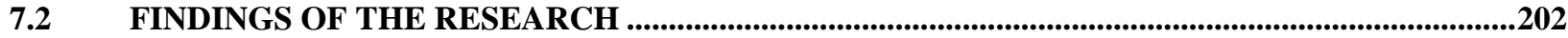

7.3 KEY PRINCIPLES USED IN DEVELOPING THE WARRANTY CLAUSE TEMPLATE.............205

7.4 CONTRIBUTIONS MADE TO THE BODY OF KNOWLEDGE AND THE IMPORTANCE OF

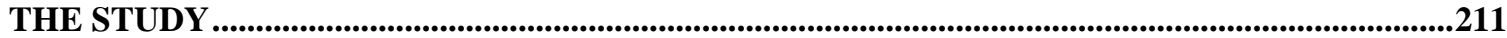

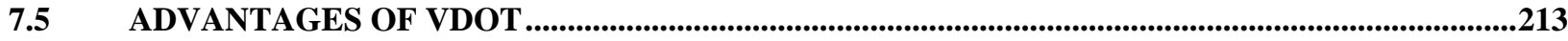

7.6 RECOMMENDATIONS FOR VDOT IN INTRODUCING THE WARRANTY CONCEPT INTO ITS PERFORMANCE BASED ROAD MAINTENANCE CONTRACTS ........................................216

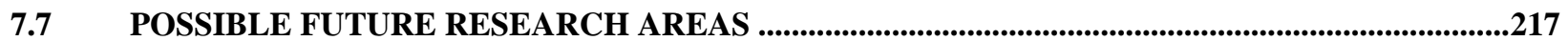

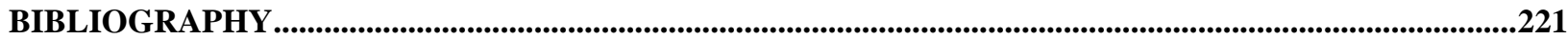

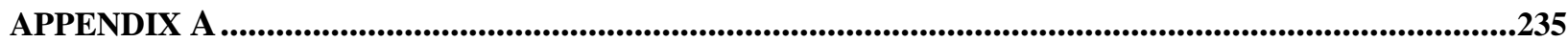

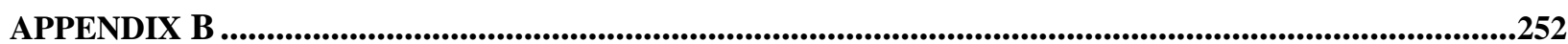

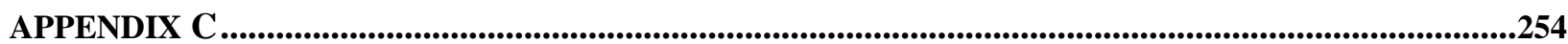

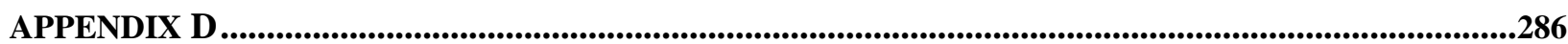

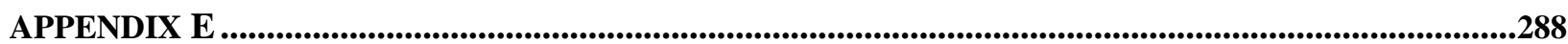

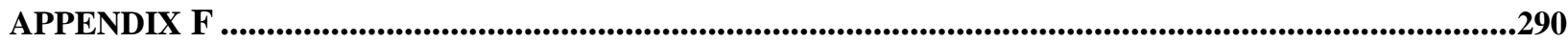

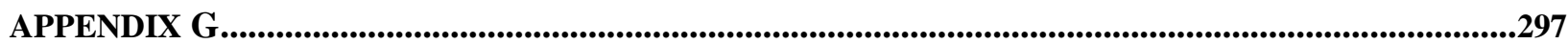

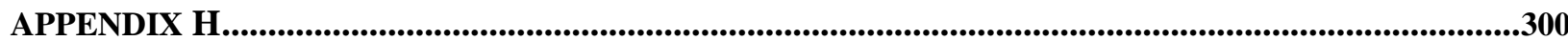

VITA 


\section{LIST OF FIGURES}

\section{CHAPTER 1}

1.1 The overall condition rating of the paved ditches asset item throughout a year...............................................15

1.2 The overall condition rating of the paved ditches asset item throughout the contract term ............................15

1.3 The overall condition rating of the paved ditches asset item before and after the contract completion ..........18

1.4 Phases of methodology of this research and corresponding thesis chapters ....................................................22

\section{CHAPTER 2}

2.1 Number of highway projects with warranties completed by year in USA ......................................................34

2.2 Distribution and number of highway projects with warranties for the years 1987-1997.................................39

2.3 Average warranty periods as required by the state DOTs .................................................................................42

2.4 Percentage increases in bid prices due to implementation of warranties ........................................................53

2.5 Impact of warranties on the project life cycle costs- State DOTs' perspectives................................................53

2.6 Impact of warranties on the project quality- State DOTs' perspectives ................................................................56

2.7 Warranty vs. Non-warranty projects average IRI comparison for Wisconsin ...................................................71

2.8 Warranty vs. Non-warranty projects average PDI comparison for Wisconsin .................................................71

\section{CHAPTER 3}

3.1 The maintenance approach of the contractor under current contract conditions .

3.2 The maintenance approach of the contractor after the implementation of warranties- First possible scheme .................................................................................................................................................................100

3.3 The maintenance approach of the contractor after the implementation of warranties- Second possible

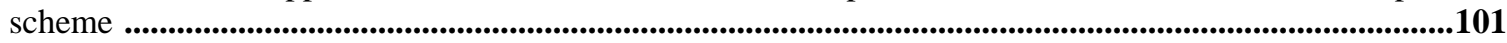

3.4 The maintenance approach of the contractor after the implementation of warranties- Third possible scheme .....................................................................................................................................................................102

3.5 Normal deterioration curve for the "Paved Ditches" asset item .................................................................110

3.6 Excessive deterioration curve for the "Paved Ditches" asset item ...............................................................110

3.7 Normal and excessive deterioration curves for the "Paved Ditches" asset item .............................................111

3.8 Not being able to meet the warranty criterion all through the warranty period, "First Case” ........................112

3.9 Not being able to meet the warranty criterion all through the warranty period, "Second Case”....................113 
3.10 Normal deterioration curve beginning with an overall condition rating which is less than $100 \%$ for the "Paved Ditches" asset item................................................................................................................................115

3.11 Different normal deterioration curves for the "Paved Ditches" asset item....................................................116

3.12 Establishment of the warranty period and possible maintenance practices ......................................................117

3.13 Establishment of the length of the warranty period using Alternative 3 ..........................................................120

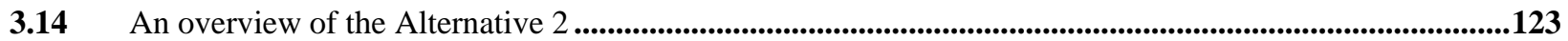

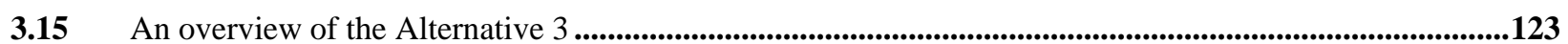

3.16 Normal deterioration curves for the "Paved Ditches" and "Sound Barriers" asset items...............................145 


\section{LIST OF TABLES}

\section{CHAPTER 1}

1.1 Comparison of nomothetic and ideographic methodologies ................................................................................21

\section{CHAPTER 3}

3.1 Performance Criteria and Performance Target for the "Paved Ditches" asset item ........................................105

3.2 Performance Criteria and Performance Targets for the "Paved Ditches" and "Sound Barriers" asset items ...............................................................................................................................................................143

\section{CHAPTER 5}

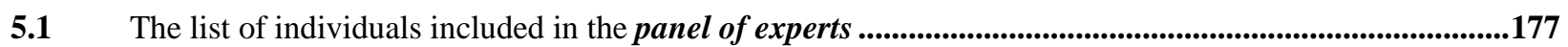

5.2 Language change suggestions made by the panel of experts and the action taken .......................................187

5.3 The changes that need to be introduced to the warranty clause template as identified by the M.S. candidate and through the legal advice

\section{CHAPTER 7}

7.1 Performance Criteria for the "Paved Ditches" asset item as extracted from the Exhibit B of the current

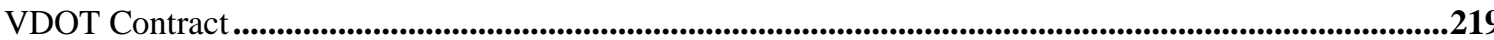




\section{LIST OF APPENDICES}

A Exhibit B of the VDOT-VMS, Inc. Contract ....................................................................................................235

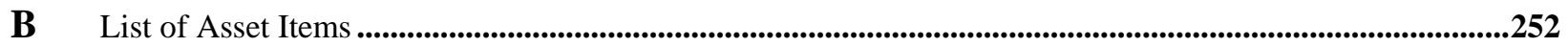

C Warranty Clauses Used by Various State DOTs.................................................................................254

D Warranty Survey Performed in Montana ................................................................................................................286

E Warranty Practices Used in the European Countries ............................................................................................288

F Defects Liability Clauses Used in Various Performance Based Road Maintenance Contracts ........................290

G FAR Warranty Clause Used in the PENREN Project ...............................................................................................297

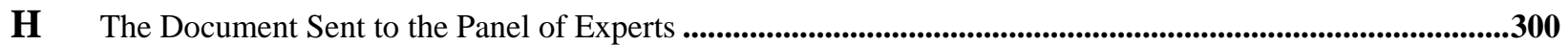




\section{CHAPTER 1}

\section{INTRODUCTION}

This chapter first discusses in depth the contract that is in the scope of this research. Afterwards, it introduces the problem that is addressed and tried to be solved. The objectives, scope, and methodology of this research as well as the structure of the thesis are also presented in this chapter.

\subsection{A SYNOPSIS OF CONTRACTS}

Contrary to earlier times in which nearly all jobs, projects, and services were undertaken by the entitled parties in a “ I trust you in doing that and thus you trust me in paying for it” way, in the present day one can hardly find a business transaction whose all aspects-from conception to finalization- are not described in some contractual forms. This situation has arisen as a direct result of dissatisfaction of the parties with the ways that the ongoing business was carried out. As the capacity of the projects (both in size and in cost) has increased with time, entities began to take issues into more consideration to protect their reasonable expectations. This, in turn, led to preparation of agreements to be endorsed by these entities, by the help of which they could seek their rights through the litigation process and legal sanctions. As the entities have become more and more sophisticated by time and with the virtue of experience, these basic agreements have developed into more comprehensive ones which are legally binding, and enforceable by laws and regulations. These laws and regulations are explicitly stated within the agreements as to be governing those agreements. These more sophisticated agreements are called contracts. In a more formal way, a contract can be defined as an agreement between two or more parties creating obligations that are enforceable or otherwise recognizable at law (Garner 2001). The existence of contracts, as often used in legal language, requires the presence of the following elements: An offer; an acceptance of that offer which results in the meeting of the minds, a concept also called mutual assent (Sweet 1999); a promise to perform; a valuable consideration 
(which can be a promise or payment in some form); a time or event when performance must be made (meet commitments); and terms and conditions for performance, including fulfilling promises. Contracts can be either written or oral, but oral contracts are more difficult to prove and, in most jurisdictions, the time to sue for oral contracts is shorter (Hill and Hill 1995).

Contracts are the tools by which the parties can get what they expect from the business transactions. Given the legal enforceability of the contracts and the sanctions that may be faced by the parties as a result of breach of contracts, the contents of the contracts- clauses and provisions- have utmost importance regarding the rights of the parties. In preparing a contract, one has to be very wary of the content and wording of the clauses to make sure that they reflect one's expectations from the contract. If parties' expectations are not specified clearly or at all in the contracts, the whole point of contracts to ensure satisfaction of the parties would be missed. The legal history, with innumerable cases of parties seeking resolution after the occurrences of disputes due to missing and deficient contract clauses, is a good illustration of this fact.

Construction contracts are very broad given the scope of the works and services that are issued under them. Hence, they should elaborate on each aspect of the service to be provided, starting with the initiation of the construction works until the after-the-completion of the works. This will ensure the satisfaction of the parties involved in the contract and make them get their expectations from the contract.

This research is aiming to deal with a very special type of contract that is named as "Performance Based Contract”, and an example of that which is in effect between the Virginia Department of Transportation (VDOT) and the Virginia Maintenance Services, Inc. (VMS) to figure out some opportunities that would enhance the performance based road maintenance contracts issued by VDOT. The research will first illustrate that the complete satisfaction of one of the parties (VDOT) may be in question due to the absence of the warranty clauses within the contract, then will list and explore the benefits that would/may be gained by the incorporation of warranty clauses into the contract, and finally will develop a warranty clause template and propose it to be used in the future performance based road maintenance contracts issued by VDOT. At the bottom line, this study aspires to help the party in question (VDOT) to reduce the risk imposed upon it and to improve the future performance based road maintenance contracts it will issue. 


\subsection{ROAD TO THE CURRENT VDOT-VMS CONTRACT}

As mentioned briefly in the previous section, the contract that this research will elaborate on is the performance based road maintenance contract that was signed by the Virginia Department of Transportation (VDOT) and the Virginia Maintenance Services Inc. (VMS), a Virginia corporation.

In July 1995, the Public-Private Transportation Act (PPTA) of Virginia was passed. This act authorized the Commonwealth of Virginia (responsible public entity) to establish contracts with private entities to acquire, construct, improve, maintain, and/or operate one or more transportation facilities within the state of Virginia. PPTA further states that this approach of privatization may result in the availability of such transportation facilities to the public in a more

timely or less costly fashion (Code of Virginia §56-558 A-3). According to the act, individually negotiated agreements would assign the rights and obligations of the responsible public entity and the private entity so that both entities may have the greatest flexibility in forming the contract with each other (Code of Virginia §56-558 C). Moreover, according to the act, the contract between the responsible public entity and the private entity should be comprehensive in many aspects (Code of Virginia §56- 566).

Three months after PPTA was passed, in October 1995, VMS submitted an unsolicited proposal to VDOT for the maintenance of assets within a portion of the interstate highway system of Virginia. After an intensive evaluation of this proposal by VDOT (including the phases of a detailed proposal re-submittal by VMS and negotiations), in December 1996, the contract was signed. The contract required VMS to administer and maintain all assets and carry out incident management and snow removal facilities on 250 miles of Virginia's interstate highways (I-81, I-77, I-95, and I-381). By this contract, a total of 20\% of Virginia's interstate highways were covered. The contract was a fixed-fee (lump-sum) 5.5 year contract with an option of renewal for one more term and with a total fee of \$131.6 million. Furthermore, the contract was renewed in June 2001 for 5 more years (contract term to commence in July 2002 and end in July 2007) at a fixed-fee of \$162 million with contract provisions (other than the fee) remaining exactly the same as the previous term's. The contract is very comprehensive in terms of its technical provisions. However, general conditions and thus the overall contract may 
furthermore be enhanced through the incorporation of warranty clauses. This fact led to the initiation of the research.

A very important aspect of the contract between VDOT and VMS is its performance based nature. A performance based contract is very different from a method based contract (traditional contract type which is common in the construction industry) in one great sense. A performance based contract, as the name implies, sets forth the performance expected from the end product of a project rather than directing the contractor with the methods to achieve that end product. In other words, a performance based contract specifies the desired outcomes rather than the desired processes to reach those outcomes. A performance based contract leaves the contractor free, in any sense, to choose and apply the construction methods he wishes to carry out. This nature of performance based contracts leads to two significant results. First, it imposes the risk of deficient design on the contractor. Thus, it is beneficial for the owners to use performance based contracts for their projects. Second, it often makes the contractor seek innovative construction methods (Zietlow 2002, Hardy 2001, Porter 2001). That is why the term “performance based contracting” is used interchangeably with the term "innovative contracting”.

\subsection{ADVENT AND DEVELOPMENT OF PERFORMANCE BASED CONTRACTING}

Before focusing on the contract that is in the scope of the research, it is essential to understand the introduction and development of the performance based contracting within the United States of America and in the international arena, especially in the transportation area. Furthermore, to be able to understand the consequences of implementing performance based contracts into transportation area, some important features and advantages of it should be identified.

\subsubsection{Introduction and Development of Performance Based Contracting in the USA}

The concept of "Performance Based Service Contracting" was initiated by the Department of Defense in the second half of the 1970s in the Air Force. Subsequently, in October 1980, the Office of Federal Procurement Policy (OFPP) issued OFPP Pamphlet 
Number 4: “A Guide for Writing and Administering Performance Statements of Work for Service Contracts." During the course of development of the performance based contracting within the USA in the early 1990s, the federal government decided to increase the use of these contracts and then issued OFPP Policy Letter 91-2, which clearly stated the policy of the federal government as to motivate the agencies to use performance based contracting methods to the maximum extent practicable.

This policy letter later became a part of the Federal Acquisition Regulation (FAR) and also a statutory requirement as a proof of clear intent of the government to proliferate the usage of these contracts (FAR §37.102). Within 1997, “Performance Based Contracting” was incorporated into the Federal Acquisition Regulation as a whole subpart, namely FAR §37.6. This subpart clearly states the policies and procedures for the use of performance based contracting methods. Within the FAR, performance based contracting is defined as structuring all aspects of an acquisition around the purpose of the work to be performed with the contract requirements set forth in clear, specific, and objective terms with measurable outcomes as opposed to either the manner by which the work is to be performed or broad and imprecise statements of work (FAR §2.101).

As can be seen through the implementations, the federal government has been very committed to increasing the use of performance based contracting within the USA. During the 20 year period of this struggle, people in authority have changed. Nonetheless, the policy of the federal government to flourish the use of performance based contracting has never changed. As the very last step in this pursuit, OFPP published "A Guide to Best Practices for Performance Based Service Contracting” in 1998. As the name implies, this document was aimed to assist the agencies by showing the best practices that have proven useful for drafting statements of work, solicitations, and quality assurance plans, and in awarding and administering performance-based service contracts (OFPP 1998).

As a result of all these implementations, many government agencies started to convert their contracts to performance based contracts under a pilot project. These agencies reported an average 15 percent reduction in contract price and an 18 percent improvement in satisfaction with the contractors' work. Agencies, furthermore, reported that this conversion reduced the prices and increased the customer satisfaction that occurred at various ranges for the nontechnical, professional, and technical services (OFPP 1998). 
Currently in the USA, many government agencies are converting their contracts to performance based contracts. Hence, it is declared as a long term goal of the Department of Defense to have $50 \%$ of its contracts as performance based by the end of 2005. Moreover, state agencies are also changing their approach of traditional contracting to performance based contracting. Constructions of some public schools nationwide are also contracted as performance based.

\subsubsection{Performance Based Contracting in the Transportation Arena}

The tendency to move toward performance based contracting has also shown itself in the arena of transportation. In a memorandum dated January 1999, which was distributed to the operating administrators of state departments of transportation, the deputy secretary of the U.S. Department of Transportation (USDOT) requested agencies to develop plans to convert their traditional contracts to performance based contracts as they come up for renewal (Tomanelli 2003.) He also demanded fixed pricing to be used for these contracts. Moreover, to ensure the success and continuity of the conversion process, state departments of transportation (DOTs) were required to prepare quarterly reports to be evaluated by the USDOT. Later on, in an October 1999 memorandum, the deputy secretary declared that the conversion to performance based contracting was to become a ONE-DOT priority (top priority level within USDOT) in state agencies. Finally, in October 2000, exactly 1 year after the date that USDOT had clearly indicated its policy as to convert traditional contracts to performance based contracts within the transportation arena, a final memorandum was issued (Tomanelli 2003.) In this memorandum deputy secretary of the USDOT announced their long term goal of $80 \%$ of DOT contracts being performance based by the end of fiscal year 2004. All of the aforementioned memorandums clearly show the willingness of the transportation authority in proliferating the use of performance based contracts within the states' transportation works such as construction and maintenance of transportation components.

DOTs within Virginia (in 1996), Florida (in 1998), Texas (in 1999), and the District of Columbia (in 2000) have been the first ones to implement performance based contracts for the maintenance of their road and highway systems. 
This trend in the USA has also been valid worldwide. Specifically in road construction and maintenance; Canada in 1988, Argentina in 1990, Uruguay in 1995, Australia in 1995, and New Zealand in 1998 took their places on the list of the countries issuing performance based contracts.

\subsubsection{Aspects and Benefits of Performance Based Contracting}

As mentioned previously, a performance based contract sets forth the performance expected from the end product of a project rather than directing the contractor with the methods and materials to achieve that end product. Until the emergence of performance based contracting and thus performance specifications, predominantly three kinds of specifications have been used in highway construction and maintenance contracts. These specifications and their brief descriptions are as follows:

i) Methods Based Specifications: The contract specifies the exact construction methods and sequence of those in building or maintaining the roadway. A contractor doing job under this kind of specifications is said to be fulfilling the contract requirements if it follows the specified methods.

ii) Material Properties Based Specifications: The contract specifies various properties that the finished (and/or intermediate) product should carry. Contract compliance is determined based on these properties independent of the construction approach used.

iii) Methods and Material Properties Based Specifications: The contract specifies both the methods that need to be used and the material properties to be achieved to produce the best possible product or to apply the best possible treatment.

If investigated thoroughly, it can be identified that the primary intention of these three kinds of specifications is to provide roadways that will safely carry traffic over a long service life (Stephens et al. 1998). All three kinds of specifications, as based on the experience, define parameters which are believed to be related to the intention and success of "providing roadways that will safely carry traffic over a long service life.” These specifications, however, 
never clearly mention the requirement that "the roadway needs to provide a long and useful service life.” They just define the intermediate steps of reaching a goal but not the goal itself. In these specifications, the quality of each individual construction item is evaluated based on meeting a specific standard without taking into consideration how the quality of each element is correlated to one another or to the overall performance of the constructed or maintained roadway. Performance based specifications differentiate itself from the others at this point and hence bring many advantages to the construction and maintenance processes. In a performance based specification, work required by the agency/owner is described in terms of the results rather than the level of effort. It emphasizes quantifiable, measurable performance requirements and the goal itself. Main advantages that a performance based contract can bring to a highway project are listed below:

- It allows a contractor to deliver a project by following its own best practices, not the agency's. Since the main focus is on the end product, the contractor may change its methods throughout the life of the contract without the burden of contract modifications, as long as end result as required by the owner is obtained.

- It maximizes innovation. Under performance based contracting, contractors have numerous opportunities and incentives to promote innovation at all stages of the project. They are flexible in proposing solutions. By this, agencies may take advantage of the advances in technology related to construction materials, equipment and methods. Furthermore, agencies can learn these technologies and then implement them for the projects that they are carrying out by their own forces. Thus, performance based contracting enables the transfer of new technology to the agencies. The implementation of research results, in both construction materials and methods, can truly be realized through the use of performance based contracting (Carpenter et al. 2003).

- In performance based contracts, the risk is shifted to the party who has much more control over the project and thus over the risk. This results in the better management of risks. In performance based contracting, the contractor has the risk of failure of the project (i.e. a roadway) due to the reason that it decides how to perform the work for that project. But although the contractor bears the risk of 
failure, the actual probability of failure should be low since the contractor is most probably using the procedures with which it is familiar (Tomanelli 2003).

- Performance based contracts are cost effective. There is a high possibility of attaining savings by both the agency (state DOT in our case) and the contractor. As mentioned before, experience in government and industry has demonstrated that the use of performance specifications results in cost savings (Tomanelli 2003).

- Since most of the time these contracts are long term contracts, a long term and stable relationship is built between the contractor and the agency as the result of performance based contracting.

- It minimizes the negative impact of highway projects on the public. Performance based contracting reduces construction time, resulting in shorter times driving through and around work zones. This enhances safety of the public. Performance based contracting reduces the negative impacts of construction works such as noise and pollution too (Carpenter et al. 2003).

- In performance based contracting, inspections are carried out less frequently and more meaningful results are obtained. Generally, the quality control (QC) process is the responsibility of the contractor, relieving the agency from allocating resources (money and staff) to the QC.

When compared to the long history of construction contracts issued worldwide, it would be fair to say that performance based contracting is a rather new concept with 20 years of history in theory but with at most 10 years of applications in practice. There are a few number of performance based contracts issued around the world. Hence, performance based contracts are still at the development stage. Some of these subjects can be enumerated as preparation of clear contract language with all of the necessary provisions, preparation of good work statements, development of valid performance measures, and efficient implementation of contract specifications. 


\subsubsection{Performance Based Contracting in Highway Maintenance- VDOT’s Case}

According to Frost and Lithgow, a performance based highway maintenance contract is “ $a$ contract under which the contractor undertakes to plan, program, design, and implement maintenance activities in order to achieve specified short and long term road condition standards for a fixed price, subject to specified risk allocation” (Frost and Lithgow 1998, pp 2). In addition to carrying the benefits mentioned in the preceding sub-section, VDOT's performance based highway maintenance contract possesses some other advantages.

The current VDOT- VMS contract is an asset management contract. In fact, the contract is for the "Interstate Highway Asset Management Services" as it is indicated on it. As Falls, Haas, McNeil, and Tighe assert, asset management is "a systematic process of maintaining, upgrading, and operating physical assets cost-effectively. In the broadest sense, the assets of a transportation agency include physical infrastructure such as pavements, bridges...” (Falls et al. 2001, pp 2). This simply means that, within the sections of the interstate highway system covered by the contract, the contractor is in charge of maintaining all assets between VDOT's right of way fences. This includes all road surfaces, guardrail, signage, and drainage assets (JLARC 2001). Moreover, the contractor is responsible to provide snow and ice removal services. Thus, this is a total maintenance contract, making it different from its predecessors which deal with a certain portion of the assets of a highway system. In addition to being a performance based asset management contract, the current VDOT-VMS contract is a fixed price contract. These aspects of the contract result in potential benefits to VDOT as listed below:

- Under the asset management aspect, condition and quality of the assets will be improved due to the timely and effective maintenance activities.

- Under the total maintenance aspect, VDOT moves away from managing a number of different maintenance contracts undertaken by different contractors but rather deals with a single contract. This will certainly cut the amount of resources spent in bidding, administering and managing a range of short term individual contracts. This also enables VDOT to allocate responsibility and risk to a single contractor. Moreover, this streamlines the delivery process because a single contractor is responsible for managing all the work, including but not limited to 
road asset maintenance, resource management, traffic management, and contract management (Bay Roads Exposed Conference 2003).

- Under the fixed price aspect, VDOT transfers the risk of cost overruns to the contractor. These overruns may be due to the unanticipated maintenance related problems such as maintenance cost increases over the term of the contract, the extraordinary costs associated with damages from incidents such as collisions and storms, and the costs for the removal of extraordinary amount of snow and ice. Fixed price nature of the contract provides VDOT with a superior budgeting tool for the remainder of its maintenance activities since it knows the amount of money to be spent on this specific contract in advance. In fact Shirley Ybarra, former Virginia Secretary of Transportation, stated this benefit as "Only through a fixed price asset management contract can we predict with $100 \%$ accuracy our highway maintenance costs in the years ahead. In an environment where unexpected costs can have devastating effects on your budget, our contract with VMS, Inc. allows us to set minimum standards of road preservation and maintenance and achieve those standards without ever going over budget" (Better Roads 2001, pp 27).

\subsection{INTRODUCTION AND STATEMENT OF THE PROBLEM}

As mentioned earlier, VDOT and VMS are the two parties that are involved in the performance based contract that sets the "rules of the game" for the maintenance of a portion of interstate highway system of the state of Virginia. This contract was signed by the representatives of both entities in December 1996 with mutual assent or, in other words, with the meeting of the minds.

VDOT, being a sophisticated public entity, has written a specification book so called "Road and Bridge Specifications Book" which contains the general and technical standards that VDOT has generated with its long time experience. Having prepared this specification book, VDOT often uses Division I of the book which establishes the "General Provisions of the Contract” for the contracts that are awarded by the Commonwealth Transportation Board. These 
provisions are some standard terms and conditions that are also called boilerplates and that may change only slightly from project to project to suit the needs of that particular project. One should note that these projects are design-bid-build projects in which VDOT sets forth the processes for the construction or maintenance activities and directs the contractor in this sense.

In preparation of the VDOT-VMS contract, VDOT has accomplished a very difficult task of introducing performance specifications to a highway contract. To be able to do this, state DOTs need to develop new specifications and guidelines; and this is a very challenging procedure given the obstacles in quantifying quality and performance for highway maintenance products (Carpenter et al. 2003). For this performance based highway maintenance project, VDOT kept the contract as flexible as possible, contrary to other contracts that it issues. PPTA is the reason underlying this change in approach. PPTA, which was the cause of the generation of this contract, required the contract to be flexible (Code of Virginia §56-558 C). The contract is a very unique one because of its performance based nature.

The benefits of performance based specifications were mentioned previously. Of the greatest benefits that performance based contracting can bring to a project are the innovations implemented into the materials and processes that are used by the contractor. But in some cases, innovations may also bring some undesirable consequences to the projects. The design, methodologies and the materials implemented by the contractor may be based on the latest proven research but incorporated innovative materials and methodologies may still reduce the quality, although ideally should improve it. Moreover, using performance specifications gives the contractor an increased control over the project. This increased control of the contractor may also reduce the quality, which is contradictory to what is aimed by performance based contracting.

In order to avoid the occurrence of such cases, there should be a kind of assurance to provide that the increased control of the contractor and innovative techniques implemented by it will yield to a product which is sought by the agency and which also has a predefined quality. A very superior way of providing this assurance goes through the implementation of warranties. Warranties provide the owner with some kind of an assurance for the quality of the services to be received. The warranty concept, which will be discussed in the following chapters in detail, ensures that performance based contracting would lead to quality products which have long 
term performances. In plain language, warranty is a buffer for agencies to overcome performance based contracting's vulnerability to the issues discussed above.

This general discussion about performance based contracting also applies to the contract type that is in the scope of this research (performance based road maintenance contracts issued by VDOT) and forms the baseline for the problem definition of this research. In order to understand and address the problem, it is essential to discuss and understand some specifics about the VDOT contract first. The following paragraphs introduce and then define the problem that will be addressed and try to be solved in this research.

The current contract ${ }^{1}$ is a performance based contract in which once per year inspections are carried out by VDOT, to ensure that the contractor is performing satisfactory enough to meet the predetermined performance criteria. Inspections for the bridges and the pavement are carried out by VDOT personnel and the inspections for the remaining asset items within the highway are carried out by independent consultants. During these inspections, the products obtained as the results of the contractor's maintenance work are evaluated. This is done by checking the conditions of the pavement, bridges, and other asset items against certain VDOT established performance criteria ${ }^{2}$. Then, overall condition ratings ${ }^{3}$ for each asset item are compared to the

\footnotetext{
${ }^{1}$ The term "current contract", whenever used within this text, means the VDOT- VMS, Inc. Contract. However, this research uses the VDOT-VMS, Inc. Contract for only the purposes of presenting the current contract's terms and conditions, establishing the baseline for the problem definition of this research, and addressing some general issues about the contract. Hence, the discussions presented in this text are for any arbitrary and prospective contractor and do not have any implications on the current contractor, VMS Inc.

${ }^{2}$ The performance criteria, as used within the contract, are set for each item. They are the measures established to assess the condition of the assets. There may be more than one performance criteria established for each asset item. For example, for the "Paved Ditches" asset item, one of the established performance criteria is set to have a maximum of 1 inch settlement. Another one is having a maximum of $25 \%$ of the entire area of the paved ditch within a sample unit to be spalled.

${ }^{3}$ For any asset item, asset item's overall condition rating is the ratio (in percentage) of the amount of the asset item meeting the performance criteria, to the number of that asset item inspected in the abovementioned annual inspections. However, the findings of these inspections can be generalized to the whole population of that asset item that is present in the interstate system maintained by the contractor. This is achieved by carefully choosing the number of samples to be inspected (for the asset item) which would be representative of the whole population for that asset item within a $\mathbf{9 5 \%}$ confidence interval. In fact, this phenomenon enables VDOT and the independent consultants to avoid inspecting all of the assets that are present in the interstate system maintained by the contractor. Given all of these discussions, it can confidently be asserted that, an asset item's overall condition rating is representative of the whole population of that asset item that is present in the interstate system maintained by the contractor. Hence, for the purposes of this research, the term "asset item's overall condition rating" means "the ratio (in percentage) of the amount of the asset item meeting the performance criteria, to the total number of that asset item present in the interstate system maintained by the contractor".
} 
VDOT established performance targets ${ }^{4}$ that are specified in the contract. In such a scheme, the contractor is said to meet the contract requirements even if the results of the inspection reveal an overall condition rating (for the asset item) which barely exceeds the VDOT established performance target for that asset item.

A hypothetical example and illustration is presented in Figure 1.1. This figure shows the percentage of the "Paved Ditches"5 asset item that meets the performance criteria during the one year period. As can be seen in Figure 1.1, for the "Paved Ditches" asset item, the VDOT established target is: meeting the predetermined performance criteria for $90 \%$ of the paved ditches. Within the context of the phenomena described above, the contractor is maintaining the asset to barely meet and exceed the performance target. There is a deterioration curve for the "Paved Ditches" asset item. And, as it deteriorates and its overall condition rating falls below the performance target of $90 \%$, it is maintained by the contractor to scarcely be pulled to the performance target. As can be observed in Figure 1.1, the contractor is trying to meet the performance criteria barely for the amount of ditches that makes up the $90 \%$ (performance target) of the all paved ditches within the highway. In simpler words, for the "Paved Ditches" asset item, the contractor is trying to reach an overall condition rating of $90 \%$ which is barely equal to the performance target. Figure 1.2 shows the application of the same kind of maintenance philosophy for all through the contract term, which is 5 years.

\footnotetext{
${ }^{4}$ The performance targets, as used within the contract, are set for each asset item. For a certain asset item, it is the percentage that defines the ratio of the minimum amount of the asset item that is required to meet the performance criteria, to the total amount of that asset item that is present in the interstate system maintained by the contractor. To give the readers an idea, the Exhibit $\boldsymbol{B}$ of the contract which includes the performance criteria and performance targets for each asset item is provided in the Appendix A.

5 "Paved Ditches" asset item is one of the 32 asset items that needs to be maintained by the contractor under the terms of the current contract. A complete list of the asset items that are covered by the current contract is provided in the Appendix B.
} 


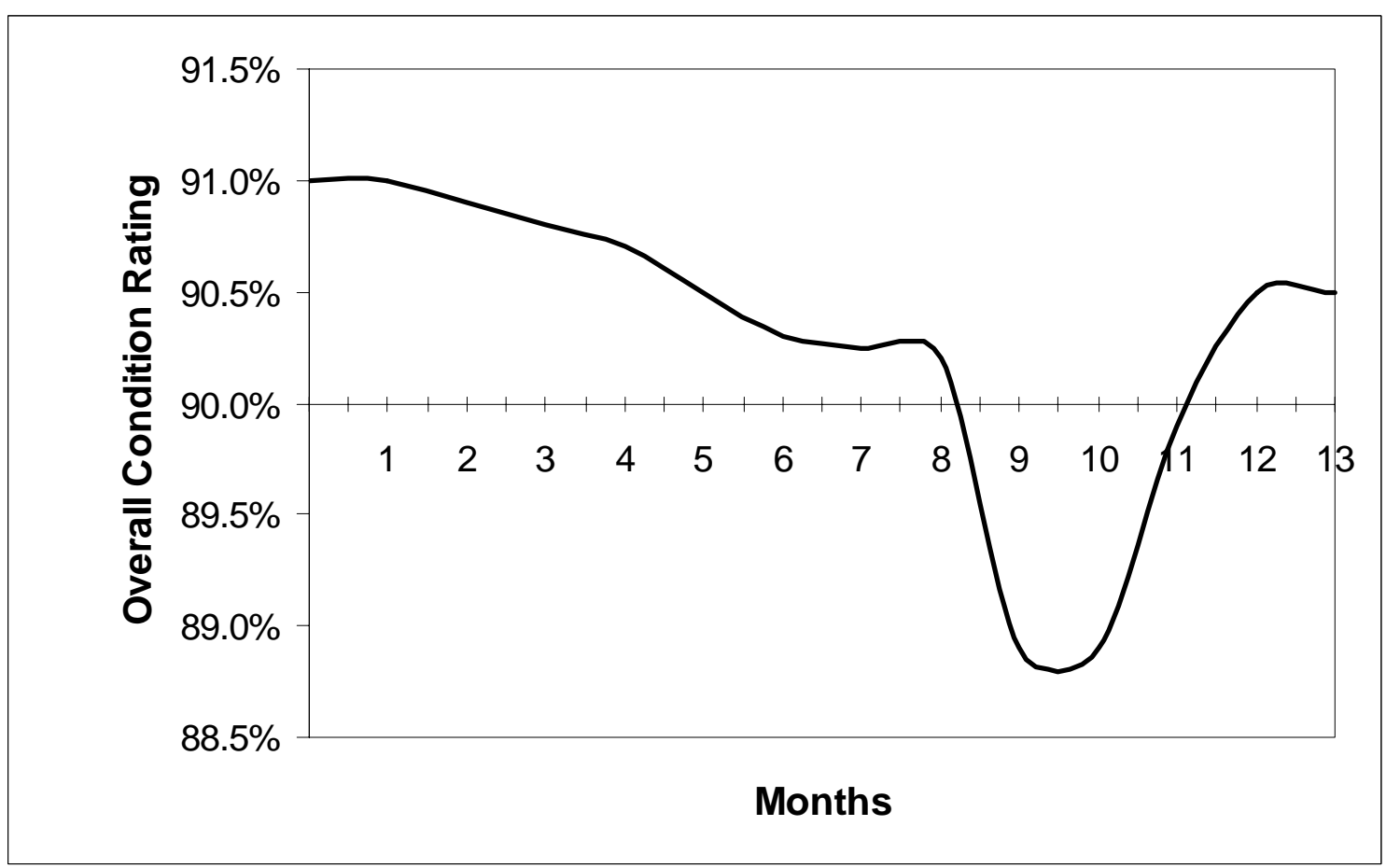

Figure 1.1: The overall condition rating of the paved ditches asset item throughout a year

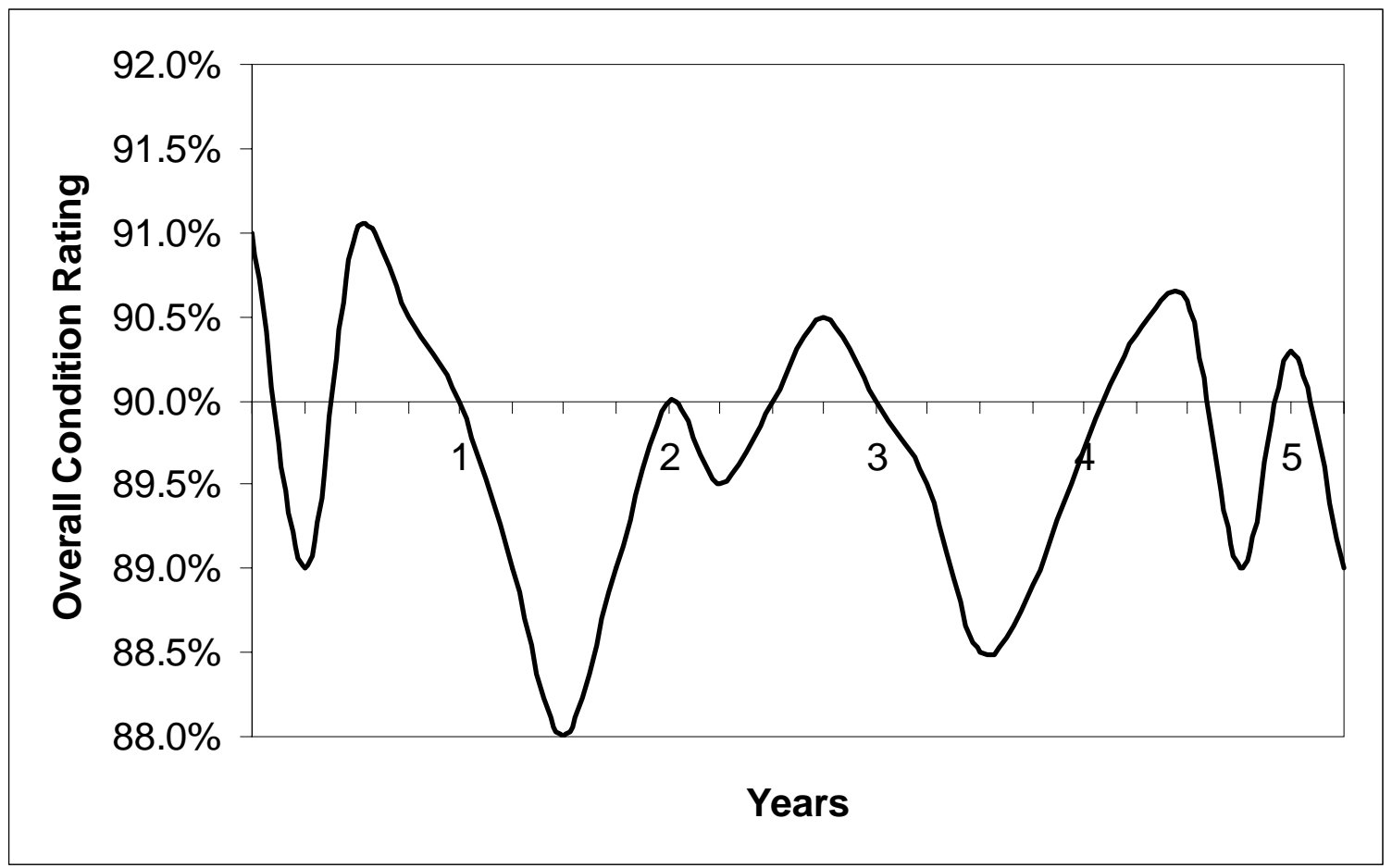

Figure 1.2: The overall condition rating of the paved ditches asset item throughout the contract term (which is 5 years) 
This is the kind of the maintenance approach which would most likely be implemented by a prospective contractor doing work under the current contract clauses. This maintenance approach provides the desired level of performance as per the contract but it does not improve the quality and overall condition of the assets. Moreover, it does not ensure the long term performance of the assets that are maintained. This significantly contradicts the concept of asset management (as mentioned before, the contract that is in the scope of the research is defined and named as an asset management contract (VDOT 1996)) which requires the assets maintained by the contractor to be upgraded (Falls et al. 2001). This also contradicts the definition of performance based road maintenance contracts which calls for the achievement of long term road condition standards (Frost and Lithgow 1998).

A number of VDOT personnel have expressed their views about this issue for the current contractor. Although the overall view was that the contractor's work was acceptable, a number of concerns were expressed such that the contractor has been focusing on short term maintenance solutions and applications rather than more extensive long term operations. VDOT personnel furthermore expressed a common concern that the contractor has been carrying out "band aid" maintenance activities that enable itself to pass visual inspection but which result in "underinvesting" in the infrastructure that would lead to poor future performance of the infrastructure. Specifically on the pavement item, it has been commented that the strategies carried out by the current contractor to achieve smoothness place more emphasis on relatively less expensive micro-surfacing, slurry seal and thin overlays (VDOT 2002).

In the "Final Report on an Action Plan for the Distributed Authority to Promote Effective Administration and Management of VDOT's Contract with VMS, Inc.” it has been stated that “VDOT's strategy tends to take a longer view by focusing more resources on correcting failures in the pavement structure. Obviously, VMS and VDOT are approaching pavement management with different strategic focus. If long term pavement performance is critical to VDOT, which arguably it should be, VDOT should work with VMS to achieve that end. The strategies employed by VMS may place VDOT at higher risk for increased costs for pavement replacement in future years. VDOT should work with VMS to ensure that pavement and bridge structures are maintained for long term performance at the lowest life cycle cost” (VDOT 2002, pp 25). 
These views and comments reveal the expectations of VDOT from the contract. VDOT clearly indicates that, it not only wants the assets to be maintained at a certain level but also requires an improvement in the overall conditions of them as well as requiring the long term performances of them. However, current contract conditions and clauses neither force nor encourage the contractor to implement a maintenance system which would result in the improvement in the overall conditions of the assets or which would provide the long term performance of the assets. Under current contract language, the contractor is only obligated to barely achieve the performance criteria and targets. Hence, it may be willing to maintain the highway assets at this level, not improving their overall condition or providing long term performance, in order to keep the costs it incurs at a minimum level. Had the contract contained a warranty provision covering the issue of defects, there would be a built-in incentive for the contractor to strive to at least ensure the long term performance of the assets since under such a provision it would otherwise incur the costs in a later time because of the warranty it provides.

In addition to this, even if the contractor carries out the maintenance activities with the best efforts and practices to improve the overall conditions of the assets and hence to provide long term performances of them, presence of some post-project completion defects would still be very likely. This is due to the nature of construction activities in which some defective materials and/or workmanship is almost always unavoidable. A contractor performing work under the current contract provisions bears no liability, making VDOT incur all the costs related to these post-project completion defects.

It is essential to comprehend what is meant by the concepts of "improvement of the overall condition of assets" and "long term performance of assets". The assets within the highway system are continuously in use and thus deteriorating. There is a point in their life cycle at which no more deterioration is acceptable due to safety and/or aesthetical reasons. This is defined as the threshold level by the agencies. Long term performance means that the time for these assets to reach that particular point (threshold level) should be long enough as dictated by the agency. And, this longevity can be attained by improving the asset's condition. During the maintenance activities, if the overall condition rating of the asset is barely kept at the level as stated in the performance targets, then as the maintenance activities are terminated, that asset item's overall condition rating drops below the acceptable performance target level in a very short time. This discussion is represented in Figure 1.3 graphically. Going back to the 
discussion presented previously, this may well be the case for the VDOT contract which does not contain any warranty clause. This fact has been the motivation in starting this research and thus establishes the problem definition of this research.

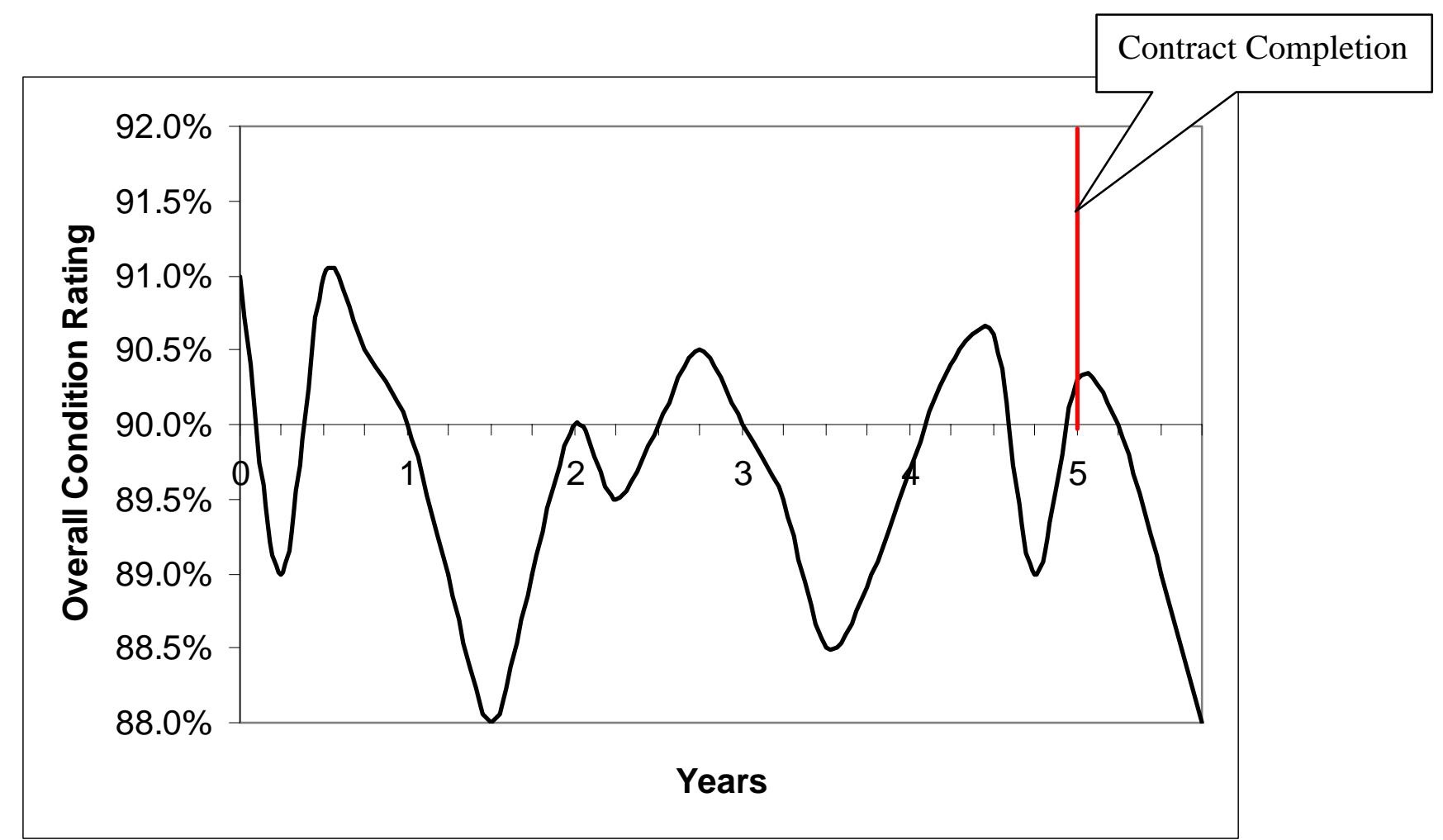

Figure 1.3: The overall condition rating of the paved ditches asset item before and after the contract completion date

The current VDOT performance based highway maintenance contract does not encompass clauses related to the warranty issues. To state more clearly, in the current contract, the contractor does not provide any warranty to the VDOT for the services it is obligated to undertake. The contract is mute in this subject, making the contractor incur no liability for the underperformance of the maintenance activities. Obviously, this might lead to some cases which VDOT would not be willing to encounter.

A very important consequence of the absence of warranty clauses is the great amount of risk imposed upon VDOT. A contractor performing maintenance services under these conditions would bear liability neither for the underperformed work nor for the defects taking place immediately after the end of the contract. There are some undesirable consequences that may be encountered by VDOT in its future contracts if it keeps the same language in those contracts. 
Warranty clauses in contracts are vital to ensure the quality and durability of the work after the project completion. Warranty clauses, if developed carefully, give the contractor the motivation to implement superior maintenance practices to improve the overall conditions of the assets during the contract period. This is done in order to lengthen the life of each asset item and achieve the long term performance; otherwise the contractor is required to come back and implement remedial actions to the asset items showing defective properties to bring them back to or above the warranty criteria required throughout the warranty period. Thus the problem discussed above can be solved through the incorporation of warranty clauses to the future contracts. This research is aiming to solve the defined problem by developing a warranty clause template which then can be incorporated into the future performance based road maintenance contracts issued by VDOT.

\subsection{PURPOSE, SCOPE, AND SPECIFIC OBJECTIVES}

\subsubsection{Purpose}

The purpose of this research is to develop a warranty clause template for performance based road maintenance contracts and then propose it to be used in the future performance based road maintenance contracts that will be issued by VDOT.

\subsubsection{Scope}

The scope of this research is limited in three senses:

i) The first limitation comes onto the scene as the usability of the research's findings by the entities other than VDOT. The research's findings are not aimed to be used in the contracts that are issued by the entities other than VDOT because the developed warranty clause template is based on the analysis of the contract that is issued by VDOT. This means that in developing the warranty clause template, special consideration was given to VDOT's needs and conditions and, most importantly, expectations from the contract.

ii) The second limitation is for the type of project. The research elaborates only on $\mathrm{road} /$ highway maintenance projects. Other types of construction projects are out of the scope of the research. 
iii) The third limitation is about the content of the research. Despite the fact that the research focuses on the current VDOT- VMS contract as a whole to figure out some opportunities to enhance VDOT's future contracts and use it as a learning document, it does not go into detail trying to explore every single clause. The research only deals with the warranty issues which are believed to be the most striking ones from the viewpoint of the owner entity- VDOT.

\subsubsection{Specific Objectives to Achieve the Purpose}

To achieve the purpose of this research, there are five objectives (which are linked to each other) that need to be fulfilled. Each objective was taken into consideration in the given order. When a satisfactory result was achieved in one objective, the next objective became the one whose answer was sought. Once all the objectives were achieved, so was the purpose of the research. These specific objectives are as follows:

i) To define "defect" for each asset item, in the context of road maintenance. This is essential to establish the warranty criterion for each asset item that will be used to asses the warranty compliance of the contractor. The warranty criterion is the most important component of the developed warranty clause template.

ii) To identify the length of the period so called "warranty period" or "defects liability period" for each asset item, which would meet the expectations of VDOT in road maintenance projects and which would also be an acceptable and reasonable duration for VDOT's prospective contractors. This is another important component of the developed warranty clause template.

iii) To identify other components that should be present in a warranty clause.

iv) To make distinctions between the various asset items of the highway system in order to propose that a different warranty clause (that takes into account the differences in properties of various asset items) needs to be developed for each asset item.

v) To develop a complete and comprehensive warranty clause template as well as a warranty clause example (by taking VDOT's specific concerns into account) which can be used in developing warranty clauses for each asset item. This warranty clause template is then to be presented to VDOT to be assessed and be incorporated into the future performance based road maintenance contracts it will issue. 


\subsection{METHODOLOGY}

\subsubsection{Overview of Universally Accepted Research Methodologies}

Before going into the details of this research's methodology, a general overview of the two universal types of research methodologies will be presented. In this research, the M.S. candidate followed a methodology which is not common for the research carried out in the field of engineering. That is the main reason for the M.S. candidate to include a synopsis of the common research methodologies as a brief discussion.

According to Burrell and Morgan, research methodologies can vary in a range. However, they define the research methodologies at the extreme ends of the continuum as nomothetic and ideographic (Burrell and Morgan 1979). In its broadest definition, nomothetic methodology focuses on highly systematic procedures and techniques. A very scientific strictness and standard is present in the process of testing the validity of the hypothesis of the research. This methodology is common for the research conducted in natural sciences. Ideographic methodology, on the other hand, emphasizes the analysis of subjective ideas which the researcher proposes. The researcher, observing the situations and involving her/himself in the everyday flow of life, generates these ideas. The comparison of some basic elements of each methodology is presented in Table 1.1.

Table 1.1: Comparison of nomothetic and ideographic methodologies (Source: Gill and Johnson 1997, pp 37)

\begin{tabular}{|l|l|}
\hline \multicolumn{1}{|c|}{ Nomothetic Methodology } & \multicolumn{1}{|c|}{ Ideographic Methodology } \\
\hline Deduction & Induction \\
\hline $\begin{array}{l}\text { Explanation through causal relationships of } \\
\text { variables and effects of those. }\end{array}$ & $\begin{array}{l}\text { Explanation of subjective meaning and } \\
\text { understanding. }\end{array}$ \\
\hline Generation and use of quantitative data & Generation and use of qualitative data \\
\hline $\begin{array}{l}\text { Use of various controls, physical or statistical } \\
\text { so as to allow the testing of hypothesis }\end{array}$ & $\begin{array}{l}\text { Commitment to research in everyday settings, } \\
\text { to allow access to and minimize reactivity } \\
\text { among the subjects of research }\end{array}$ \\
\hline Highly structured research methodology & Minimum structured research methodology \\
\hline
\end{tabular}


This distinction between methodologies is a widely accepted phenomenon. Remenyi, although using two different names for the corresponding methodologies as empirical and theoretical respectively, highlights the characteristics of those in collaboration with Gill and Johnson (Remenyi 1996).

As mentioned earlier, research methodologies cover a range. On the one extreme end of the range, the so called nomothetic methodology, research is carried out by laboratory experiments, quasi-experiments, and surveys. On the other extreme end, the so called ideographic methodology, research is conducted using action research and ethnography.

\subsubsection{Research's Methodology, Research's Phases, and the Corresponding Thesis Outline}

Typically, researchers with a scientific or engineering background are inclined to use methodologies close to nomothetic methodology. On the other hand, this research was set to use a methodology which is closer to the ideographic end of the spectrum. Thus, contrary to most engineering research that possesses quantitative natures, this research has a qualitative nature.

This research's methodology consists of five phases which will be discussed below. As far as this thesis's outline is concerned, each phase is presented in one chapter. These phases and corresponding thesis chapters are also illustrated in Figure 1.4.

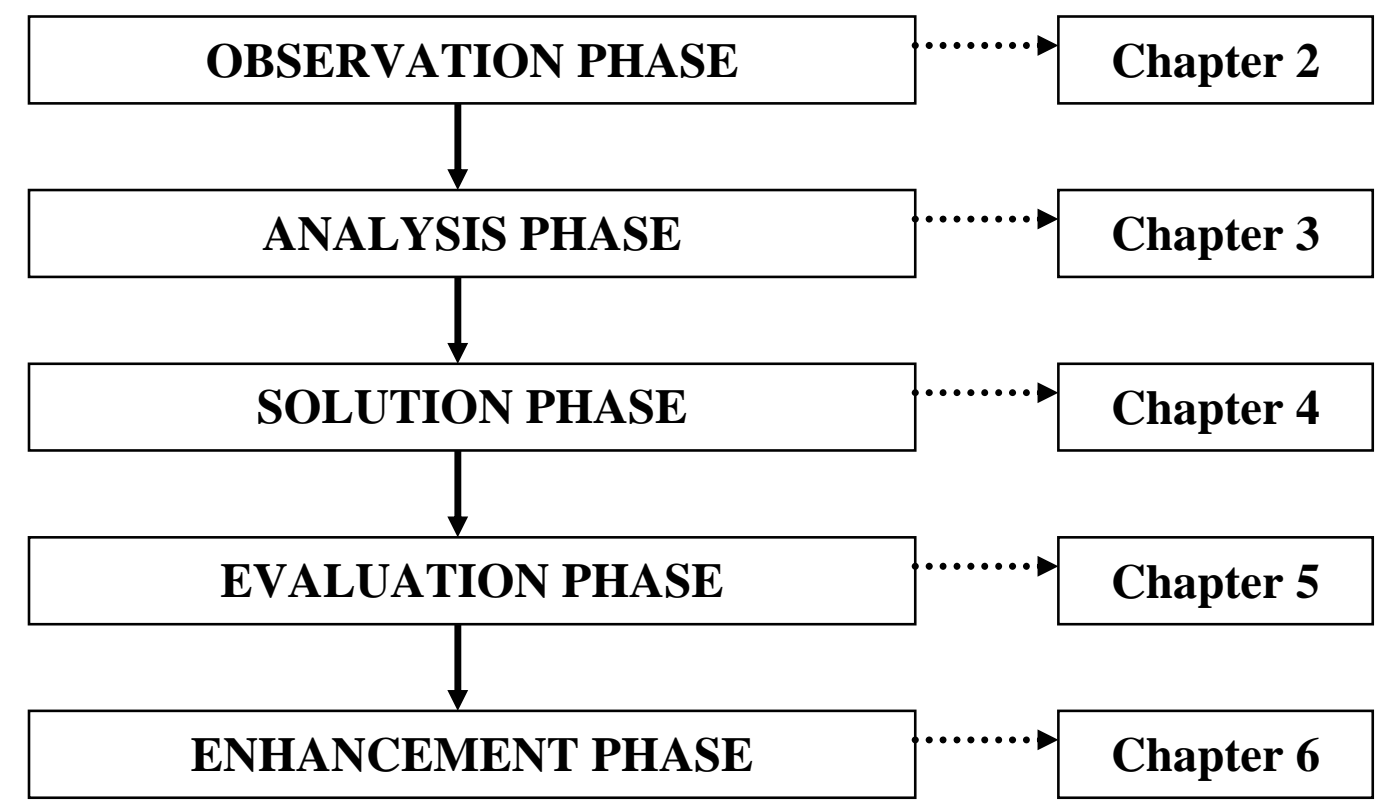

Figure 1.4: Phases of the methodology of this research and corresponding thesis chapters 


\subsubsection{Phase 1: Observation Phase}

As discussed above, ideographic methodology highly depends on observing situations and then analyzing those in order to produce subjective ideas to achieve the research goals. Thus, the first phase to achieve the objectives of this research was to perform a significant amount of literature review to be able to observe the situation. In the mean time, an interview was conducted with a contract professional and workshops about the subject matter were attended. These also helped the M.S. candidate to observe the situation comprehensively. The observation phase of this research's methodology is presented in Chapter 2.

A very intense literature review was performed to reach the objectives of the research. In fact, the literature review carried out has been pertinent to the development of the warranty clause template as aimed by this research. This literature review, which is presented in Chapter 2, was performed in four steps. In the initial step, a comprehensive understanding of the warranty concept was achieved by the M.S. candidate. In the following step, the literature review's main focus has been on the highway construction and maintenance contracts that included warranty provisions. Specially, the contracts that were issued by various state departments of transportation (DOT) within the USA were examined in this phase. The contracts examined were written either with "performance based" or "methods and materials based" specifications. This step was essential to observe the usage of warranties, particularly within the USA. By the end of this step, sufficient information was gathered with respect to the issues related to the implementation of warranties. Moreover, the experiences of the state DOTs with the highway warranty concept were identified. This helped the M.S. candidate to understand the components, consequences, advantages, disadvantages, and common pitfalls of the highway warranties. This detailed observation of the warranties initiated the M.S. candidate to think of ways to develop warranties that would avoid these pitfalls and that would be applicable to the maximum extent possible. In the third step of the literature review, the M.S. candidate narrowed down the scope to identify literature that was directly related to the contract that is in the scope of the research. This time, performance based road maintenance contracts that included warranty provisions (both in the USA and around the world) were identified. By elaborating on these, the M.S. candidate was able to collect more specific information related to the implementation of warranties within performance based road maintenance contracts. The last step of the literature review was to examine and study the language used within the contracts that were identified in 
the previous steps of the literature review. This helped the M.S. candidate to get familiar with the contract clauses and languages. To supplement the objectives of these steps, standard forms of contracts prepared by EJCDC, AIA, FIDIC and also highway and bridge specifications prepared by various states were also worked on. Also, two performance based contracts which are executed under the Federal Acquisition Regulation and which have scopes other than road maintenance were examined in order to get an idea about the usage of warranties within these contracts in accordance with the Federal Acquisition Regulation.

This literature review, which was performed within the observation phase of the methodology, had utmost importance to make the M.S. candidate become familiar with various contract types, the language used within the contracts, and common important issues within the contracts. By the help of this literature review, the M.S. candidate was able to identify the various contracts' styles of usage of warranty clauses and then was able to use these clauses to be tailored to meet the specific needs of VDOT performance based road maintenance contracts. Later on, the warranty language used within these contracts were adopted and then adapted to the contract that is in the scope of this research.

Also during the observation phase, the M.S. candidate has conducted an interview with the contracting officer, Nancy Gunderson, of the Pentagon Renovation Project (PENREN). Some information regarding the optimization of the length of the warranty period has been gathered from her. Also, applicable laws and regulations that are related to warranty issues have been discussed with this government employee who has a sizeable amount of experience and good insight into contracts.

One other task that the M.S candidate has completed for the observation phase was attending workshops. Given the fact that performance based contracting is a new concept which is at the development stage, there are numerous conferences and workshops being held about it. The M.S. candidate has attended two workshops about the subject matter. The first workshop that the M.S. candidate attended was called "Performance Based Contracting Workshop.” It was taught by Vernon Edwards who is currently working as a consultant and who has worked in various divisions of the Department of Defense as a contracting officer for 14 years. During the workshop, he emphasized the development of the statement of work in a performance based service contract. Thus, the M.S. candidate has highly benefited from this workshop regarding very important issues related to the language of a contract and the composition of sentences and 
selection of good words that should be present in the clauses of a contract. A great deal of background information about performance based contracting has also been gained in this workshop. The M.S. candidate has also attended another workshop called "Evaluating and Managing Performance Based Contracts” presented by Robert Bowes. This workshop has also been a good guideline for the M.S. candidate in the issues related to the administration of performance based contracts.

\subsubsection{Phase 2: Analysis Phase}

After the observation phase, the observed situations were analyzed. This phase was essential to develop the solution to the problem, which was identified in this research (in Section 1.4). This was the analysis phase. This phase is presented in Chapter 3.

\subsubsection{Phase 3: Solution Phase}

This was the phase in which the solution was developed. In the solution phase, a complete and comprehensive warranty clause template, which is believed to form the solution to the identified problem, was developed. This phase is presented in Chapter 4.

\subsubsection{Phase 4: Evaluation Phase}

The solution as developed through the ideas of the M.S candidate was subjective and somehow representing the views of the M.S. candidate. Therefore, this solution needed to be presented to a group of individuals, who are knowledgeable and experienced in the subject matter, to get some feedback. This formed the evaluation phase of the research. After the warranty language was developed, it was presented to a panel of experts, members of which were professionals who are highly involved in highway construction and maintenance projects and who also have sizeable knowledge in the administration of warranties. The panel basically was composed of professionals representing the each party involved in a highway construction and/or maintenance project (i.e. the contractor and the state DOT,) and professors within the academia that have been performing research about the warranty concept for a long time. This phase was imperative to gain sufficient feedback on the applicability of the developed clauses 
and whether they could be incorporated into the future performance based road maintenance contracts issued by VDOT. This phase is presented in Chapter 5.

\subsubsection{Phase 5: Enhancement Phase}

The received feedback was then analyzed to correct the deficiencies in the solution as identified by the panel of experts. This final phase was the enhancement phase. Through this exercise, the solution was enhanced and thus the research was finalized. This phase and final results of the research are presented in Chapter 6 .

As can be grasped form the content of the phases discussed above, the methodology used in this research is significantly different from the methodology of a quantitative research in three ways. First, the methodology intensely depends on the literature review and the comments of the professionals that are involved and knowledgeable in the subject matter. This is actually what the ideographic methodology is all about. In ideographic methodology, the researcher uses professionals' ideas and, by using her/his own intellectual skills, adds other or different opinions to achieve the solution of the problem. Second, the methodology does not contain evidences as opposed to quantitative research which substantially depends on firm evidences. The lack of evidence is also perfectly okay for the ideographic methodology to be used in this qualitative research. Lastly, findings of this research cannot be tested or verified easily by making experiments or running simulation models as in the case of quantitative research. This research's findings can be tested at earliest in the next performance based road maintenance contract issued by VDOT. In current conditions, it looks like that it will not be earlier than July 2007 (as discussed in Section 1.2). Nonetheless, even if this research's findings are not tested at all, if it can show the community and authorized people the reasons behind the research, the methodology of the research, and the end product of the research are good enough to be tested, it will have significantly contributed to the body of knowledge. 


\section{CHAPTER 2}

\section{PHASE 1- OBSERVATION PHASE}

As mentioned in the previous chapter, the first phase of the methodology of this research is the observation phase in which a significant amount of literature review is performed. This chapter presents the findings of this intense literature review.

\subsection{PREVIOUS STUDIES ABOUT THE RESEARCH}

As far as the M.S. candidate knows, there has not been any study about this particular issue of development of warranties to be incorporated into the VDOT written performance based road maintenance contracts. This is mainly due to the fact that this is the first performance based road maintenance contract that has been issued by VDOT. The initial term of the contract was decided to commence in December 1996 and end in July 2002. The contract was renewed for a five year period to start in July 2002 by the agreement signed in June 2001. Even though the contract was renewed, no change within the contract language, and particularly within the problematic areas mentioned before, has been introduced to the renewed contract. This fact, combined with the extensive literature review carried out until now led to the M.S. candidate's belief of the absence of a previous comprehensive study about the subject matter, i.e. development of warranties for the performance based road maintenance contracts issued by VDOT.

Contrary to absence of previous work that addresses this particular issue of VDOT written contracts, there is a wide range of literature with varying scopes related to the research. They will be presented under $\mathbf{8}$ main sections: Introduction and development of highway warranties in the USA., examination of highway warranties in the USA, highway warranties in the European countries, examples of international performance based road maintenance contracts, performance based road maintenance contracts issued in the USA, standard forms of traditional design-bid-build contracts, highway and bridge specifications prepared by state DOTs, examples of performance based contracts other than road maintenance contracts in the USA. In 
order to familiarize the reader with the legal concepts, a definition section will be presented before going further to examine the literature related to the research.

\subsection{LEGAL DEFINITIONS OF RELATED TERMS}

In the research, some concepts will often be used to describe the setting of the problems. These terms will also be used to enumerate objectives of the research and to propose valid results. The definitions of these concepts within legal context as extracted from legal dictionaries are as follows: (Garner 2001, Hill and Hill 1995)

Warranty: a promise in a contract which states that the subject of the contract is as represented, as in being free from defective workmanship. Written guarantee of the integrity of a consumer product and of the maker's responsibility for the repair or replacement of defective parts. An express or implied promise that something in furtherance of the contract is guaranteed by one of the contracting parties.

Guarantee: to pledge or agree to be responsible for another's debt or contractual performance if that other person does not pay or perform. Usually, the party receiving the guarantee will first try to collect or obtain performance from the debtor before trying to collect from the one making the guarantee (guarantor). A guarantee is the promise to pay another's debt or fulfill contract obligations if that party fails to pay or perform.

Express Warranty: a warranty that is created in a contract by a statement of fact (as a description) which is made about the object of the contract and which forms a basis of the bargain.

Implied warranty: an assumption at law that products are "merchantable," meaning they work and are useable as normally expected by consumers. A warranty that is not expressly stated but that is recognized or imposed by the law based on the nature of the transaction. A warranty arising by operation of law because of the circumstances of a sale, rather than by the seller's express promise.

Full warranty: A warranty that fully covers labor and materials for repairs. Under federal law, the warrantor must remedy the consumer product within a reasonable time and without charge after notice of a defect or malfunction. 
Constructional Warranty: A warranty from the building contractor of a new home that the home is free of structural, electrical, plumbing, and other defects and is fit for its intended purpose.

Liability: one of the most significant words in the field of law, liability means legal responsibility for one's acts or omissions. Failure of a person or entity to meet that responsibility leaves him/her/it open to a lawsuit for any resulting damages or a court order to perform (as in a breach of contract or violation of statute). In order to win a lawsuit the suing party (plaintiff) must prove the legal liability of the defendant if the plaintiff's allegations are shown to be true. This requires evidence of the duty to act, the failure to fulfill that duty and the connection (proximate cause) of that failure to some injury or harm to the plaintiff. Liability is the quality of being legally obligated or accountable. It is the legal responsibility to another or to society enforceable by civil remedy or criminal punishment.

Strict Liability: automatic responsibility (without having to prove negligence) for damages due to possession and/or use of equipment, materials or possessions which are inherently dangerous. In this concept, there is no need to prove fault or negligence to establish that a person or entity is liable for some act or failure to act. The fact that the act or failure to act occurred is all that is necessary to establish liability. Strict liability does not depend on actual negligence or intent to harm, but it is based on the breach of an absolute duty to make something safe.

$\underline{\text { Defect: }}$ An imperfection or shortcoming especially in a part that is essential to the operation or safety of a product.

Defective: Containing an imperfection or shortcoming in a part essential to the product's safe operation.

Latent Defect (Hidden Defect): A product imperfection that is not discoverable by reasonable inspection and for which a seller is generally liable if the flaw causes harm. Upon discovering a hidden defect, a purchaser may revoke a prior acceptance.

Standard of Care: The care and skill ordinarily used by members of the engineer's profession practicing under similar circumstances at the same time and in the same locality. Engineers should perform the same level of expertise with the people of their profession under the same circumstances. Standard of care is the watchfulness, attention, caution and prudence that a reasonable person in the circumstances would exercise. If a person's actions do not meet this standard of care, then his/her acts fail to meet the duty of care which all people (supposedly) 
have toward others. Failure to meet the standard is negligence, and any damages resulting therefrom may be claimed in a lawsuit by the injured party. The problem is that the "standard" is often a subjective issue upon which reasonable people can differ.

Common Law: The body of law derived from judicial decisions, rather than from statutes or constitutions.

\subsection{INTRODUCTION AND DEVELOPMENT OF HIGHWAY WARRANTIES IN THE USA}

Historically, the contractors of a highway construction or maintenance project were not required, nor have they offered to warrant the after-the-contract performances of their services and products. This was mainly due to two reasons. First, the design was performed by a separate entity (i.e. designer) and the contractors did not know the existing conditions upon which a highway design was based. Moreover, contractors have not been able to know the demand that a highway would encounter after it is placed in service. Secondly, the contractors were doing what they were told to do. They were being directed by the owners and designers as which materials to use and which methods to implement. This approach has been implemented for decades and believed to be resulting in the best value to the public (Stephens et al. 2002).

Unlike many consumer products which are produced in large quantities within certain, identical and controlled conditions, each highway project (whether it is a new construction or a maintenance project) is unique with regards to variables such as climatic, soil, traffic and pavement conditions. Moreover, these factors affect the long term performance of the highway after the construction or maintenance activity is completed but the dynamics in which they affect the highway's performance individually as well as collectively have not been completely identified (Stephens et al. 2002). Thus, it has been almost impossible to predict how well a highway would perform after it has been placed in service. As a result of this, designers and contractors have been relieved of explicitly warranting that their work will perform as anticipated. By statute, engineers have been obligated to produce the best design with the information they have and the contractors have been required to build as per the design. To ensure this and the integrity of the contractors’ work, contractors have been required to carry a 
performance bond in some states by the DOTs. This bond is generally used in governmentfunded projects and simply is an assurance that the materials and the workmanship of the contractor will satisfy the requirements of the contract documents during the project and up to one year after project completion and acceptance (Hancher 1999). While this is still an assurance for the owner, this is not as comprehensive as a warranty clause. Moreover, this performance bond does not guarantee the long term performance of the products or services provided by the contractor (Russell et al. 1999).

Contractors did not have input in the design and thus after-the-project defects could not be directly, confidently, and entirely attributed to them. In fact, a study conducted by Josephson and Hammarlund reveals that the causes of defects in construction are difficult to identify in the traditional contracting environment (design-bid-build) in which materials based or methods based specifications are used (Josephson and Hammarlund 1999). Thus, in such an environment, the contractor may not be held responsible for the long term performance of the construction or the maintenance it performs. As design responsibility started to be given to the contractor through the design-build concept (a procurement method in which the builder also designs the project), states have started to believe that it was time to revisit the warranty issue. In fact, the warranty concept was very common for so many consumer products that their merits in the highway construction and maintenance started to be reconsidered. Within design-build and performance based concepts, since the control for the both stages (design and construct or maintain) of the project is given to the contractor, the defects occurring after the completion of the project can almost entirely be attributed to the contractor. That was the reason that initiated the "search for the warranty" in the federal level and in many states. States started to require warranties to ensure the quality and long term performance of the projects and to completely transfer the risk of the after-the-project completion defects to the contractors.

The search for the warranty was a part of an overall endeavor initiated by the Federal Highway Administration (FHWA). FHWA initiated Special Experimental Project (SEP-14, Innovative Contracting) to encourage the use of nontraditional contracting practices which have the potential to improve the overall quality of the US highways and minimize the adverse effects to the road users. SEP-14 commenced in 1988 with the establishment of a Transportation Research Board (TRB) task force to evaluate the "Innovative Contracting Practices”. Within the "Innovative Contracting Practices" concept, the task force identified four areas that needed 
consideration: Bidding procedures, materials control, quality considerations, and insurance and surety issues. After considering these and making a thorough study, the task force has made several significant recommendations, two of which were:

- A nationwide effort should be initiated to transition from method specifications to performance related specifications and the performance related specifications should include incentive and disincentive provisions to encourage better quality (FHWA 2002, pp 2).

- The potential for use of warranties or guarantees and the design-build contracting should be investigated (FHWA 2002, pp 2).

The task force subsequently requested that FHWA establish a project to be able to evaluate the task force's recommendations and then FHWA initiated the SEP-14 in 1991. The objective of the SEP-14 was "to evaluate "project specific" innovative contracting practices, undertaken by the state highway agencies, that have the potential to reduce the life cycle cost of projects, while at the same time, maintain product quality" (FHWA 2002, pp 2). SEP-14 provided some administrative flexibility to the states that were willing to participate in the project to evaluate promising innovative (non traditional) contracting practices. Some of the innovative contracting practices that were implemented and evaluated under SEP-14 were cost plus time bidding, lane rental, design-build contracting, and warranty clauses.

Concurrently, the highway community who was willing to explore the innovative contracting practices has decided to visit the European countries who had been very sophisticated in innovative contracting practices for years. Within this context, in 1990 and 1992, a group of highway professionals visited some European countries (European Asphalt Tour and European Concrete Tour respectively). Numerous European practices, one of which was the warranty concept, were listed by the tour's participants as the possible causes of the observed higher quality of European roadways compared to the ones in the USA. In addition to these tours, in 1993, a study tour named "Contract Administration Techniques for Quality Enhancement” (CATQEST) was undertaken in which Germany, France, Austria, and Spain were visited. The study team was composed of various professionals from FHWA, state highway agencies, Associated General Contractors (AGC) and American Road and Transportation 
Builders Association (ARTBA). The study team primarily focused on the procedures implemented in Europe to assure that a high quality product is achieved. The main finding of the study team was that in Europe, the quality consciousness was present within both the agencies and the contractors.

Prior to 1991, FHWA had a longstanding policy that restricted the use of warranties on Federal-aid projects to electrical and mechanical equipment only (FHWA 2002). The basis for this restriction was that the warranties may somehow result in the funds (Federal aid funds) to contribute to the maintenance costs; and the use of Federal-aid funds for routine maintenance is against the law (FHWA 2002). Nonetheless, a very few number of states were implementing warranties on non-Federal projects prior to 1991, North Carolina being the first state to implement a warranty in a pavement marking project in 1987. Then, The Intermodal Surface Transportation Efficiency Act (1991 Highway Act-ISTEA) was introduced. A ruling within this act allowed states to exempt themselves from this warranty restriction for Federal aid projects located off the National Highway System. For projects meeting these conditions, states began to use warranty clauses in accordance with their procedures. By this ruling and under SEP14, the FHWA has approved state proposed warranties on an experimental basis. The objective of the ruling was to encourage quality and contractor accountability and evaluate the results. Four years later, on August 25, 1995, FHWA issued an Interim Final Rule, changing its approach to the warranties greatly. This rule allowed greater use of warranties and encouraged states to use warranties for projects on the National Highway System with the requirement that the warranty provisions shall be for a specific construction product or feature. Routine maintenance items are not eligible. This rule furthermore prohibits warranties for items that are not within the control of the contractors. This Interim Final Rule drew 20 responses and comments from 19 organizations including 11 associations, 6 State DOTs and 2 private companies. Even though the majority (13) of the responses were critical of the warranty concept, FHWA was not convinced that the comments were significant enough to change the Interim Final Rule (23 CFR Part 635) and thus adopted it as final without any change. The Warranty Final Rule was published in the April 19, 1996 Federal Register (Hughes 1996).

Prior to the 1995 Interim Final Rule, 8 states had incorporated warranties into their contracts to participate in the SEP-14. After the 1996 Warranty Final Rule, FHWA stated that the warranties were no longer experimental. And with this, the use of warranties by state DOTs 
across the country has increased significantly. In fact, several states have introduced legislations to require their DOTs to implement warranties for their highway construction and maintenance projects. Between the approval of the Interim Final Rule in 1995 and 1997, the number of warranty implementations in USA has increased by over 1000 percent as shown in Figure 2.1 (Russell et al. 1999).

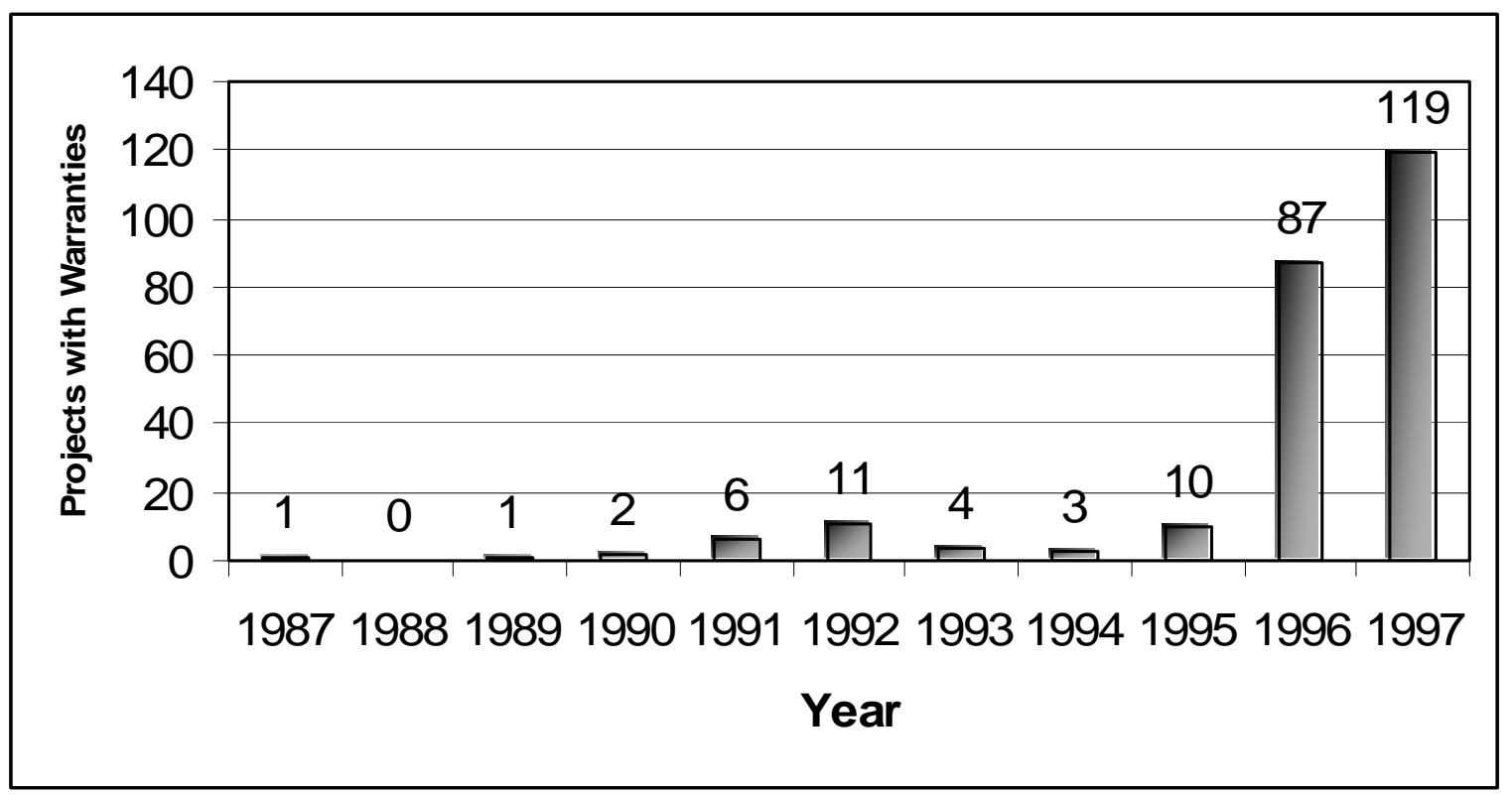

Figure 2.1: Number of highway projects with warranties completed by year in USA (Source: Russell et al. 1999, pp 15)

Moreover, in September 2002, a panel with the attendance of professionals from the Federal, State, and local government and industry executed another study tour; to investigate specifically the warranty concept this time. The countries visited were Spain, Germany, Denmark, Sweden, and Great Britain. The name of the tour, which was sponsored by the FHWA and American Association of State Highway and Transportation Officials (AASHTO) under the guidance of the National Cooperative Highway Research Program (NCHRP), was "European Asphalt Pavement Warranties Scan.” The main purpose of the study team was to understand the policies used in Europe to administer the warranty concept and determine risk assessment for the agencies and the contractors. One of the conclusions arrived, as stated by the team co-chair 
John D’Angelo, was “They (the European countries) are achieving a better quality product and better relation with contractors" (Focus 2003, pp 1-paranthesis added). As a result of this tour, the team recommended that short term warranties be required by the Federal government to be used on all federally funded projects. The team furthermore commented that the state and local highway agencies should develop warranty programs by in-house education and industry involvement and then implement short- term warranties whenever it is suitable.

As a result of all of the abovementioned initiatives and efforts undertaken at various stages and by various agencies, there has been a considerable spread in the use of warranties for the highway construction and maintenance projects issued by the state DOTs. State DOTs that have used warranties for their highway construction and maintenance projects are Alabama, Arizona, California, Colorado, Florida, Illinois, Indiana, Kansas, Kentucky, Louisiana, Maine, Maryland, Michigan, Minnesota, Missouri, Montana, Nevada, New Hampshire, New Mexico, North Carolina, Ohio, Oregon, Pennsylvania, South Carolina, Utah, Virginia, Washington, West Virginia, and Wisconsin. Since 1987 (the first warranty implemented in the USA), around 250 projects have been completed using warranties. The details of some of the states' warranty experience will be presented in the following section.

\subsection{EXAMINATION OF HIGHWAY WARRANTIES IN THE USA}

As can be grasped from the information presented within the previous section, warranty concept to be implemented to the highway construction and maintenance projects is very new for the USA. It has been around for the last decade and although its use is promoted by the entities such as FHWA and NCHRP very vigorously, there has not been a very great number of applications up to the current date. This may be attributed to the perception of the warranty concept as "being challenging to implement" by the state DOTs. State DOTs bring up some concerns (which will be discussed in the following sub-sections) about the administration and applicability of the warranty concept within their projects. In fact, not only the state DOTs, but also the contractors and the surety companies raise some issues with respect to their perspectives for the applicability of warranty clauses within the transportation arena. Nevertheless, although the real applications are very few, there is a continuously growing interest in warranties. States 
perform research to address the concerns and issues raised by the mentioned parties in order to figure out the usability of the warranty concept by the state DOTs.

In the following sub-sections, first, some general aspects and remarks for the highway warranty concept will be elaborated on. Afterwards, the issues raised by various states, industry and the bonding agencies as well as the perspectives of these parties on the warranty concept will be presented. Then the experiences of some states with the warranty concept and perspective of FHWA on the warranty concept will be presented. And finally, advantages and disadvantages of the highway warranties will be listed.

\subsubsection{General Remarks about the Highway Warranty Concept}

As defined previously, " $a$ warranty is a guarantee of the integrity of a product and of the contractor's responsibility for the repair or replacement of deficiencies for a given period of time after the project completion. A warranty is an absolute liability on the part of the Warrantor, and the contract is void unless it is strictly and literally performed" (Hancher 1994, pp 5). By a warranty clause, the contractor is forced to come back to maintain the highway and thus to implement remedial actions whenever certain warranty criteria are not met after the completion of the project. In highway contracting, warranties may be applicable to the two types of construction activities and they are named as: Warranties for new construction and warranties for the maintenance work. Warranties are implemented to allocate the long term performance risk of a project to the contractor, to assure the increased quality of the constructed product and eventually to reduce the life cycle cost of the highway or the components of the highway. By warranties, the responsibility for the post construction performance is incumbent upon the contractor.

There are two kinds of warranties for the construction projects: Materials and workmanship warranty, and performance warranty. Under the materials and workmanship warranty, the contractor is responsible for correcting defects in work elements within contractor's control (materials and workmanship), during the warranty period (Hamilton 2001). There are a number of occasions under which a contractor cannot be held responsible for a defect or failure. On the other hand, under the performance warranty, quality is measured on the actual performance of the product, not on the properties of the construction materials or workmanship implemented. The contractor’s liability in performance warranties is significantly 
greater than the liability it incurs in materials and workmanship warranties. Unlike a materials and workmanship warranty, there are very few exceptions to contractor responsibility.

In either type of warranty, contractor's liability needs to be balanced with the contractor's control of the design. Generally materials and workmanship warranties are implemented for design-bid-build projects in which a separate entity other than the contractor is responsible for the design. Thus the contractor does not assume responsibility for the performance problems occurring due to design decisions. On the other hand, performance warranties are implemented for design-build projects or performance based contracts. Thus, in a scheme where performance warranties are implemented, the design decisions are on the contractor and the contractor is completely free in choosing the materials and methods to implement. Under both materials and workmanship warranties and performance warranties, all required remedial actions (repair or replacement of deficiencies) must be executed by the contractor at no cost to the owner.

Materials and workmanship warranties are easier to implement and may in fact only require the addition of one short paragraph into the project general conditions such as: “The Contractor will be required to warrant the workmanship and materials on all items for __ year(s), from the date of final acceptance” (Johnson 1999, pp 17). This type of warranty is very similar to the performance bonds issued in some states which is good up to one year after the completion of the project and which warrants the materials used and the workmanship of the contractor. On the other hand, performance warranties require major changes to the contract specifications and are harder to administer.

\subsubsection{Issues to be Taken into Consideration for the Highway Warranty Concept}

Up to this sub-section, a general picture of the warranty concept is presented. In the subsequent sub-sections the advantages and disadvantages will also be explained. This subsection elaborates on the issues that must be taken into consideration before implementing the warranty concept into a contract. These issues have been developed throughout the warranty experiences of the state DOTs, industry, and the surety companies and reflect a consensus of those as which items need to be considered in implementing warranties. 


\subsubsection{Type of Projects Appropriate for Warranty Implementation}

Not every project is suitable to implement warranties. The selection of right projects to implement warranties should be ensured. The natural inclination of a state DOT in choosing the project to apply warranties would be to identify the previous projects that had problems. Then the DOT may want to select projects which have similar conditions with the previous projects identified as having problems and implement warranties to prevent the occurrence of similar problems. However, this is not the correct approach (ODOT 1999).

The proper allocation of warranties begins with understanding the existing conditions of the project area. State DOTs should select the projects with uniform and average to good conditions so that these conditions may promptly be upgraded through the implementation of warranties (ODOT 1999). UTAH Technology Transfer Center has identified the projects covering the interstate system as good candidates to implement warranties. Furthermore, the same entity has identified hot mix asphalt (HMA) and bridge projects as possible contracts to implement warranties (Utah T2 Center 2002).

To implement warranties, the projects with the end products whose performances are affected by the least number of variables should be selected. Otherwise the contractor may argue that the cause of the defect present is something that the contractor has nothing to do with and which is beyond the control of itself. Montana Department of Transportation committee on warranties has identified the maintenance overlay projects as appropriate for warranty contracting. The committee commented on this selection stating that those projects are under the preventive maintenance concept and thus the overlays are typically done in roadways that are in reasonable condition with regards to cracking and rutting. Therefore, the performance of such an overlay would probably reflect the quality of the overlay itself independent of the pre-existing conditions of the highway. However in a later discussion, highway reconstruction over good sub-grade and chip sealing projects have been identified as to be more appropriate for warranty implementation (Stephens et al. 1998).

The transportation projects that state DOTs have asked for warranties up to current date are: Asphalt pavement, concrete pavement, pavement marking, bridge deck, crack treatment, micro-surfacing, patching, bridge painting, chip sealing, intelligent transportation system (ITS) components, landscaping, bridge components, and reflective sheeting for signs. Figure 
2.2 illustrates the distribution of completed projects with warranties (between the years of 1987 and 1997) with regards to the project type.

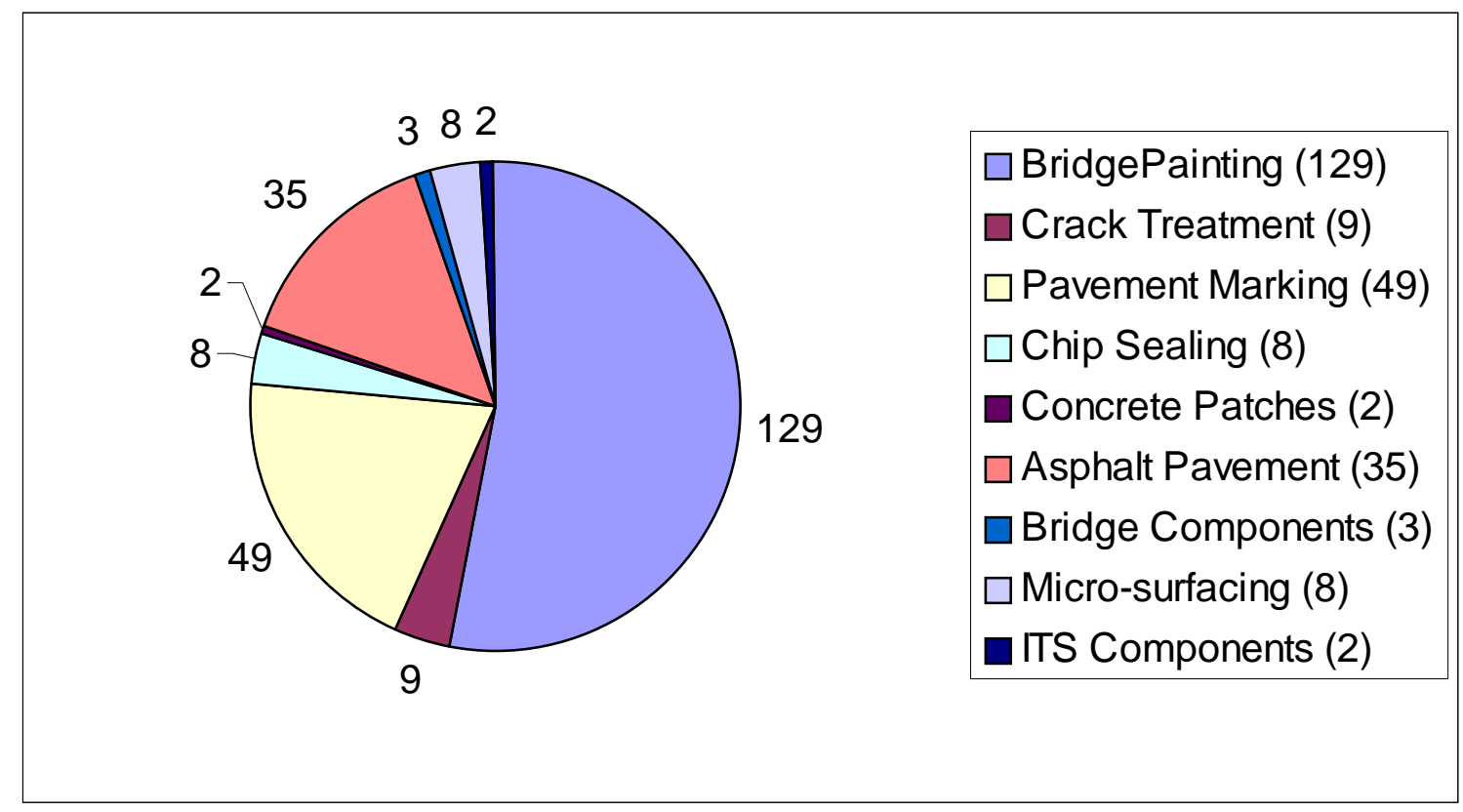

Figure 2.2: Distribution and number of highway projects with warranties for the years 1987-1997 (Source: Russell et al. 1999, pp 16)

\subsubsection{Length of the Warranty Period}

The required length of the warranty period for a highway construction or maintenance project is hard to establish. There is neither any straightforward way, nor established guidelines to be used in determining the length of the warranty period. In all the warranties implemented up to date, states have used periods ranging from two to twenty years. In fact, warranty period is a function of many variables. Some of the factors listed by the entities are: (a) the type of the project, (b) the state DOT's past experience with similar projects (i.e. historical data), (c) the input of the contractor in design (whether it is a design-bid-build or a design-build contract), (d) the type of specifications used (materials based, workmanship based or performance based specifications), (e) the region of the project, (f) the average daily traffic (ADT) and equivalent 
single axle loads $\left(\right.$ ESALs $\left.^{1}\right)$ that the completed product will carry, and (g) the sub-grade of the highway to be constructed or maintained.

The duration of the warranties for many consumer products (cars, toasters, etc.) is shorter than the design life of the product. Hence, the same concept applies to highway warranties. In determining the warranties, the main approach should be to find the time in which possible defects or failures (problems) may take place within the end product and then to establish the warranty period accordingly. In other words, enough time should be allowed for failures (if any present) to appear. Specifically in road maintenance projects, the warranty period should be long enough for maintenance defects (if any present) to become apparent but not so long that the treatment will deteriorate through the normal use. State DOTs may choose to cooperate with the construction industry and the surety companies to come up with a consensus on the warranty period's length. The deterioration of the highway resulting from the continuous usage and the weather effects is another factor to consider. Thus, in certain cases, the warranty period may need to be expressed in terms of both the age of the highway and the amount of traffic it carries such as “5 years or 50000 ESALs, whichever comes earlier” (Stephens et al. 2002). In fact this approach is similar to the one used by the automobile manufacturers. Car parts deteriorate as time passes and also as used. Thus, the duration of the car warranties are also stated in terms of the mileage made or the age of the car, whichever comes earlier, i.e. 5 years, 50,000 miles warranty.

In determining the duration of the warranties, there is one very important thing to be aware of. The duration chosen should be an optimum duration. The optimum warranty period denotes a duration which is long enough to provide assurance of the long term performance of the highway to the DOT, but which is not too long as not to needlessly escalate contract prices. A state DOT can issue a warranty for the whole design life of a pavement, say 50 years, believing that it will highly benefit from that since it will not assume responsibility of the defects occurring during the whole design life of the product. But in turn, what it would receive may be the highest bids it has ever encountered. Warranty is an assurance on the owner side which forces contractors to construct quality products which have long term performances. However, warranties should not create excessive burden on the contractors and be unreasonable for them.

\footnotetext{
${ }^{1}$ An ESAL is a measure of the load demand placed on a pavement by an 18,000 pound axle. The load demands of all the different types of vehicles expected to use a highway can be quantified in terms of the number of 18,000 pound axles that will generate the same total demand on the pavement as the actual traffic (Stephens et al. 2002).
} 
The more risk and responsibility the contractor assumes, the more money it will cost to the state DOT. That is why extended warranties (as expressed in consumer products like toasters etc.) should be avoided and warranty duration should be optimized in highway construction projects. Extended warranties are very common in consumer products which may sometimes be useful and save money to the consumer for very unreliable and delicate products. The benefits may worth the cost in such a case. But it is very unlikely for this to happen in highway construction projects. As a matter of fact, even in consumer products, if a consumer is offered an extended warranty and she/he accepts it, the salesperson does not give a better product to her/him. The consumer gets the same product with a money assurance in return for paying more money. In conclusion, keeping the warranty period as long as possible in order not to assume any responsibility for failures or defects for an extended period of time is not a suitable approach for highway construction projects and thus should not be implemented by state DOTs. A similar approach in determining the length of the warranty period that may be used by the state DOTs is what is called an “A-B System”. In this system, state DOT sets a minimum warranty period and the contractor is allowed to bid beyond this pre-established minimum period to increase the length of the warranty period. However, there is a maximum that the contractor can go up to in increasing the length of the warranty period (Johnson 1999). The A-B System will be discussed furthermore later in Sub-section 2.4.2.4.

The length of the warranty period is also very important as far as the bonding capabilities of the contractors are concerned. Bonding industry and contractors have brought up many issues about this. This is another issue which will be discussed in depth in the coming sub-sections.

Some of the average warranty period requirements of the state DOTs for different projects, as identified through a survey based on 37 projects, are presented in Figure 2.3 (Cui et al. 2003). 


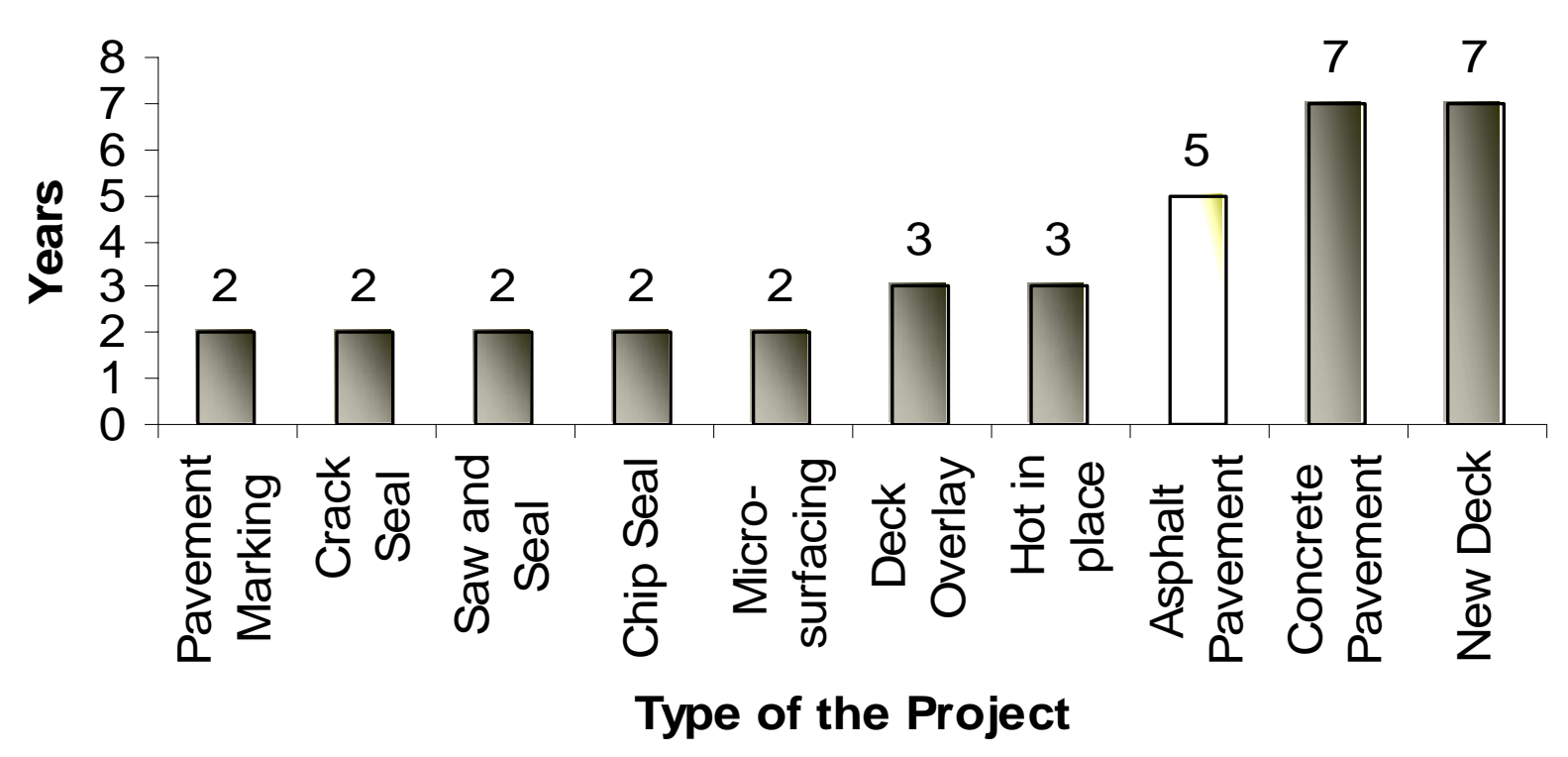

Figure 2.3: Average warranty periods as required by the state DOTs (Source: Cui et al. 2003, pp 4)

\subsubsection{Criteria to be used in Evaluating Warranty Compliance}

Establishing good, fair and clear warranty criteria to be used by the state DOTs in assessing the warranty compliance of the contractor has utmost importance in efficiently implementing the warranty concept. However, this may be very challenging. As previously mentioned, there are two different kinds of warranties for the construction projects: Materials and workmanship warranties, and performance warranties. Hence, warranty criteria for each kind are different. For materials and workmanship warranties, warranty specifications should explicitly define the material and workmanship attributes and failure thresholds of the individual work items. On the other hand, for performance warranties, the criteria used to assess compliance during the warranty period should be closely related to the overall condition and the performance of the contractor's product.

The criteria and parameters to be used in evaluating the compliance with the warranty terms should be quantitative in nature in order to eliminate the disagreements that may arise when subjective qualitative criteria is used for evaluation purposes. The criteria which directly affect the road user should be chosen. State DOTs should examine their performance 
requirements and objectives in determining the performance indicators to be used in evaluating the end product. Typically, these performance indicators should be based on the performance records of the previous projects. The data for this may come from the "Infrastructure Management System” such as pavement management system, and bridge management system (Russell et al. 1999). This will assure that the warranty criteria are achievable (as they are achieved in the past projects) and no extraordinary performance is expected from the contractor. At the bottom line, established warranty criteria should both be satisfactory for the end user and the state DOT, and attainable by the contractor.

Some external factors that are taking place during the warranty period and which are beyond the contractor's control and thus which have not been considered in advance by the contractor during the design and execution phase of its operations (either construction or maintenance), may have adverse impacts on the warranted work during the warranty period. The established warranty criteria should take these into consideration and hold some exclusions and waivers within itself. For example, as the ADT or ESALs on a highway increases over the warranty period significantly, some products and/or services provided by the contractor may deteriorate faster. In such an occasion, the criteria used in assessing the warranty compliance need to be loosened or in some more severe cases those criteria need to be totally waived. This may be the case for extreme weather conditions taking place during the warranty period too. Specifically for road maintenance projects, the performance of the treatment applied during the contract term may be adversely affected by activities such as snow plowing (carried out by an entity other than the contractor, i.e. State DOT or another contractor) performed during the warranty period (Stephens et al. 2002). Such cases should be taken into consideration while establishing the criteria to be used in assessing the compliance of the contractor with the warranty terms. To take such issues into consideration, some states incorporate specific language into their warranty clauses which waive the warranty requirements if ESALs or ADT increase by a certain percentage (generally 25\%-50\%) over their design values (Russell et al. 1999, Stephens et al. 1998).

An alternative approach in establishing the warranty criteria is to use a graduated scale throughout the warranty period. In this approach, warranty criteria and parameters are set at a certain value for the first year of the contract and then reduced each year until the termination of the warranty period (Stephens et al. 2002). This approach of changing the warranty criteria 
may complicate the administration of the warranty concept and the warranty evaluation process. This may result in increased disagreements between the contractor and the agency.

\subsubsection{Evaluation and Award of the Contract}

Generally, for the contracts containing performance warranties, the bid evaluations should be carried out through negotiations. In the proposal evaluation process, the "warranty service plan” of the contractor should be given a certain amount of weight to be assessed. In performance based contracting, the proposal of the contractor is evaluated in order to understand the merits of the contractor's ideas for putting the project in place. Contractor's design, methodologies, and material selection are assessed and project is awarded through negotiations. Since performance warranties go hand to hand with performance based contracting, during the bid evaluation and award stage, the same amount of consideration should be given to the merits of the contractor's warranty service plan, i.e. remedial action (repair and replacement) procedures.

For the contracts that embrace materials and workmanship warranties, the projects can be awarded based simply on the lowest bid. As mentioned earlier, this type of warranty is a straightforward one, and since there is not much to be done (as far as the design and methodologies are concerned) by the contractor, a warranty service plan assessment is not needed. In fact, state DOTs using materials and workmanship warranties specify the warranty service plan and remedial actions to be taken in detail, leaving no option to the contractors.

In the “A-B System," which was mentioned in Sub-section 2.4.2.2, for each year that the contractor increases the warranty period, a pre-established amount of money is deducted from the contractor's bid price (just for bid comparison purposes) and contractors are evaluated in this way to be awarded the contracts (Johnson 1999).

A group of researchers propose another way of evaluating the contracts with warranties (Cui et al. 2003). They suggest that the warranty in a contract should be an option that may be bought at the later stages of the project. They furthermore state that this decision should be left to the state DOT which would be able to evaluate the pros and cons of buying a warranty at the later stages of the construction or maintenance project in a better way. In supporting their proposition, researchers assert that a warranty does not present any benefit to the state DOT in a well performed project due to the fact that the project is expected to finish the warranty period 
without major problems anyway. They comment that the warranty approach is reasonable only if the project failure cost (costs incurred to correct the failures occurring after the project completion) is higher than the extra money that the contractor introduced into its bid price (so called the warranty price) for assuming the risks during the warranty period. Within this context, state DOTs should delay their decisions of buying warranties until the time (which may even be the project completion time) at which they are able to observe the performance of the construction and/or maintenance projects (Cui et al. 2003).

\subsubsection{Evaluating Warranty Compliance and Implementation of Remedies}

As soon as the construction or maintenance project is completed, the warranty period begins. During this period, the contractor's product, whether it is a new construction or merely a treatment, should be evaluated and compared to the warranty criteria and parameters established. The decision as what data to collect is entirely based on these established warranty criteria.

Generally, annual inspections should be performed by the state DOT to assess the condition of the end product during the warranty period. However, to minimize the disputes, the contractor should be allowed to monitor the inspection process and to perform follow-up surveys in the event of any disagreements about the results. These annual inspections should be at no cost to the contractor. Random sampling technique should be implemented in these inspections and sufficient number of samples which would be representative of the whole product should be inspected. The first inspection should be conducted right at the completion of the project. The inspections should be non destructive. The time frame for these annual inspections is to be decided by the state DOT. However, it is suggested to conduct these inspections after the frost season and in time for the contractor to schedule and implement any necessary remedial work before the beginning of the cold weather in fall (Stephens et al. 2002). The time period satisfying both conditions would be the beginning of the summer. In theory, the inspections should be completed in a month and results should be provided to the contractor as early as possible. In addition to these comprehensive annual surveys, the DOTs may conduct some inspections and identify repair or replacement needs anytime in between the annual surveys too. These needs may arise from emergency and safety situations such as large potholes or concrete blow-ups.

As the results of the comprehensive surveys are reported, the remedial action (either a repair or a replacement) should be implemented by the contractor as soon as possible. The time 
frames for starting and completing the remedial actions are stated in the warranty clauses of the contracts and can vary from state to state. The range for this time frame that is valid for many of the states using the warranty concept is 15-45 days (Russell et al. 1999). In the cases of emergency repair or replacement needs identified by the state DOT at any time (other than the comprehensive annual survey), the contractor should be notified immediately. In such cases, the contractor is expected to complete the remedial action in a very short time compared to the 1545 day range. Otherwise, the DOT may fix the problem and charge the costs incurred to the contractor.

If for any reason, the contractor refuses to accept responsibility for the poor performance as documented by the inspections, the "Conflict Resolution Procedure" may be invoked (Anderson and Russell 2001). In many of the states employing the warranty concept, the "Conflict Resolution Team” (CRT) is composed of five members, two of which are chosen by the contractor, two of which are chosen by the state DOT, and one of which is chosen by both entities. In this procedure, what is decided by the CRT is said to be binding both for the contractor and the state DOT. If the contractor refuses to take responsibility for the poor performance even after it is decided so by the CRT, this will be deemed as a default on the contractor and the surety company may be notified. A majority of the states using warranties require CRTs on their projects. Mainly, warranties for the projects with road maintenance applications such as chip sealing and micro-surfacing contain CRTs due to the difficulties that may be faced in determining the cause of the failures and thus in assigning the responsibilities to the related parties. On the other hand, the projects with end products whose failure reasons can more easily be identified, such as pavement marking and bridge painting, tend not to have CRTs (Russell et al. 1999).

The warranty clause may either direct the contractor by specifying what kind of a remedial action to execute or merely establish guidelines and require the approval of the DOT before the contractor may proceed with the remedial actions it chooses to implement. Or, the warranty clause may include only the timeframe for the remedial action and leave the contractor completely free in choosing and implementing the remedial action. The DOT may also place limitations on the time of the day that work may be done to protect the road users from any safety hazards. As remedial action is completed, a re-inspection corresponding to the problematic 
area may be carried out as to ensure that the problematic highway portion has been brought back to the condition dictated by the warranty.

Some states also allow contractors to do preventive/elective (routine) maintenance during the warranty period. If the contractor identifies any maintenance needs during the warranty period, then it is allowed to carry out this maintenance to avoid any future possible remedial actions that can be required from it within the context of the warranty compliance inspections. But in identifying the maintenance needs, non-destructive methods should be used by the contractor. The preventive/elective (routine) maintenance concept, which is a proactive approach as mentioned here, is totally different from the remedial actions, which are reactive in nature, implemented by the contractor after being notified to do so by the state DOT.

\subsubsection{Bonding Issues}

Bonding is used in highway projects to protect the DOT and thus the public interest in the occasion that the contractor is unable to complete the project in accordance with the contract terms and specifications. In the traditional contracts that do not encompass any warranty provisions, the bonding does not provide any post construction performance protection. As mentioned earlier, some states use performance bonds which are good for material and workmanship defects and which last for up to one year after the project completion. But it is not a comprehensive coverage.

By providing a bond to the contractor, the bonding company (surety) indicates that, in its acceptable level of risk, it believes that the contractor will be able to complete the project as per the design. Bonding companies perform comprehensive assessments of the contractor's past experience, equipment, and outstanding level of bonds prior to endorsing a bonding agreement with the contractor for a new job. Thus, the contractor is implicitly "pre-qualified" through the bonding process.

Sureties have a general idea of the risks associated with any job contracted out under the traditional design-bid-build system without warranties. This is possible mainly due to the fact that the traditional system has been functioning for a long time. The type of work to be performed and the ability of contactors to perform it have been established well within the surety companies' structure by means of historical records. In addition to these, administrative details of the contract process have been set in detail. With all these in hand, surety companies have 
comfortably been offering performance bonds for up to one year after the project completion in the traditional system for a long time.

However, for the contracts with warranties, bonding issues need to be reconsidered. A mechanism has to be adopted to guarantee the contractor's work for the length of the warranty period. Traditional bonding practices have been valid through the term of the contract and up to one year after the project completion. But, the contracts with warranties should contain two different bonds. In addition to the performance bond that is valid for the construction or maintenance phase and that lasts for the project duration, the concept of the "warranty bond" should be introduced. This new concept brings the following issues with it:

First of all, since warranties have been in use for a very short time, there is not much historical data to be able to assess the risk of failure. Especially for performance warranties, which are implemented in design-build projects or in projects with performance based specifications, surety companies are having difficult times to identify the risk factor present due to the lack of the historical data. Contractors' capabilities of implementing design, choosing materials and methodologies have not been sufficiently evaluated. As discussed above, surety companies should have an idea of the risk for the projects they are providing bonds. To overcome this issue, the relationship between the long term performances of the previously built or maintained highways and the performance requirement of the current contract for the warranty period, should be shown to the surety companies. This would convince the surety companies that the warranty criteria (thresholds) are readily achievable. If criteria are perceived to be unattainable, the project would look too risky to the surety company and necessary bonding would not be provided. Furthermore, clear definitions of warranty criteria and parameters can also help the surety companies to assess and quantify the risks associated with the warranty period of a project. Implementation of these two measures would make surety companies more comfortable in issuing warranty bonds for performance warranties.

Another issue that the warranty bonds bring about is the reduced bid competition. As a result of the surety companies' inability of risk assessment for long term warranties, fewer contractors will qualify for the bonds. Especially smaller contractors might get eliminated from bidding for the projects with warranties as they have less chance of securing bonds. To resolve this issue, Surety Association of America (SAA) suggested for warranties which have a duration of more than five years that; "the bond should be successively renewed at 3 to 5 year 
intervals, the amount of bond should be $10 \%$ of the project cost, and the cost to the contractor of meeting the warranty obligation should be listed as a separate line item in the bid to be paid across the warranty period" (Stephens et al. 2002, pp 8). Thereby, if the contractor defaults during the warranty period, the surety company can use the remaining funds in completing the project. For the same reason, SAA further recommends that the contractor should not be paid all of the warranty cost at the beginning of the warranty period (Stephens et al. 2002).

Thirdly, the prolonged nature of the warranty periods of five to twenty years would result in outstanding bonds during the warranty term and thus could create backlog for the contractor. In making their decisions, surety companies assume that a contractor's assets will offset any losses they may experience if the contractor defaults on the project. The assets of a company are finite and thus there is a limit on the total value of bonds that a contractor can obtain (Stephens et al. 1998). Under the traditional bonding system, the bonds last for only one year at a maximum after the completion of the project and thus the bonding capacity of the contractor is restored in a short time. Whereas, within the concept of long term warranties, the bonding capacity of the contractor is not restored until the end of the warranty period which may extend up to twenty years. Thus after a few years, contractors may possess a sizeable number of projects with outstanding performance and warranty bonds. This affects a contractor's ability to secure bonding for new projects. As indicated by a professional from the SAA, if long term warranties are bonded, the work will be added to the contractor's backlog which is likely to result in a less amount of work that a contractor can bid if its financial position remains the same. On the other hand, since the contractor has to carry its warranties as a current liability in its financial statement, its financial position is very likely to be negatively impacted. Surety bonds are legislated and designed to cover only construction and thus bonding for warranties may result in many unresolved problems (Cook 1998).

To resolve the backlog issue, three measures can be implemented. First, the bonding capacity of contractors may be increased. This in turn will result in higher bond costs because of the reduced probability of surety companies to recover their costs using contractor's assets. Secondly, the required amount for bonds may be decreased by the state DOT as successive years of the warranty period are completed (Stephens et al. 1998). Finally, the warranty duration can be optimized as to prevent the backlog on the contractor. This is a solution that should be 
examined carefully at the beginning of the project while deciding on the length of the warranty period (as discussed in Sub-section 2.4.2.2).

As far as the amount (penal value) of the warranty bond required by the state DOT is concerned, two options are present. The bond can either be a percentage of the total contract amount or an established amount. For the first option, there are a variety of percentages ranging from $10 \%$ to $100 \%$ applied by various state DOTs (Russell et al. 1999). For the second option, some state DOTs use a "most likely case scenario" approach in establishing the amount of the warranty bond. They are simply calculating the cost of the most expensive reasonable remedy (repair or replacement) that would be applied in a most likely case problem with the performance of the project during the warranty period, and then setting this amount as the warranty bond amount (Anderson and Russell 2001).

An approach which would be able to solve all of the abovementioned issues would be waiving the warranty bonds completely and using the retainage procedure instead. This is an alternative to bonding in which a certain amount of payment is withheld from the earned amounts of the contractor as an assurance for the state DOT. As satisfactory performance is achieved during the warranty period, retained amount can be paid to the contractor. A combination of bonds and retainage can also be implemented (Anderson and Russell 2001). Again, the amount of the payment withheld can be decided based on the most expensive remedy associated with each element of the warranty.

\subsubsection{Cost Issues}

Evaluating the cost effectiveness of a warranty program is difficult, if not impossible, until sufficient performance data showing the long term trends within the performance of the constructed or maintained highway is obtained. And since warranty is a new concept, which practically has a history of 10 years, such data, especially for the projects with performance warranties (due to the fact that the number of performance warranties issued up to date is very few), is not available at the present time. Many of the projects with warranties are still in the construction phase. Many have not expired their warranty period yet. And for the remaining projects which have expired their warranty periods, there is not sufficient data that represent the long term performances of the constructed or maintained highways. A few states (such as 
Wisconsin and Ohio) have performed some cost analysis but their findings cannot be generalized to all warranty projects to reach a conclusion.

It is anticipated that the contractors are charging an extra amount for the warranty term. This can be attributed to the fact that they are carrying the risks of failure and thus they need to implement remedial actions whenever they are told to so during the warranty period. In a way, they factor the increased risk to their bid prices. Moreover, contractors may also reflect the high costs of obtaining a warranty bond (as mentioned in Sub-section 2.4.2.6) within their bid prices. However, the amount that the contractors charge more has not been determined exactly. Another reason of increased bid prices may be the reduced bid competition. As the number of the contractors entering a bid decreases due to the reasons mentioned in Sub-section 2.4.2.6, it is likely that the bid prices of the attending contractors will increase.

A number of states believe that their warranty projects could have had lower bids if they were bid without warranties and a few states assert just the opposite. However the efficient and superior way of assessing the cost impact of the warranties is carrying out a life cycle cost analysis. Even though the initial costs incurred by the DOTs (due to higher bid and contract administration prices) may be relatively higher in their contracts with warranties, it is highly probable that these costs will be offset by a reduction in the life cycle costs of the constructed or maintained highway as long term performance is achieved through the implementation of warranties. In such a case, the extra cost, or the initial investment, is spread over the entire warranty period. This results in more cost effective contracts than the traditional contracts. The benefits of a contract with warranties, i.e. increased quality (which will be discussed in the following sub-section) will eventually result in lower life cycle costs. Moreover, since remedial activity (repair and/or replacement) costs are not incurred by the state DOT during the warranty term, life cycle cost is likely to diminish. As mentioned before, with the current data in hand, it is very hard to evaluate the life cycle costs of the warranty projects. In fact, a survey of 6 states (including Arizona, Florida, Michigan, Ohio, Virginia, and Washington) revealed that there were no data to determine the marginal cost of warranties (Carpenter et al. 2003).

Research carried out to date has revealed that the cost impact of the warranties on a highway construction or maintenance project is dependent on the type of the project and the length of the warranty period (Cui et al. 2003). Usually, the projects with warranty periods of 
one year or less do not cost more money to the DOT than the traditional contracts without warranties. On the other hand, longer warranties have an increasing impact on the cost.

A survey performed by a group of researchers assessed some of the warranty issues by analyzing the responses received from 13 states, 16 contractors and 6 bonding companies. Some of the findings of the survey for the cost impact of warranties are as follows (Cui et al. 2003):

- $40 \%$ of responding states reported $5-10 \%$ increase in bid prices due to the incorporation of warranty clauses, whereas none of the respondents reported an increase over 50\%. The complete survey results for the issue of "increases in bid prices” are presented in Figure 2.4.

- According to the contractors, the possible future maintenance costs and the bond costs are the main sources of the increases in the bid prices.

- Contractors believed that although there was the risk of taking remedial actions in case of the presence of defects during the warranty period, the tight construction market tends to keep the bid prices down, lower than what they would be in a less competitive market.

- Small contractors asserted that large contractors have a competitive advantage since they can spread out their cost of warranty among other jobs and reduce their bid price.

- 8 out of 9 states indicated that the expected savings of their projects with warranties, in remedial activity costs, compared to the remedial activity costs incurred in non-warranty projects, is less than $10 \%$. Only one state DOT expected more than $50 \%$ saving in remedial activity costs (for a pavement marking project).

- $8 \%$ of state DOTs stated that they expect a significant saving in the project life cycle costs of their projects with warranties as compared to their non-warranty projects. On the other hand, $46 \%$ indicated little increase in the life cycle costs for the projects with warranties. The complete survey results showing the state DOTs' perspectives on the "impact of warranties on the life cycle costs" are presented in Figure 2.5. 


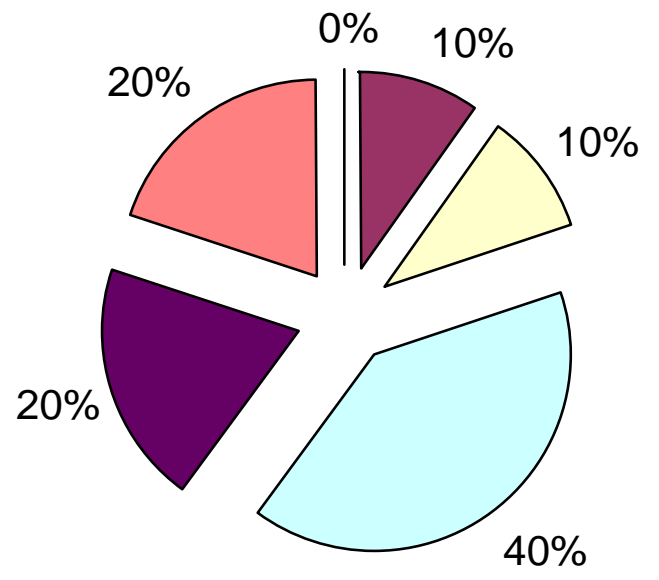

Over $50 \%$

$\square 20-50 \%$

$\square 10-20 \%$

$\square$ 5-10\%

$\square$ Below 5\%

$\square$ No Effect

Figure 2.4: Percentage increases in bid prices due to the implementation of warranties (Source: Cui et al. 2003, pp 4)

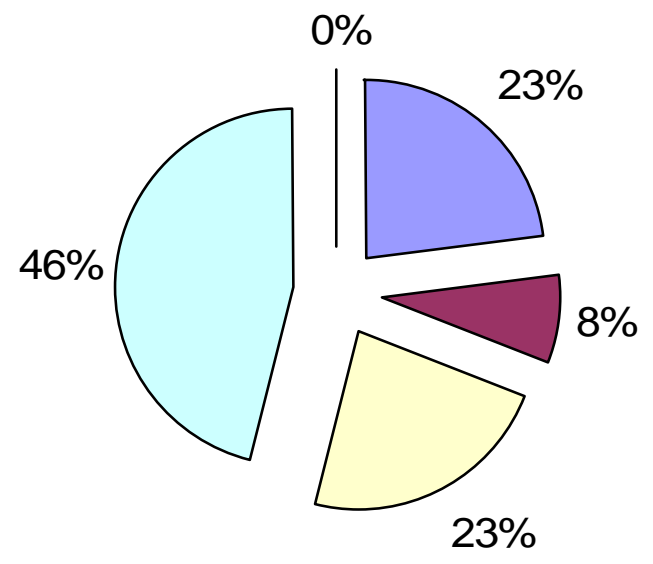

Little Savings

Substantial Savings

$\square$ No Effect

$\square$ Little Increase

Substantial Increase

Figure 2.5: Impact of warranties on the project life cycle costs- State DOTs' perspectives (Source: Cui et al. 2003, pp 4) 


\subsubsection{Quality Issues}

As discussed before, one of the main anticipated advantages of using warranties is the overall improvement of quality and thus the long term performance. In order to avoid returning to the project after its completion to apply remedies in the case of presence of defects, contractors are anticipated to have more concerns to provide better performance on warranted projects than on non-warranted projects. In other words, in the contracts with warranties, there is a greater incentive for the contractor to construct or maintain to achieve a higher quality product from the onset, rather than barely meeting the minimum requirements set by the contract specifications (either materials and workmanship or performance specifications).

In achieving their aim of improving quality during the contract term in which construction or maintenance activities are performed, contractors are expected to implement efficient measures such as providing additional project supervision, and using only qualified and experienced labor and better equipment (Cui et al. 2003). Moreover, in the case of performance warranties which are implemented for performance based contracts or design-build projects, contractors are expected to use innovative construction practices and materials since they are free in doing so.

Although chances are low, there is still a possibility that the contractors may complete the project without considering any quality improvements depending on that the remedies that may be needed in the presence of defects would not bother the contractor at all (Hancher 1994). The contractor may construct or maintain the road with exactly the same amount of effort that it spends in a non-warranty project and then if any remedial action is needed during the warranty period, it can just implement the remedial actions using the extra amount of money (warranty price) that it has included in its bid price (as stated in Sub-section 2.4.2.7). Such an approach can be avoided if the length of the warranty period is optimized. When the warranty period is kept at an optimum length (as discussed in Sub-section 2.4.2.2), a contractor is more likely to do a good job to improve the quality of its services and/or products believing that it would avoid the defects and thus the remedial action calls from the state DOT, rather than doing an average job and taking the risk of being called by the state DOT to come back to remedy the defects occurring during the warranty period. In the case of design-bid-build projects in which there is a low bid contracting environment and, materials and workmanship warranties are implemented, the contractors' trend may be to minimize costs as they identify where to be less considerate and still 
meet the warranty criteria (ODOT 1999). Moreover, in the case of performance warranties, contractors may take a conservative approach rather than implementing innovations due to the fear of carrying additional risks (Cui et al. 2003).

Just as in the case of cost comparisons, it is early to make quality comparisons and reach definite conclusions before examining the trends within the long term performance of the constructed and/or maintained highways. As these trends are observed in the upcoming years, the effect of warranties in the overall quality and long term performance of the projects will be identified. Nonetheless, the survey conducted to understand the state DOTs' and the contractors' perspectives of the impact of warranties on the quality issues revealed the following for the current experience with warranted projects (Cui et al. 2003):

- $46 \%$ of the state DOTs indicated that the warranty provisions slightly improved the project quality and $23 \%$ asserted that great improvement on the project quality was achieved through the usage of warranty clauses. The complete survey results showing the state DOTs' perspectives on the "impact of warranties on the project quality” are presented in Figure 2.6.

- $62 \%$ of the contractors surveyed indicated that the warranty requirements encourage them to provide higher quality and thus better long term performance. On the other hand, remaining 38\% stated that they have not implemented any significant improvement in quality as a result of warranty provisions. 


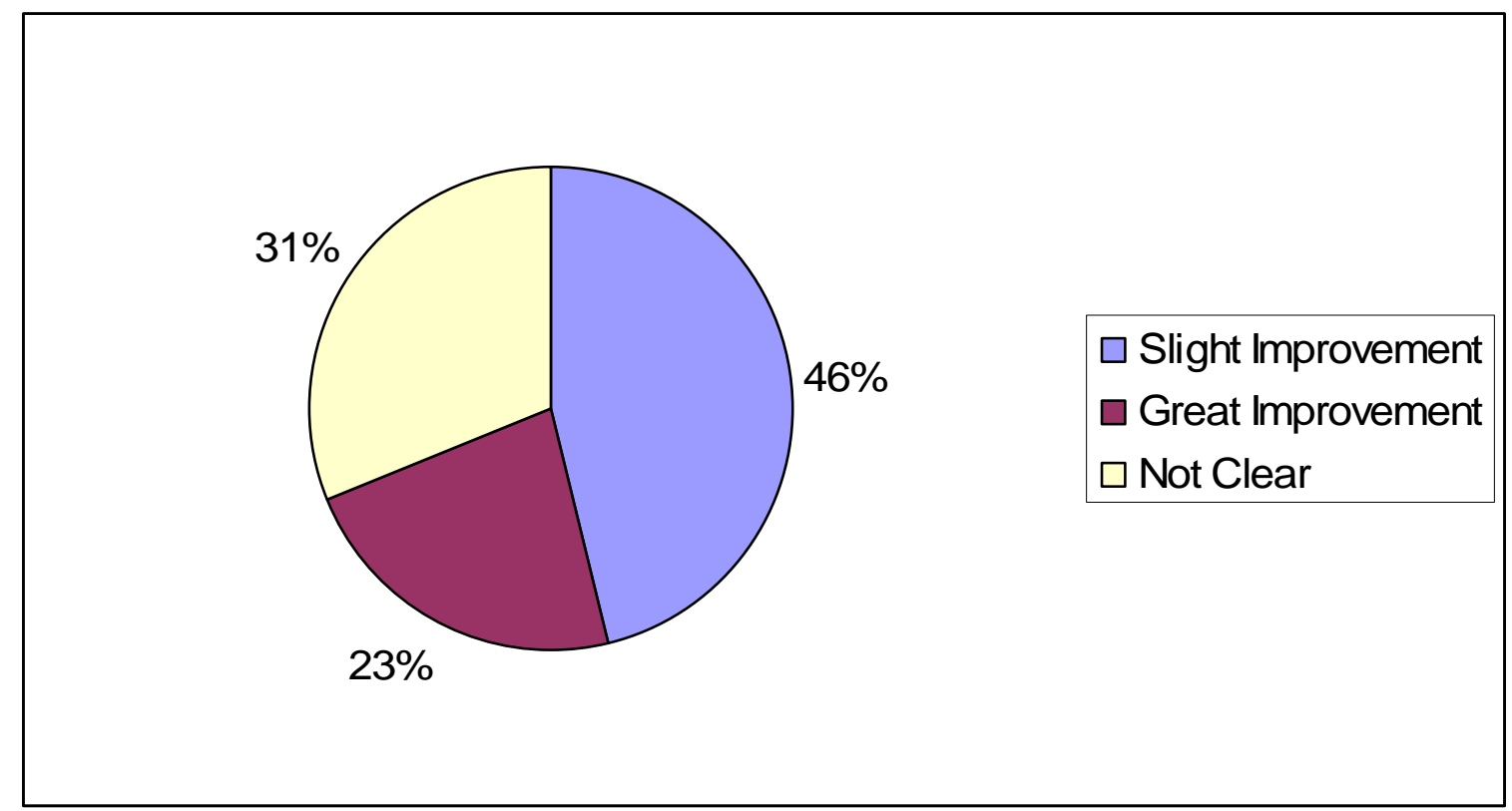

Figure 2.6: Impact of warranties on the project quality- State DOTs’ perspectives (Source: Cui et al. 2003, pp 5)

\subsubsection{Disputes and Litigation}

The implementation of warranties for the construction and/or maintenance of highways are likely to result in fewer contract disputes and less amount of claims and litigation in the long run. That is mainly due to the fact that warranty provisions possess explicit language to apportion risk and responsibility as compared to the implicit language used in the contracts that brings about disputes and claims. In a study carried out by a group of professionals, it was revealed that of all the states that were implementing warranties interviewed by them, only one state had a claim in one of its warranted projects and there was no litigation arisen in any of the remaining projects (Russell et al. 1999).

As the warranty concept is implemented for the first few times, there may be disagreements mainly in the issues related to the apportionment of the post project failure responsibilities between the contractor and the state DOT. Conflict Resolution Teams (CRT) are established to take care of such situations. Nonetheless, in the long term, as warranties become common and as clearer language are used within the warranty clauses as far as the warranty 
criteria, the allocation of the responsibilities for the defects, warranty period, and remedies are concerned, these disputes are likely to diminish.

\subsubsection{Quality Assurance/Quality Control and Inspection by the State DOT}

Generally speaking, when warranties are implemented, the need for extensive inspection and oversight of the state DOTs on the project diminish. Since a great amount of risk is imposed upon the contractor under the warranty concept, the contractor becomes more self conscious and responsible as far as the quality of its work is concerned. Contractors implement the quality controls through the project term to ensure the quality and long term performance of their products. This self consciousness relieves the state DOTs from implementing extensive quality control and inspection procedures. Rather, the state DOTs carry out the quality assurance processes which is far less comprehensive and costly than the quality control. This is a tendency that has evolved as a result of the nature of warranties. Moreover, some state DOTs contractually require its contractors to implement the quality control procedures and they also establish minimum requirements of the quality control program to be submitted by the contractor (MDOT 2002). In fact, the results of the survey conducted by Cui et al. revealed that the $\mathbf{7 7 \%}$ of the state DOTs believe that the warranty provisions have reduced the need for site inspections (Cui et al. 2003). However, it is important to note that, this tendency is valid for only highway construction projects. In fact, it cannot be valid for the warranted highway maintenance contracts. Since these contracts cover maintenance activities that are performed when highways are open to the traffic and thus are in use, strict quality control and inspections should be implemented by the state DOT in order to be able to address the safety issues for the road users, i.e. motorists.

The reduction in the need of inspections results in a reduction in the resources that have been used by the state DOTs during the administration of its contracts. Thus, the staff used by the DOTs for the inspections can be diverted to other projects and savings can be achieved by the state DOTs.

\subsubsection{Warranty Practices in State DOTs}

As mentioned earlier, the implementation of the warranty concept for highway construction and maintenance projects is not very common in the USA. There are around 29 state DOTs who 
have implemented warranties. Nonetheless, their experience is limited due to the very few number of projects administered by them. Many of the states have only implemented pilot projects. And moreover, many of these projects have not been completed, and if completed have not expired their warranty periods. Thus, warranty concept is still in its development and evaluation phase. After the evaluation of the pilot projects is completed by the state DOTs, more conclusive results will be gathered. For the time being, there are only some initial and short term experiences and some preliminary evaluations of the warranty concept. These experiences of the state DOTs, as well as the views of the contractors and surety companies within those states, with regards to the issues discussed in Sub-section 2.4.2 will be presented in the following subsections.

\subsubsection{Michigan DOT Experience}

Michigan has been a pioneer in the warranty concept and it is also the state which has issued the largest number of contracts with warranties. The warranty concept was initially covered in Michigan’s 1996 transportation appropriations bill and after going through some changes; it has been placed in the 1999 Transportation Budget Acts as: "The legislature encourages the department to work with the road construction industry to develop performance and road construction warranties for construction contracts. The development of warranties shall include warranties on materials, workmanship, performance criteria, and design-build projects...” (1999 PA 136, Section 602, Hamilton 2001, pp 9). Finally in 2000, Act 51 stated that: "The committee recommends that all road agencies seek warranties from construction contractors, where appropriate. Legislation should encourage experimentation with warranties covering the design and construction of bridges without mandating warranty details and particular applications” (Hamilton 2001, pp 9-10). All of these legislations were established during a period in which the public was carrying many concerns about the condition of the Michigan’s roads. Assigning the contractor a warranty responsibility for failures was thought to be the best way of addressing these concerns and ensuring that the state was getting what it paid for. A very important aspect of these legislations is that they do not specify the details of the warranty implementation. In other words, they do not restrict the road agencies in the ways that they develop and administer warranties. Rather, these legislations encourage the road agencies to work with the road construction industry to arrive a consensus for the implementation of 
warranties. They also do not specify the details of the language to be used in the warranty clauses but encourage the road agencies to find out ways of developing good warranty language and administering warranties. In initiating the warranty concept, MDOT’s philosophy was to balance the enhanced opportunity for the contractor input and control by a greater assumption of liability (through the warranties) by the contractor (MDOT 2002).

Michigan DOT (MDOT) let its first warranty project in 1995. From that time until 2000, 300 contracts which had warranties for the pavement were awarded by MDOT. The majority of these contracts were for the "Capital Preventive Maintenance” (CPM) projects, 35 were for pavement rehabilitation and 12 were for complete reconstruction projects. All of these contracts' warranties cover only the pavement portion of the highway, regardless of whether it is a construction or maintenance project. No warranties are issued for other highway assets. Thus for a highway construction or maintenance project, certain items are covered by the warranty and certain are not. Nonetheless, MDOT is interested in and working on expanding the coverage of the warranties to the other components of the highway. Lately, bridge deck and bridge painting projects have started to be covered with short term warranties (Cui et al. 2003).

In Michigan, between the years of 1998 and 2000, warranties with periods of 5 years were used in 13 reconstruction and new construction projects. These projects' scopes include complete removal and construction of the existing pavement and/or the existing base and repaving. MDOT has mainly used the material and workmanship warranties for its new construction and reconstruction projects. This is mainly due to the fact that MDOT has the design responsibility and thus specifies the method of base preparation, materials, pavement type, and pavement thickness. MDOT is also responsible for the field conditions. In fact, Michigan is recognized as the national leader in terms of materials and workmanship warranty specifications. During 2000, 20-30\% of Michigan’s trunk line pavement constructions were awarded using materials and workmanship warranties (Stephens et al. 2002).Within the context of this type of warranty, if the highway fails during the warranty period, the reason of this failure is investigated. If it is found to be due to the design, MDOT becomes responsible for the repair. However, for materials and/or workmanship failures, the contractor is required to implement the remedial action. The remedial actions required from the contractor are not specified in the warranty clause but some guidelines are included. Nonetheless, the contractor is required to submit a plan, stating the 
possible remedial actions to correct the problem. This plan goes through an approval process by MDOT.

In Michigan, CPM projects are put in place to increase the long term performance and thus to extend the life of an existing pavement that is still in good or fair condition. These projects are limited in scope when compared to the new construction and reconstruction projects. The preventive maintenance program is established to protect the highway assets such as pavement and bridge structures, slow the rate of deterioration, and target the minor defects such as the ones in the pavement that are caused by environmental effects. Major structural deficiencies are not within the context of this program. The pavement treatments that are issued under the CPM projects are non-structural bituminous overlay, chip seals, micro-surfacing, surface milling, slurry seals, dowel bar retrofits, minor spall repairs, diamond grinding surface seals, crack filling, joint resealing, and crack sealing. The treatment for the drainage assets is limited to outlet cleanout and repairs. For bridge structures, maintenance work is limited to seal replacement, deck spall repair, and spot painting. Given these facts, and considering the project selection criteria discussed in Sub-section 2.4.2.1, it can be stated that warranties are very suitable for the projects within the preventive maintenance program. Between 1997 and 2000, pavement warranties that have a period of 2-3 years were implemented in 270 CPM projects. In deciding the duration of these warranties, MDOT identified the fact that not all treatments had equal design life and thus the duration should be adjusted for the type of the maintenance activity performed. As a result of this approach, chip seals, micro-surfacing, slurry seals, crack sealing, and joint resealing were chosen to have warranty periods of 2 years. On the other hand, cold milling and placement of a non-structural bituminous overlay, hot-in-place recycling and concrete pavement repairs were designated a warranty period of 3 years. Good quality pavements, rather than the severely distressed and deformed ones, were selected for the warranty projects. MDOT has used both performance and materials and workmanship warranties for its CPM projects. MDOT is very pleased with its implementation of warranties for preventive maintenance projects and is willing to continue issuing warranties for CPM projects (Johnson 1999). The performance warranties used in some of the CPM projects may be considered as limited warranties since there is much exclusion in which the contractor is not responsible for the maintenance failure (Hamilton 2001). As a result of the implementation of warranties to the CPM projects for the pavement, higher quality and longer lasting surface treatments have been achieved in Michigan. 
Rehabilitation projects, which typically include multiple-course resurfacing of an existing bituminous pavement or extensive patching, have greater scopes than CPM projects. They are performed when CPM projects cannot fix the problems. Between 1996 and 2000, warranties with periods of 5 years were used in 35 rehabilitation projects. It is important to note that only one of these projects had a performance warranty, all of the remaining projects contained materials and workmanship warranties (Hamilton 2001).

The performance of the warranted pavement during the warranty period is measured using criteria such as ride quality, surface distress parameters (transverse, longitudinal, block, joints/edge faulting, delamination, shattered areas, settlement, flushing, raveling, stripping and alligator cracking mainly), and rutting. In general, the bonding amount for the warranty periods is chosen to be $\mathbf{1 0 \%}$ of the contract amount for the new construction, reconstruction, and rehabilitation projects. Whereas, bonding amount is chosen to be $\mathbf{1 0 0} \%$ of the contract amount for the maintenance projects. This has raised concerns among the contractors. However, surety experts have relieved the concerns stating that the issuance of large number of warranty bonds would not preclude the contractors to obtain bonds for their other projects. In certain cases, $10 \%$ retainage is used as an assurance for the remedies and warranty bonds are not required. The retained amount is returned to the contractor in pre-established percentages as acceptable performance is achieved during the warranty period.

In the case of a disagreement in the apportionment of the responsibility for the failure, the Conflict Resolution Team (consisting of five people, two of which are the representatives of MDOT, two of which are the representatives of the contractor, and one of which is a person mutually agreed on by the two parties) is formed. In addition to MDOT's inspections, the contractor is also allowed and encouraged to perform inspections to be able to point out the inconsistencies that may arise within MDOT’s inspections.

Quality control has been shifted to the contractor in MDOT’s contracts with warranties. Up to date, for the projects with materials and workmanship warranties, there has been a sharp decrease in the need for state inspections carried out during the contract period. In fact, MDOT has asserted that warranted projects cost 5\% less than the non-warranted projects as far as the expenditures in inspections are concerned (Hamilton 2001). For its pavement warranty projects, MDOT uses one inspector who visits the site once a day just to monitor progress and answer questions. This allows the inspector to monitor several projects. Whereas, MDOT assigns a 
permanent inspector to the projects without warranties, which results in more administrative costs. It is believed that, more frequent use of performance warranties would further reduce the need for state inspections and material tests (Hamilton 2001). By implementing warranties, quality assurance responsibility of MDOT is fulfilled through the inspections carried out by MDOT during the warranty period, in which warranty criteria compliance is evaluated.

In Michigan, warranties have also reduced the need for the maintenance staff. Through the usage of warranties, initial repair burden is transferred to the contractors. Thus MDOT does not have to rely on its in-house forces as much as it used to do. MDOT also believes that the use of warranties has not affected the bid prices of the contractors. This is very advantageous for MDOT because with the same bid price, MDOT is assuring higher product and/or service quality and longer term performance. This also means that MDOT is very likely to enjoy the remedial actions implemented by the contractor during the warranty period (in case of the presence of defects) at no extra cost.

To check and evaluate the warranty criteria compliance of the contractor during the warranty period, MDOT employs two kinds of inspections. First one is the "cursory inspection”, in which portions of the highway that may not be meeting the warranty criteria are quickly identified through a windshield inspection and some basic measurements. If the contractor questions the findings of the cursory inspection, the "detailed inspection," which consists of detailed measurements and comparisons, is performed. These inspections are completed in one month and results are immediately reported to the contractor for it to implement remedial actions if needed. The number and frequency of inspections depend on the duration of the warranty (MDOT 2002). If anytime during the warranty period but prior to the inspections mentioned above, a safety/emergency issue or a significant defect is observed at any portion of the highway, this portion is then put into a watch list so that the "interim inspection" and then the call for remedies (which will be directed to the contractor) can be initiated. After the remedial work is completed, another inspection, focusing only on the remedial work, is performed and then remedial work is accepted. MDOT has developed a very comprehensive guideline book named as "Guidelines for Administering Warranties on Road and Bridge Construction Contracts" which contains informative flowcharts and a great deal of information to streamline the processes of the administration of warranties and the inspections within the warranty period. 
The warranty periods enacted by MDOT both for its current projects and its proposed projects are far less than the design life of the pavement. Nonetheless, MDOT and the contractors agree that the major pavement failures would come out in the first several years after the completion of the construction or maintenance work. Thus, implemented warranty periods in Michigan provide reasonable assurance to MDOT.

MDOT has indicated that it plans to increase the use of performance warranties in its future projects and has cooperated with the representatives of the construction industry to develop performance warranty specifications for one of its projects. However, if MDOT wishes to achieve this goal of increasing the use of performance warranties, it needs to allow contractors to take design decisions (Hamilton 2001). If MDOT tries to keep the design responsibility to itself, no contractor would be willing to warrant the increased quality and long term performance of the highway.

The implementation of warranties within the Michigan brought about a great deal of cooperation between MDOT and the contractors. Moreover, all parties involved other than MDOT, i.e. contractors and sureties, were invited to participate in the preparation of the warranty criteria and the warranty provisions. Finally, as drafts were created, attorneys reviewed them to check the conformity of those with state and federal laws. Attorneys concluded the warranty provisions should be acting as a separate legal instrument and should not be combined with the contract specifications (Galehouse 1998). Furthermore, it was commented that the warranty criteria should be different for each kind of project (for each kind of treatment applied in the cases of capital preventive maintenance projects) and also should address the rights and responsibilities of MDOT and the contractor. It was also decided that the warranty clause should possess some guidelines for corrective actions to be followed by the contractor. As a result of these comments, for each kind of project (for each kind of treatment applied in the cases of capital preventive maintenance projects), a warranty document with certain warranty criteria and also the contract documents with corresponding technical specifications were developed to be used in the projects with warranties. The warranty document was then standardized to possess a common format (but not a common content) for each type of project (Galehouse 1998).

During the initial stages of the development of warranties in Michigan, contractors have raised objections in many points. In fact, a large segment of the road building industry consisting 
of Michigan Road Builders Association, Associated Underground Contractors, Michigan Concrete Paving Association, and Michigan Pavement Association sued MDOT because of its insistence in implementing warranties (MDOT 2002). Generally, three issues were pointed out by the industry. The contractors asserted that the warranty work would have harming impacts on their business. Moreover, they believed that MDOT would choose to implement warranties in highways that are severely distressed. They also stated that during the warranty period, MDOT would continuously call them to remedy the defects that occur beyond their control. After seeing the opposition from the construction industry, MDOT realized that it had to address these concerns, especially for the preventive maintenance projects. To do this, first, MDOT has used a field evaluation report named "Field Condition Review of Completed Highway Preventive Maintenance Projects.” This report describes the long term performances of the previously completed treatments. This report relieved many contractors as they realized that the treatments put in place many years ago were performing to the state expectations (Galehouse 1998). Next, contractors needed to be assured that distressed highways would not be chosen for the warranty projects. To achieve this, MDOT distributed a list of the prospective warranty projects, a considerable time before initiating the bidding process. By this way, the contractors had the opportunity to review the project locations in detail and notify MDOT if a project was identified by them as an unacceptable candidate for warranty, before bidding on them. And for the final concern of dealing with situations beyond their control, contractors were assured by MDOT that there would be conflict resolution teams (CRT) which would be able to resolve the disagreements arising between MDOT and the contractors due to the assignment of the failure responsibilities (Galehouse 1998).

\subsubsection{Ohio DOT Experience}

Ohio, along with Michigan and Wisconsin, has been one of the frontrunners in the implementation of warranties within the USA. In Ohio, the implementation of warranty concept began with the passage of the House Bill 163 in July 1999. As a response to this bill, contract documents with warranty clauses were developed by the Ohio Department of Transportation (ODOT) in collaboration with the groups from Federal Highway Administration (FHWA), Ohio Contractors Association, Flexible Pavements of Ohio, American Concrete Pavement Association, and various other entities from the construction industry. To develop the warranty clauses, more 
than 50 meetings with attendance of 250 individuals were held. One of the stages in development of the clauses was to interview the states that have implemented warranties. House Bill 163 is a bill which highly encourages the use of warranties for highway projects carried out in Ohio. In fact, it mandates that each year at least $20 \%$ of ODOT projects shall contain warranty clauses. The bill furthermore states that at least 10\% of ODOT's budget shall be for projects requiring pavement warranties. The bill also defines the warranty periods as (ODOT 2000):

- Not less than seven years for pavement in the case of new construction (ODOT 2000, pp 13).

- Not less than five years in the case of resurfacing and rehabilitation (ODOT 2000, pp 13).

- Not less than two years in the case of pavement preventive maintenance, bridge painting, pavement marking, raised pavement markers, guardrail and other project items as determined by the Director (ODOT 2000, pp 13).

Up to the current date, warranties are implemented for only pavement construction or maintenance, and bridge projects. Although it was present in the bill, warranties were not implemented for guardrail installation since ODOT experience indicated that there has never been a case in which defects occurred after the installation of the guardrail. The warranty criteria used for pavement projects are common pavement distresses including but not limited to rutting, raveling, delamination, patching, flashing, and spalling. For bridges, warranty criteria are deck scaling and cracking.

The contractors initially had some issues with the warranties because they had limited knowledge and understanding of what they were expected through the usage of the warranty concept. But later on, these concerns and issues were diminished. The overall assessment performed by ODOT to get an idea of the efficiency of its contracts with warranties revealed that contractors doing work under warranty provisions are willing to achieve better quality products and long term performance. ODOT maintenance staff also indicated that there would be potential savings in time and materials since ODOT does not need to maintain pavements during the warranty period. 
On the other side, staff within ODOT thinks that ODOT has lost control of the product under warranty provisions. ODOT has further commented that the inclusion of warranty provisions is increasing the bid prices. As a matter of fact, it has been reported that the bid prices for the projects with asphalt pavement warranties are 8.5\% higher than similar non-warranty projects. The same trend is also valid for concrete pavement projects with an average increase of 11\% (ODOT 2000). The average bid price increase for bridge painting projects was found to be $26 \%$. This increase might have arisen due to the nature of the project. Since bridge painting is a time consuming and expensive work item, extra measures might have been taken by the contractor to ensure warranty compliance which would avoid the possibility of follow up remedy calls (Stephens et al. 2002). The largest price increase for warranties was found to be in pavement marking projects. There was $171 \%$ bid price increase in the pavement marking projects (Stephens et al. 2002). This may be due to the short lifespan of the pavement markings in northern climates which causes them to be redone several times during the warranty period (Stephens et al. 2002). Due to the significant bid price increases incurred in pavement marking projects, these projects were removed from ODOT's warranty program. ODOT believes that pavement marking projects have been performed well enough in traditional contracts without warranties and thus there is not much benefit in warranting this item and paying a great amount of money for that.

In Ohio, the bonds required for the warranty period are called maintenance bonds. The amount required for these bonds varies from $\mathbf{3 0 \%}$ to $\mathbf{9 0 \%}$ of the contract amount. Generally the bond amount and the warranty period for pavement preventive maintenance projects are $75 \%$ of the contract amount and 3 years respectively. For most of the projects, the yearly inspection for the warranty period is performed by the District Review Team (DRT) during March and April and results are immediately reported to the contractor for it to implement remedial actions if necessary. Contractors are allowed to observe inspections and comment on them. Depending on the project type, the contractor is required to complete the remedial actions by the end of September, August or mid-November. ODOT also specifies in detail the remedial actions to be undertaken by the contractor. If any emergency situation that threatens the safety of the traveling public is identified in between regular inspections, the contractor is required to implement remedial action immediately. If it cannot implement that in a timely manner, ODOT remedies the problem and the contractor is charged for the costs incurred. If the defect giving rise to the 
emergency work is not the contractor's fault or it is beyond the contractor's control, it is not required to remedy that. In certain cases, the contractor is allowed to perform routine maintenance to prevent the occurrence of defects in order to assure meeting the warranty criteria during the inspections. But there are some limitations to this. The warranty provisions are also covering the issues that may arise during the remedial actions. For example, warranties state that the pavement markings or markers, which are removed or damaged while the contractor is implementing the remedial work, need to be replaced with equal or better ones at the contractor's cost. If the contractor and ODOT have disagreements on the results of the inspections, the contractor can appeal. The District Construction Engineer (DCE) evaluates this appeal and decides on the issue of the disagreement. If unsatisfied with this decision, the contractor can use Dispute Resolution and Administrative Claim Process (ODOT 2002).

To successfully evaluate the impacts of warranties in Ohio, there is a research program going on which was initiated by ODOT and which is being carried out by the University of Cincinnati. The results have not been published yet but the research's findings in life cycle cost analysis and project selection criteria are believed to assist ODOT in its prospective warranty projects. ODOT requested a legislative action to be able to issue performance based contracts rather than issuing materials and/or workmanship specifications based contracts (ODOT 2000). To implement performance warranties, ODOT should elaborate on determining the highway projects and components that are best suited for performance warranty provisions and then develop performance specifications and warranty criteria for these projects and components. As the current practice, ODOT is warranting the existing conditions of a project upon which it is asking the contractor to construct or maintain the highway (ODOT 1999). By this way, it assures the contractors that the performance of the highway components that they will be warranting is totally depending on the work performed by them, but not on any other external factor.

There are some disadvantages and shortcomings of the warranty concept as observed by ODOT and the contractors. First of all, contrary to the case in Michigan, field reports indicate that the warranties did not reduce the amount of inspections performed by ODOT staff. Secondly, there are some concerns related to the logistics of the administration of warranties for large, multi-phase projects. The large projects which have many warranted components may contain as many as 20 warranty expiration dates for each of these components. This may make the warranty 
administration more complicated and challenging for ODOT. Thirdly, contractors have raised some concerns about the possible exclusions for warranties. Significantly heavy vehicles (that have an ESAL of 18000 or greater) which are referred as super-loads may void the warranty requirements and this has not been addressed as an exclusion in the warranty provisions (ODOT 2000). Finally, for some projects, contractors have pointed out the existence of faulty soil conditions and the impossibility of implementing warranties in such projects. They furthermore offered ODOT that they improve these existing conditions and be compensated for that (ODOT 2000). This is a case which ODOT needs to address very quickly because this shows that even though ODOT is trying to be careful in selecting the appropriate type of project to implement warranties (by checking and warranting the initial conditions as discussed in the previous paragraph), it has not been completely successful in this and thus needs to improve its project selection criteria. The full text of some of the warranty provisions used in ODOT highway contracts is provided in the Appendix C.

\subsubsection{Wisconsin DOT Experience}

Implementation of warranties in Wisconsin started under SEP-14 in 1995 after the development of pavement warranty provisions by a team whose members are from the Wisconsin Department of Transportation (WisDOT), Federal Highway Administration (FHWA) and the Wisconsin Asphalt Pavement Association (WAPA). From the beginning, the team agreed on establishing a non-restrictive approach to the warranty concept and developed the warranty clauses by keeping the following in mind (Krebs et al. 2001):

- The final product should be defined in terms of condition and performance, not in terms of materials or processes to reach the final product.

- Performance evaluations should focus not only on the final product but also on the factors that are considered important by the road user.

- The contractor should decide how to construct the pavement and thus possess the product responsibility.

- The implementation of the developed warranties should result in improved quality and reduced costs. 
WisDOT had 2 main goals in initiating the development of warranties. First, it wanted to help national effort (as mentioned in Section 2.3) by exploring alternative contracting methods. Secondly, it was aiming to change its specifications from traditional to performance based specifications and thus used warranty implementation as an opportunity to be able to accomplish this change (Krebs et al. 2001). Warranties developed by WisDOT are performance warranties.

The warranty program was established to give the contractors freedom to the maximum extent and obtain quality products with long term performances. Contractors have the freedom to select the materials, perform the mix designs, and use any methodology they want. The only items that are specified by WisDOT are the pavement thickness and the type of base selected. This is done to allow WisDOT to award bids to the lowest price using the baseline design information. Otherwise, it would have been receiving bids with different pavement thicknesses and thus with highly varying prices. To date, Wisconsin contractors have been very enthusiastic and supportive of the program. Moreover, they have not presented any opposition. The same perspective has been present on the public too. An industry representative stated that the primary reason for the contractors to be so enthusiastic is WisDOT's noticeable interest in the warranty concept (Stephens et al. 1998).

The developed warranties were for asphaltic and concrete pavement construction projects and they have durations of 5 years. The warranty criteria were based on specific pavement distresses and historical values. The threshold levels were established using the data in WisDOT's pavement management system. The thresholds were chosen to be at a level that was typical for 5-year old asphaltic pavements. Warranty criteria for warranty evaluations were set so that $90 \%$ of the 5-year old pavements in WisDOT's pavement management system would satisfy the warranty requirements (Anderson and Russell 2001). However, contractors are not held responsible for the factors beyond their control. Moreover, the contractor is not responsible for the damages that were created by coring, milling, and other destructive actions conducted during the inspections. In Wisconsin, between the years of 1995 and 2000, warranties were implemented for 24 asphaltic pavement projects (Krebs et al. 2001). 
WisDOT reports that the warranted pavements are performing better than the typical unwarranted ones. A study completed in 2001 reveals that the typical international roughness index $\left(\mathbf{I R I}^{2}\right)$ for a 5 year old standard asphaltic pavement is $\mathbf{1 . 4 5}$. On the other hand, the warranted asphaltic pavement turned out to have a significantly better IRI of $\mathbf{0 . 9 4}$. Similarly the pavement distress index (PDI ${ }^{3}$ ) of a 5-year old standard pavement is $\mathbf{2 6}$ and the same index for a warranted pavement was found to be $\mathbf{9}$. The results of this study are presented in Figure $\mathbf{2 . 7}$ and Figure 2.8. These values reflect a great possibility of achieving the long term performance of the pavement. The same study states that, considering all factors, warranted pavements cost less per ton than non-warranted ones. To reach this conclusion, life cycle analysis were performed for 24 warranted pavement projects. Then, the results were compared to the values calculated for the situation in which had the projects been contracted out without warranties. For the warranted pavement projects performed in the years 1995-1999 (based on 18 projects), the life cycle cost was found to be $\mathbf{\$ 2 4 . 3 4 / t o n}$. If those contracts were let without warranties the cost would be \$27.72/ton. Same values for the projects performed in the year 2000 (based on 6 projects) were calculated as \$29.45 and \$31.25 respectively. However, this finding is based on limited data. (Krebs et al. 2001).

\footnotetext{
${ }^{2}$ IRI: is a profile index that describes the roughness of the pavement. The IRI was proposed by The World Bank as a standard roughness statistic (Sayers and Karamihas 1998). IRI ranges in value from zero ("perfect ride") to an indefinite upper-end. As an example, four (4) is considered a "very rough ride" (Krebs et al. 2001).

${ }^{3}$ PDI: is a subjective evaluation of pavement conditions by experienced pavement engineers, based on a userdefined scale, such as $0-5,0-10$, or 0-100. It summarizes the pavement condition in terms of individual distress, so that pavement performance may be evaluated, predicted, and improved using effective treatments (Wang 2000). Zero (0) value for PDI represents the "best possible condition” (Krebs et al. 2001).
} 


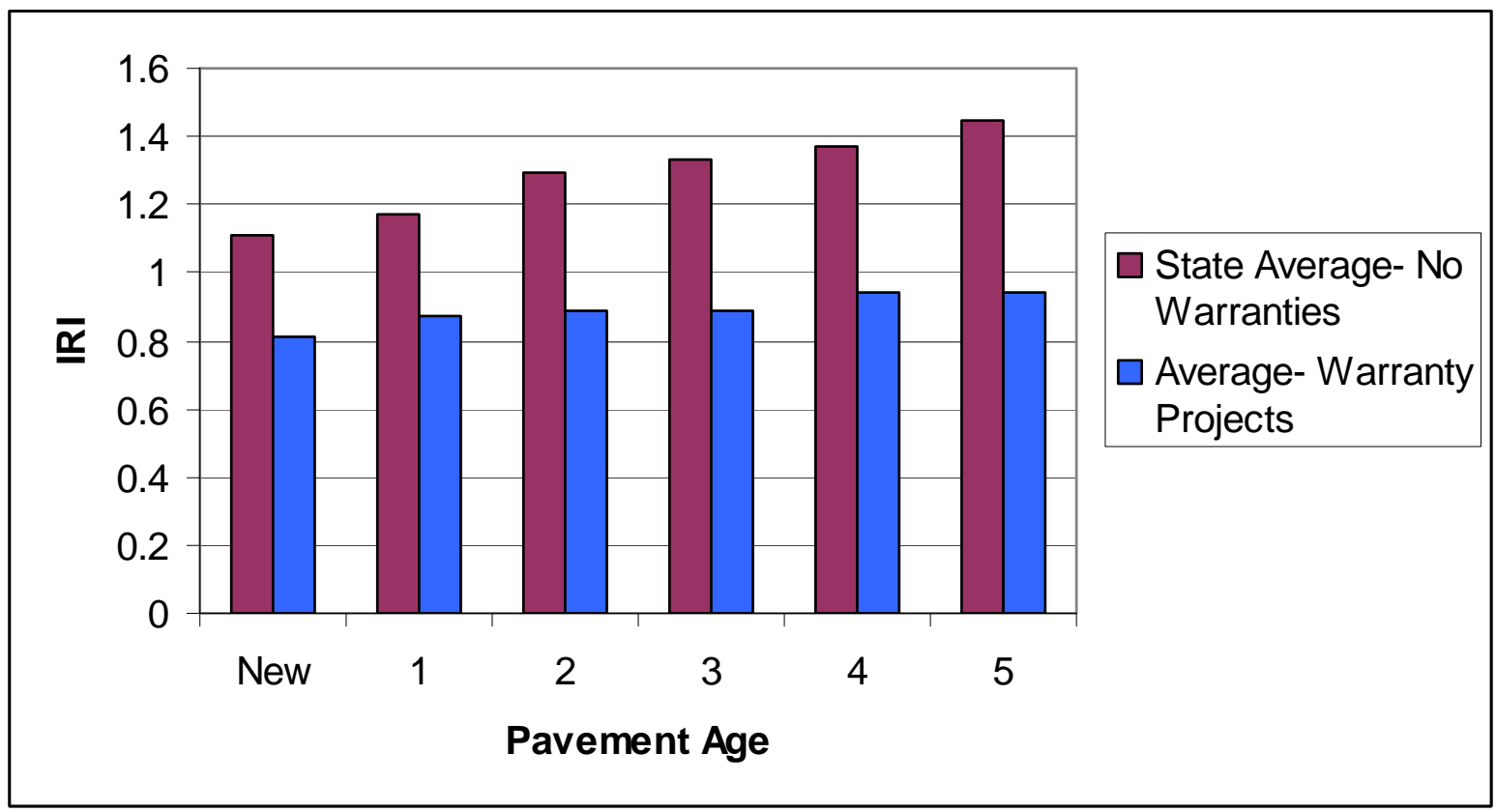

Figure 2.7: Warranty vs. Non-warranty projects average IRI comparison for Wisconsin (Source: Krebs et al. 2001, pp 6)

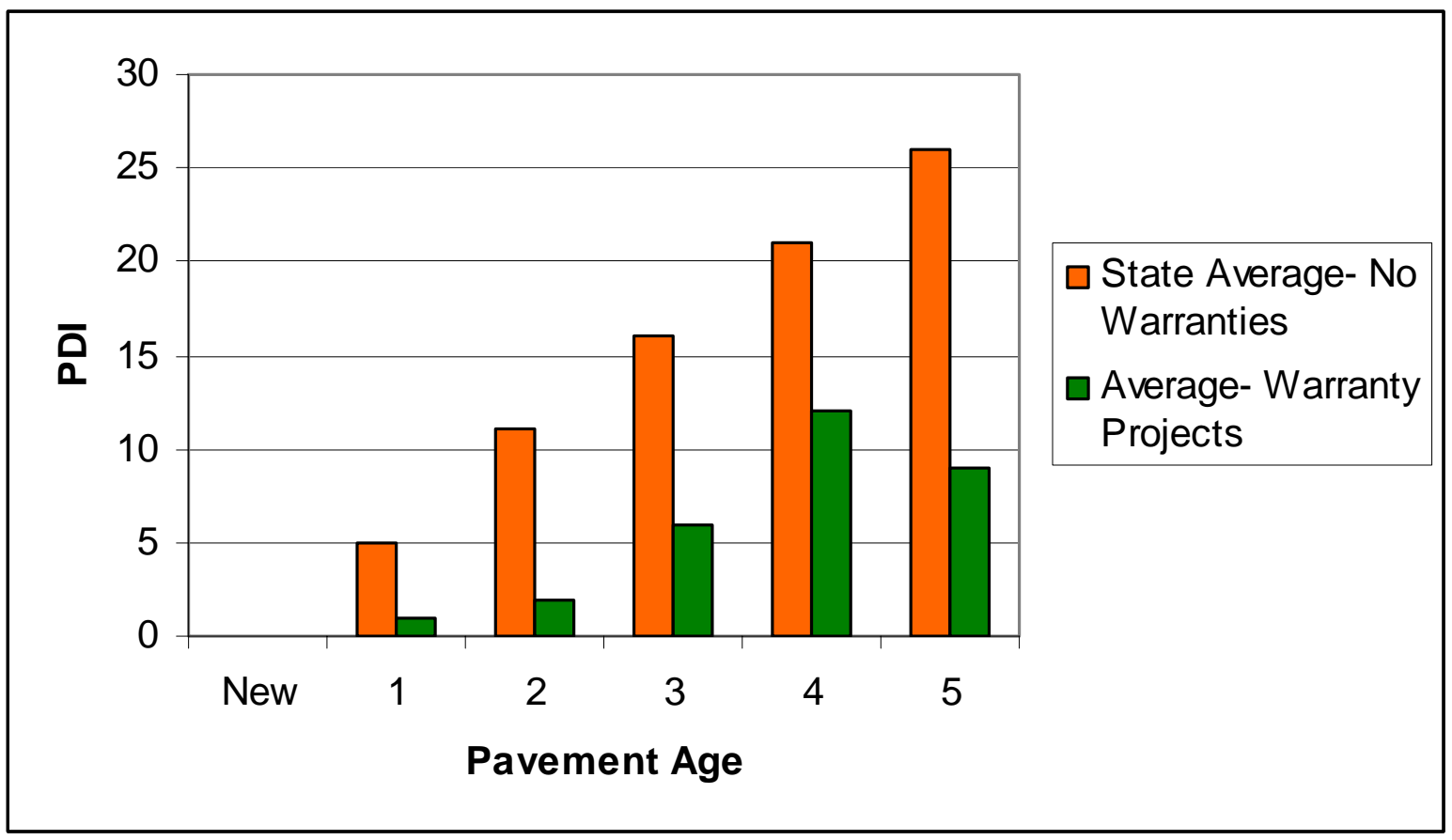

Figure 2.8: Warranty vs. Non-warranty projects average PDI comparison for Wisconsin (Source: Krebs et al. 2001, pp 6) 
It is important to note that, a few projects that were bid with warranties were not awarded due to the fact that the lowest bid was still considerably higher than the engineer's estimate. In fact, for all of the projects, the engineer's estimate has been lower than the lowest bid (Krebs et al. 2001). However, this difference is expected to diminish as WisDOT and the contractors become more experienced with the warranty concept. By contract terms, quality assurance and quality control is assigned to the contractor. Contractors are required to submit their quality control plan even before the project begins. Thus, warranted projects require less supervision and inspection, reduce the staff requirements, and thus decrease WisDOT's contract administration costs.

Given the above findings related to the quality and cost impacts of the warranty projects, it can be concluded that WisDOT was able to achieve exactly the results that it aimed in implementing warranties: Better quality with long term performance and cost savings.

For warranty compliance evaluations, once per year inspections are carried out by WisDOT. These inspections take place between April and May. The warranty criteria for asphalt pavement projects are composed of some distress items such as rutting, flushing, longitudinal cracking, and raveling. During the inspections, the distress data is collected and then analyzed in WisDOT Pavement Monitoring Lab. For general performance evaluations, these distress values are incorporated into the PDI which ranges from 0 (being best) to 100 (being worst). A plot of PDI versus time is a good way of assessing long term performance of the highway. Data for IRI, which is ranging from 0 (being best) to an indefinite value is also collected on these surveys (by WisDOT's Video Distress Van). But the values for IRI are not used to evaluate warranty compliance because it is believed that IRI generally does not control the life of an asphaltic pavement (Krebs et al. 2001).

Some distress items that had initially been considered to be included for the warranty evaluations were later omitted due to the absence of standard techniques to measure those and the lack of sufficient data to confidently establish warranty criteria for them. These distress items can be listed as roughness, appearance, noise, maintenance minimization, and delineation. Within 14 days after the completion of inspections, results and portions of the highway for which remedies will be requested are reported to the contractor. WisDOT specifies in detail the remedial action to be performed and materials to be used by the contractor for each type of warranty non-compliance. Remedial work needs to be performed within the same calendar year 
that the pavement distresses are recorded. The remedial work shall be performed in all portions of the project where warranty non-compliance is reported. The remedial work needs to be applied to the entire portions, adjacent lanes, and asphaltic shoulders. If during the warranty period, $30 \%$ or more of the highway is deemed as defective, then the contractor has to remedy whole highway that is in the scope of the warranties. In addition to the remedies requested after yearly inspections, the contractor can be requested to implement remedial actions if at anytime a problem that requires immediate attention (due to the safety issues it may create) is discovered by WisDOT. If the contractor cannot perform the remedial action within 8 hours after it is notified, it will be done by WisDOT at the contractor's expense. The contractor has the right to perform elective/preventive maintenance during the warranty period but for this, it needs to get approval of WisDOT as far as the nature of maintenance to be performed and the type of materials to be used are concerned. To identify the need for elective/preventive maintenance, the contractor can monitor the pavement. However, it should use non-destructive procedures in doing so (Krebs et al. 2001).

Certain exclusions are also present in the provisions. Some warranty criteria are waived when at any time during the warranty period, the accumulated ESALs are $50 \%$ or more above the projected fifth year accumulated ESALs (Krebs et al. 2001). If any disagreement arises due to the assignment of defect responsibility between the contractor and WisDOT, the Conflict Resolution Team (CRT) has the final authority to make decisions. The composition of the CRT is the same as the CRT's that is used in Michigan.

A warranty bond that will last for the warranty period is required by WisDOT. For the first year of the warranty period, contract performance bond is valid. For the remaining 4 years, the contractor can either provide a single term four year bond, or a two year renewable and noncumulative bond for two consecutive terms (Krebs et al. 2001). WisDOT has decided to use this approach in order to give the contractors a better chance to secure bonds from the surety companies, as suggested by the Surety Association of America (as discussed in Sub-section 2.4.2.6). In determining the amount of the warranty bond, WisDOT decided that the most likely remedial action that would be needed during the warranty period was a thin overlay (1.5 in. compacted) placed on the whole highway. Then, it determined the estimated cost of this remedial action in order to keep the bond amount reasonable. The failure of the whole pavement was decided to be very unlikely and was not used in the determination of the amount of the warranty 
bond (Anderson and Russell 2001). This again, was believed to help the contractors in securing bonds from the sureties. Moreover, sureties were informed that the warranty criteria were based on WisDOT's data for previous projects (as extracted from the pavement management system). This provided proof that the warranty criteria could be met and also made it easier for contractors to secure bonding (as discussed in Sub-section 2.4.2.6). If the warranted pavement is placed by a subcontractor, then it may provide the bond. And that bond should be a dual obligee bond which is naming WisDOT and the contractor as obligees (Krebs et al. 2001). Thus, subcontractors are required to meet stringent specifications. There is a risk sharing with subcontractors and suppliers. In such a setting, every entity that has an interest in the product assumes the responsibility, not just the paving contractor. This forces the contractor to choose the best subcontractor, not the one with the lowest bid.

As mentioned before, WisDOT performed a life cycle cost analysis and identified that the warranted pavements are more cost effective than the non-warranted ones. Thus, the warranty implementation of WisDOT has been a great accomplishment. WisDOT has identified the reasons this phenomena as follows (Krebs et al. 2001):

- WisDOT has carefully selected the projects to implement warranties. In the selection process it considered the initial conditions of the project. Projects with poor subgrades were not selected.

- The warranty concept triggered contractors to implement good materials science and construction practices with having quality in mind all the time. Contractors seemed to have more concern for quality workmanship too.

- By eliminating the state inspection and assigning QA/QC responsibilities to the contractor, substantial amount of savings are achieved due to the diminished administrative costs.

FHWA believes that the implementation of warranties within Wisconsin has provided a great deal of benefits both to WisDOT and to asphalt contracting industry. WisDOT comments that they have realized more awareness on the contractor for both quality of workmanship; and quality and quantity of personnel, equipment, and materials used. WisDOT recognizes its experience with warranty projects as very encouraging. Nonetheless, some issues were raised by 
the construction industry. One of those was that the contractors would like to learn whether all distresses used to evaluate their work reflect the long term performance of the highway. To address this, WisDOT needs to present the relation between the warranty criteria and the performance expected from the end product by the road user (Krebs et al. 2001).

There are a number of recommendations presented to WisDOT to implement in its prospective warranty projects (Krebs et al. 2001). Firstly, it is recommended that WisDOT introduces an incentive provision into its contracts. This could be either to reduce the warranty period or to pay extra amounts to the contractor for an exceptionally good performing pavement. This is an incentive to maximize the long term performance of the highway. A pavement performance that is considerably exceeding the performance of a typical pavement can be rewarded under this incentive. It is further recommended that either the warranty criteria be tighter for the same warranty period or the warranty criteria remain the same and the warranty period be increased. Both would assure better quality and longer term performance. However, WisDOT should be cautious in implementing such a decision and be aware of the limits it can go to because it may end up getting very high bid prices due to the extended length of warranty and reactions from the bidders due to the unachievable warranty criteria (as discussed in Sub-section 2.4.2.2 and Sub-section 2.4.2.3). WisDOT may also examine the possibility of bidding the projects traditionally and with a warranty. In such a case, WisDOT would award the bid based upon the traditional bid and then decide on whether or not to buy the warranty. This, if implemented carefully, may save money to WisDOT. As mentioned before, projects with performance warranties result in many innovations. In order for WisDOT to make use of these innovations and implement them in self performed jobs, contractors should be required to provide the records of the construction practices and materials they implement in warranty projects to WisDOT. Finally it is recommended that WisDOT extend the implementation of warranties. In such a context, all projects and its components should be considered as warranty candidates and after a careful examination of the initial conditions and risks, they should be awarded with warranties. Even for the projects which have poor initial conditions (i.e. subgrade), WisDOT should improve these conditions and award the project with warranties.

Throughout the implementation of warranties in Wisconsin, it was recognized that the main barrier for local agencies in implementing the performance warranty concept is the lack of staff with expertise to conduct pavement condition surveys to evaluate the warranty compliance. It 
was furthermore noted that, to overcome this issue, state DOT staff or consultants can be used (Johnson 1999). The full text of the warranty provision used in WisDOT highway contracts is provided in the Appendix $\mathbf{C}$.

\subsubsection{Highlights from the Warranty Experiences of Some Other States}

As discussed, Michigan, Ohio, and Wisconsin have been using warranties very comprehensively and widely. However, a few other states are also using warranties to a certain extent. It is a worthwhile effort to examine and underline some important aspects of the warranty implementation within these states since they are related literature to this research. Thus, the experiences of various entities (i.e. DOTs, contractors, and sureties) in these states with regards to the warranty concept are provided in this sub-section without going into too much detail.

A number of draft warranty specifications have been prepared in Florida and the Florida Department of Transportation (FDOT) is piloting some of these specifications in certain projects. However, Florida differs from the previously presented states in one great sense. Florida has written warranty specifications and developed warranty compliance criteria not only for the pavement and bridge components but also for some other asset items present in the highway such as turf, landscape, signalization, traffic stripes, and traffic markings. For signalization, the time frame for the remedial actions to be completed by the contractor is stated as 12 hours in the warranty clause. This is mainly due to emergency nature of the failure and the safety issues that may arise. Florida has also drafted a specification for an umbrella warranty provision that covers all of the project features constructed by the contractor. However this specification is drafted for only design-build projects. Just like Michigan, Ohio, and Wisconsin, Florida's warranty clause talks about the conflict resolution procedures in the case of a disagreement between the contractor and FDOT for the assignment of the defect responsibility. In the warranty clause, it is also stated that if the contractor does not comply with the dispute review board's decision, FDOT shall suspend, revoke or deny the contractor's certificate of qualification until the remedial action is performed or complete payment for the remedial work is made to the FDOT (FDOT 2003). This clearly written section of the warranty clause is a significant disincentive which would prevent the contractors from violating the warranty provisions. The warranty clauses prepared by FDOT relieve the contractor of the obligation to meet the warranty criteria in the case of $25 \%$ or more increase over the design values of ESALs or ADT during the warranty period (FDOT 
2003). The full text of some of the draft warranty provisions used in the FDOT highway contracts is provided in the Appendix C.

In Kansas, a warranty project was bid with a 15 year warranty. However, none of the bidders were able to obtain a warranty bond for that period of time. As a result of this, Kansas Department of Transportation (KDOT) had to decrease its warranty period to 5 years for which contractors were able to secure bonds. But, KDOT expressed its concern for this issue asserting that the pavement for that project was unlikely to fail during that warranty period and thus KDOT would not receive any benefits from the warranty (Stephens et al. 2002).

Missouri and New Mexico have let long term warranties of 15 and 20 years respectively. Both of the projects are for new pavement construction and then followed by long term warranties. However, these warranties are different in context than the warranties that are in the scope of this research. It can be asserted that these warranties are parts of the initial construction contracts but they really are maintenance contracts which are independent from the construction contracts. The DOTs are paying a large sum of extra amounts (\$62 million in New Mexico’s case) of money in addition to the money they pay for the construction (\$220 million in New Mexico's case) to keep the contractor of the project on the highway for the maintenance of the project during the 15-20 year warranty period. The advantage of such an approach is that, since the same contractor is both constructing and maintaining the highway, the contractor may possess a greater awareness during the construction in order to minimize the maintenance costs it would incur later on. Nonetheless, in such a setting where the warranty term is 20 years old (which may be the design life of the pavement), defects and failures are unavoidable due to the normal deterioration no matter how superior the construction practices are. Thus, the warranties implemented in these contracts do not match the warranty concept presented in this research due to the reasons stated in Sub-section 2.4.2.2. They are more like "construct and maintain for a long term" contracts than "construct and warrant for an optimized term" contracts. Issuing long term warranties requires the DOTs to be much more sensitive and careful in the development of the warranty clauses. Since many parameters used in the design of the highway such as the ESAL and ADT are prone to change over the long warranty period significantly, exclusions and/or waivers must be established in long term warranties to take care of these situations which are beyond the contractor's control. For these reasons, the warranty clause used by the New Mexico State Highway and Transportation Department (NMSHTD) 
states that the warranty obligations of the contractor are to be waived if the level of traffic during the warranty period exceeds the level which is designed for 10 years. This waiver was defined in terms of the ESALs, 4 million ESALs being the 10 year design level (Carpenter et al. 2003).

The warranty clause written by South Carolina Department of Transportation (SCDOT) has the potential of extending the duration of the warranty (for the items which failed during the warranty period), which is normally 3 years, each time a remedial action is implemented. The clause reads as "The warranty of the repaired or replaced component should be longer of one year from date of completed repair or replacement, or the remainder of the warranty period" (Stephens et al. 2002, pp 18). By using such a warranty clause, SCDOT not only assures the quality and the long term performance of the work performed during the contract period but also assures the quality of the remedial action performed after the identification of a defect during the warranty period.

The warranty clause used by the Minnesota Department of Transportation (MnDOT) elaborates on the duration of the warranty bond which is to be provided by the contractor. It states that the warranty bond shall be released at the end of the warranty period or after all warranty work is completed whichever is latest. By using this language in its warranty clause, MnDOT assures that it will have the benefit of the warranty bond until all the remedial actions dictated by MnDOT are completed. Thus, there will not be a case in which there is an outstanding remedial work and the warranty bond is released due to the expiration of the warranty term. Same warranty clause elaborates on the time frame to begin the remedial action, not to complete it. In this clause, there is not any time frame defined to complete the remedial action. The contractor is merely required to begin the remedial action within 30 days after notice by MnDOT. Finally, MnDOT requires the contractor to implement remedial action to the entire mile, if it is identified through the inspections that $50 \%$ or more of that particular inspected mile has not met the warranty criteria (Stephens et al. 2002). If this percentage is found to be less than $50 \%$, then remedial actions need only to be implemented to the portion that has not met the warranty criteria. In 1999, MnDOT implemented warranties for a statewide micro-surfacing project. The warranty period for this project was selected as 2 years because it was determined that the failures arising from poor application of the treatment (micro-surfacing) would be visible and thus identified within 2 years after the project completion (Johnson 1999). 
One of the contracts that was awarded by the California Department of Transportation (Caltrans) with warranties was an asphalt concrete overlay project. The project had a design life of 10 years and the duration of the warranty was selected as 5 years by the Caltrans. The rationale behind choosing the warranty period as such was that "there have been pavement failures in the vicinity of the project in the first four years” (Stephens et al. 1998, pp 28). Thus, in choosing the duration of the warranty, Caltrans has made sure that the duration was long enough for possible failures (if any) to occur as discussed in Sub-section 2.4.2.2. In the same project, Caltrans not only required a warranty bond for 5 years, but also retained $10 \%$ of the contract price to assure the compliance of the contractors with the warranty provisions. Nonetheless, the retained amount was paid to the contractor with a certain percentage after compliance to the warranty criteria was observed by the inspections performed at the end of each year of the warranty period. For concrete pavement projects issued by Caltrans, a substantial amount of increase in the bid prices was realized. When compared to the cost of similar type projects without warranties, the increases were estimated as $36 \%$ and $23 \%$ on concrete and rubberized concrete projects with 3-year warranties respectively. For the same projects with 5 year warranties, the increases turned out to be $62 \%$ and $25 \%$ respectively (Cui et al. 2003). California had a claim presented by the contractor in one of its warranty projects (Russell et al. 1999).

Before preparing the warranty provisions, the representatives of the Indiana Department of Transportation (InDOT) met with the representatives from WisDOT and WAPA to learn from their experiences. In fact, collaborating and using neighbor states' experiences has been very common for the states that decide to implement warranties in their projects. Unlike many other states, InDOT has chosen to implement its first warranty project, which was an asphalt concrete overlay project, on a crowded (ADT being 35000) highway. The warranty compliance was evaluated mainly using the pre-established IRI criteria, contrary to the other states in which many types of distress criteria are used to evaluate the warranty compliance. Before letting the contract, InDOT took contractors on a tour of several sections of pavement in order to make them be able to relate numerical distress (IRI) criteria to the physical pavement condition. This enabled the contractors to clearly understand what was expected from them during the warranty period. The warranty period was chosen to be 5 years considering the design life of the pavement as 20 years. The warranty criteria were set using the historical data from the previously constructed highways. Warranty criteria were established at a level which was two standard 
deviations below the observed mean performance for the existing 5-year old pavements. This theoretically was representing the condition of $95 \%$ of the 5-year old pavements present in Indiana (Anderson and Russell 2001). Some guidelines for remedial actions were provided to the contractor but the contractor did not have to follow those remedial actions. However, the contractor had to develop a remedy plan and submit this to InDOT for approval before beginning the correction of the defects (Stephens et al. 1998). InDOT was highly satisfied with the performance of this project (Cui et al. 2003).

Montana has implemented warranties for pavement striping projects under SEP-14. However, significant failures occurred in one of these projects which had a 4-year warranty. Thus, before moving further to initiate warranties for highway pavement projects, it was decided that Montana construction and surety industries were needed to be consulted to get feedback in the development of the warranty provisions. Within this context, a presentation was given by Montana State University to the members of Highway Committee of the Montana Contractors Association (Stephens et al. 1998). The presentation covered a broad overview of the warranty concept for the pavement projects and potential benefits that may be incurred by both the contractors and the Montana Department of Transportation (MDT). After the presentation, several concerns and issues were raised by the contractors and these were tried to be addressed. However, as the level of interest possessed by the contractors were realized, MDT decided to formally and comprehensively receive comments of the contractors. This decision was made mainly because it was believed that contractors would bring more insight to the projects with respect to the use of warranties. Later on, MDT decided that the best mechanism to collect the contractor input would be mail surveys sent to them. Thus, surveys were prepared and contractors' views on several issues (which are mostly the ones presented in Sub-section 2.4.2) about the warranty concept were gathered (Stephens et al. 1998). In general the contractors stated that they were not sure whether there would be any benefits for them or for MDT through the usage of warranties. They furthermore stated that the bid prices would increase significantly due to the shift in responsibility for the defects from the state to the contractor. They also asserted that this increase in bid prices might even occur without any significant improvements in the quality and long term performance of the product and thus without any decrease in the life cycle costs incurred by MDT. Small and medium sized companies have expressed concerns in surviving in a market with warranties mainly due to their lack of securing warranty bonds. 
However, despite these raised concerns, it was concluded that the majority of the contractors in Montana were willing to participate in entering the contracts with warranties. They indicated that they would be most willing to bid for total reconstruction projects if warranties were to be implemented. The warranty criteria they would be willing to be evaluated against turned out to be cracking, rutting, and ride. A table presenting the summary of the results of this survey is provided in the Appendix D.

In addition to this survey, the comments of the surety industry on the warranty concept were gathered. The surety industry stated some concerns in providing long term warranty bonds to the contractors. They have indicated that construction companies have the second highest rate of bankruptcy of any kind of business and providing long term bonds to this industry would be detrimental to the surety companies. They have commented that retainage rather than warranty bonds would provide the contractors more incentive in producing a quality product. But in such a case, contractors would increase their bids in order to offset the retained funds. Thus, the surety industry recommended that the combination of bonds and retainage be used to assure contractor compliance (Stephens et al. 1998). Even though the mentioned study has been carried out and the results were published, MDT has not implemented any warranty for its pavement construction or maintenance projects yet.

Colorado and Missouri have not experienced any excessive increase in the bids for their projects with short term warranties (which are 3 years) compared to the traditional projects. In Colorado, the performances of the warranted and non warranted projects were found to be very similar. North Carolina stopped using warranties due to an early failure on an epoxy pavement marking project (Cui et al. 2003).

\subsubsection{Federal Highway Administration's Perspective on Highway Warranties}

As mentioned before, FHWA has made the necessary rulings that have removed the obstacles for the warranties to be implemented in the highway construction and maintenance arena. After issuing the Interim Final Rule, FHWA has received 20 responses and comments from 19 organizations including 11 associations, 6 State DOTs and 2 private companies. Of the 20 responses, 13 were critical of the Interim Final Rule and thus the warranty concept (Hughes 1996). As stated in Section 2.3, although majority of the received responses were disapproving, FHWA was not convinced that the comments were significant enough to change the Interim 
Final Rule and thus adopted it as final without any change. Many of the negative comments were related to the same issues such as concerns about bonding capacity, reduced competition, increased costs and design liability. Certain issues raised by the organizations and FHWA's responses to those are as follows:

Some of the organizations commented that the bonds required in the implementation of warranty provisions were quite large and thus could affect the overall bonding capacity of the contractors and their ability to get work. It was furthermore commented that this would more likely affect the small contractors, reducing the bid competition and thus increasing the cost of the projects to the state DOTs. FHWA did not agree with these comments and stated that warranties would not affect small contractors' bonding capacity and ability to get work. FHWA stated that experience to date has shown no negative impact on the bonding capacity of the small contractors. Even before the issuance of the Warranty Interim Final Rule in 1995, states had been using warranties for the federal aid projects highways located off the national highway system (NHS) since the passage of the ISTEA in 1991. These non-NHS projects approximately constituted a one third of the FHWA's whole Federal-aid program. In these projects, FHWA has not observed any problems in this issue of "bonding capacity of the small contractors". The Interim Final Rule was not introducing anything new, but just extending the use of warranties to the remaining two thirds of the Federal-aid program. Thus the concerns related to the bonding capacities were pointless. FHWA furthermore stated that the warranties were more likely to be implemented for specialty and experimental components of the projects. This is mainly due to the fact that without warranties, state agencies usually had not contracted out such specialty components as they were not getting any assurance for those. However, with the implementation of warranties, state agencies would be willing to contract those out and small specialty contractors might have the opportunity to enter the market with their experimental items because state agencies could be assured with warranties. FHWA stated that given the relatively short term duration (maximum 5 years) of the warranties, small contractors would not have too much difficulty in obtaining warranty bonds. Finally, FHWA asserted that, if bonding still posed a problem, state DOTs could use the retainage approach instead of bonds to assure the compliance of the contractor with the warranty provisions (Hughes 1996).

One other issue that created opposition to warranty implementation was "the contractor being liable for the design under the umbrella of a warranty”. Such design exposure was outside 
the control of the contractor and thus inappropriate. FHWA responded to this by commenting that the warranty regulation was stating that the contractor would not be obligated for items over which it did not have control. Thus, if the contractor did not have control over the design, it would not be held responsible for the design defects (Hughes 1996).

As could be understood from the comments made by FHWA, it greatly supports the implementation of warranties for highway projects. FHWA believes that the warranties will help state DOTs to avoid unnecessary maintenance and repair/replacement costs that are resulting from the early failures due to the contractor's defective work (Hughes 1996).

To help the states in preparing the warranty provisions, FHWA has prepared a guide for the development of warranty specifications for micro-surfacing. This guide includes the warranty criteria that must be met by the contractor such as flushing, bleeding, raveling, ruts, and some other criteria. The guide suggests the warranty period to be two years due to the fact that the surfaces that have lasted two years have been found to have good long term performances. Recommended warranty bond amount varies between $50 \%$ and $100 \%$ of the contract amount. The remedial actions are needed to be completed within 30 days after the notification of the contractor by the transportation agency. Ontario Ministry of Transportation within Canada has developed warranty specifications for micro-surfacing projects using the guide prepared by FHWA. However, slight modifications were introduced. Ontario chose the time frame for remedial action as 2 weeks for the cases in which defects pose a safety problem Ontario furthermore chose the warranty bond amount as $10 \%$ of the contract price stating that the recommended amount of 50\%-100\% was too high. Ontario used the 2- year warranty period as recommended by the FHWA. In deciding on the duration of the warranty, Ontario also asked the industry for their preferences on the duration and furthermore used the measured performance of existing micro-surfaces (Stephens et al. 1998).

\subsubsection{Advantages and Disadvantages of Highway Warranties as Deemed by the State DOTs, Contractors, and Surety Companies- A Summary}

In the previous sections, the issues related to the highway construction and maintenance warranties as identified by various state DOTs, contractors, and surety companies as well as the experiences of those entities with the warranty concept were presented. This sub-section lists the 
advantages and disadvantages of the highway warranties as realized by these entities through their experiences with warranties.

\subsubsection{Advantages and Opportunities}

Advantages and opportunities as realized by participating entities through the usage of warranties can be listed as (Anderson and Russell 2001, Johnson 1999, Krebs et al. 2001, ODOT 1999, ODOT 2000, Russell et al. 1999, Stephens et al. 1998, Stephens et al. 2002, Utah T2 Center 2002):

- The most significant and potential benefit is the increased quality of the construction and maintenance with long term performance of the services or the products.

- There is the potential of cost savings incurred by the state DOTs when compared to the projects without warranties. This is mainly because of the transfer of maintenance costs to the contractor during the warranty period and then the reduction of maintenance costs incurred by the state DOTs after the warranty period due to the increased quality and long term performance of the product. Moreover, savings are achieved in some cases, where quality assurance and quality control (QA/QC) are contractually transferred to the contractor, due to the reduced inspection and administrative costs incurred by the state DOTs. At the bottom line, although bid prices for warranty projects may be higher than the ones without warranties, the potential for the reduced life cycle costs of the product results in cost savings by the state DOT and thus by the taxpayers.

- When warranties are implemented, contractors become more proactive and self conscious. Thus, they have a higher focus on the project quality and long term performance. Thereby, they are likely to implement good construction practices.

- When used in association with performance based specifications, warranties provide the contractors with the incentive to bring about innovations. Moreover, these innovations can be introduced fast due to the absence of extensive acceptance testing and evaluation steps performed by the state DOT. And this causes economic benefits realized by all parties. 
- The implementation of warranties encourages the team concept among the contractor's employees. Contractor's employees and subcontractors are more aware of the value they add to the project and pay greater attention to be able to produce a better quality product.

- Better QA/QC is implemented by the contractor. Since it is the responsible party for the remedial actions in the presence of defects, its QA/AC plan should be good. Only by having a good QA/QC plan, it would be able to identify any problems that would lead to failures in advance and can immediately take precautions to prevent the potential failures from occurrence.

- Warranties may be used when the design, contract administration and/or inspection capabilities of the state DOT are inadequate for the project.

- Warranties are compatible with the low bid award system.

- Increased involvement and input of the contractor in the design phase lead to fewer disputes, claims and litigation.

- The substantial amount of failure risk that is assumed by the state DOT for traditional contracting is significantly reduced through the usage of warranties.

- Qualified and stable construction companies may emerge to be able to do all the tasks needed for transportation projects with warranties.

\subsubsection{Disadvantages and Concerns}

Disadvantages and concerns as realized by participating entities through the usage of warranties can be listed as (Anderson and Russell 2001, Johnson 1999, Krebs et al. 2001, ODOT 1999, ODOT 2000, Russell et al. 1999, Stephens et al. 1998, Stephens et al. 2002, Utah T2 Center 2002):

- In some cases initial bid prices and life cycle costs increase so much that this increase may not offset the maintenance or inspection savings.

- The use of warranties may not always improve the quality and provide long term performance. Especially in a low bid award environment, the trend may be to minimize cost once contractors learn where to be less considerate and still meet the warranty requirements. 
- Use of warranties does not always reduce the need for inspection during the contract period.

- Warranties are only good as the contractor and the surety company are involved. If the contractor and the surety company go out of business, then there is no way for the state DOT to obtain remedial work for the failures occurring during the warranty period.

- Since state DOTs are inexperienced with the warranty concept, they may have some difficulty in administering them over extended periods. Particularly, inspections made throughout the warranty period to assess the warranty compliance may put an extra burden on the state DOT.

- State DOTs may have difficulties in drafting the warranty provisions, especially for the warranty clause's components that specify the warranty criteria and the length of the warranty period. Establishment of warranty criteria for the distress indicators calls for large amount of historical data and thus a great deal of time invested in research. States may also have difficulties in selecting the appropriate project to implement warranties.

- To implement warranties, initial conditions such as traffic loads and sub-base should be well defined. Moreover the warranty provisions should contain some exclusions and waivers to cover the cases in which these initial conditions change substantially. To establish this "exclusions" component of the warranty clause may be very challenging for the state DOTs.

- There is an uncertainty in whether the surety companies will be able to provide long term warranty bonds for projects which carry larger risks than the ones they supply bonds in traditional contracts. Furthermore, requiring warranty bonds with high amounts (i.e. $100 \%$ of the contract cost) may result in significant increases in contractors' bid prices. Moreover, requiring warranty bonds with high amounts would result in even fewer contractors to be able to secure bonding.

- Construction industry may be negatively impacted due to the difficulties that the contractors encounter in obtaining bonds. Small companies, even though having good work records, may be eliminated from the bidding process. This in turn may reduce the competition and result in even higher bid prices. 
- Although majority of the beliefs are to the contrary, there is a potential for increased disputes and litigation due to the premature implementation of warranties without adequate technology and procedures to handle the contracts. This may prevent the widespread adoption of warranties in the USA.

- Up to date, the entire project consisting of many construction or maintenance items (work) has not been covered under a total warranty concept. Only certain items of a project are covered under the warranty concept. This limits the state DOTs in receiving the potential benefits of the warranties to the maximum extent.

- Enforcement of warranties for the services provided by the subcontractors is unclear.

- Some professionals assert that the state DOTs lose control of the products when using performance warranties and thus performance based specifications.

- Warranty implementation may increase the project completion time. Contractors would be reluctant to complete their construction or maintenance work until all factors that may affect the performance of their product have been addressed. However, this increase in time can be offset by the reduction in time generated through the usage of innovative construction practices as introduced by the implementation of warranties. Thus, this disadvantage of the warranty concept can be offset by an advantage introduced by it.

As can be seen, even for the same issues like cost, quality, and many others, warranty implementation is perceived differently (as being advantageous or disadvantageous) by different parties. As a matter of fact, results of the survey conducted by Adam Ross with the attendance of 5 state DOTs also reveal the diverse perceptions about the warranty concept (Hancher 1999). In this survey, the benefits received through the implementation of warranties were rated as 3.2 in a scale in which 1.0 represented low and 5.0 represented high. Similarly, difficulty of implementation was rated as 3.0 in the same scale (Hancher 1999). The ratings given by the state DOTs to both of the criteria indicate the DOTs have not reached to a specific conclusion about the warranty concept yet. A reason for this may be the fact that the warranty is a rather new concept. Thus, entities have insufficient and different experience with it up to date. Therefore, definite conclusions, as agreed by everybody cannot be drawn yet. This will be possible 
through the implementation of warranties in a wider range of highway projects by a wider range of state DOTs. Another reason for having counter ideas for exactly the same issues may be the different approaches of entities to the warranty concept in different states. The states, which are aware of the possible drawbacks of the warranties, may be cautious in such issues and then convert these drawbacks to benefits. Thereby, these states may be perceiving the warranty concept as a panacea. Other states, however, may not be doing this and thus may be perceiving that the warranties possess more drawbacks than advantages.

Given these conditions, it is a worthwhile effort for the state DOTs to implement warranties in highway construction and maintenance projects, at least for a trial basis on the pilot projects, in order to get an idea. By this, the state DOT can experience the advantages and disadvantages that the warranties bring about and may then decide on whether to proceed with warranties or not. But, considering the discussions presented in the preceding sections and also the ones that will be presented in the following sections, it is more likely that the benefits will outnumber the drawbacks if the state DOTs and highway contractors become cautious in possible drawbacks and then do their best to convert these drawbacks to benefits.

\subsection{HIGHWAY WARRANTY PRACTICES IN EUROPE}

Contrary to the case in the USA, warranties have been widely implemented for the construction and maintenance of the European pavements. In fact, European agencies often implement warranties for nearly all of their road projects. These warranties typically last for 5 years and are strictly enforced by the transportation agencies. Contractors are responsible for the quality control and the agencies are responsible for the quality assurance. Either performance based or method based specifications are used. However, in both cases contractors are given significant freedom in design, innovation, and implementation (Johnson 1999).

Through the implementation of warranties, European contractors assume considerable risk. This risk made many of the European contractors invest tremendous amounts of money in research, laboratory facilities, staff, and equipment. On the other hand, this risk pushed many of the smaller contractors who were not able to invest such amounts out of the bids, leaving only the highly competent and well financed contractors in the warranty market (Johnson 1999). 
By transferring the risk of additional responsibilities such as the quality control, poor performance, and post project failures to the contractor, transportation agencies undertake a certain amount of risk too. One way to reduce this risk is choosing the right contractor. This can be accomplished only through an extensive pre-qualification process in which bonding capacity, previous record on warranties, and technical competence of the contractor is thoroughly evaluated (Johnson 1999).

In Europe, contracts are generally awarded using the low bid selection criteria. However, selection through the evaluation of alternative bids and through negotiations is also implemented. The required warranty bond amount is typically $5 \%$ of the contract price and thus is not enough to cover the cost of the remedial actions (Johnson 1999). However, this does not pose a problem since agencies trust the contractors in meeting the warranty provisions' requirements.

The political, social, and economical conditions as well as the transportation network are dissimilar in Europe and USA. Due to these dissimilarities, implementing warranties for road construction and maintenance projects is easier in Europe. Some of the differences and the consequences of those as identified by the professionals within the 1990 European Asphalt Tour and 1992 European Concrete Tour are as follows (Hancher 1994, Johnson 1999):

- Disputes are generally settled through negotiations in Europe. Thus, the amount of litigation within Europe is far less when compared to the USA. Due to this difference, both the contractors and transportation agencies in Europe are less hesitant than the ones in the USA in entering to the contracts with warranties.

- In Europe, there are fewer but bigger contractors. These contractors are comfortable in undertaking warranty projects both for financial reasons and their ability to produce a high quality product through the usage of superior staff and equipment.

- Awarding bids through negotiations is very common in Europe. This enables the transportation agencies to negotiate the price and scope of the contractors' efforts on the construction work both during the award and the warranty period.

- Contractors in Europe have a significant amount of input on the design which enables them to gain control on the warranted work.

- In Europe, quality check is the contractor's responsibility and quality assurance is the agency's responsibility. Often, contractors perform the testing for the 
projects and transportation agencies verify these through random checks. Thereby, contractors are experienced in quality checks, which is a responsibility that is transferred to the contractors through the implementation of warranties.

- Several European countries have already switched to performance based specifications. This enabled them to implement warranties (especially performance warranties) in a more appropriate way.

- In Europe, there is a considerable cooperation between the industry and the transportation agencies to achieve high quality products and long term performance. Any increase in construction costs associated with this purpose is accepted by the transportation agencies. And, implementation of warranties serves this purpose perfectly.

- The European construction community is much more involved in research and development than the contractors in the USA. This enables them to be much more confident in their work. With this confidence, they do not see any problem in warranting their products.

- Transportation agencies in Europe have the legal right to restrict bids to well qualified contractors. This enables the highway agencies to choose the qualified contractor which would not pose any problems in complying with the contract and warranty provisions.

Some practices used in the European countries in the administration of the contracts with warranties are quite different from the ones used in the USA (Hancher 1994). For example, in Austria, disagreements over the results of the warranty compliance inspections are not brought to the attention of a conflict resolution team. Rather, an independent consultant is hired by the contractor to resolve the dispute. In Denmark, contractors have the input on the mix design of the pavement and also have the option of extending the length of the minimum warranty period to make their bids more attractive. Contracts are awarded based not on the lowest bid, but on the lowest life cycle cost as would be achieved by the warranty which the contractor is offering. In Denmark, less than $2 \%$ of the projects have warranty related problems. Highway contracts in France include a 10-year warranty. However, failures taking place only in the first year of the warranty period are remedied by the contractor. Thereafter, costs associated with remedies are 
shared between the contractor and the transportation agency on a case-by-case basis. In Germany, warranty periods are set by law as 4 years for highway and 5 years for bridge projects. $5 \%$ of the contract cost is retained as an assurance for the contractor to comply with the warranty provisions. This amount is reduced to $3 \%$ when it is concurred by the transportation agency that the project is proceeding smoothly. The remedial work implemented during the warranty period is then re-warranted for a minimum of two years. The contractor has the right to negotiate for additional compensation if the remedial action improves the quality of the highway significantly. In Norway, bids are evaluated considering both the price and the warranty plan (i.e. type of the remedial actions that will be implemented in case of the presence of defects) of the contractor. A performance bond that has an amount of $15 \%$ of the contract price is required from the contractor for the term of the project. After the completion of the project and thus with the beginning of the warranty period, this amount is reduced to $3 \%, 2 \%$, and $1 \%$ for the first, second, and the last year of the warranty period respectively. Sweden transportation agency requires the contractor to remedy the defects occurring in the warranty period for the first time. In the event of a subsequent failure, the contractor is required to replace and re-warrant the whole project. In resurfacing projects, contractors are not held responsible if the defect is found to be caused due to an underlying layer (Hancher 1994). A table summarizing the warranty practices used in the European countries is presented in the Appendix E.

\subsection{EXAMPLES OF PERFORMANCE BASED ROAD MAINTENANCE CONTRACTS WITH WARRANTIES}

As mentioned previously, performance based contracting has been around for twenty or so years within the USA. However, performance based contracting in the area of maintenance, specifically in road maintenance, has a shorter history going back ten years. Thus, there are limited numbers of examples available regarding performance based road maintenance contracts written up to the current date.

New Zealand has written some very sophisticated performance based road maintenance contracts. These contracts are very clear and comprehensive in many ways. They establish guidelines from the outset of the project, elaborate on the bidding process and award of contract, 
and define the statement of work and performance measures in great depth. Most importantly, as far as this research's scope is considered, these contracts possess warranty provisions. The contracts written by Transit New Zealand in New Zealand are good illustrations of performance based contracts.

In February 2002, the World Bank prepared a document entitled "Procurement of Performance Based Management and Maintenance of Roads”, which is a prototype for the performance based road maintenance contracts. This is also a very comprehensive document and also possesses warranty clauses covering the maintenance activities undertaken by the contractor.

Both of the abovementioned contracts have direct correspondence to the contract that is in the scope of this research. They both contain performance based specifications just like the contract issued by VDOT. Moreover, they both are "fence to fence" highway maintenance contracts covering all asset items within the highway system. Thus, to address the problem presented in this research, these contracts and Transit New Zealand's and the World Bank's approaches in preparing the language used in the warranty provisions of these contracts will be expanded herein. In the following chapters where the warranties for the VDOT contract are developed, these contracts will be examined in more detail. However, at this point it is important to note that the warranty provisions used in the New Zealand and the World Bank contracts are written in very general language and do not go into details in the specific issues that were discussed previously in Sub-section 2.4.2. Moreover, New Zealand and USA are two very different countries. Thus, in developing the warranty provisions for the VDOT contract, warranty clauses within these contracts can only be used in the conceptual level and the content and language of these clauses can only be referred to as to form minimal guidelines to reach the purpose of this research.

Both of the contracts refer to warranty period as "the defects liability period". Some clauses as extracted from the abovementioned contracts will be illustrated below to give the reader an idea about the approach of these contracts to the warranty issue that is in the scope of this research:

The contract prepared by the World Bank covers the warranty issue within clause 41. This clause is written as: "The contractor warrants that the Works and Services or any part thereof shall be free from defects in the design, engineering, materials, and 
workmanship...The Defect Liability Period shall be eighteen (18) months from the date of Completion of the Contract (or any part thereof) or twelve (12) months from the date of Operational Acceptance of the Works and Services whichever occurs first. If during the Defect Liability Period any defect should be found in the design, engineering, materials and workmanship of the Works and Services executed by the Contractor, the Contractor shall promptly, in consultation and agreement with the Employer regarding appropriate remedying of the defects, and at its cost, repair, replace or otherwise make good (as the Contractor shall, at its discretion, determine) such defect as well as any damage to the Road caused by such defect. The contractor shall not be responsible for the repair, replacement, or making good of any defect or of any damage to the Road arising out of or resulting from improper operation or maintenance of the Road by the Employer after taking over. The Contractor's obligations under this clause shall not apply to any materials that are.... normally consumed in operation or have a normal life shorter than the Defect Liability Period stated herein...” (The World Bank, Clause 41 2002, Full clause provided in the Appendix F).

The contract that is prepared by Transit New Zealand mentions the defects liability period within the clause: “The Contractor will not be responsible for maintenance of any assets which... for the time being, are the maintenance responsibility of another contractor between the date of practical completion and the end of the defects liability period of those other contracts... A joint inspection, conducted by the Superintendent and the Contractor at the end of the defects liability of other contracts, will identify any particular maintenance or omission responsibilities of the other contractor that may exist at the date of the defects liability period. The Contractor will not resume responsibility for the Assets in question until the identified reasonable responsibilities of the other contractor are discharged..." (Transit New Zealand, Clause 1.12.2 2002, Full clause provided in the Appendix F). 


\subsection{EXAMPLES OF PERFORMANCE BASED ROAD MAINTENANCE CONTRACTS ISSUED IN THE USA}

There are some performance based road maintenance contracts that are issued in Florida and Texas by the Florida Department of Transportation (FDOT) and the Texas Department of Transportation (TxDOT) respectively. These contracts are successors of the one issued by VDOT, and their scopes are very similar to the one issued by VDOT. Just like the VDOT contract that is in the scope of this research, these contracts do not contain any warranty provisions. Hence the M.S. candidate believes that, VDOT's contract, as improved by the inclusion of warranty provisions, can be a learning document which can be used by other state DOTs that are issuing similar contracts. VDOT, being a pioneer in using performance based highway maintenance contracts, may also lead the way in incorporating warranties into these contracts.

\subsection{STANDARD FORMS OF TRADITIONAL DESIGN-BID-BUILD CONTRACTS}

The standard contract forms for construction projects are the documents that encompass some general conditions and clauses for the contracts. These clauses do not contain any technical specifications that may change from project to project. They contain, rather, legal language that is developed to meet the needs of the projects and their participants. The standard contract forms have been developed by professionals working in the construction industry; and by decades of experience, they reached their final forms. Nonetheless, they are still in the phase of evolution and thus modified from time to time. The construction industry widely makes use of these standard forms. Due to the fact that they are very generic in content, the clauses within these standard forms may be applied to a variety of projects. The standard forms are developed for the traditional procurement method within the construction industry, which is the design-bid-build method. This method calls for the delegation of the project to two different entities. Design is carried out by one entity, the designer, and construction is carried out by another, the contractor. Therefore, projects carried under this method generally result in two separate contracts: Ownercontractor contracts and owner-designer contracts. As a result of the different needs of these 
different kinds of contracts, the industry has developed two separate standard contract forms: Owner-contractor standard form of contract and owner-designer standard form of contract.

The most common standard forms used in the USA are the ones that are prepared by The American Institute of Architects (AIA) and by the Engineers Joint Contract Documents Committee (EJCDC). The most common standard form used in Europe is the one that is prepared by the Federation Internationale Des Ingenieurs-Conseils (FIDIC).

These standard forms are written for design-bid-build contract types. On the other hand, the research is dealing with a performance based contract. Nonetheless, some common principles may be extracted from these standard forms to be tailored to suit the needs of the performance based road maintenance contract that is in question.

The aforementioned standard forms are very comprehensive in all of the matters related to construction projects. Moreover, they include very sophisticated language and clauses related to warranty. These characteristics of the standard forms are of particular interest since the language used in them is a valid and widely accepted language and therefore can be used in the adoption and adaptation purposes mentioned in Sub-section 1.6.2 where methodology of the research is discussed.

\subsection{HIGHWAY AND BRIDGE SPECIFICATIONS PREPARED BY STATE DOTS}

The M.S candidate has also gone through the latest version as well as the earlier versions of the standard specification books that are prepared and used by the state DOTs in the preparation and administration of their highway contracts. These books are generally called as "Standard Specifications for the Construction and Maintenance of Bridges and Highways", and as the name implies, possess the general and technical standards for construction and maintenance work items. This literature review was performed in order to get familiarized with the language used within these contracts and also to identify the usage of warranty clauses within these specifications, if there are any. The states whose standard specification books were examined are

Texas, Florida, Pennsylvania, and Virginia. Also the standard specification book for the District of Columbia was examined. As a result of this literature review, it was identified that none of these standard books possesses any warranty clause. 


\subsection{SOME OTHER EXAMPLES OF PERFORMANCE BASED CONTRACTS ISSUED IN THE USA}

Although the research is aiming to deal with only the performance based contracts that have the scope of road maintenance, it is a worthy effort to observe other types of construction projects that are running under performance based contracts. The most remarkable example is the Pentagon Renovation Project (PENREN). PENREN is a project consisting of multi-phases, including a secure bypass, metro entrance facility, fitness center, mall, and the wedges of the Pentagon. Each of these constituents is contracted out at different times and has been awarded to various contractors. Specifically, the Wedge 2-5 Renovation and the Metro Entrance Facility Construction projects are contracted out as performance based contracts. Due to the Department of Defense's position, all of these contracts are governed by the Federal Acquisition Regulation (FAR). Hence, they contain many clauses that are extracted directly from FAR. Being comprehensive in warranty issues, the abovementioned contracts can also be regarded as related literature for the research for the purposes of adoption and adaptation as discussed in Sub-section 1.6.2. Full text of the warranty clause (as extracted from FAR) used in these contracts is provided in the Appendix G. 


\section{CHAPTER 3}

\section{PHASE 2- ANALYSIS PHASE}

The methodology of this research calls for the analysis of the problem that was identified in Section 1.4, after the completion of the literature review. Thus, the Observation Phase is followed by the Analysis Phase which is presented in this chapter.

In this chapter, first the rationale behind developing warranty clauses to overcome the identified problem is discussed. Then, the analyses of the first four specific objectives that are identified in Sub-section 1.5.3 are presented. It is important to note that the complete and comprehensive warranty clause template is developed through achieving the first four objectives in a step by step fashion. The developed warranty clause template, which is presented in the next chapter (Chapter 4), is believed to form the solution sought for the problem identified in this research. One important remark to be kept in mind while reading Section 3.1, Section 3.2, Section 3.3, and Section 3.4 is that, the discussions presented in these sections are based on one asset item, "Paved Ditches" namely. This is done in order to present the discussions and the proposed approaches in a more simplified way. Nonetheless, exactly the same discussions are also valid for the remaining 31 asset items that are listed in the Appendix B.

\subsection{THE RATIONALE BEHIND DEVELOPING THE WARRANTY CLAUSES}

As briefly discussed in the Section 1.4, the warranty concept is one of the most efficient ways to ensure overall condition improvement, better quality and long term performance for the road maintenance projects with performance specifications. In fact, that is why the purpose of this research is to develop a warranty clause template to address and overcome the problems identified previously. However, before proceeding to develop the template, it is essential to explain the rationale behind proposing the warranty concept as a possible solution to the identified problems. The discussion presented in the following paragraphs uses the expressions 
"contract term" and "warranty period" frequently. Within the context of the discussion, the "contract term" is the period in which maintenance activities are performed, beginning with the issuance of the "Notice to Proceed" by VDOT and ending with the issuance of the "Certification for the Final Acceptance" by VDOT. Similarly the "warranty period" is the period beginning with the issuance of "Certification for the Final Acceptance" by VDOT and ending with the completion of the duration that is assigned to the warranty within the warranty clause.

As asserted previously, warranty clauses give the contractor the motivation to implement superior maintenance practices and to improve the overall condition of the assets during the contract term. This is mainly due to the fact that within the warranty period, in which the contractor does not perform maintenance activities as the way it does during the contract term, the warranty concept requires the overall condition of the assets to be at a certain level. This level, which is a part of the warranty clause, will be defined during the development of the warranty clause template in the upcoming sections.

In a way, the warranty concept extends the duration of the contract term for the length of the warranty period by defining certain warranty criterion for each asset item to be applicable over that warranty period. And since the contractor does not perform maintenance activities during the warranty period as the way it does during the contract term, it cannot just maintain the assets to improve their conditions whenever their overall conditions drop below the established warranty criterion during this period. During the warranty period, the contractor does not have complete control over the asset items as it has during the contract term. However, it has the total liability for the performance of those asset items as if it still has the complete control over them. In essence, what a warranty does is to make the contractor incur continuous liability for a certain period after the completion of the contract term.

In such a setting, the contractor would do its best to improve the overall condition of each of the asset items as much as possible when it has complete control over the project (i.e. the contract term), in order to completely avoid or minimize the liability issues it may encounter after it loses its complete control over the project (i.e. the warranty period). The following figures may help the reader understand the impact of the warranty concept on the contractor's work. Figure 3.1 shows the maintenance approach applied for the "Paved Ditches" asset item. This figure has already been presented in the problem discussion (in Section 1.4) in which 90\% performance target is tried to be barely met by the contractor as the overall condition rating of 
the "Paved Ditches" asset item drops below that value. This is the kind of the maintenance approach that may be implemented by any contractor performing work under the current contract language which does not possess any warranty clause. With the introduction of warranties to the contract, it is highly possible that the contractor's maintenance approach leading to the problem of "not achieving overall condition improvement and thus long term performance" is going to be replaced with an entirely different maintenance approach. This new and desired maintenance approach is illustrated in Figure 3.2. This time, the contractor is implementing maintenance not to barely reach the performance target but rather to achieve an improvement in the asset item's overall condition. The contractor is much more considerate about the post project completion performance of the "Paved Ditches" asset item, at least for the performance during the warranty period, in order to minimize the amount of liability it incurs. Therefore, during the contract term, improvement in the overall condition of the "Paved Ditches" asset item is sought and achieved by the contractor in order to lengthen the life of that asset item and to provide the long term performance of that asset item. The contractor is much more considerate because it is aware of the fact that in the case of unsatisfactory performance, the warranty concept requires the contractor to return to the completed project and implement remedial actions to the "Paved Ditches" asset item to bring it back to or above the warranty criterion established in the warranty clause. The warranty criterion required through the warranty period will be defined in the later sections of this research where the warranty clause template is developed. For the time being, for the sake of simplicity in understanding the presented figures, they can be assumed to be same as the performance targets required within the contract term, as presented in the Exhibit B of the current VDOT contract. 


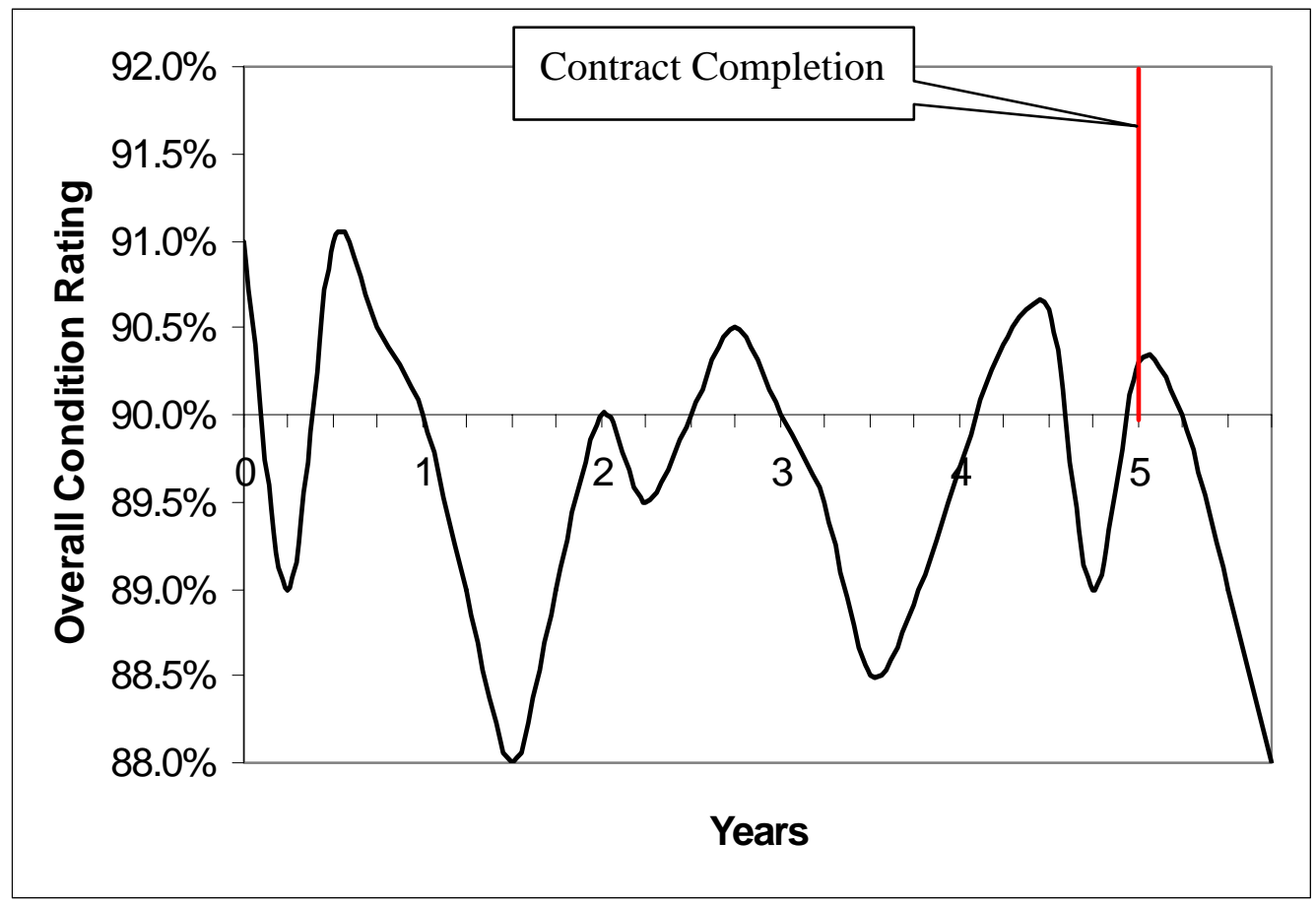

Figure 3.1: The maintenance approach of the contractor under current contract conditions

“Contract without warranty” case- The PROBLEM

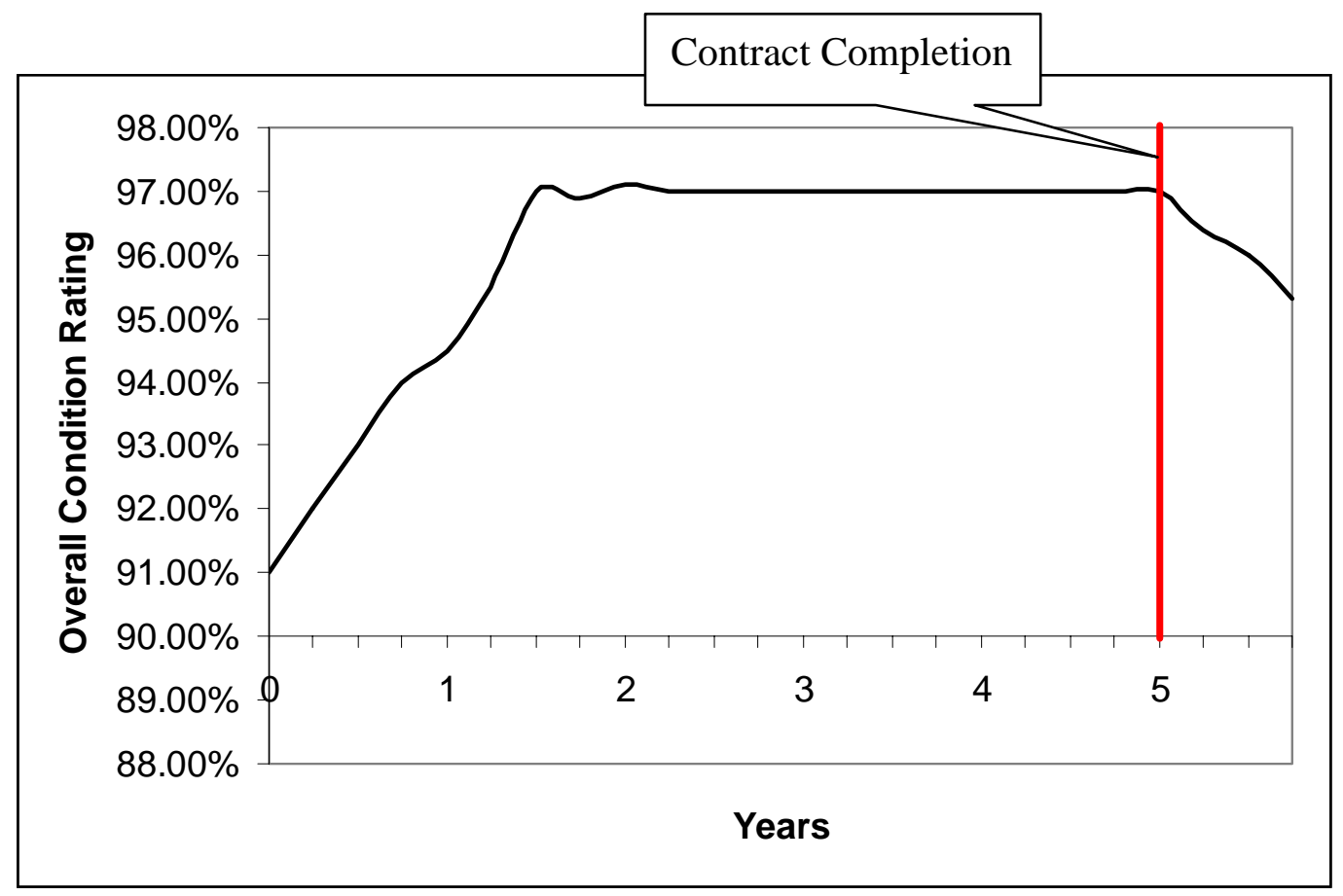

Figure 3.2: The maintenance approach of the contractor after the implementation of warranties “Contract with warranties" case- The SOLUTION to the PROBLEM First possible scheme 
In conclusion, the introduction of the warranty concept makes the contractor implement a maintenance philosophy that establishes an improvement in the asset item's overall condition. However, it is very important to note that this improvement may take place at any time during the contract term. One scheme of improvement is already presented in Figure 3.2. This kind of improvement would be the one that is most likely desired by VDOT, since it provides the better overall condition (and thus quality) of the asset item for a very long duration all through the contract term. However, other schemes of improvement may also be implemented. These are illustrated in Figure 3.3 and Figure 3.4. Figure 3.3 presents a maintenance scheme in which the contractor introduces a continuous and consistent improvement over the contract term in order to reach an overall condition rating (for the "Paved Ditches" asset item) that would last for the warranty period. This maintenance scheme is very likely to be implemented by a well-planned contractor. And, Figure 3.4 presents a scheme in which the contractor keeps the "without warranty” approach for a long duration within the contract term and then improves the asset item's overall condition towards the end of the contract term. Although not being optimum, these schemes of maintenance approaches also provide improvements in the asset item's overall condition and also result in asset item performances which would last long enough as desired by VDOT.

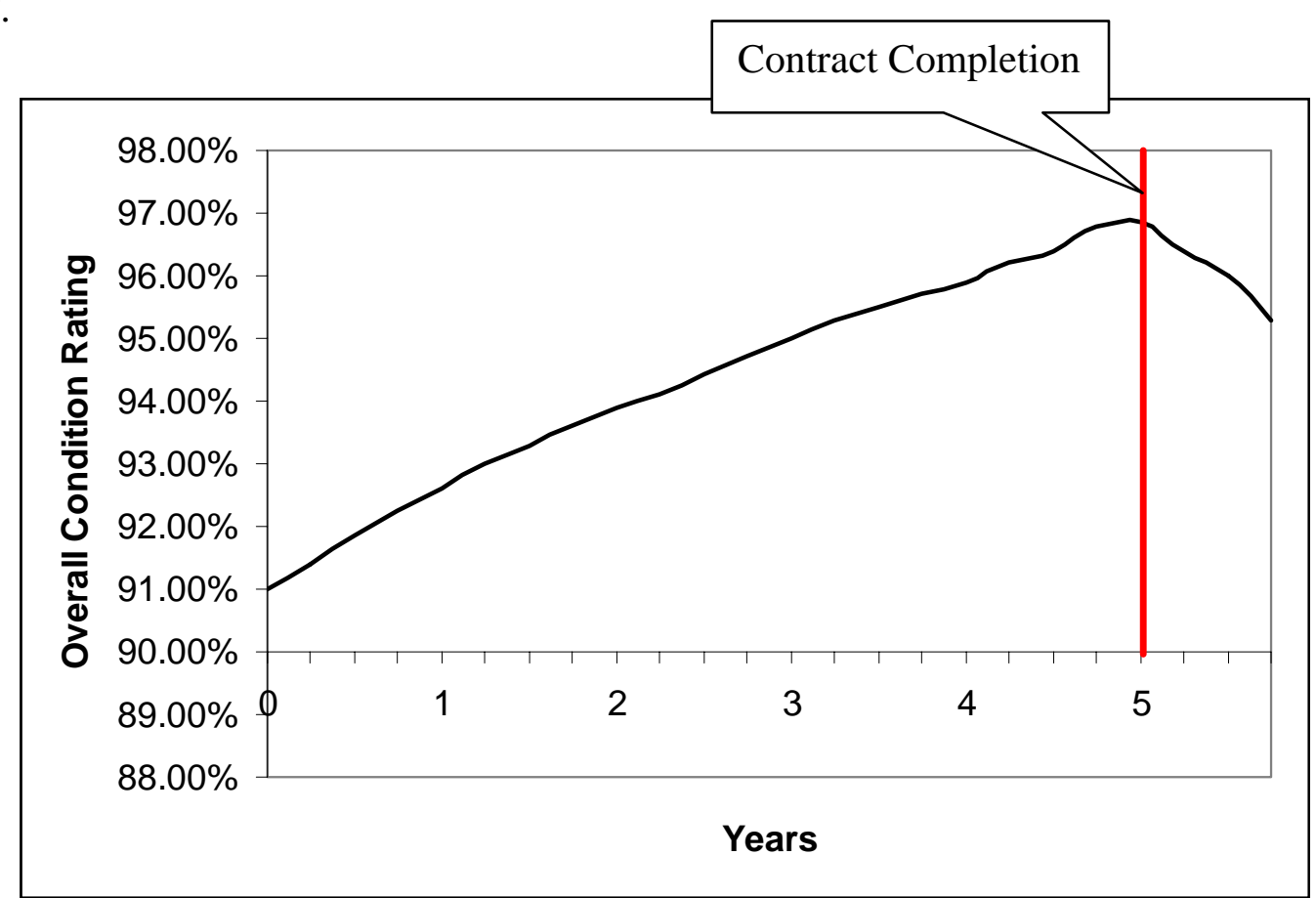

Figure 3.3: The maintenance approach of the contractor after the implementation of warranties Second possible scheme 


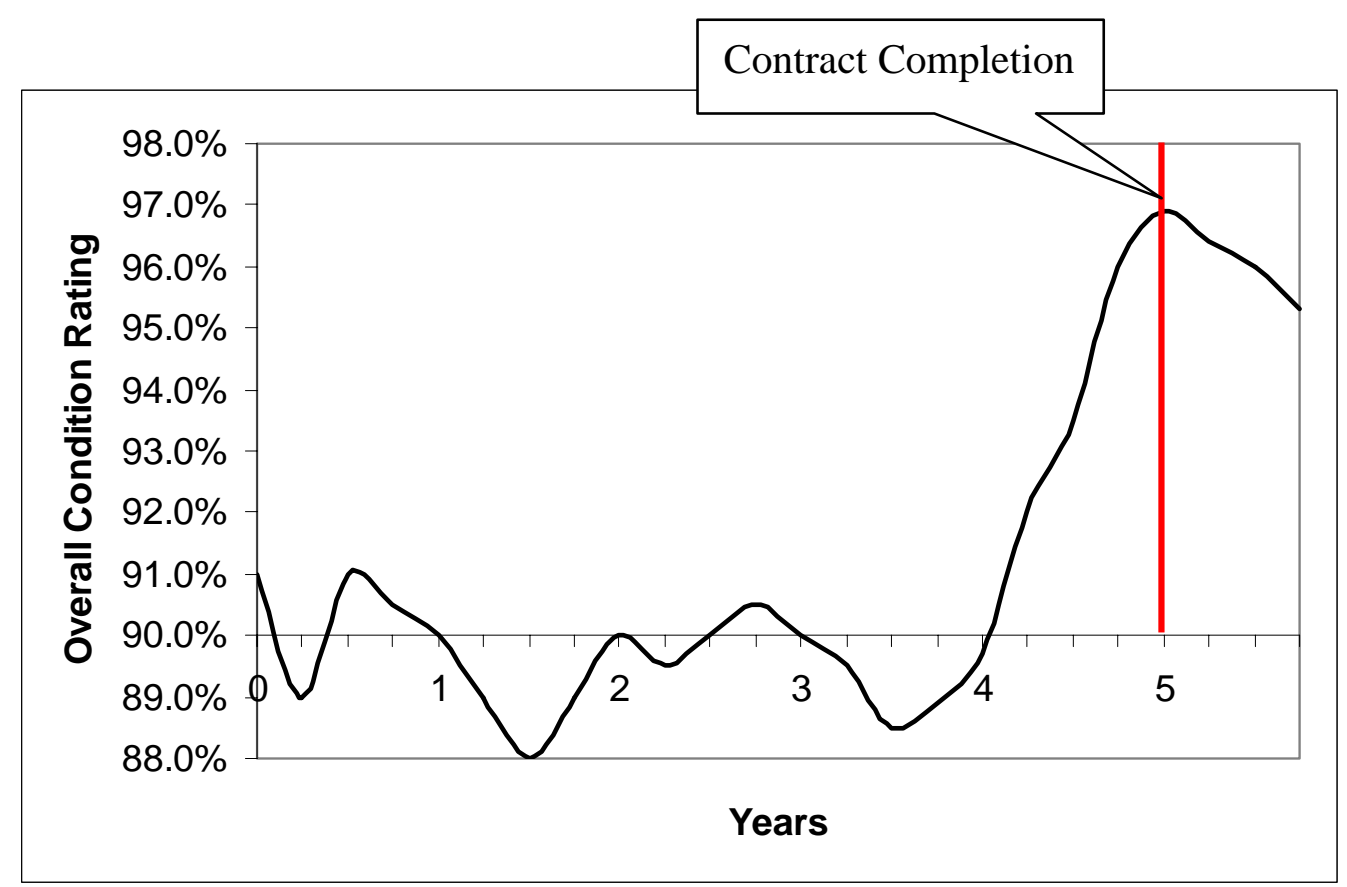

Figure 3.4: The maintenance approach of the contractor after the implementation of warranties Third possible scheme

Another important rationale for the implementation of the warranty concept relates to the performance based nature of the VDOT contract. As discussed in the previous chapter (Observation Phase), ODOT has been using methods and materials based specifications for its contracts with warranties. However, it was furthermore mentioned that ODOT is seriously thinking to switch its specifications to performance based specifications. This can be attributed to the fact that the warranties cannot be implemented efficiently and to their full extent within its current contract type which contains methods and materials based specifications. In other words, the contractors cannot be held liable for many of the failures occurring during the warranty period due to the fact that the contractors do not have input in the design. Performance based contracts would give the contractors the freedom in performing the construction or maintenance activities and thus in implementing innovations. Moreover, performance based contracts would give the contractors the complete control over the projects. These two facts would allow ODOT to implement warranties more efficiently, holding the contractors liable for most of the failures without having to deal with the liability limitations. When investigated thoroughly, it can be identified that VDOT's case is just the opposite of ODOT's case. VDOT is 
using performance based contracts and thereby giving the contractor the freedom in performing the maintenance activities and in implementing innovations. Moreover, VDOT is also giving the contractor the complete control over the project. In giving this much freedom and control to the contractor, VDOT should seek some kind of an assurance from the contractor. In conclusion, the increased control of the contractor needs to be balanced by the greater assumption of liability by the contractor. And that is the rationale in developing warranties to be implemented in the VDOT performance based road maintenance contracts.

\subsection{FIRST OBJECTIVE: DEFINING DEFECT}

\subsubsection{General Discussions About “Defects” in the Construction Industry}

Defect in the construction industry has traditionally been defined as "the nonconformity with the design expectations" (Feld 1968, pp 2). However within the context of performance based contracting, this definition can be stated as "the nonconformity with the performance expectations." Sometimes there is a single explanation for a defect, but in most of the cases it arises as a result of a combination of circumstances such as mistakes, misunderstandings, ignorance, incompetence, oversights, and even dishonest performance (Feld 1968). Defects, as discussed previously, can be attributed to improper design, poor material usage, and poor workmanship. In a study conducted by the Building Research Advisory Service, $\mathbf{5 8 \%}$ of the failures were found to be resulting from the improper design, $\mathbf{1 2 \%}$ were found to be due to poor materials, and $\mathbf{3 5 \%}$ were found to be attributable to poor execution and workmanship by the contractor (Ransom 1981). Notice that there is a certain amount of overlap between these categories. Given the nature of the similar operations performed, these statistics are most probably applicable to road maintenance activities that are in the scope of this research too.

Apart from the above definition of the defect, some of the contracts that have been elaborated in the Phase 1 of this research as a part of the literature review possess clauses that define the defect. For example, in the AIA General Conditions of the Contract for Construction, defect is defined as the "Work not conforming to the requirements of the Contract Documents" (AIA A-201, Clause 3.5 .1 1997). Similarly in EJCDC Standard General Conditions of the Construction Contract, defective is defined as "the Work that is unsatisfactory, faulty, or deficient in that it does not conform to the Contract Documents or does 
not meet the requirements of any inspection, reference standard, test, or approval referred to in the Contract Documents..." (EJCDC 1910-8, Clause 1.02-C 1996). As can be identified from both of the clauses, the defect is defined in some generic language without going into too much detail.

When the contracts that are more related to this research are examined, it can be realized that the same approach is used for defining “defect.” For example, the prototype prepared by the World Bank for the performance based road maintenance contracts defines the defect as "any part of the Works and Services not completed in accordance with the contract” (The World Bank, Clause 1.1 2002). Similarly, the performance based road maintenance contract used in New Zealand defines the terms defect and defective as "any Condition not consistent with the Required Condition or as otherwise required in the Contract Documents” (Transit New Zealand, Clause 1.1.1 2002).

\subsubsection{Definition of Defect for VDOT's Case}

As discussed in the previous chapter, the most challenging item in developing a warranty clause is to establish the warranty criteria to be met during the warranty period. In order to be able to establish the warranty criteria for the VDOT issued performance based road maintenance contracts, the defect should be defined within the context of road maintenance.

The definition of defect is essential to develop the warranty criteria because what VDOT wants to include in the warranty criteria (which will be used in assessing the warranty compliance) as an indicator of poor performance or poor overall condition of an asset item is totally dependent on what it perceives as a defect resulting from the unacceptable work of the contractor. For the purposes of this research, in which a comprehensive warranty clause template is aimed to be developed, it can be stated that the defect is already and clearly defined in the current VDOT-VMS contract. In fact, the defect for each of the asset item present in the highway system is defined within that contract.

As mentioned in the previous sub-section, defect within the performance based contracting is defined as the "nonconformity with the performance expectations". Thus for the VDOT-VMS contract, defect for each asset item can be characterized in terms of the performance criteria and performance target (which are presented in the Exhibit B of the current contract) established for that asset item. For example by examining the Exhibit B, for the "Paved Ditches" 
asset item, the defect can be defined as "meeting the performance criteria for less than $\mathbf{9 0 \%}$ of the total amount of paved ditches present in the interstate system maintained by the contractor". Vice versa, same statement can be made as "not meeting the performance criteria for more than $10 \%$ (100\% minus $90 \%)$ of the total amount of paved ditches present in the interstate system maintained by the contractor”. For the purposes of this research the former statement will be used throughout the rest of this write-up. It can be noticed that the first part of this statement (presented in italics format) is established using the performance criteria and the second part (presented in bold format) is established using the performance target defined in the Exhibit B of the current contract.

To be more specific, the same statement can be modified as "having less than 1 inch of settlement for less than $90 \%$ of the total amount of paved ditches present in the interstate system maintained by the contractor." Another statement may be "having no obstruction to flow of water that requires action for less than $90 \%$ of the total amount of paved ditches present in the interstate system maintained by the contractor." In fact, the definition of defect for the "Paved Ditches” asset item can be a combination of all of these. Thus, the broadest definition of defect for the "Paved Ditches” asset item is “(a) having less than 1 inch of settlement or (b) having no undermining or undercut that requires action or (c) having less than $25 \%$ of the area spalled or (d) having no obstruction to flow of water that requires action or (e) any combination of (a), (b), (c) and (d); for less than $\mathbf{9 0 \%}$ of the total amount of paved ditches present in the interstate system maintained by the contractor." These statements are made using the "Paved Ditches" row of the table that is present in the Exhibit B of the VDOT- VMS contract. This row as extracted from the Exhibit B is provided in Table 3.1.

Table 3.1: Performance Criteria and Performance Target for the "Paved Ditches" asset item as extracted from the Exhibit B of the VDOT-VMS Contract

\begin{tabular}{|c|c|c|c|}
\hline Asset & Outcome & $\begin{array}{l}\text { Performance Target } \\
\text { (\% of asset that shall } \\
\text { be in the outcome } \\
\text { described condition) }\end{array}$ & $\begin{array}{l}\text { Condition assessment acceptance tolerances and } \\
\text { criteria (Service Delivery) }\end{array}$ \\
\hline $\begin{array}{l}\text { Paved } \\
\text { Ditches }\end{array}$ & $\begin{array}{l}\text { Aligned } \\
\text { Structurally sound } \\
\text { Clean }\end{array}$ & $90 \%$ & $\begin{array}{l}\text { - }<1 \text { '’ settlement } \\
\text { - no undermining or undercut requiring action } \\
\text { - }<25 \% \text { spalled } \\
\text { - no obstruction to flow of water that requires action }\end{array}$ \\
\hline
\end{tabular}


It is important to note that the discussion presented above is applicable for the duration of the contract term. In other words, in preparing the contract, VDOT established the performance criteria and performance targets (both of which are used in the definition of the defect for each asset item) for the contract term. However, if VDOT perceives "meeting certain performance criteria for less than a pre-defined target for (or similarly, not meeting certain performance criteria for more than a certain percentage of) an asset item” as a defect for the contract term, same definition of defect can be applicable after the contract term too. To state it more clearly, the performance criteria and targets are established with the long time experience of VDOT, and hence, an asset item, perceived to be defective during the contract term (by using performance criteria and performance targets) when maintenance work is being performed may well be perceived to be defective after the completion of the contract term if it possesses the criteria and overall condition rating that make it defective. Therefore, there is no point in generating two different definitions for defect; one for the contract term, and one for the warranty period, for exactly the same asset item. With all these in hand, it can confidently be asserted that the definition of defect which will be used in developing the warranty criterion (which will be the most important component of the developed warranty clause template) can be the same as the definition of defect that is applicable over the contract term. Furthermore, it can also confidently be stated that this definition of the defect for each asset item as used for the contract term simply depends on two variables that are established in the current contract: Performance criteria and performance target.

Given all of the above discussions, the warranty criterion for the "Paved Ditches" asset item can be established as "meeting the performance criteria for at least equal or more than $90 \%$ of the total amount of paved ditches present in the interstate system maintained by the contractor". Using the previous example, the warranty criterion (in its broadest sense) for the "Paved Ditches” asset item can be stated as “(a) having less than 1 inch of settlement and (b) having no undermining or undercut that requires action and (c) having less than 25\% of the area spalled and (d) having no obstruction to flow of water that requires action; for at least equal or more than $90 \%$ of the total amount of paved ditches present in the interstate system maintained by the contractor." 
One very important fact to note at this point is that, in order to be able to use the performance criteria and performance targets that are established in the contract as the constituents of the warranty criteria, the developed warranties should be performance warranties. This is very inherent given the fact that the performance criteria and the performance targets define the conditions of the asset items in terms of performance, as their names imply. Thus, if same performance criteria and performance targets are to be used as parts of the warranty criteria during the warranty period, those warranties should be performance warranties as discussed in Sub-section 2.4.1. In fact, performance warranties go hand to hand with performance based contracts.

In conclusion, the warranty criterion (for each of the asset item) that will be used in the developed clauses consists of the two parameters discussed above. It is important to note that the warranty criteria are established to be constant all through the warranty period whose length will be identified in the following section. The alternative approach of using a graduated scale (as discussed in Sub-section 2.4.2.3) for the warranty criteria throughout the warranty period is out of the question due to the difficulties and inconveniences it may introduce as presented in Subsection 2.4.2.3.

\subsection{SECOND OBJECTIVE: IDENTIFYING THE LENGTH OF THE WARRANTY PERIOD}

After establishing the warranty criteria to be used throughout the warranty period, the second step is to identify the length of the warranty period. Establishing the length of the warranty period is as challenging as establishing the warranty criteria because of the reasons presented in Sub-section 2.4.2.2. This research is proposing three alternatives to establish the length of the warranty period for the VDOT issued performance based road maintenance contracts. These three alternatives, which are discussed in the following sub-sections, were then presented to the panel of experts in order to get feedback about the applicability of each for the VDOT issued performance based road maintenance contracts. The feedback received from the panel of experts is presented in Chapter 5. 


\subsubsection{Alternative 1}

This alternative is aiming to establish the length of the warranty period by using the warranty criteria established in the previous sub-section. In other words, both the warranty criteria and the time concept will be considered and they will be examined together to define the length of the warranty period which will be a very important component of the developed warranty clause template. The correlation between the time concept and the warranty criteria, which will be used to define the length of the warranty period is explained below.

Assets within the interstate system; such as pavement, pavement markers, pavement stripping, and numerous others, are constantly and continuously in use. The continuous usage of these assets makes them deteriorate day by day. As they deteriorate, their overall conditions get worse. This may be the case both during the contract term, in which maintenance activities are performed by the contractor to slow the rate of this deterioration, and during the warranty period (after the completion of the contract term) in which the contractor does not perform any maintenance and thus does not have any control over the assets at all.

During the contract term, in which maintenance is performed, this deterioration is tried to be slowed down and ideally, completely brought to an halt and transformed into an improvement in the asset item's overall condition (as aimed by the establishment of the warranty concept) by the contractor. On the other hand, in the warranty period where assets are continuously in use and there is not any maintenance activity going on, this deterioration and thus the worsening of the asset item's overall condition cannot be controlled. As soon as the maintenance activities are terminated, the asset item starts to deteriorate with a certain rate. This deterioration may be at the normal (expected) rate, or at an accelerated rate which reflects that there are some problems with the maintenance performed during the contract term.

Within the warranty concept, in order to assert the presence of defects to call back the contractor to remedy those defects, a very clear line, distinguishing the normal wear and tear (deterioration) from accelerated (excessive) wear and tear (deterioration) leading to these defects should be drawn.

This concept of normal wear and tear versus excessive wear and tear is addressed in some of the contracts that were discussed in the Observation Phase. For example the clause related to the "Defects Liability Period" within the standard form of contract prepared by FIDIC reads as "To the intent that the Works shall, at or as soon as practicable after the expiration of the 
Defects Liability Period, be delivered to the Employer in the condition required by the Contract, fair wear and tear excepted, to the satisfaction of the Engineer..." (FIDIC, Clause 49.2 1987). Same concept is also presented in the Standard Specification Book prepared by FDOT as "Perform all necessary repairs or renewals, on any section of the roadway or bridge thus opened to traffic under instructions from the Engineer, due to defective material or work or to any cause other than ordinary wear and tear, pending completion...” (FDOT, Clause 7.15 2000).

Given all of the above discussions, it is obvious that the issue of "fair wear and tear versus excessive wear and tear" should be elaborated on. And, this is the point where the time concept comes into the picture to address the issue. The excessive wear and tear can be differentiated from the fair wear and tear by using the time frame. If for any highway asset, the normal deterioration curve showing the decline in the asset item's overall condition with respect to time can be plotted, this curve would enable people to identify the time necessary for that asset item to deteriorate from its new state to the state where it is said to be defective. Such a curve should reflect the situation in which the asset item deteriorates from normal daily usage without being maintained. Moreover, this curve should be plotted for only normal daily conditions in which there are not any extreme events such as very severe weather and/or very heavy traffic.

Figure 3.5 presents the normal deterioration curve which reflects the normal wear and tear on the "Paved Ditches" asset item from its new state to its defective state. In the graph, the time for the asset item to deteriorate from its new state to the defective state is represented with the parameter " $\mathrm{X}$ " since its exact value does not need to be known at this stage. The value of "X" will be discussed in this research at a later time. There are two very important notes that should be made at this point: Firstly, the term "new state" means the state in which the "Paved Ditches" asset item is in its best possible condition, i.e. newly (just) constructed and in strict compliance with the requirements of the construction documents. This implies that the overall condition rating for the "Paved Ditches" asset item is $\mathbf{1 0 0 \%}$, meaning that all of the paved ditches present in the interstate system maintained by the contractor are meeting the performance criteria. Secondly, the "defective state" for the "Paved Ditches" asset item presented in the graph is exactly the state for which "Paved Ditches" asset item was defined to be defective in the previous sub-section. In other words, the defective state that is illustrated in the graph is the state in which the pre-established performance criteria are not met for the performance target (as defined in the previous sub-section). Thus, this defective state for the "Paved Ditches" asset 
item is presented in terms of the performance target established in the current VDOT-VMS contract.

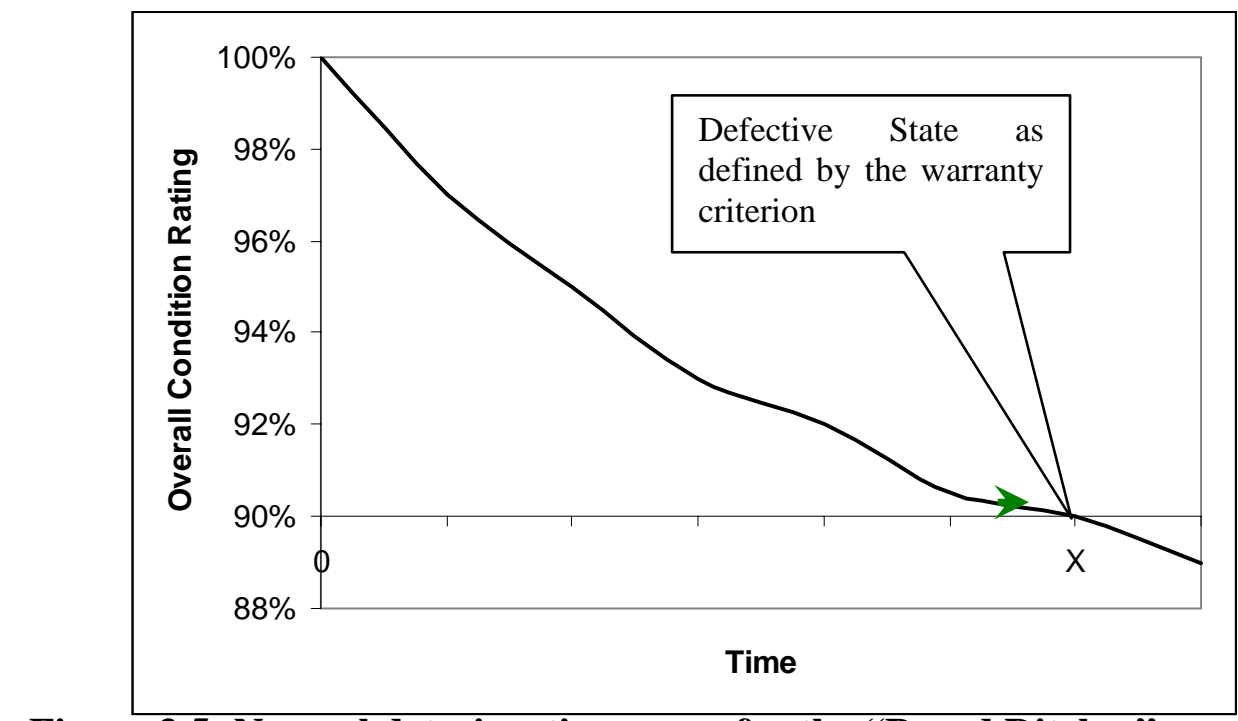

Figure 3.5: Normal deterioration curve for the "Paved Ditches" asset item

Figure 3.5 presents the normal deterioration (fair wear and tear as used in the contract language) over time for the "Paved Ditches” asset item. Now let's consider the situation of excessive (accelerated) wear and tear in which the rate of deterioration is faster than it should be in a normal case. Figure 3.6 presents the excessive deterioration curve for the "Paved Ditches” asset item. In this excessive deterioration case, the time for the asset item to deteriorate from its new state to the defective state is represented with another parameter, "Y" since it is different from the case of normal deterioration.

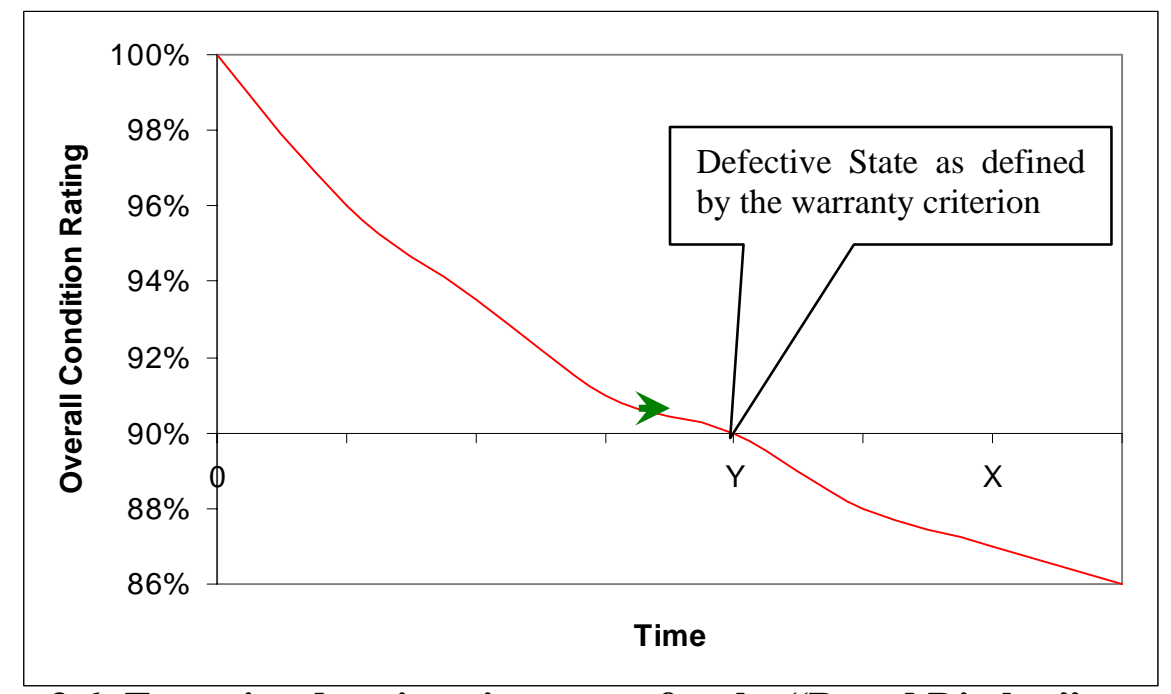

Figure 3.6: Excessive deterioration curve for the "Paved Ditches" asset item 
Figure 3.7 presents both the normal deterioration and excessive deterioration curves for the "Paved Ditches" asset item on the same graph. By comparing the two curves it can be identified that, in the excessive deterioration case, the time it takes for the asset item to deteriorate from its new state to defective state is less than the time that it takes to deteriorate from new state to defective state in the normal deterioration case. This is mainly due to the accelerated rate of deterioration. In fact, the more severe the rate of excessive deterioration, the less time it takes for the asset item to reach its defective state.

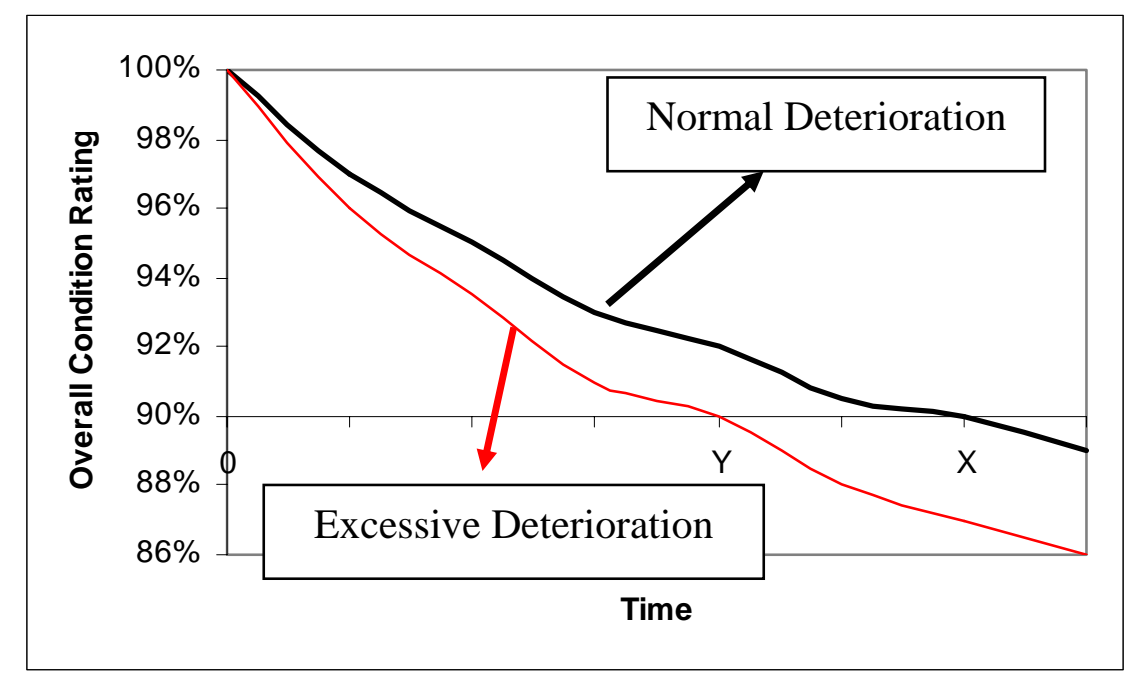

Figure 3.7: Normal and excessive deterioration curves for the "Paved Ditches" asset item

Now that the normal deterioration and excessive deterioration are defined and illustrated graphically, these concepts can be used to discuss and establish the length of the warranty period for the "Paved Ditches" asset item. For this purpose, the normal deterioration curve will be used. As discussed above, this curve reflects the situation in which no maintenance activity is performed (which, in fact, is similar to the case for the warranty period in which the contractor is allowed to implement minimal maintenance activities as explained in Sub-section 3.4.8). It would be fair to assert that an asset item, which is well maintained during the contract term, should reach to its best possible condition (i.e. its new state) by the completion of the contract term. And it would also be fair to state that; upon the completion of the contract, and thus with the beginning of the warranty period, same well maintained asset item would begin to deteriorate in accordance with its normal deterioration curve (deteriorate with the rate that is plotted in its normal deterioration curve) and thus would reach to its defective stage at the time 
that is specified in its normal deterioration curve. And given all of these conditions, it would be fair to assert that; this time, in which the well maintained asset reaches to its defective stage, marks the end of the warranty period. Note that this time is represented as " $X$ " in Figure 3.5. In conclusion, the warranty period may be established as "the period starting with the completion of the contract term and ending with the time which reflects the defective state of the asset item in the normal deterioration curve of that asset item.”

When length of the warranty period is established using the discussion above, there are three possible reasons for which a contractor cannot meet the warranty criterion all through the warranty period. These cases are presented below with the related illustrations:

First case is the one in which the contractor is unable to implement the necessary maintenance practices to bring the asset item to its best possible condition by the end of the contract term. In other words, the asset item's overall condition is not improved sufficiently during the contract term to reach the overall condition rating of $100 \%$ by the end of the contract term as required by the above definition of the warranty period. In such a case, since the asset item is not in its best possible condition (it does not have an overall condition rating of 100\%) at the completion of the contract term (and thus at the beginning of the warranty period), its overall condition rating is very likely to drop below the required performance target as stated in the warranty criterion before the completion of the warranty period. Hence, in such a case, it is very unlikely for the asset item to meet the warranty criterion all through the warranty period. Such a hypothetical case is illustrated in Figure 3.8 for the "Paved Ditches" asset item.

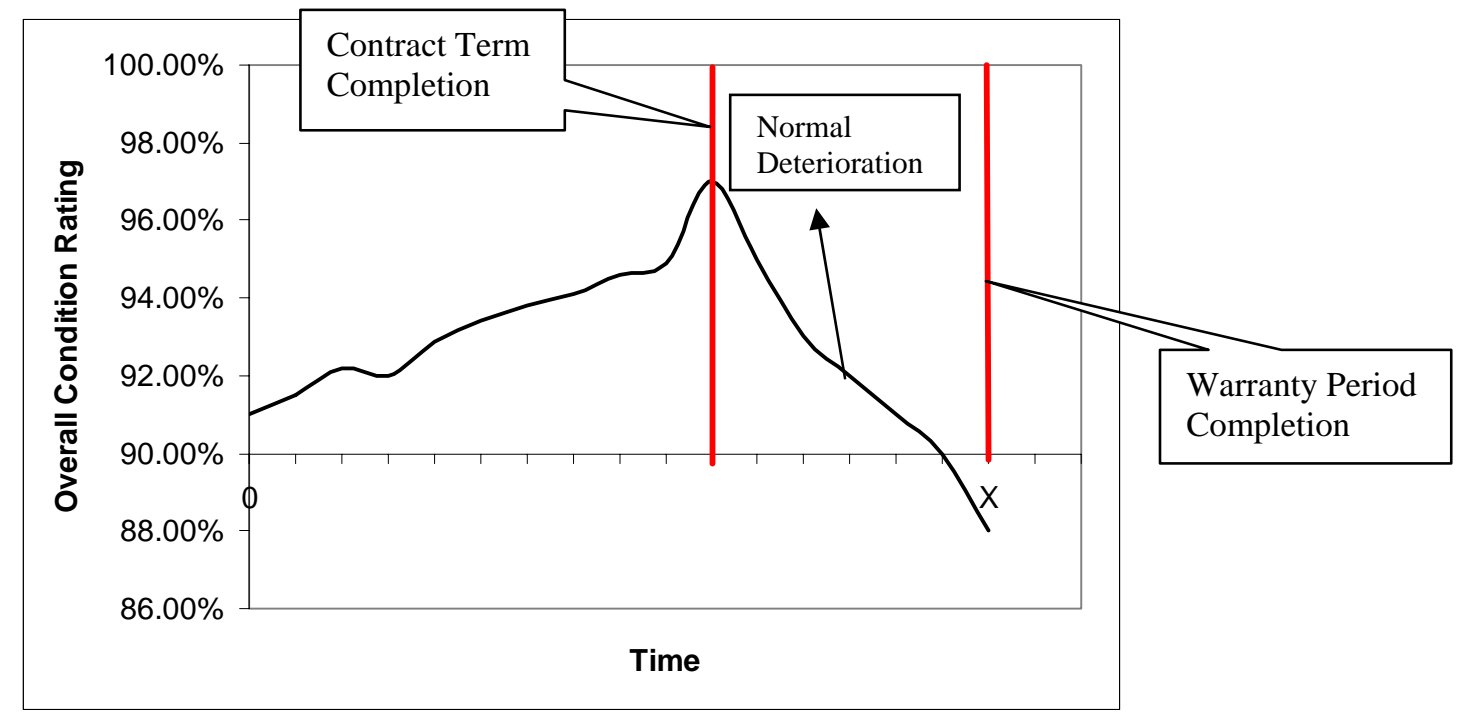

Figure 3.8: Not being able to meet the warranty criterion all through the warranty period, "First Case” 
In the second case, the contractor implements the necessary maintenance practices to bring the asset item to its best possible condition by the end of the contract term. In other words, the asset item's overall condition is improved to reach the overall condition rating of $100 \%$ by the end of the contract term as required by the above definition of the warranty period. However, maintenance is performed in such a way that although it may seem like there is sufficient improvement in the asset item's condition to make its overall condition rating reach $100 \%$ by the end of the contract, this improvement lasts for a shorter time than it is supposed to do. This is the case for inefficient and momentary improvement in the asset item's overall condition which would lead to excessive (accelerated) deterioration as discussed previously. Hence in this case, since the asset item would deteriorate with a faster rate than it is supposed to do, its overall condition rating is very likely to drop below the required performance target as stated in the warranty criterion before the completion of the warranty period. In conclusion, since its deterioration would be in a faster pace than what is plotted in its normal deterioration curve, it is very unlikely for the asset item to meet the warranty criterion all through the warranty period. Such a hypothetical case is illustrated in Figure 3.9 for the "Paved Ditches" asset item.

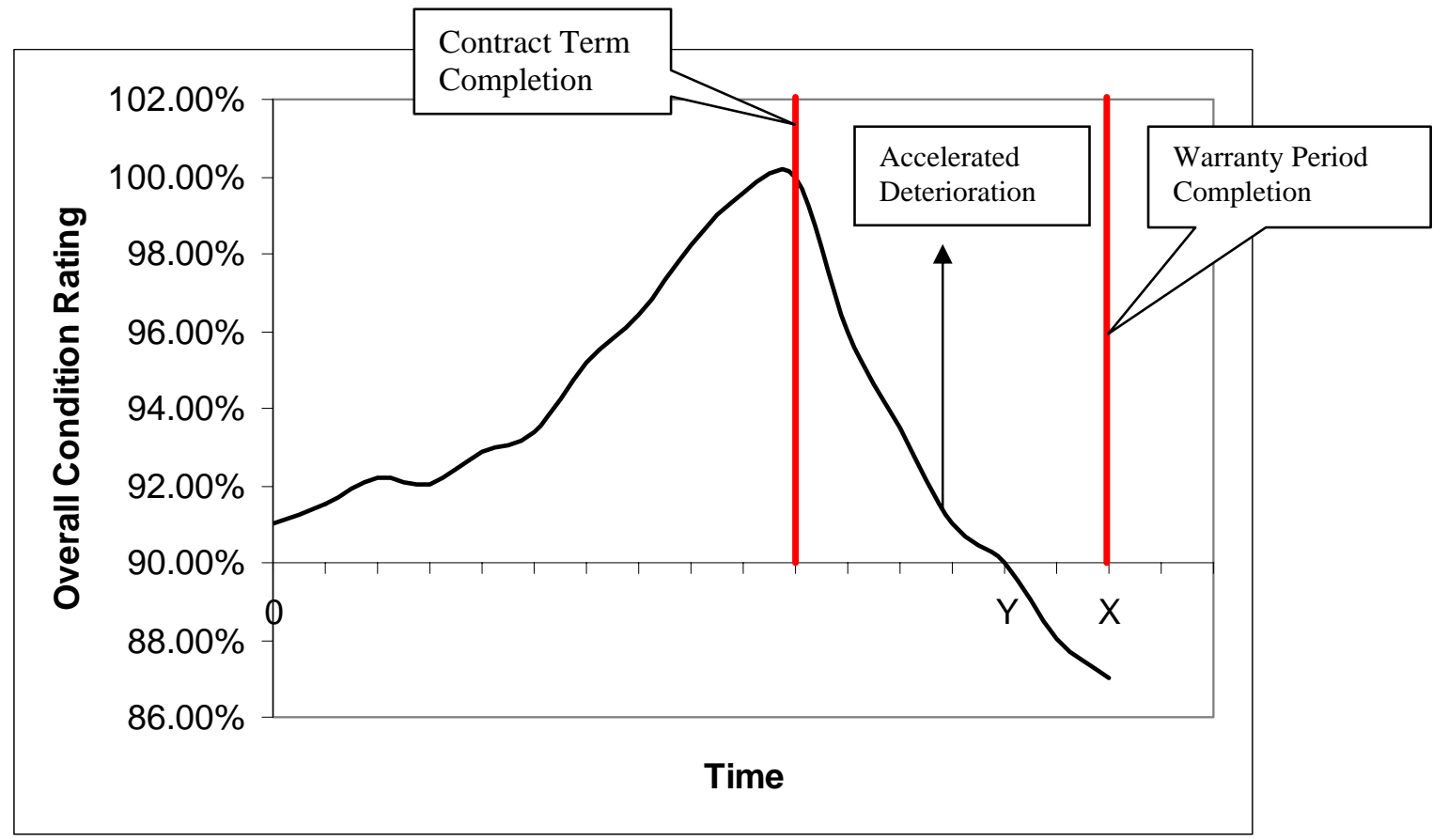

Figure 3.9: Not being able to meet the warranty criterion all through the warranty period, “Second Case" 
It is also possible to have a third case, which is the combination of the first and second cases. In this case, the asset item is not brought to its best possible condition (i.e. asset item's overall condition rating is not $100 \%$ ) by the end of the contract term (and thus at the beginning of the warranty period). Moreover the asset item is not maintained well enough during the contract term and thus it deteriorates in a faster rate than it should do (in a normal case) during the warranty period. The combined effect of the two cases would yield even a shorter time for the asset item to reach its defective state in this third case and would cause the contractor not to meet the warranty criterion all through the warranty period.

As illustrated in the figures above, when length of the warranty period is established using the Alternative 1, all of the cases that would yield to the defect of the maintained asset item can be covered within the warranty clause. To be more specific, all defects (arising due to all of the reasons discussed above) that are likely to occur would occur within the established warranty period and thus would have to be remedied by the contractor under the warranty concept.

\subsubsection{Alternative 2}

The above proposed alternative of establishing the warranty duration has a major drawback when examined thoroughly within the road maintenance concept. As presented above, Alternative 1 assumes and requires that at the end of the warranty period, as the maintenance activities are terminated, the asset item's overall condition rating should be $\mathbf{1 0 0 \%}$. This implies that the maintenance activities performed during the contract term should be in such a way that, they should improve the asset item's overall condition to the maximum extent possible. This means that the asset item should be brought up to its new state, making it as new as newly (just) constructed. This approach in setting the length of the warranty period certainly assures better maintenance practices that would yield a significant amount of improvement in the asset item's condition. This is exactly what is aimed by developing warranty clauses to be incorporated to the VDOT issued performance based road maintenance contracts. However, expecting the contractor to improve the asset item's overall condition to the maximum extent possible to reach an overall condition rating of $\mathbf{1 0 0 \%}$ is both unreasonable and unrealistic given the nature of the road maintenance projects. In such projects, the contractor is undertaking the job to maintain the highway assets that were constructed years, if not decades, 
ago. No matter how they were maintained previously and how they were taken care of, these assets have deteriorated to a certain extent after they have been put in service and until the contractor undertakes the job of maintaining those for the current contract term. There are many factors behind this unavoidable and irreversible deterioration such as aging, severe weather, the condition of the sub-base, traffic loads, etc. Given these, it is impossible for a contractor performing maintenance work to bring any asset to its best possible condition during the contract term. Even if the contractor implements the best maintenance practices that can be performed, there is no way for it to make the asset item as new as newly (just) constructed. The contractor cannot make the asset item reach to its new state simply because it does not have the full control on the factors that have affected the asset item previously such as aging, weather, the condition of the sub-base, traffic loads, etc. The contractor is not reconstructing the highway; it is merely maintaining the assets of the highway that was already constructed.

To resolve this issue, the length of the warranty period, which was established previously, should be reconsidered. The warranty period can be re-established using a different portion of the normal deterioration curve. For this purpose, a normal deterioration curve which begins with an overall condition rating that is below $\mathbf{1 0 0 \%}$ should be used. Such a curve for the "Paved Ditches" asset item is presented in Figure 3.10.

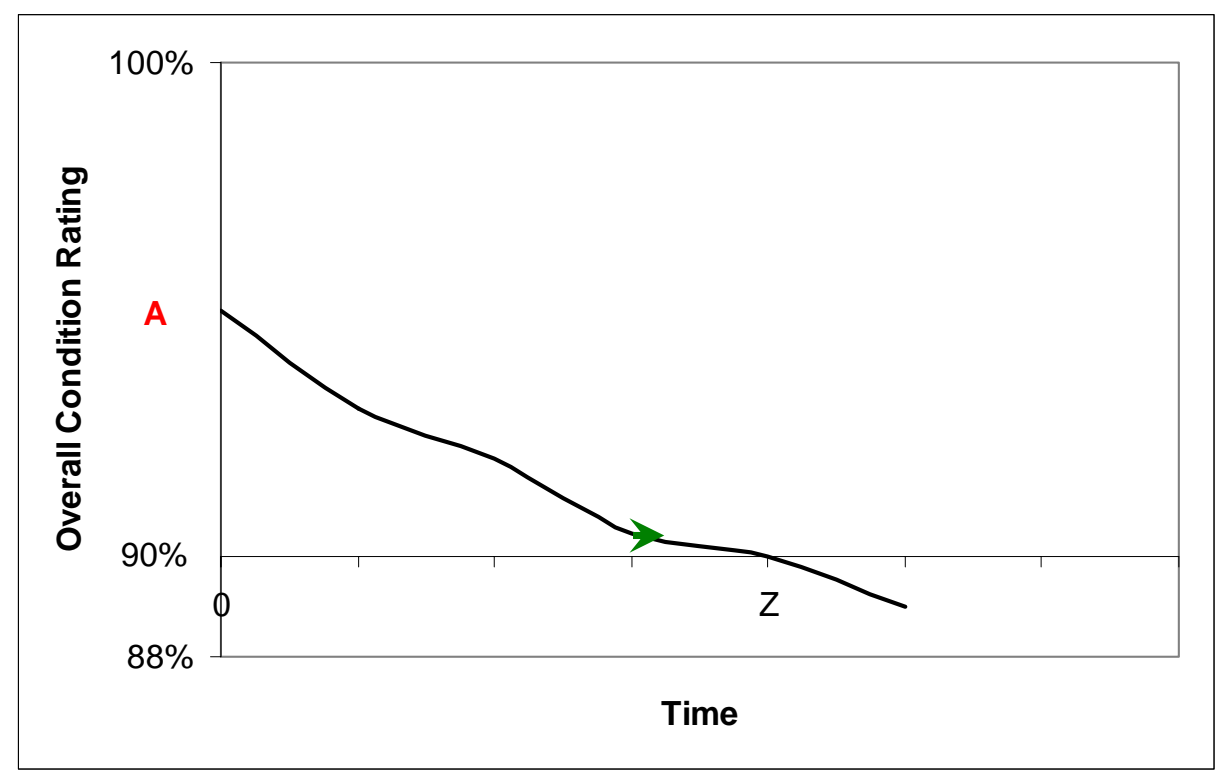

Figure 3.10: Normal deterioration curve beginning with an overall condition rating which is less than $100 \%$ for the "Paved Ditches" asset item 
As can be seen in Figure 3.10, the normal deterioration curve starts with the overall condition rating of "A". Value "A" is an arbitrary value which is less than $\mathbf{1 0 0 \%}$. This curve illustrates the normal deterioration of the "Paved Ditches" asset item over time. This curve does not begin with the asset item's new state. It begins with a value, "A", that is representing an asset item condition which is below the asset item's best possible condition (i.e. overall condition rating of $100 \%)$. In this case, the time for the asset item to deteriorate from its state represented by "A" to the defective state is represented by the parameter "Z". And as can be identified in the Figure 3.11, which illustrates the hypothetical normal deterioration curves for the "Paved Ditches" asset item, the value "Z" is less than the value " $\mathrm{X}$ " which was established previously as to be the length of the warranty period.

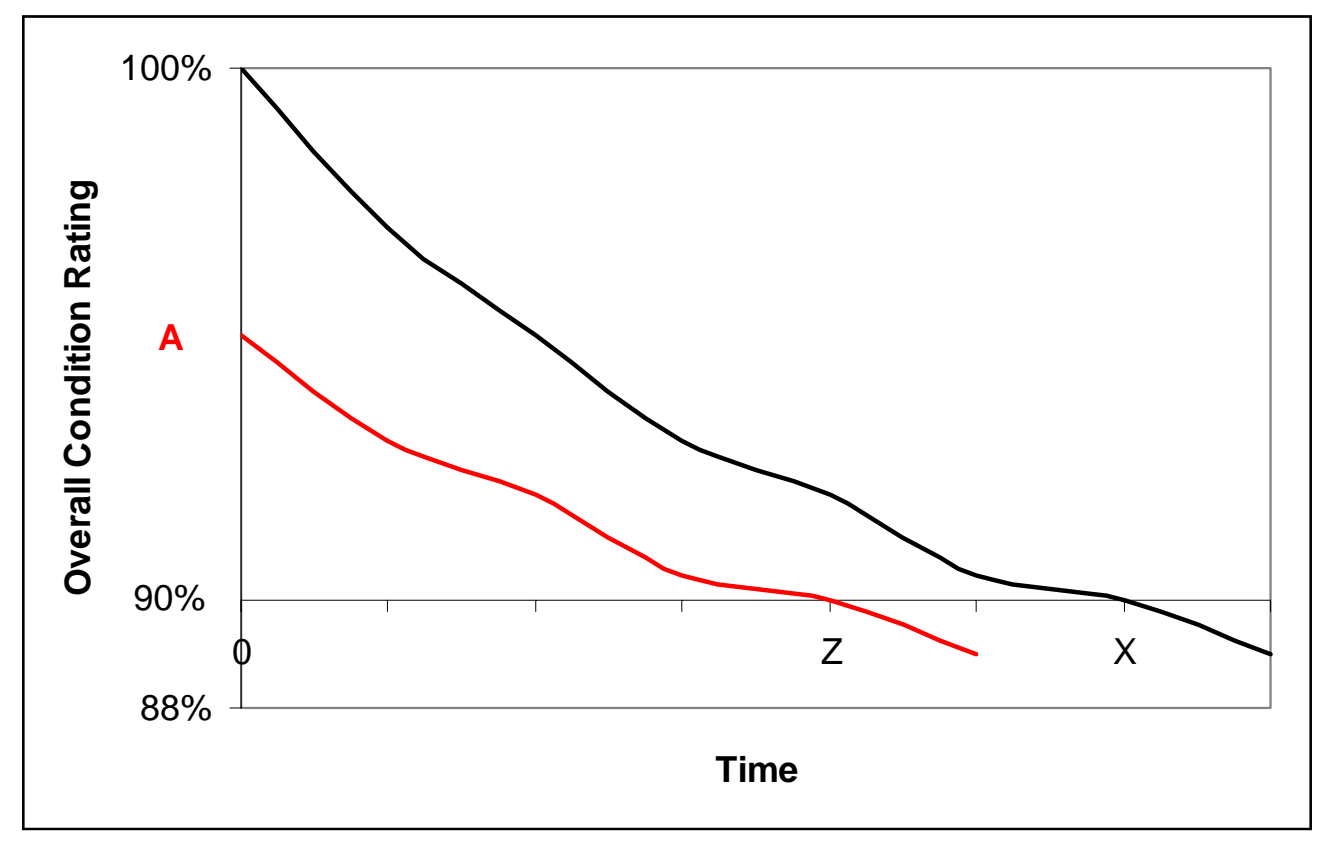

Figure 3.11: Different normal deterioration curves for the "Paved Ditches" asset item

In conclusion, to avoid the drawback introduced when the length of the warranty period was determined by using a normal deterioration curve in which the initial overall condition rating of the asset item was assumed to be $100 \%$, this alternative of determining the length of the warranty period by using a normal deterioration curve in which the initial overall condition rating of the asset is assumed to be at a certain level above ("A") of the performance target (but below 100\%) should be used. This alternative, which will be named as Alternative 2 
from now on, yields to the establishment of a shorter duration for the warranty period. Nonetheless, this alternative still requires the contractor to improve the asset item's overall condition during the contract term, which is the motive of this research and the rationale behind developing warranty clauses.

It is important to note that, although it is unreasonable (as discussed before) to establish the length of the warranty period as " $X$ " using Alternative 1, " $X$ " does define the maximum length of the warranty period which would help VDOT in determining how reasonable and feasible the warranty length (“Z”) established by using Alternative 2 is.

An illustration which summarizes all of the discussions presented in this sub-section with respect to the establishment of the warranty period and possible maintenance practices that would be applied by the contractor is presented in Figure 3.12.

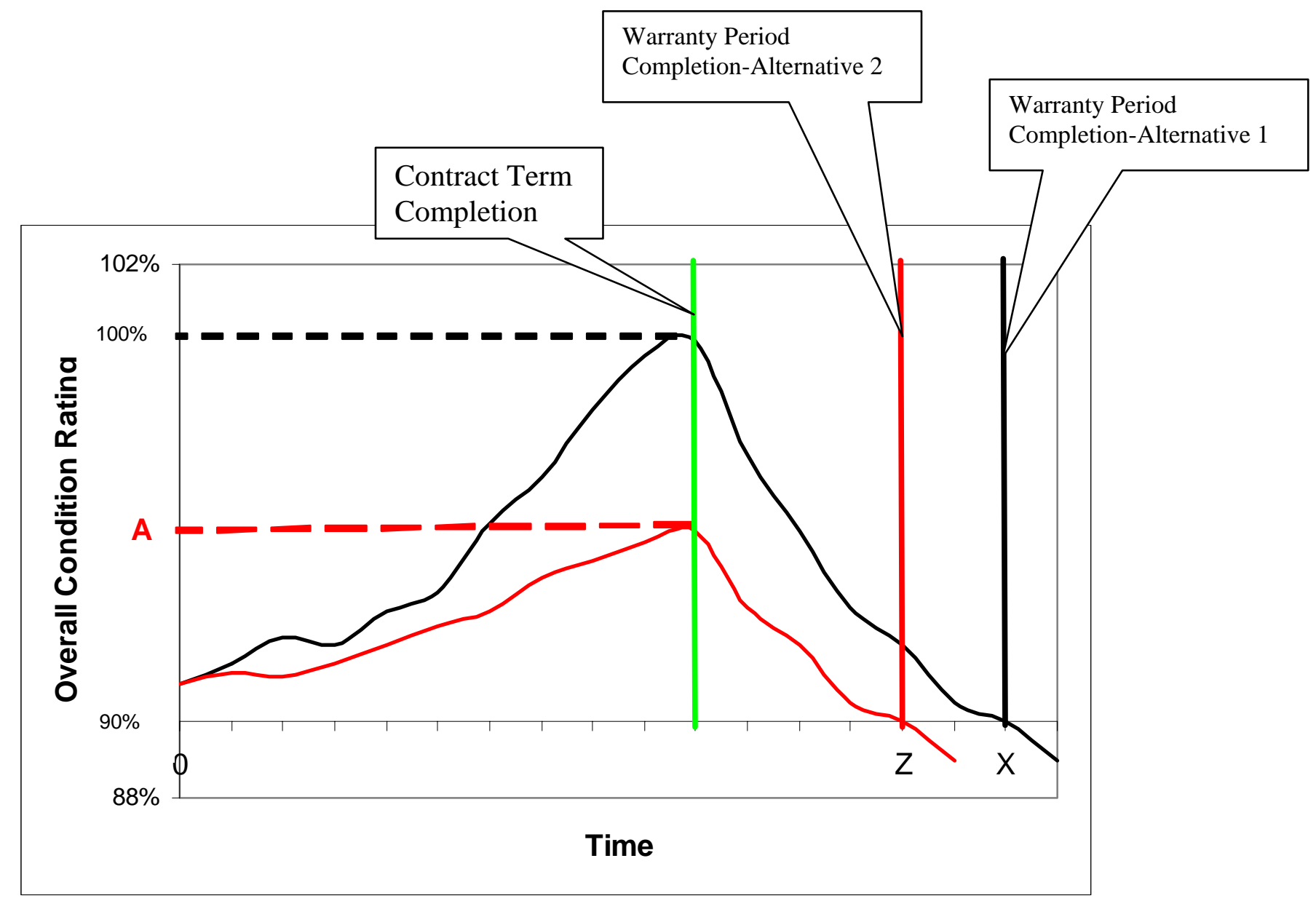

Figure 3.12: Establishment of the warranty period and possible maintenance practices 
The amount of the condition improvement achieved in Alternative 2, which will be less than the amount of the improvement achieved in the case of assuming a 100\% overall condition rating at the end of the contract term (and hence at the beginning of the warranty period), entirely depends on the chosen value, "A". Considering the discussions presented in Sub-section 2.4.2.2, where it has been stated that the state DOTs should cooperate with the construction industry and the surety companies to come up with a consensus on the warranty period's length, the M.S. candidate has requested the panel of experts (which, as mentioned before, is consisting of individuals with diverse backgrounds) to supply feedback on the value "A" that should be chosen to calculate the length of the warranty period. The received feedback is presented in Chapter 5.

The value "A", as utilized by the M.S. candidate in this research in developing the length of the warranty period to be included in the warranty clauses, is merely a guideline for VDOT to use in calculating the length of the warranty period for the warranties to be implemented in its prospective performance based road maintenance contracts. VDOT certainly needs to establish this value ("A") according to its own needs and expectations.

After finalizing the establishment of this value, VDOT should proceed to calculate the length of the warranty period by using this value and the normal deterioration curve as presented in this sub-section. As the length of the warranty period is identified by making the necessary calculations, this length needs to be discussed with the prospective contractors and the bonding industry and be adjusted if needed, to reach a final consensus.

It is important to note that the value " $\mathrm{A}$ " should not be a part of the language of the warranty clause. This is mainly due to the fact that the inclusion of the value " $\mathrm{A}$ " to the language of the warranty clause may lead to occasions in which VDOT incurs liability as a result of specifying both the value " $\mathrm{A}$ " and the length of the warranty period. Thus, the value " $\mathrm{A}$ " is merely to be utilized in developing the length of the warranty period, which is an important component of the language of the warranty clause. However, the value " $\mathrm{A}$ " needs to be presented to the contractors. This is vital to give the contractors the feeling of what is expected from them in terms of the overall condition rating of the asset item at the end of the contract term and thus the amount of improvement that needs to be provided by them with respect to the asset item condition during the contract term. 


\subsubsection{Alternative 3}

As presented in the previous sub-section, Alternative 2 defines a value ("A" for the time being) for the overall condition rating of the asset item that should be established at the end of the contract term (thus at the beginning of the warranty period). Afterwards, this value and the normal deterioration curve of the asset item are used to calculate the length of the warranty period to be implemented. It was noted in the previous sub-section that the length of the warranty period calculated using the value "A" should be agreed upon by the representatives of VDOT, the contracting industry, and the sureties. It was furthermore stated that the value "A" needs to be presented to the contractors in order to give them the feeling of what is expected from them.

Alternative 3, on the other hand, calls for the establishment of the warranty period without defining any intermediate value like " $\mathrm{A}$ " that helps to calculate the length of the warranty period. This alternative proposes that the length of the warranty period should be determined by the state agency, VDOT, according to its expectations with regards to the performance of the highway and its assets. However, just as in the case of the Alternative 2, this length, as determined by VDOT according to its expectations, should be presented to the contracting community and the bonding industry before being implemented. In the case of raised concerns and disagreements by these entities, the length of the warranty period should be adjusted accordingly to reach a complete consensus. The process for the Alternative 3 is presented below with an example for one of the asset items.

First of all, VDOT defines its expectations with regards to the performance of the "Paved Ditches” asset item. For this, VDOT needs to set the time period in which it would not be willing to maintain the asset item or to pay for the maintenance of the asset item, after the completion of the contract term. This time period, in fact, constitutes the warranty period it wishes to implement.

After this, VDOT should perform a calculation in order to find the value of the overall condition rating required at the end of the contract term for the contractor to be able to meet the warranty criterion during (all through) the warranty period. For this, VDOT needs to use the normal deterioration curve and the length of the warranty period that it would be willing to implement. Such a calculation performed in terms of parameters is presented in Figure 3.13. In Figure 3.13, "W" represents the length of the warranty period determined by VDOT and "B" 
represents the overall condition rating of the asset item required at the end of the contract term, (for the contractor to be able to meet the warranty criterion all through the warranty period) as calculated using the normal deterioration curve of the "Paved Ditches" asset item. As can be noticed, this calculation is the reverse of the calculation that was presented in Alternative 2. In Alternative 2, the length of the warranty period was calculated using the normal deterioration curve and the overall condition rating to be achieved at the end of the contract term by the contractor.

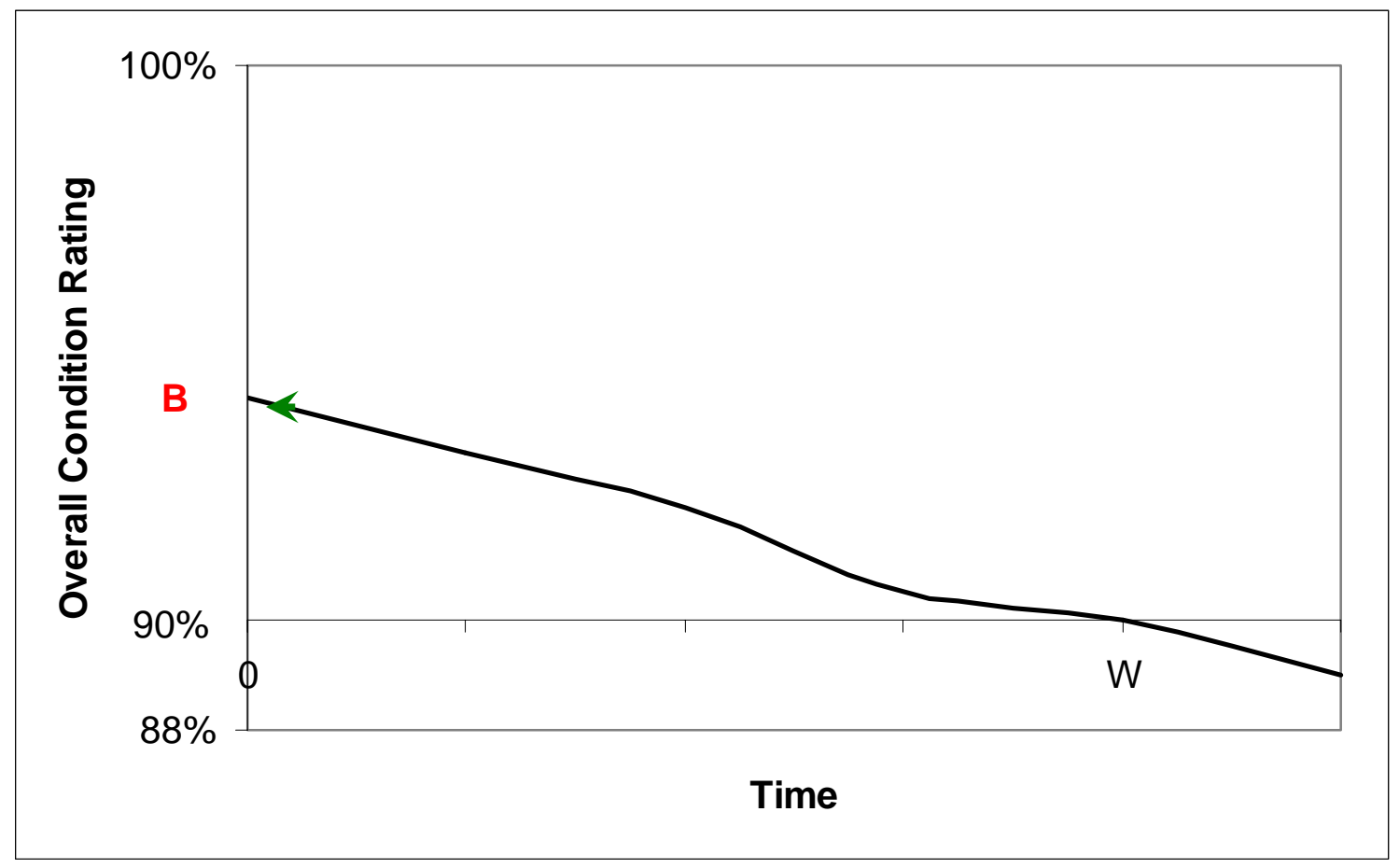

Figure 3.13: Establishment of the length of the warranty period using Alternative 3

The process of calculating the overall condition rating required at the end of the contract term by using the normal deterioration curve and the length of the warranty period that VDOT is willing to implement has two important benefits. First, it prevents VDOT from establishing a warranty length that would be impossible for the contractor to satisfy. After

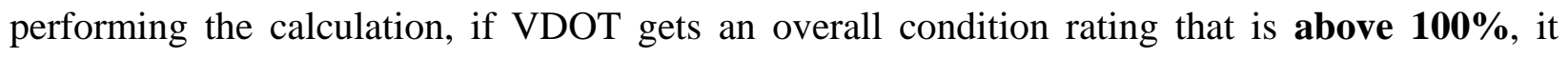
would indicate that VDOT has established the length of the warranty period unreasonably long. This simply means that the contractor can meet the warranty criterion during the warranty period only if it provides an overall condition rating that is above $100 \%$ at the end of the contract term 
(hence at the beginning of the warranty period). Without any doubt, expecting such an improvement in the asset item's overall condition from the contractor is unrealistic. The second benefit of performing such a calculation is to provide the result to the prospective contractors in order to make them understand what is expected from them to be provided by the end of the contract term in terms of the asset item's overall condition rating.

Just as in the case of Alternative 2 and for the same reasons presented in Alternative 2, the value " $B$ " should not be a part of the language of the warranty clause. However, after deciding on the length of the warranty period and calculating the value "B", VDOT needs the proceed to set up a meeting, just like a pre-bid meeting, in which it will present its decision with regards to the length of the warranty period to the prospective contractors and representatives of the bonding industry. In presenting its decision, VDOT also needs to present its finding of the value " $\mathrm{B}$ " in order to give the contractors a feeling of what is expected from them. After getting these entities' feedback on its decision of the length of the warranty period, VDOT should adjust the length accordingly for the sake of achieving a full consensus among the all participants of the performance based road maintenance project.

In Sub-section 2.4.2.2, some examples of different warranty periods for different highway projects as used by various state DOTs were presented. Moreover, the question of the "length of the warranty period required by VDOT" was directed to the panel of experts (one member of which is a representative of VDOT) and the received feedback is provided in Chapter 5. These are believed to give VDOT an idea (if it wishes to choose Alternative 3 to establish the length of the warranty period for its projects) in deciding on the length of the warranty period for its highway/road maintenance projects.

\subsubsection{The Summary and Comparison of Alternative 2 and Alternative 3}

Until now, three different alternatives are presented for establishing the length of the warranty period in VDOT issued performance based road maintenance contracts. The M.S. candidate has presented all of the alternatives to the panel of experts and their feedback is presented in Chapter 5. As discussed before, Alternative 1 is somehow unrealistic and may produce unreasonable results. However Alternative 2 and Alternative 3 are both realistic and reasonable alternatives. Having these two viable alternatives in hand, VDOT can choose the one which is more suitable for its expectations from the contracts. However, both of the alternatives 
have their own merits and they both result in a realistic and an optimum warranty period that would serve to the needs of VDOT. Moreover, both of the alternatives call for the establishment of a consensus among the project participants, i.e., VDOT, contractors, and sureties. This enables the length of the warranty period to be reasonable from the viewpoint of the contractors and bonding agencies. Finally both of the alternatives require VDOT to present the overall condition rating required at the end of the contract to the prospective contractors. This enables the contractors to understand what is expected from them at the end of the contract term (hence at the beginning of the warranty period) as far as the asset item's overall condition rating is concerned. This furthermore gives the contractors the idea of how much they should elaborate on improving the asset item's overall condition during the contract term. The main difference between 2 alternatives is their beginning points in establishing the length of the warranty period.

If VDOT is more interested in the overall condition improvement that should be performed during the contract term and wishes to define the asset item's overall condition rating that it is willing to get at the end of the contract term, it should choose Alternative 2 for defining the length of the warranty period. This is simply because, in Alternative 2, initially the overall condition rating of the asset item that is required at the end of the contract term (hence at the beginning of the warranty period) needs to be decided on by VDOT. Then, by using this value and the normal deterioration curve of the asset item, the length of the warranty period is calculated. This process and the direction of the calculation are presented in Figure 3.14.

On the other hand, if VDOT is more interested in setting the time period in which it would not be willing to maintain the asset item or to pay for the maintenance of the asset item, after the completion of the contract term, it should proceed with Alternative 3 for defining the length of the warranty period. This is simply because, in Alternative 3, initially the length of the period in which VDOT would not be willing to maintain the asset item or to pay for its maintenance needs to be decided on by VDOT. Then, this period should be established as the warranty period. And finally, the value of the overall condition rating required at the end of the contract term for the contractor to be able to meet the warranty criterion all through this established warranty period is calculated by using the normal deterioration curve and the established length of the warranty period. This process and the direction of the calculation are presented in Figure 3.15. 


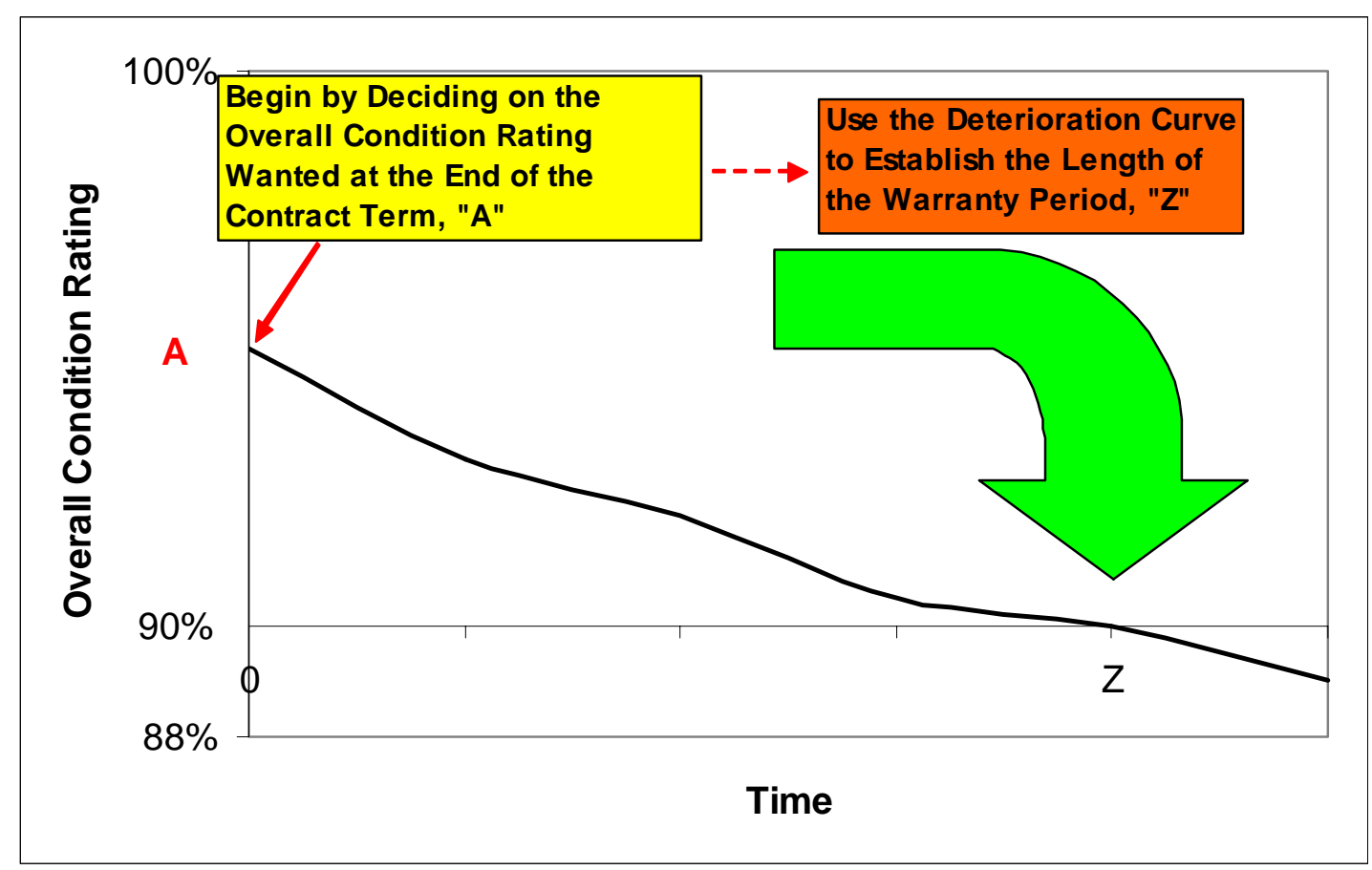

Figure 3.14: An overview of the Alternative 2

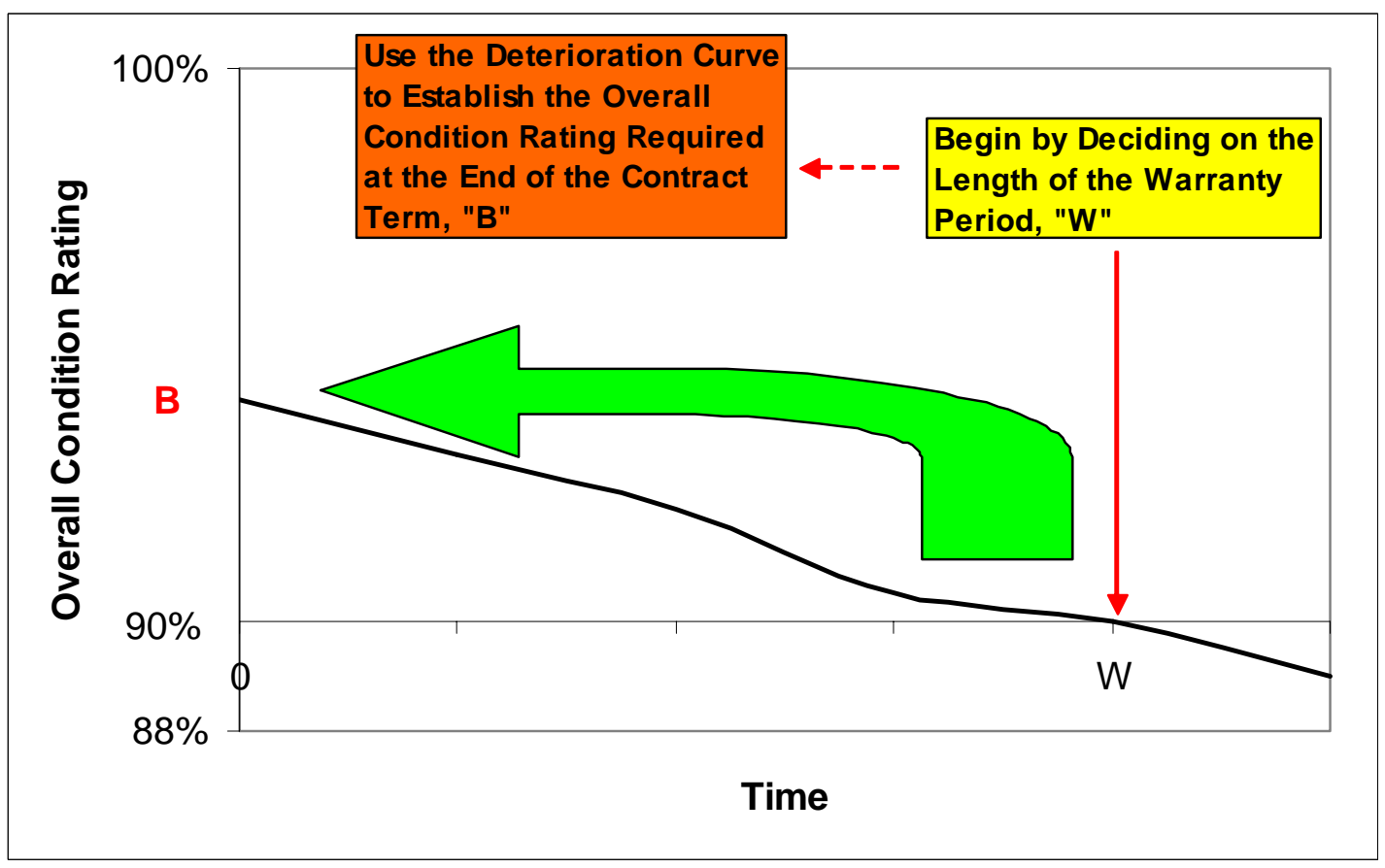

Figure 3.15: An overview of the Alternative 3 


\subsection{THIRD OBJECTIVE: IDENTIFYING OTHER COMPONENTS THAT SHOULD BE PRESENT IN A WARRANTY CLAUSE}

In the preceding sections, the two most important components of the warranty clauses, warranty criterion and the length of the warranty period, were discussed. Moreover, for VDOT issued performance based road maintenance contracts, these two components were established, or at least were made ready to be established. However, for developing a comprehensive warranty clause template as aimed by this research, other components of a warranty clause need to be identified too. This section identifies these components and presents discussions about those within the context of the VDOT case. As can be realized, in identifying and establishing these other components, the literature review presented in Chapter 2 has been used frequently.

\subsubsection{Components that Should be Present in a Warranty Clause as Identified Through the Literature Review}

The important components that should be present in a comprehensive warranty clause have been identified by the help of the extensive literature review performed by the M.S. candidate. As mentioned previously, within this literature review (which constituted the Observation Phase of this research) many contracts and their warranty clauses were scrutinized. Moreover, some very important papers and reports presenting the guidelines in developing warranty clauses for highway construction and maintenance projects were examined. Then, applicability of each of the identified components to the VDOT case was investigated.

The list of the components of a warranty clause as decided to be applicable to the VDOT case is presented below (Carpenter et al. 2003, Anderson and Russell 2001, Krebs et al. 2001, ODOT 1999, FDOT 2002, MDOT 2002, Stephens et al. 2002):

1. Extent of the work that the warranty covers and the definition of defect. 
2. Warranty criterion which is composed of performance targets and performance criteria.

3. Length of the warranty period.

4. Exclusions and waivers within the warranty period.

5. The process of warranty compliance evaluations (inspections) performed by VDOT.

6. The extent and time frame of the remedial action required from the contractor in the case of identification of non-compliance with the warranty criteria.

7. Conflict resolution procedures for the warranty period.

8. Actions to be taken by VDOT in the case of the contractor's default within the warranty period.

9. Bonding requirements for the warranty period.

10. The option of routine (preventive) maintenance during the warranty period.

11. The responsibilities of VDOT during the warranty period.

The first, second, and third components as presented in the list above have already been discussed and established for VDOT's case in the previous sections of this chapter. Those three components constitute the skeleton of a warranty clause and thus can be said to be the major components of a warranty clause. The following sub-sections present the discussions about the remaining components of a warranty clause and hence establish those components for VDOT's case, in order to accomplish the effort of developing performance warranties for VDOT issued performance based road maintenance contracts.

\subsubsection{Exclusions and Waivers within the Warranty Period}

Exclusions and/or waivers are very important components of a warranty clause. Certainly, they do not have to be present in every warranty clause, but a majority of the warranty clauses examined by the M.S. candidate contains exclusions and/or waivers. As mentioned previously in Sub-section 2.4.2.3, exclusions and/or waivers in a warranty clause are needed to relieve the contractor of meeting the warranty obligations in the cases where some external factors which are beyond the contractor's control are present. Since these factors are not considered by the contractor or the state DOT during the design and execution phases of the implemented 
construction or maintenance activities, they may impact the warranted work adversely during the warranty period.

In VDOT's case, such external factors can be listed as:

- Unexpected increases in the amount of the Average Daily Traffic (ADT) during the warranty period.

- Significant increases in the amount of the Equal Single Axle Loads (ESALs) traveling on the highway within the warranty period.

- Extreme weather conditions taking place during the warranty period.

- Maintenance activities performed during the warranty period. Especially, the winter weather maintenance activities performed during the warranty period (by an entity other than the contractor, i.e. VDOT or another contractor that VDOT pays for such activities) such as snow plowing may affect the long term performance of the treatment that has been applied during the contract term by the contractor.

- Traffic accidents or similar incidents that result in damage to the highway assets.

- The problems with the sub-grade, base, and pre-existing layers of the highway.

- The problems introduced during the construction of the highway (i.e. construction defects).

This list of external factors can further be expanded with such similar items. For example, the frequent usage of tire chains during the winter can be added to this list as an external factor which is beyond the contractor's control and which may have adverse effects on the contractor's work that is performed in the contract term (Stephens et al. 1998). Nonetheless, the presented list covers the majority of external factors that would affect the contractor's work due to a variety of reasons.

All of the abovementioned factors may cause the highway assets to deteriorate in a faster rate than they are supposed to do. This excessive deterioration (as introduced in Sub-section 3.3.1) in turn would make the asset items drop below the performance targets, which are required by the warranty clause, during the warranty period. 
If investigated thoroughly, it can be a realized that this list has a very important attribute. The list contains external factors which take place either before or after the contractor's maintenance work. Given the unpredictable nature of these factors, the contractor should not be held liable for the defects occurring within the warranty period due to these factors. For this, some exclusions and/or waivers need to be added to the warranty clause template that will be proposed to be incorporated into the VDOT issued performance based road maintenance contracts. These exclusions and waivers must be stated very clearly in order to avoid different interpretations that may be possessed by different parties.

A phenomenon which is very similar to the abovementioned exclusions and waivers is widely used in scheduling specifications of the construction contracts. This phenomenon is used to relieve the contractor to meet the strict time requirements of a project in the presence of incidents that are beyond the control of the contractor. Therefore, the language used in these scheduling clauses has been referred to in certain amounts while developing the language for the exclusions and/or waivers within the warranty clause template.

Given the presence of 32 asset items (as listed in the Appendix B) that are different from each other, the exclusions and waivers cannot be generic and thus they should be established for each of the asset items separately. An exclusion or waiver that is needed in one asset item may be completely irrelevant for another asset item. For example, applying the ADT or ESAL waivers which are commonly used for the "Pavement" asset item, to the "Luminaries" asset item would be pointless. This is simply due to the fact that an unexpected increase in the average daily traffic during the warranty period would not cause an excessive deterioration within the overall condition of the luminaries. If the "Luminaries” asset item's overall condition rating was brought up to the level that would enable it to meet the warranty criterion throughout the warranty period, they in fact would meet the warranty criterion during the warranty period regardless of whether the average daily traffic increases or not. Thus the aforementioned exclusions and waivers should be identified within the context of each asset item by considering the properties of each and thus the applicability of the exclusions and waivers to each.

\subsubsection{Warranty Compliance Evaluations (Inspections)}

The developed warranty clause template should elaborate well enough on the warranty compliance evaluations. Considering the practices in other states as well as the ones in other 
countries, it would be fair to say that the warranty compliance of the contractor needs to be evaluated at least once a year by VDOT. VDOT should have the burden of performing these inspections. The inspections should be non-destructive. If any portion of the highway is destructed for the sake of the inspections, VDOT should possess the burden of remedying that portion.

For the current VDOT-VMS contract, the inspections for the contract term are performed by VDOT for the pavement and bridges. The inspections for other asset items are performed by an independent and objective consultant who is retained by VDOT. If it wishes, VDOT may well apply the same inspection scheme for the warranty period too. The contractor should be allowed to monitor the inspection process and to perform follow-up surveys in the event of any disagreements about the results. In the current VDOT-VMS contract, for the inspections performed within the contract term, stratified random sampling technique is used. This technique assures that the sufficient number of samples for each asset item, which would be representative of the whole population of each asset item, is inspected. Again, the same inspection methodology with regards to the stratified random sampling technique as implemented during the contract term can easily be deployed for the inspections performed within the warranty period.

As far as the issues related to the time frame of the inspections are concerned, it would be appropriate to conduct the first inspection right at the completion of the project (i.e. at the end of the contract term). This would give VDOT an idea of how well the overall condition of each of the asset items has been improved throughout the contract term. In fact, by just looking at each asset item's overall condition rating, as obtained at the end of this first inspection, VDOT can get a very firm idea of whether the contractor would be able to meet the warranty criteria or not until the completion of the warranty period (by using the normal deterioration curve of each asset item). It would be ideal if the annual inspections are conducted in June or July. As mentioned in Sub-section 2.4.2.5, this would ensure that the inspections are conducted after the frost season and in time for the contractor to schedule and implement any necessary remedial work before the beginning of the cold weather in fall (Stephens et al. 2002). VDOT should assure that these inspections are completed in the shortest time possible, ideally in $\mathbf{1}$ month. This in turn would assure that the remedial actions are implemented (if the results of the inspections indicate that there is a need for remedial actions) by the contractor as early as possible before the 
beginning of the cold weather in fall. Once remedial actions are completed by the contractor, the portion of the highway, for which remedial actions were performed, needs to be re-inspected by VDOT to ensure that the remedial actions were indeed successful in bringing the asset item's overall condition rating above the performance target that is stated within its warranty criterion. The last inspection should be conducted right before the completion of the warranty period. This would ensure that the warranty compliance of the contractor is evaluated until the very last day of the warranty period. In fact, considering the discussions presented in Section 3.2, if the overall condition of each of the asset item is improved sufficiently during the contract term as required by the warranty clauses, this inspection conducted towards to the completion of the warranty period would reveal a full compliance with the warranty criteria. In a sense, this last inspection would act as a punch list to make the contractor remedy the defects before the warranty period is closed out.

In addition to these comprehensive annual surveys, VDOT should conduct some visual (windshield) and easy-to-perform (less detailed) inspections which would help it in identifying the repair or replacement needs anytime in between these annual surveys. This would take care of the emergency and safety situations such as the ones arising due to large defects that are present in the pavement or shoulders or the ones arising due to some warranty criteria noncompliance that may be present in asset items such as luminaries or traffic signs.

\subsubsection{Remedial Actions}

As soon as the comprehensive annual surveys are completed and reported to the contractor, necessary remedial actions need to be implemented by the contractor. The developed warranty clause template needs to define 2 important aspects related to these remedial actions: The extent and content of these remedial actions and the time frame for these remedial actions.

As far as the extent and content of these remedial actions are concerned, VDOT should not direct the contractors by specifying in detail the remedial actions it wants to be executed in the case of warranty non-compliance. Although this is the current practice of many state DOTs that are implementing warranties, this should not be the case for VDOT. This is mainly due to the fact that the developed warranties are performance warranties which are aimed to ensure the quality of the maintenance work that is carried out under a performance based contract. Thus, if the maintenance activities performed during the contract term are not specified by 
VDOT and thus chosen by the contractor, there is not any point for VDOT to specify the remedial actions that need to be implemented to correct the deficiencies resulting from the contractor's poor maintenance work. Just as it was given the freedom in choosing the maintenance activities to apply during the contract term, the contractor should be given the freedom in choosing the remedial actions it wishes to perform during the warranty period. In conclusion, in directing the contractor to proceed with the remedial actions when needed (whenever there is warranty non-compliance), the warranty clauses should not specify the ways and methods that the contractor should implement to complete those remedial actions. Moreover, there should not be an approval process (like the one used by MDOT) associated with the implementation of remedial actions. In other words, the contractor should not be required to get the approval of VDOT for the remedial actions it wishes to implement before proceeding with those remedial actions. In the bottom line, the warranty clause template should be written in such a way that it would allow the contractor to implement the remedial actions it chooses as soon as it is notified of the warranty non-compliance. This would both save time due to the elimination of the time lost during the approval process and be congruent with the performance based nature of the contract.

If during the remedial actions, performed by the contractor for an asset item, other asset items present in the highway are damaged or become defective due to the contractor's actions, these damaged asset items also need to be remedied by the contractor. Examples for such an occasion are the pavement markings and/or pavement markers (raised or recessed) that are damaged or removed while contractor is implementing a remedial action corresponding to the pavement defects. The developed warranty clause template needs to place limitations on the time of the day that the remedial work may be done in an effort to protect the road users from any safety hazards. Moreover the contractor should be required to follow a VDOT approved traffic control plan while performing the remedial actions.

The contractor may be required to do remedial work after the annual inspections if any non-compliance with the warranty criteria is determined during these inspections. The contractor may also be required to do remedial work if VDOT observes a safety issue or a significant defect which may lead to an emergency situation, during its visual (windshield) inspections which are performed in between the scheduled annual inspections. For this, the developed warranty clause template needs to define what constitutes an emergency situation for each asset 
item. This definition should be made by VDOT. Thereby, the issue of "defining emergency situations for each asset item" was directed to the panel of experts (one member of which is a representative of VDOT) and the received feedback is presented in Chapter 5.

As far as the time frame for the remedial actions are concerned, the warranty clauses need to set definite deadlines for the contractor to complete the remedial works. The most common time frame used in the state DOTs is 30 days. Thus, the warranty clause can be worded to require the contractor to complete the remedial and corrective actions within 30 days after it is notified of the warranty non-compliance. However, to be able to address VDOT's expectations in this issue, it would be best if this time frame was chosen by VDOT. That is why the M.S. candidate has requested the panel of experts (one member of which is a representative from VDOT) to give feedback on this issue of time frame for remedial actions. The received feedback is presented in Chapter 5. The warranty clause may also state the time frame and deadline for starting the remedial actions. This decision should also be made by VDOT. In the cases of emergency/safety remedial action needs identified by the state DOT at any time (other than the comprehensive annual survey), the contractor is expected to complete the remedial action in a very short time (which is expressed in terms of hours) compared to the time frame for completing the remedial actions identified in annual surveys (which is expressed in terms of months). Again, this time frame should be decided on by VDOT by considering its timeliness expectations for such emergency occasions. This question was also directed to the panel of experts and the received feedback is presented in Chapter 5.

\subsubsection{Conflict Resolution Procedures for the Warranty Period}

As mentioned earlier, there may be many reasons for an asset item not to meet the warranty criterion. These reasons can either be attributed to the contractor and hence named as contractor's warranty non-compliance or they can be attributed to external factors which are beyond the contractor's control and hence result in waivers for warranty incompliance. As presented in the preceding sub-sections, when defects are identified by VDOT in the comprehensive annual or less detailed visual (windshield) inspections, the contractor should be notified for the defects it is deemed to be responsible, so that it could implement remedial actions as early as possible. And, if the defects are believed to be arising due to the external factors (such as severe cracking on the pavement structure resulting from the detrimental snow plowing 
operations performed by VDOT) that would be listed in the "Exclusions and Waivers" section of the warranty clause template, the contractor should not be held responsible and should not be required to implement remedial actions.

However, in such a setting, there may be some cases in which the contractor would not be willing to accept responsibility for the poor performance and thus for the warranty noncompliance as documented by the inspections. This may eventually result in some disagreements between the contractor and VDOT. As discussed in the Observation Phase, the states implementing the warranty concept deal with such disagreements through the deployment of the "Conflict Resolution Procedures". These disagreements in the issue of apportioning the responsibility of the defects may be very common for such warranty projects and can be overcome easily by implementing procedures such as re-inspecting the portion of the highway which is disputed. And hence, Conflict Resolution Procedures are believed to be very effective in resolving this kind of disputes. In conclusion, in order to avoid the litigation that may arise from such disagreements, a simpler procedure should be used. That is why "Conflict Resolution Procedures”, which promote the partnering of the contractor and VDOT, should be used for the resolution of such disputes.

The warranty clause template should clearly state the specifics of the "Conflict Resolution Procedures”. Considering the practices used within other states and due to practical reasons, it is recommended that the "Conflict Resolution Team" consist of $\mathbf{3}$ members. One of these members should be the representative of VDOT, one should be the representative of the contractor and the remaining one should be an individual agreed on by both of the entities. This would assure the partnering concept that is inherent in the practice of "Conflict Resolution Procedures". This team should be composed of individuals who have technical expertise in evaluating the performance of the asset items. They should also be knowledgeable in conducting inspections to evaluate the maintenance work performed by the contractor. The members of the Conflict Resolution Team should be identified prior to the beginning of the warranty period. Only the disagreements arising due to the apportionment of the responsibility for warranty noncompliance (as determined through the inspections) should be presented to this team. This team should debate on the issues, call for a re-inspection if deemed necessary and afterwards finalize their decision on the conflict by the majority of vote. This decision of the team should be binding both for the contractor and VDOT. Moreover neither of the parties may have a right to 
appeal to this decision. All of the costs associated with the "Conflict Resolution Procedures" should be borne by the contractor. This is mainly due to the fact that, this whole process is initiated by the request of the contractor. However, if the Conflict Resolution Team gives a decision that have been sought by the contractor (i.e. that is in the favor of the contractor), VDOT should pay for the cost of the "Conflict Resolution Procedures”.

The time frame for the contractor to initiate the Conflict Resolution Procedures after receiving the inspection results, as well as the time frame for the Conflict Resolution Team to reach a decision after receiving a request from the contractor for doing so should be elaborated in the warranty clause template. Given the recommendation that the contractor should schedule and implement any necessary remedial work before the beginning of the cold weather in fall (as stated in Sub-section 3.4.3), these time frames should be minimized as much as possible. In the light of this discussion, it would be fair to assert that these time frames can be chosen as $\mathbf{2}$ weeks and 4 weeks respectively. Nonetheless, this is an issue that should be decided by VDOT. This issue of establishing these time frames has been directed to the panel of experts for the professionals' comments. The feedback of the panel of experts is presented in Chapter 5.

One very important note to make at this point is that, the conflict resolution procedures, which are discussed above and which are included in the developed warranty clause template, are applicable only to the warranty period. In other words, they are not designed to be valid during the contract term. In fact, VDOT elaborates on the issue of "Disputes" that are taking place during the contract term extensively within one whole section, Article 12, of the current contract (VDOT 1996). As presented in the scope development section (Sub-section 1.5.2), this research is aiming only to develop a warranty clause template for performance based road maintenance contracts issued by VDOT. In doing that, this research will not interfere with the other parts and clauses that are already present within the contract. The warranty clauses are aimed to be incorporated to the contract within a whole new section and thus they will neither change nor affect any other provisions and clauses that are already present in the contract. 


\subsubsection{Actions to be Taken in the Case of the Contractor's Default within the Warranty Period}

The developed warranty clause template needs to be clear in defining what constitutes a default on the contractor. Furthermore, it should elaborate on the actions to be taken in the case of the contractor's default.

For VDOT's case, there are $\mathbf{2}$ main events that would constitute a default on the contractor side. The first one is related to complying with the decisions of the Conflict Resolution Team. If the contractor insists on refusing to take responsibility for the poor performance and does not implement the necessary remedial actions as required from it even after it is decided so by the Conflict Resolution Team, this can be deemed as a default on the contractor. The second issue is related to the complying with the time frames established in the warranty clauses. If the contractor cannot meet the various timeliness obligations and deadlines as stated in the warranty clauses on a continuous basis, this can constitute a default on the contractor. These deadlines can be listed as; the deadlines for implementing remedial actions as identified through the annual inspections, the deadlines for implementing emergency remedial actions as identified through the visual (windshield) inspections and the deadlines for initiating the Conflict Resolution Procedures.

The occurrence of the abovementioned events are sufficient for VDOT to declare default on the contractor and to proceed with the curative actions. However, such occurrences do not necessarily have to yield to the default on the contractor. VDOT should have the option and right to declare the contractor's default by considering the severity and frequency of the abovementioned events. In other words, VDOT may disregard these events and relieve the contractor from declaring default on it, if it has good reasons to believe that such events are incidental and hence would not be repeated by the contractor in the future (until the completion of the warranty period).

Once VDOT decides to declare default on the contractor due to the occurrence of the abovementioned events, there are 2 options that it can proceed with. For the first option, VDOT may notify the surety that has the agreement with the contractor and require it to perform the remedial actions as identified through the warranty compliance evaluations. For the second option, VDOT may perform the remedial actions itself or have them performed by another 
contractor, and then require the contractor to compensate it for the costs it incurred with respect to those remedial actions.

In order to assure better contractor performance, the developed warranty clause template is designed to possess some disincentive language as is widely used in the warranty clauses developed by FDOT. Such disincentive language (as will be noticed in the developed warranty clause template) calls for the suspension, revocation or denial of the qualification of the contractor for a certain period of time (FDOT 2003).

Just as in the case of Conflict Resolution Procedures, the discussions (about the actions that are specified to be taken by VDOT in the case of the contractor's default) presented in this subsection are applicable only to the warranty period, not to the contract term. In other words, the language within the warranty clause template is developed to cover the issues related to the default of the contractor that occurs during the warranty period. VDOT already elaborates on the issue of “Contractor's Default" that is taking place during the contract term extensively within one whole section, Article 10, of the current contract (VDOT 1996).

\subsubsection{Bonding Requirements for the Warranty Period}

The developed warranty clause template should establish the requirements related to the warranty bonds that must be furnished by the contractor. As discussed in Sub-section 2.4.2.6, a project with warranties requires a warranty bond that would be valid for the warranty period, in addition to the performance bond that is valid for the contract term. These two bonds would guarantee the contractor's work not only for the contract term, but also for the warranty period.

In establishing the requirements for the warranty bonds, the issues that are presented in Sub-section 2.4.2.6 should be considered. In order to avoid the occurrences in which contractors are not able to obtain bonds for the warranty period, VDOT's requirements for the warranty bonding should be as flexible as possible.

One option may be to require bonds for each year of the warranty period. In other words, the warranty clause should not require the contractor to furnish a bond that would last for all through the length of the warranty period (as identified in Section 3.3). Rather, the warranty clause should require the contractor to furnish a bond that would last for a pre-established period of time, i.e. 1 year, and then require the contractor to renew the bond in a non-cumulative manner and furnish a new bond for each consecutive year until the completion of the warranty 
period. These 1 year bonds would be easier to obtain than the longer term bonds due to the reasons discussed in Sub-section 2.4.2.6. However, for this option to be implemented, the contractor should present VDOT the proof that it will be able to renew the bond in each consecutive year. The warranty clause should specify the penalties in the event that this renewal is not accomplished by the contractor (Anderson and Russell 2001). Furthermore the contractor can be given the opportunity to furnish bonds whose amounts are reduced at each renewal (i.e. in successive years during the warranty period). These 2 measures would alleviate the contractor in obtaining the warranty bonds from the surety companies.

The warranty clauses also need to establish the amount (penal value) of the warranty bond that is required from the contractor. In the light of the discussions presented in Sub-section 2.4.2.6, it would be better for VDOT to establish this amount using the "most likely case scenario" approach rather than establishing this amount based on a certain and arbitrary percentage of the total contract amount. As presented in Sub-section 2.4.2.6, the "most likely case scenario" approach requires VDOT to calculate the cost of the most expensive reasonable remedy (repair or replacement) that would be applied in a most likely case problem with the performance of the project during the warranty period, and then to establish this amount as the required warranty bond amount. This realistic approach would further alleviate the contractor in securing warranty bonds simply because the sureties would be more willing to issue a warranty bond for the amount that has been determined realistically by considering reasonable remedies than to issue a warranty bond for the amount which is simply a percentage of the total contract cost and which may be extremely high in certain occasions where the total cost of the contract is very high. The dollar amount of the most expensive reasonable remedy needs to be determined by VDOT according to its long time experience with the highway work. Thus, just like some of the previous cases, this issue was presented to the panel of experts (one member of which is a representative from VDOT) for the professionals to comment on the dollar amount of the most expensive reasonable remedy. Their feedback is presented in Chapter $\mathbf{5}$.

If it is identified in the future (after the usage of these bonding requirements) that the contractors are still having difficulties in obtaining the warranty bonds even though the abovementioned precautions are implemented in establishing the requirements of the warranty bond, VDOT may proceed with the "retainage method" as discussed in Sub-section 2.4.2.6. VDOT may also proceed with the method that calls for the combination of bonding and 
retainage. However, the languages for these two options are not included in the developed warranty clause template and can be developed by VDOT in the future, if deemed necessary.

One very important issue that should be considered in establishing the requirements for the warranty bonds is the time for the release of the warranty bond by VDOT. This time should not merely be the completion of the warranty period due to the fact that there may be some outstanding remedial works that need to be performed after the completion of the warranty period. Thus, in order for VDOT to have the benefits of the warranty bonds until the completion of all of the outstanding remedial works that have been found to be necessary by VDOT, the warranty clause should explicitly state that the time for the release of the warranty bond should be either the end of the warranty period or after all remedial work is completed, whichever is latest.

Finally, as a part of the warranty bonding requirement, the bonding company's rating as established within the A.M. Best Rating ${ }^{1}$ standards should be specified. Moreover, the procedure that is to be followed in the event that the bonding company falls below the required rating should be presented in detail within the developed warranty clause template (Anderson and Russell 2001).

\subsubsection{The Option of Preventive (Routine) Maintenance During the Warranty Period}

As discussed in Sub-section 2.4.2.5 and illustrated in Sub-section 2.4.3.2 and Sub-section

2.4.3.3, some states allow contractors to do preventive/elective (routine) maintenance during the warranty period. Within the context of road maintenance, preventive maintenance is applying treatments to an existing highway and its assets to preserve the system, slow the rate of deterioration, increase the time in which they become defective (extend the service life of the whole system) and to maintain or improve the overall functional condition of the system without substantially enhancing the structural capacity (ODOT Office of Pavement Engineering 2001). The preventive/elective (routine) maintenance concept, which is a proactive approach as mentioned here, is totally different from the remedial actions, which are reactive in nature, implemented by the contractor to correct the defects after being notified to do so by the state

\footnotetext{
${ }^{1}$ A.M. Best Rating: It is a rating system implemented by the A.M. Best Company which is recognized worldwide as the benchmark for assessing insurers' financial strength. It provides an opinion of an insurer's financial strength and ability to meet ongoing obligations to policyholders (www.ambest.com).
} 
DOT. In fact, preventive maintenance is exactly the kind of maintenance performed during the contract term under the conditions of the VDOT's current contract.

Although some of the states allow the contractors to perform any kind of preventive maintenance as they wish during the warranty period (so that those contractors can prevent the occurrence of defects in an effort to assure meeting the warranty criteria during the inspections), this should not be the exact case for VDOT's performance based road maintenance contracts. This is simply because, allowing the contractors to perform preventive maintenance during the warranty period would enable them to gain control over the asset items for the warranty period in addition to the contract term. Such a case would miss the whole point of the warranty concept by means of which the contractor is forced to increase the asset items' overall condition during the contract term sufficiently in order to be able to meet the warranty criteria throughout the warranty period in which it does not have complete control over the highway's assets. In other words, allowing the contractors to perform preventive maintenance during the warranty period would contradict the rationale behind developing warranty clauses for the performance based road maintenance projects as discussed in Section 3.1 in great depth. As an example, let's assume a case in which the contract term is 5 years and the warranty period is 2 years for an asset item. If given the preventive maintenance opportunity during the warranty period, the contractor may easily think that this is a 7-year contract and plan its maintenance activities accordingly. This extra 2 years may also reflect the bid price of this contractor. The main intent of the warranty concept is to make the contractor improve the overall condition rating of each asset item during the contract term in an effort to provide long term performances of the asset items. It is also the main intent of the warranties to provide a maintenance free highway during the warranty period.

However, completely prohibiting the contractor to implement any maintenance activity during the warranty period is also not appropriate. This, in fact, would be a radical and somehow controversial decision as a result of which some disagreements may arise during the establishment of the contract with a prospective contractor. Given the fact that WisDOT and ODOT allow the contractors to perform certain maintenance activities during the warranty period as approved by the DOT, it would be appropriate to say that this should be the case for VDOT too. However, it is important to note that in order not to contradict the rationale behind developing warranty clauses and thus in order to make use of the warranty concept to the 
maximum extent possible, VDOT should be very selective in deciding on the maintenance work that the contractor is allowed to perform during the warranty period and only approve minimal maintenance work as the allowable maintenance work for the warranty period.

In conclusion, the warranty clause template should clearly put some limitations on the maintenance work that the contractor can perform during the warranty period. And the best way to accomplish this is to introduce an approval procedure for the maintenance work proposed by the contractor during the warranty period. Such approval process may prevent the contractor from doing any major or capital maintenance work during the warranty period.

\subsubsection{The responsibilities of VDOT During the Warranty Period}

It was discussed in the preceding sub-section that VDOT should allow the contractor to perform only minimal and certain maintenance activities (as approved by VDOT) during the warranty period. However this brings about the question of "whether any preventive (routine) maintenance activity is needed to be performed by any other entity (i.e. any other contractor or VDOT) at all during the warranty period or not”. In one sense the answer to this question is no. As mentioned before, the warranty clauses are developed to contain the language which would make the contractor liable in the case of presence of defects in any of the asset items during the warranty period. Within this context, the contractor is required to come back and remedy the defects that are identified through inspections. Thus VDOT does not need to perform or pay another contractor to perform maintenance activities during the warranty period. This would also prevent any liability issues that may arise during the warranty period. For example, suppose that a contractor is paid by VDOT to maintain the assets during the warranty period of another (previous) contractor. If any inspection performed to evaluate the warranty compliance of the contractor reveals that there are some defects present in the highway, the apportionment of these defects between the current contractor and the previous contractor whose work is being evaluated would create some conflicts. In other words, the previous contractor may easily assert that the reason of the identified defect could be attributed to the current contractor who is performing maintenance work during the warranty period. And eventually this could be an irresolvable conflict. As presented in Section 2.6, Transit New Zealand prevents the occurrence of such conflicts by using the language: "The Contractor will not be responsible for maintenance of any assets which... for the time being, are the maintenance responsibility of 
another contractor between the date of practical completion and the end of the defects liability period of those other contracts... A joint inspection, conducted by the Superintendent and the Contractor at the end of the defects liability of other contracts, will identify any particular maintenance or omission responsibilities of the other contractor that may exist at the date of the defects liability period. The Contractor will not resume responsibility for the Assets in question until the identified reasonable responsibilities of the other contractor are discharged...” (Transit New Zealand, Clause 1.12.2 2002, Full clause provided in the Appendix F). Thus, generally speaking and considering the discussions presented in the preceding sub-section, neither the contractor, whose maintenance work is under warranty, nor any other contractor and/or VDOT should perform maintenance work during the warranty period.

However, there are some special cases that overwrite such a generalization. There are some maintenance activities that are completely different form the abovementioned maintenance activities. They need to be performed on an ongoing basis. In other words, they cannot be included in the warranty clauses as "to be taken care of by the contractor if any defect is identified”. Such maintenance activities can be classified into $\mathbf{2}$ kinds: Incident management and winter weather maintenance activities. Such maintenance activities need to be performed by an entity other than the contractor (either any other contractor and/or VDOT) during the warranty period. These activities cannot be included in the warranty clause template as the responsibilities of the contractor because they are independent of the maintenance work that is performed by the contractor during the contract term. For example, a concrete barrier is very likely to become defective during the warranty period when run over by a truck, regardless of the fact that it was maintained perfectly (i.e. its quality was sufficiently improved) during the contract term by the contractor. As mentioned in the discussions for "Exclusions and Waivers" in Sub-section 3.4.2., for such occurrences the contractor cannot be held responsible within the context of the warranty concept. However, such occurrences need to be taken care of by an entity during the warranty period. The same discussion applies to the second kind of maintenance activities (winter weather maintenance activities) too.

The developed warranty clause template should clearly indicate the responsibility of VDOT with respect to the abovementioned two kinds of maintenance activities that should be performed during the warranty period. This responsibility can be stated in two ways. VDOT may 
either have the responsibility of performing these maintenance activities or may have the responsibility of paying a contractor to perform those. This entirely depends on the VDOT's preferences with regards to such an issue. Nonetheless, in either case, ultimately VDOT should have the responsibility to take care of these two kinds of maintenance activities.

\subsubsection{Other Responsibilities of VDOT During the Warranty Period}

The developed warranty clause template should also state the responsibilities of VDOT other than the abovementioned major responsibility. One area relates to the warranty compliance evaluations. The warranty clause should talk about the specifics of the inspections (as discussed in Sub-section 3.4.3). It also needs to assign the responsibility to VDOT of preparation and timely submission of a comprehensive report containing the results of these inspections and the asset items that need remedial actions as identified through these inspections, to the contractor. The time frame for this needs to be clearly indicated in the clause. Moreover, VDOT should be required to notify the contractor in a timely fashion (the exact time frame to be included in the clause) for the emergency remedial actions (not the specifics of the remedial actions, but rather just the asset items that need emergency remedial actions) it wants to be implemented.

Another area that the developed warranty clause template should elaborate on as far as VDOT's responsibilities are concerned is the emergency situation remedial actions. For the cases in which the contractor cannot perform the emergency remedial actions within the required time frame, VDOT should have the responsibility of performing those remedial actions or having those performed. Then VDOT can charge the contractor for the costs it incurred. However, if the contractor disagrees that the emergency remedial actions were necessitated due to its fault and thus refuses to pay the amount asked from it, it may initiate the Conflict Resolution Procedures at a time after the emergency remedial actions are completed. 


\subsection{FOURTH OBJECTIVE: MAKING DISTINCTIONS BETWEEN THE ASSET ITEMS}

As mentioned before and presented in the Appendix B, there are 32 asset items that are required to be maintained under the terms of the current contract. The warranty clauses are aimed to assure that the contractor maintains each of them to improve their overall conditions (and hence each's overall condition rating as discussed in Section 3.1) in order for each to meet the warranty criterion during the warranty period (as established in Section 3.3). Every discussion presented up to this point of the thesis is based on one single asset item, namely "Paved Ditches". As mentioned before, this is done for the sake of simplicity and exactly the same discussions are also valid for the remaining 31 asset items. However, different warranty clauses need to be developed for each of the asset items. This is mainly due to the fact that each asset item is unique and has its own properties defining its lifetime. Each asset item is exposed to different conditions causing it to deteriorate in different amounts when compared to other asset items. Moreover, some asset items have relatively higher importance than others as far as the road users' safeties are concerned. For example fences, signs and signals are much more important than sound barriers for the sake of safety. Thus this diversity between various asset items requires them to be treated differently from each other as far as a warranty clause is concerned. Some asset items need higher standards of warranty statements with longer warranty periods whereas others require just the opposite.

In conclusion, there needs to be a standard format containing all of the components (that have been identified throughout this chapter) to be applicable to each of the developed warranty clauses. However, in order to compensate for the different natures of the asset items, the content of each of the developed warranty clauses needs to reflect the properties of the asset item it is developed for. The following sub-sections illustrate the differences between 2 asset items, "Paved Ditches" and "Sound Barriers", and how they would relate to the components of a warranty clause which are defined in Section 3.2, Section 3.3, and Section 3.4 in order to present the possible content differences between the warranty clauses developed for each asset item. 


\subsubsection{Definition of Defect and Establishment of the Warranty Criterion}

As discussed in Section 3.2, the definition of defect which establishes the warranty criterion to be used in warranty compliance evaluations has 2 components. These 2 components are performance criteria and performance target. And since, the performance criteria and performance target for each asset item are different from the other asset item's performance criteria and performance target, definition of defect and thus the established warranty criterion will be different for each of the asset items. Table 3.2 presents the performance criteria and performance targets for the "Paved Ditches” and "Sound Barriers" asset items.

Table 3.2: Performance Criteria and Performance Targets for the "Paved Ditches" and "Sound Barriers" asset items as extracted from the Exhibit B of the VDOT-VMS Contract

\begin{tabular}{|c|c|c|c|}
\hline Asset & Outcome & $\begin{array}{l}\text { Performance Target } \\
\text { (\% of asset that shall } \\
\text { be in the outcome } \\
\text { described condition) }\end{array}$ & $\begin{array}{l}\text { Condition assessment acceptance tolerances and } \\
\text { criteria (Service Delivery) }\end{array}$ \\
\hline $\begin{array}{l}\text { Paved } \\
\text { Ditches }\end{array}$ & $\begin{array}{l}\text { Aligned } \\
\text { Structurally sound } \\
\text { Clean }\end{array}$ & $90 \%$ & $\begin{array}{l}\text { - }<1 \text { '’ settlement } \\
\text { - no undermining or undercut requiring action } \\
\text { - }<25 \% \text { spalled } \\
\text { - no obstruction to flow of water that requires action }\end{array}$ \\
\hline $\begin{array}{l}\text { Sound } \\
\text { Barriers }\end{array}$ & $\begin{array}{l}\text { Sound } \\
\text { Functional }\end{array}$ & $95 \%$ & $\begin{array}{l}\text { - no settlement indicating structural distress } \\
\text { - free of damaging vegetation } \\
\text { - }<10 \% \text { of any applied sound retardant material is } \\
\text { damaged } \\
\text { - no graffiti }\end{array}$ \\
\hline
\end{tabular}

As can be recalled, for the "Paved Ditches" asset item, the broadest definition of defect is “(a) having less than 1 inch of settlement or (b) having no undermining or undercut that requires action or (c) having less than $25 \%$ of the area spalled or (d) having no obstruction to flow of water that requires action or (e) any combination of (a), (b), (c) and (d); for less than $\mathbf{9 0 \%}$ of the total amount of paved ditches present in the interstate system maintained by the contractor." In a similar way, the broadest definition of defect for the "Sound Barriers" asset item can be made as “(a) having no settlement indicating structural distress or (b) being free of damaging 
vegetation or (c) having less than $10 \%$ of any applied sound retardant material damaged or (d) having no graffiti or (e) any combination of (a), (b), (c) and (d); for less than 95\% of the total amount of sound barriers present in the interstate system maintained by the contractor." As illustrated clearly, the performance criteria and performance target and hence the definition of defect for each of the 2 asset item is quite different from each other. This fact calls for different warranty criteria and thus different warranty clauses to be established for each asset item.

The warranty criterion (in its broadest sense) for the "Paved Ditches" asset item was stated (in Sub-section 3.2.2) as “(a) having less than 1 inch of settlement and (b) having no undermining or undercut that requires action and (c) having less than $25 \%$ of the area spalled and (d) having no obstruction to flow of water that requires action; for at least equal or more than $90 \%$ of the total amount of paved ditches present in the interstate system maintained by the contractor.” By using the same approach, the warranty criterion (in its broadest sense) for the "Sound Barriers" asset item can be established as “(a) having no settlement indicating structural distress and (b) being free of damaging vegetation and (c) having less than $10 \%$ of any applied sound retardant material damaged and (d) having no graffiti; for at least equal or more than $95 \%$ of the total amount of sound barriers present in the interstate system maintained by the contractor." As can be realized, the warranty criterion for each asset item ("Paved Ditches” and “Sound Barriers”) is different from the other's warranty criterion.

\subsubsection{Identification of the Length of the Warranty Period}

As discussed in Section 3.3, there are 3 alternatives to establish the length of the warranty period. However, to present the distinction between the asset items and its reflection to the "length of the warranty period" component of the warranty clauses, only the second alternative will be used. The very same discussion presented in this sub-section applies to the first and third alternatives too.

As can be recalled, in the second alternative, the overall condition rating required at the end of the contract term, and the normal deterioration curve for the "Paved Ditches" asset item are used to establish the length of the warranty period for that asset item. Given the fact that each asset item is exposed to different conditions causing it to deteriorate in different amounts when compared to other asset items, it would be fair to assert that each asset item has different normal deterioration curve. Moreover, the overall condition rating required at the end of the contract 
(which is to be decided by VDOT) may be different from asset item to asset item. The overall condition rating required at the end of the contract for an asset item entirely depends on VDOT's preferences on that particular asset item. VDOT may well require an asset item's overall condition to be improved more than another asset item's overall condition based on the fact that VDOT deems the former to be more important than the latter due to safety reasons. Figure 3.16 illustrates the normal deterioration curves (in which hypothetical values are used) for the "Paved Ditches" and "Sound Barriers" asset items. It is important to note that these deterioration curves begin with an assumed overall condition rating for each asset item (97\% for the "Sound Barriers" asset item and 95\% for the "Paved Ditches" asset item) as required by VDOT to be at the end of the contract term.

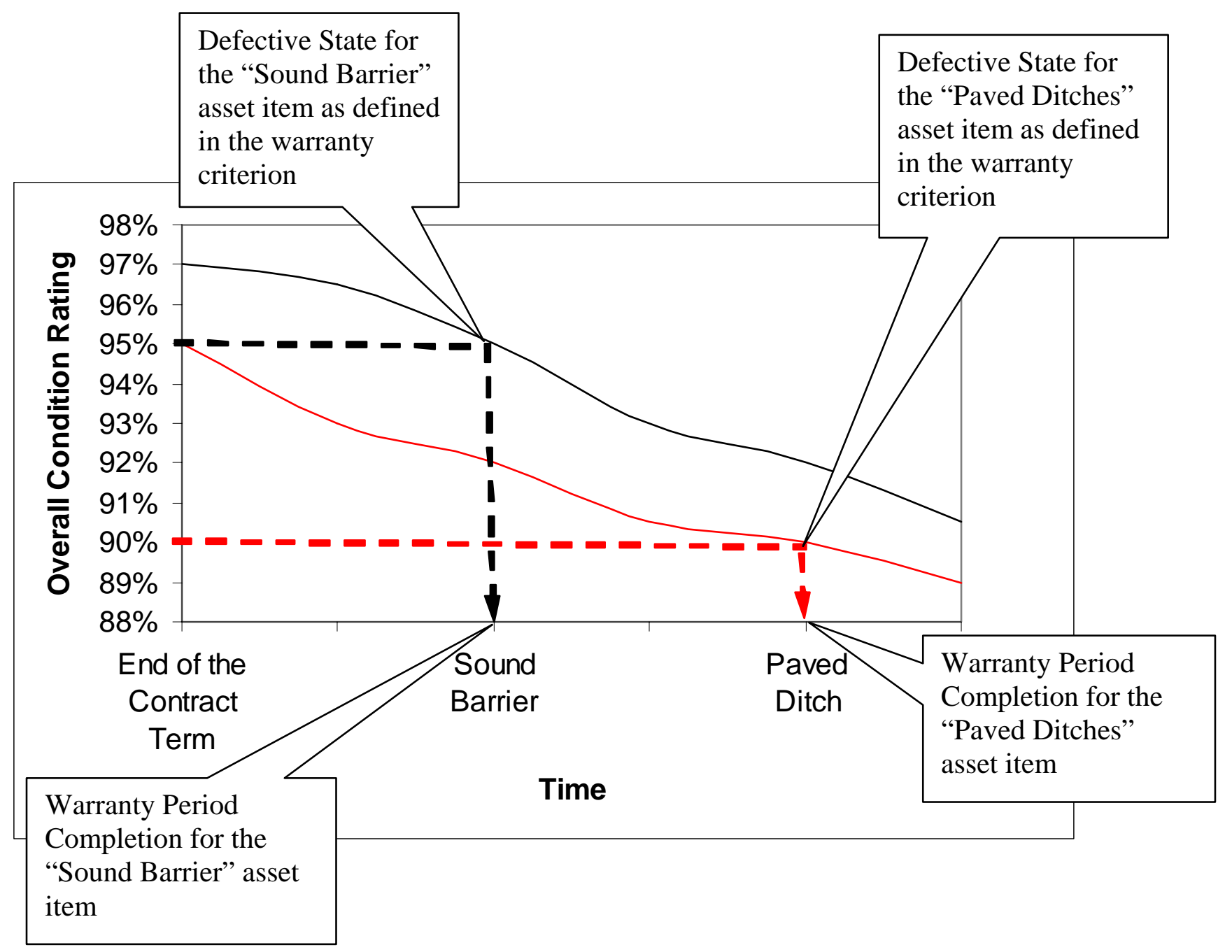

Figure 3.16: Normal deterioration curves for the "Paved Ditches" and "Sound Barriers" asset items 
As can be seen in the figure, for the "Sound Barriers" asset item, the overall condition rating required at the end of the warranty period is chosen as 97\% (arbitrarily) which is just 2\% above the performance target (i.e. defective state) for that asset item. This also means that the value "A" (as defined in Sub-section 3.3.1) is chosen to be $2 \%$. This shows that the VDOT is requiring only a $2 \%$ increase over the asset item's performance target during the contract term. "Sound Barriers" asset item, having the deterioration curve that is drawn in black, then reaches to its defective state in the time denoted by "Sound Barrier". This time is said to be the length of the warranty period for the "Sound Barriers" asset item.

On the other hand, for the "Paved Ditches" asset item, the overall condition rating required at the end of the warranty period is chosen to be $95 \%$ (arbitrarily) which is $5 \%$ above the performance target (i.e. defective state) for that asset item. This also means that the value "A" (as defined in Sub-section 3.3.1) is chosen to be 5\%. This shows that the VDOT is requiring a 5\% increase over the asset item's performance target during the contract term. "Paved Ditches" asset item, having the deterioration curve that is drawn in red, then reaches to its defective state in the time denoted by "Paved Ditch". This time is said to be the length of the warranty period for the "Paved Ditches" asset item.

As illustrated clearly in the figure, the length of the warranty period for the "Sound Barriers" asset item is shorter than the length of the warranty period for the "Paved Ditches" asset item. This is entirely due to having different deterioration curve, requiring different overall condition rating, and having different warranty criterion for each asset item. This fact, again calls for different lengths of the warranty period and thus different warranty clauses to be established for each asset item.

\subsubsection{Exclusions and Waivers within the Warranty Period}

As discussed in Sub-section 3.4.2, there may be many external factors which cause asset items to be defective and which also are beyond the control of the contractor performing the maintenance work. However, not every asset item would be affected by every external factor. In other words an external factor that affects an asset item negatively may not affect another asset item at all. This fact can be illustrated using the example asset items, "Paved Ditches" and "Sound Barriers." 
A very severe hurricane that moves trees and debris from one place to another can easily bring such items onto the paved ditches. These items may act as obstacles that impede the flow of water within the paved ditches and hence prevent them from being functional. In fact this is one of the definitions of defect for the "Paved Ditches" asset item and thus is a part of the warranty criterion against which the contractor is to be evaluated. However, due to the fact that it is entirely beyond the contractor's control, such an occurrence would waive the warranty criterion. Therefore the defects occurring because of "a severe hurricane” should be stated as an exclusion in the warranty clause developed exclusively for the "Paved Ditches" asset item.

On the other hand, the same hurricane would have no effect on the sound barriers at all. In other words, the hurricane would not cause any of the sound barriers to become defective (as defined in Table 3.2) no matter how severe it is. Thus, there is no point in including "a severe hurricane" as a waiver of the warranty criterion developed for the "Sound Barriers" asset item.

Given this discussion, the exclusions and waivers should be identified within the context of each asset item by considering the properties of each and thus the applicability of the exclusions and waivers to each. This would ensure that each of the developed warranty clauses will have the waivers and exclusions that are specific to the asset item for which the warranty clause is developed.

\subsubsection{Remedial Actions}

As discussed in Sub-section 3.4.4, the warranty clauses should not specify the specifics of the remedial actions required from the contractor. It was furthermore stated that the warranty clauses need to elaborate on the time frame for the remedial actions to be implemented by the contractor.

The time frame for the remedial actions required for each asset item needs to be established considering the importance of each asset item as deemed by VDOT. Some asset items have relatively higher importance than others as far as the road users' safeties are concerned. For this reason, those asset items need to be remedied at a faster pace to be put into service earlier than the regular asset items which are not that important as far as the safety element is concerned. As mentioned before, some asset items need higher standards of warranty statements than the others for the safety traits they possess. The presented discussion is valid for both the regular remedial 
actions as identified through comprehensive annual inspections and emergency remedial actions as identified anytime through less detailed windshield inspections.

Another aspect related to the time frame for the remedial actions is the actual possibility of the remedial action to be completed within the established time frame. Due to the different natures they possess, the remedial actions implemented to different asset items can be completed in different time frames. As an example, correcting the deficiencies present in the paved ditches may take less time than correcting the deficiencies present in the sound barriers. To be more specific, removing the obstacles that are present on paved ditches may take far less time than applying the sound retardant material to the sound barriers. It can be noticed that, both are remedial actions required from the contractor after the identification of its warranty noncompliance. However, VDOT should be realistic and reasonable in establishing the required time frame for these remedial actions to be completed considering the nature of the remedial actions.

Given the abovementioned issues, it is obvious that the warranty clause that is developed for each asset item should establish the time frames for the remedial actions by considering the properties of the asset item as well as the nature of the remedial actions required for that particular asset item.

\subsubsection{Bonding Requirements for the Warranty Period}

It was discussed in Sub-section 3.4.7 in detail that, in establishing the amount (penal value) of the warranty bond that is required from the contractor, VDOT should use the "most likely case scenario" approach rather than establishing this amount based on a certain and arbitrary percentage of the total contract amount. As presented in Sub-section 2.4.2.6, the "most likely case scenario" approach requires VDOT to calculate the cost of the most expensive reasonable remedy (repair or replacement) that would be applied in a most likely case problem with the performance of the project during the warranty period, and then to establish this amount as the required warranty bond amount. However this method brings about 2 important questions that need to be addressed. First one is, whether the most likely case problem (and hence the cost of the most expensive reasonable remedy to correct that problem) needs to be defined for each of the asset items or for just one of the asset items. And the second question is whether the contractor needs to obtain separate bonds for each asset item. 
The answer to the first question should be yes. Even though identifying the most likely case problem (and hence the cost of the most expensive reasonable remedy to correct that problem) for each of the 32 asset items may be cumbersome, doing that would put VDOT on the safe side and give VDOT the ultimate assurance that it is willing to get through the requirement of the warranty bonds. If the most likely case problem (and hence the cost of the most expensive reasonable remedy to correct that problem) was identified for just one asset item, the bond amount as established using this cost would not cover the failures of other asset items. And in the presence of the failure of other asset items in addition to the failure of the one for which the bond amount is determined, VDOT would not receive all of the benefits it would be willing to receive (if it was to direct the bonding company to take care of those failures). Thereby, the most likely case problem and the cost of the most expensive reasonable remedy to correct that problem need to be defined for each asset item so that any failure with regards to any asset item can be covered by the bond provided by the contractor.

As far as the second question is concerned, the contractor should be required to obtain separate bonds for each asset item. This serves mainly 2 purposes. First, when the contractor has the option of obtaining separate bonds for each asset item, it is more likely to secure different bonds (even from different sureties) each of which has a face value (penal value) that would not be too costly. Secondly, requiring separate bonds for each asset item would simplify the administration of different warranties (for each asset item) which have different lengths of the warranty periods.

Another important issue which is not related to the subject of "making distinctions between the asset items" but which somehow relates to the discussion presented here is the subcontractor bonds. The current VDOT performance based road maintenance contract covers a sizeable portion of the interstate highway system within the state of Virginia. Given this nature of the contract, many local subcontractors are employed by the contractor to do a substantial amount of the maintenance work that had been contracted out in 1996. In fact, for the first 2 years, $90 \%$ of the maintenance work was contracted out by the contractor (Better Roads 2001). Given the nature of the maintenance activities that are performed on a large portion of the interstate highway system, this may also be the case for the future performance based road maintenance contracts that will be issued by VDOT. Thus, in a setting where most of the work is performed by subcontractors, one can argue that the bond should be provided by the 
subcontractors. However, it is important to note that each of these subcontractors are performing individual and specialty jobs like to maintain each of the asset items. In such a setting, requiring bonds from the subcontractors would only complicate the process of bonding. This is simply because each subcontractor would be required to provide a bond for the amount related to its work and this would result in complicated situations. Moreover, due to the issues discussed in Sub-section 2.4.2.6 small subcontractors are less likely to secure bonds from the surety companies. Considering these and the discussion presented above (requiring separate bonds whose face values (penal values) are equal to the most expensive reasonable remedies for each asset item) it would be fair to say that there should be separate bonds provided by the contractor for each asset item to cover the most likely failures that would occur during the warranty period.

The discussions presented above demonstrated the differences between the asset items and how they would relate to the components of a warranty clause. As can be grasped, not all of the components of a warranty clause (which are defined in Section 3.2, Section 3.3, and Section 3.4.) are discussed above. This is mainly due to the fact that some components of the developed warranty clause template are generic and thus almost identical for each asset item. These components can be listed as: Warranty compliance evaluations, conflict resolution procedures for the warranty period, contractor's default within the warranty period, the option of preventive maintenance during the warranty period, and the responsibilities of VDOT during the warranty period. 


\section{CHAPTER 4}

\section{PHASE 3- SOLUTION PHASE}

In this chapter, the complete and comprehensive warranty clause template, as developed by the help of the findings of the Observation Phase and the Analysis Phase, is presented. As discussed while presenting the methodology of this research, the warranty clause template developed in this phase (Solution Phase) is reflecting the outcomes that are achieved through the subjective analysis of the observations, as performed by the M.S. candidate. Thus, the warranty clause template presented in this chapter can be regarded as the first draft that is to be evaluated by the panel of experts. This evaluation process forms the next phase of this research and will be presented in Chapter 5. And final form of the developed warranty clause template, as enhanced after the evaluation phase, will be presented in Chapter 6.

\subsection{FIFTH OBJECTIVE: DEVELOPING THE COMPREHENSIVE WARRANTY CLAUSE TEMPLATE AND AN EXAMPLE WARRANTY CLAUSE FOR THE “PAVED DITCHES” ASSET ITEM}

In the previous chapters, the problem and the way to address this problem were presented. Later on, the warranty concept was discussed in great depth. And afterwards, the components that should be present in a warranty clause were elaborated on. All of these discussions have been presented within the context of VDOT issued performance based road maintenance contract, which is the contract that is in the scope of this research. In this chapter, (Solution Phase), the comprehensive warranty clause template and an example warranty clause for the "Paved Ditches" asset item is developed.

In Section 3.5, it was underlined that due to the different properties that each asset item has, a different warranty clause needs to be developed for each of them. However, for the purposes of this research, a warranty clause is developed for only one of the asset items. The M.S. candidate believes that once the language for the warranty clause template is developed, the warranty clauses for each of the asset items can be developed by studying the components of this warranty 
clause template. As discussed earlier, the warranty clauses developed for each asset item need to have a common and standard format and thus a common and standard language. However, in order to compensate for the different natures of the asset items, the content of each of the developed warranty clauses needs to reflect the properties of the asset item it is developed for.

In the following sub-section, a warranty clause is developed without considering the asset item it is developed for. It is merely a template which possesses all of the components (as identified in Section 3.2, Section 3.3, and Section 3.4) of a warranty clause. As can be observed, this clause possesses some blanks which need to be filled in by considering the properties of the asset item it is developed for. Hence, the language and the format of this template can be used to develop the warranty clauses for each asset item. Then, in the next sub-section, that template is used to develop a comprehensive warranty clause. The "Paved Ditches" asset item is chosen to be the one for which the warranty clause is developed. Thus, the developed warranty clause has the components (as discussed in Section 3.2, Section 3.3, and Section 3.4) that reflect the properties of the "Paved Ditches" asset item. In other words, the blanks within the warranty clause template have been filled in with the words and values which are representing not only the properties of the "Paved Ditches" asset item but also VDOT's expectations with respect to the "Paved Ditches" asset item. This is done to illustrate the process of developing different warranty clauses for different asset items. Thereby, the warranty clause developed for the "Paved Ditches” asset item can be used as an example for developing the warranty clauses for the remaining 31 asset items.

There are two important remarks that need to be made at this point. The first one is that, while developing the warranty clause template, the boilerplate language that is present in a number of states' warranty clauses has been used to some extent. This is done to make sure that the developed warranty clause is compatible with the language used in the USA's legal system and should be valid as far as the court's point of view is concerned. This is very crucial because in the case of a dispute whose resolution is sought in the courts, the warranty clause should be well-matched to the USA's legal system for the claimant to be able to present the validity of the claims by using the warranty clause. The states whose warranty clause languages are used as boilerplates are Wisconsin, Ohio, Minnesota, and Florida. Within this group, Wisconsin and Ohio were particularly chosen due to their long time experiences with the warranty concept. Moreover, the model asphalt warranty specification that has been developed by Anderson and 
Russell (Anderson and Russell 2001) as a part of a NCHRP Project (NCHRP Project 10-49) is also used.

The second remark is that the developed warranty clause template is designed to act as a part of the current performance based road maintenance contract issued by VDOT as opposed to acting as a separate legal instrument as stressed by the attorneys within the state of Michigan (Galehouse 1998). Thus, as warranty clauses are developed for each asset item, they should be incorporated into the contract as new documents, perhaps under the main section, Article XVI, which has the heading, "Warranties” (Current contract has 15 main sections, i.e. up to Article $X V$ ). Given this fact, it can be asserted that all the statements that are made within the earlier 15 sections (Articles) as well as in the following Exhibits are valid for the warranty period too. In other words, all the rights and the responsibilities that VDOT and the contractor are said to possess as set forth in the previous 15 sections (Articles) as well as in the following Exhibits are to remain in effect during the warranty period too. The developed warranty clause template, as filled in with the related information for each asset item, should be incorporated into the VDOT issued performance based road maintenance contracts as a document which is a part of the contract overall. It is not intended to be a separate document. This would assure that the developed warranty clauses are incorporated into the contract within a whole new Article as to be a part of the contract and to possess the general tone of the Articles coming before it as well as the Exhibits coming after it. Thus the warranty clauses will neither change nor affect and thus interfere with any other provisions and clauses that are already present in the contract.

\subsubsection{The Warranty Clause Template for the VDOT Issued Performance Based Road Maintenance Contracts}

In this sub-section, the template developed for the warranty clauses is presented. The following remarks should be kept in mind while examining the template:

1.) The text to be used in the standard format of the warranty clauses is presented in Times New Roman font as used in this line.

2.) The specific details that are different for each asset item are presented in blanks with the symbol “ “. These blanks need to be filled in by considering each 
asset item's specific properties and also VDOT's expectations with respect to each asset item.

3.) Throughout the document, the text is supplemented with a number of footnotes. These footnotes are intended to present information about the parameters that should be inserted into the blanks (__ ) that are present in the text. In certain occasions, these footnotes also present some other explanations, options, and/or instructions related to the text. The footnotes are written in Times New Roman font as illustrated in this line. Within these footnotes, the key parameter (if applicable) is bolded.

4.) The footnotes only serve the purpose of assisting the end user who develops the real warranty clauses. Thus, the footnotes should be removed as the real warranty clauses are developed.

The developed warranty clause template is presented on the following page. 


\section{ARTICLE XVI \\ WARRANTIES}

WARRANTY FOR THE “ ” ASSET ITEM

\section{Section 16.1: GENERAL DESCRIPTION}

This document specifies the requirements for the Contractor to warrant the maintenance work it (the Contractor) has performed for the " "1 asset item for a period of ${ }^{2}$ year(s)/month(s) ${ }^{3}$.

The Contractor shall assume full responsibility for all the associated work specified in this Document for a period of ${ }_{1}^{4}$ year(s)/month(s) after the final acceptance of the Contract in accordance with the Section $\mathbf{1 1 . 3}{ }^{\mathbf{5}}$, including continued responsibility as to any defects discovered by the Department and as to which timely notice was provided within such warranty period until all such pre-existing defects are corrected.

\section{Section 16.2: WARRANTY BOND}

The Contractor shall provide a warranty bond which will be in effect for a minimum of the length of the warranty period which begins upon the final acceptance of the contract in accordance with the Section 11.3. The effective starting date of the warranty bond shall be the date of final acceptance. The warranty bond will be released at the end of the warranty period or after all warranty remedial work has been completed, whichever is latest.

\footnotetext{
${ }^{1}$ Insert: the name of the asset item for which the warranty clause is developed.

${ }^{2}$ Insert: the length of the warranty period as identified (for the asset item for which the warranty clause is developed) using either Alternative 1 or Alternative 2 or Alternative 3.

${ }^{3}$ year(s) or month(s), whichever is applicable.

${ }^{4}$ Insert: the length of the warranty period as identified (for the asset item for which the warranty clause is developed) using either Alternative 1 or Alternative 2 or Alternative 3.

${ }^{5}$ Section 11.3 (which is under the Article XI of the current contract) establishes the completion of the Contract Term.
} 
The surety of the bond shall be a surety company authorized to transact business in the State and shall have A.M. Best unit rating not less than " $\mathrm{A}$ "6 throughout the warranty period. If the A.M. Best unit rating of the surety company drops below " $A$ ”, then the Department will 7 .

The warranty bond(s) will be $\_{ }^{8}$. The bonds will ensure the proper and prompt completion of required remedial work, including payments for all labor performed, and all equipment and materials used.

The warranty bond(s) will be provided in one of the following manners:

1. A single term _ ${ }^{9}$ year/month ${ }^{10}$ warranty bond.

2. A ${ }^{11}$ year/month renewable, non-cumulative warranty bond for 12 consecutive terms.

Whichever option the Contractor chooses, the Contractor will provide documentation which can act as a proof of $\_$_ ${ }^{13}$ year/month bond commitment before the execution of the contract.

\footnotetext{
${ }^{6}$ This is the rating that has been required for the performance bond (which only covers the Contract Term) of the current contract.

${ }^{7}$ Insert: a list of all of the steps that need to be taken if the A.M. Best unit rating of the surety company drops below the required rating as set forth in this section.

${ }^{8}$ Insert: the bond amount (for the asset item for which the warranty clause is developed) as established using the "most likely case" scenario.

${ }^{9}$ Insert: the length of the warranty period as identified (for the asset item for which the warranty clause is developed) using either Alternative 1 or Alternative 2 or Alternative 3.

${ }^{10}$ year or month, whichever is applicable.

${ }^{11}$ Insert: the monthly or yearly (whichever is applicable) intervals at which a non-cumulative warranty bond is required by VDOT.

${ }^{12}$ Insert: the number which is calculated by dividing the length of the warranty period as identified (for the asset item for which the warranty clause is developed) using either Alternative 1 or Alternative 2 or Alternative 3 to the monthly or yearly (whichever is applicable) intervals at which a non-cumulative warranty bond is required by VDOT.

${ }^{13}$ Insert: the length of the warranty period as identified (for the asset item for which the warranty clause is developed) using either Alternative 1 or Alternative 2 or Alternative 3.
} 
No separate Subcontractor bond is required. However, the bond(s) provided pursuant to this section will cover any work, no matter whether it is performed by the Contractor or any Subcontractor that is employed by the Contractor to perform a part or whole parts of the maintenance work during the contract term.

\section{Section 16.3: WARRANTY COVERAGE AND WARRANTY CRITERION}

Warranty criterion $^{14}$ is established by using the parameters that are listed in Table $\mathbf{1}^{15}$.

\section{Table 1: Warranty Criterion}

\begin{tabular}{|l|l|l|l|}
\hline Asset & Outcome & $\begin{array}{l}\text { Performance Target } \\
\text { (\% of asset that shall } \\
\text { be in the outcome } \\
\text { described condition) }\end{array}$ & $\begin{array}{l}\text { Condition assessment acceptance tolerances and } \\
\text { criteria (Service Delivery) }\end{array}$ \\
\hline & & \\
\hline
\end{tabular}

$\Upsilon^{Y}$

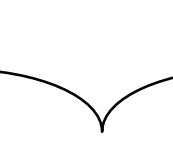

This table needs to be extracted from the Exhibit B of the current contract. The information within this table needs to correspond to the asset item for which the warranty clause is developed.

\section{Section 16.4: WARRANTY COMPLIANCE EVALUATIONS}

The Department (and/or its authorized agent) will conduct an inspection at the beginning of the warranty period which shall be completed in ${ }^{16}$ days. For the remaining years of the warranty period, the Department (and/or its authorized agent) will conduct annual inspections

\footnotetext{
${ }^{14}$ Warranty criterion is established using the performance criteria and the performance target for the asset item for which the warranty clause is developed. Warranty criterion for any asset item can be stated as "meeting the performance criteria for at least equal or more than the performance target established for that asset item".

${ }^{15}$ Insert: Table 1 which lists the performance criteria and performance target (for the asset item for which the warranty clause is developed) that are established for the Contract Term within the Exhibit B of the current contract.

${ }^{16}$ Insert: the number of days that is allowed for VDOT to complete the initial inspection. This time frame should be minimized to allow the Contractor to start remedial work as soon as possible.
} 
between ___ ${ }^{17}$ and ___ ${ }^{18} \cdot{ }^{19}$ The last inspection will be performed by the Department (and/or its authorized agent) just before the completion of the warranty period and shall be completed in ${ }^{20}$ days. The methodology of these inspections will be same as the ones' that are conducted within the Evaluation Program that is defined in Section $\mathbf{2 . 1 8}{ }^{\mathbf{2 1}}$ and described in Exhibit $\mathbf{G}^{22}$ of the Contract.

The Department (and/or its authorized agent) will conduct these inspections at no cost to the Contractor. The Department shall notify the Contractor of the scheduled review. The Contractor or any other interested party may attend the inspections for observation purposes only. Any comments by the Contractor or other interested party may be recorded by the Department. A comprehensive report containing the results of the inspection and the remedial work (as expanded in Section 16.5) required from the Contractor shall be made available to the Contractor within ${ }^{23}$ days after the completion of the inspection. The Department (and/or its authorized agent) shall use non-destructive procedures in performing the inspections. If destructive procedures are used by the Department, the Contractor will not be responsible for damages that result from coring, milling or other destructive procedures conducted by the Department.

The Department (and/or its authorized agent) may also conduct special evaluations on a more frequent basis in order to identify the emergency remedial work needs (as expanded in

\footnotetext{
${ }^{17}$ Insert: the beginning date of the annual inspections.

${ }^{18}$ Insert: the completion date of the annual inspections.

${ }^{19}$ This time frame should be minimized to allow the Contractor to start remedial work as soon as possible. If the warranty period is less than 1 year for the asset item for which the warranty clause is developed, then this sentence needs to be removed from the clause.

${ }^{20}$ Insert: the number of days that is allowed for VDOT to complete the final inspection. This time frame should be minimized to allow the Contractor to start remedial work as soon as possible.

${ }^{21}$ Section 2.18 defines the highway maintenance evaluation program that is implemented in the Contract Term in order to assess the work of the contractor during the Contract Term.

${ }^{22}$ Exhibit G describes in detail the highway maintenance evaluation program that is implemented in the Contract Term in order to assess the work of the contractor during the Contract Term.

${ }^{23}$ Insert: the number of days that is allowed for VDOT to prepare and submit the report possessing the results of the inspection. This time frame should be minimized to allow the Contractor to start remedial work as soon as possible.
} 
Section 16.5). If any emergency situation is discovered during these special evaluations, the Contractor shall be notified within ${ }^{24}$ hours upon the discovery of such situation.

As soon as the identified remedial work is completed (as expanded in Section 16.5), the Department (and/or its authorized agent) shall re-inspect the portions of the highway for which remedial work was required.

\section{Section 16.5: REMEDIAL WORK}

During the warranty period, if the results of the warranty compliance evaluations reveal that the warranty criterion (as expanded in Section 16.3) is not met, and the Contractor agrees to the validity of the evaluation results, the remedial work, as identified to be necessary through the warranty compliance evaluations (that are expanded in Section 16.4), will be performed by the Contractor at no cost to the Department. The Contractor is free to implement any method in performing the remedial work. The Contractor is also free to choose any material to use in performing the remedial work. At all times the remedial work is performed, the Contractor shall follow a Department- approved traffic control plan.

The Contractor shall notify the Department and submit a written plan for performing the required remedial work within ___ ${ }^{25}$ days after being notified by the Department for the remedial work required from it and before starting that remedial work, except in case of emergency remedial work as detailed in this section. The submittal shall only propose the schedule for performing the remedial work, no other information regarding the Contractor's remedial work need to be submitted by the Contractor. The times of the day for performing the remedial work shall be subject to the approval of the Department. The written plan shall be approved by the Department within ___ ${ }^{26}$ days upon the receipt of the written plan. The Contractor shall begin the remedial work upon the approval of its remedial work schedule.

\footnotetext{
${ }^{24}$ Insert: the number of hours that is allowed for VDOT to notify the contractor of the emergency situation. This time frame should be minimized to allow the Contractor to start emergency remedial work as soon as possible.

${ }^{25}$ Insert: the number of days for the Contractor to submit its schedule to perform the required remedial work.

${ }^{26}$ Insert: the number of days for VDOT to approve the submitted schedule of the required remedial work. This time frame should be minimized to allow the Contractor to start remedial work as soon as possible.
} 
The remedial work shall be performed by the Contractor to improve the asset item's ${ }^{27}$ overall condition sufficiently to meet the warranty criterion. The remedial work shall be completed within ${ }^{28}$ days following approval of the Contractor's remedial work schedule by the Department. If the remedial work cannot be completed within ${ }^{29}$ days following approval of the Contractor's remedial work schedule by the Department due to seasonal limitations, the Contractor shall notify the Department in writing and determine a schedule for completion of the remedial work.

If the results of the warranty compliance evaluations reveal that the warranty criterion (as expanded in Section 16.3) is not met, but the Contractor does not agree to the validity of the evaluation results, the Conflict Resolution Procedures (which are expanded in Section 16.6) shall be implemented.

If, in the opinion of the Department, any portion of the highway which is covered by the warranty possesses emergency situations which require immediate attention for the safety of the traveling public, the Contractor shall be notified (as expanded in Section 16.4) to perform the emergency remedial work. Such situations which necessitate emergency remedial work can be listed as ${ }^{30}$. If the Contractor cannot perform the required emergency remedial work in 31 hours, the Department may have the work performed, at the Contractor's expense, by Department personnel and/or through a Department procurement. Any work thus performed will not alter the requirements, responsibilities, or obligations of the warranty. If the Contractor refuses to pay for such emergency remedial work depending on the grounds that the emergency situation was caused by factors beyond its control, the Conflict Resolution Procedures (as expanded in Section 16.6) shall be implemented.

\footnotetext{
${ }^{27}$ This is the asset item for which the warranty clause is developed.

${ }^{28}$ Insert: the number of days for the Contractor to complete all of the required remedial work related to the asset item for which the warranty clause is developed. This time frame should be minimized to restore the defective portions of the highway to their acceptable and safe conditions as soon as possible.

${ }^{29}$ Insert: the number of days for the Contractor to complete all of the required remedial work related to the asset item for which the warranty clause is developed.

${ }^{30}$ Insert: the complete list of the occasions that constitute an emergency situation for the asset item for which the warranty clause is developed.

${ }^{31}$ Insert: the number of hours for the Contractor to complete all of the required emergency remedial work related to the asset item for which the warranty clause is developed. This time frame should be minimized to prevent any safety issues that may arise due to these emergency situations.
} 
If the remedial work performed by the Contractor necessitates the removal of asset items other than the one that is warranted under the Section 16.1 of this Contract, including but not limited to the pavement markings, pavement markers, adjacent lane(s), roadway shoulders, signs, and mile markers, then such asset items shall be removed and replaced at the Contractor's expense.

At the end of the warranty period, the Contractor will be released from further warranty work or responsibility, provided that all previously required remedial work has been completed.

\section{Section 16.6: CONFLICT RESOLUTION PROCEDURES}

A Conflict Resolution Team (CRT), which deals exclusively with the issues related to the warranty, will be established prior to the initiation of the warranty period to resolve any conflicts arising between the Contractor and the Department regarding the warranty requirements. This team will be composed of one representative appointed by the Contractor, one representative appointed by the Department, and an independent party mutually agreed upon by the Contractor and the Department. Decisions of the Conflict Resolution Team will be based on a simple majority vote. The Contractor and the Department acknowledge that use of the Conflict Resolution Procedures is required and the determinations of the Conflict Resolution Team for conflicts arising between them will be binding on both the Contractor and the Department, with no right to appeal by either party, for the purposes of this document.

All Conflict Resolution Team meetings shall be initiated and paid for by the Contractor. The Department will reimburse the Contractor for all fees associated with meetings only if the Conflict Resolution Team rules substantially in favor of the Contractor, otherwise the Contractor shall be solely responsible for all such costs. The term "substantially" is defined as fifty percent of the issues when entitlement is disputed or fifty percent of the total dollar amount when costs associated with such entitlement are disputed. 
The Conflict Resolution Procedures shall be initiated by the Contractor within 32 days after the comprehensive report containing the results of the inspection and the remedial work requested from the Contractor is made available to the Contractor (as expanded in Section 16.4). The CRT will evaluate the dispute. This evaluation may include inspecting the disputed area in the field. The evaluation may also include reviewing the inspection data, obtaining samples, and/or interviewing Department (District or Central Office) or Contractor employees. The CRT will receive the Maintenance Rating Program (MRP) training when it is determined necessary to perform an inspection to resolve the conflict. The CRT's determination(s) will be issued in writing to the Contractor and to the Department within 33 days after the Conflict Resolution Procedures are initiated by the Contractor.

If the Conflict Resolution Procedures are initiated for an emergency remedial work (as expanded in Section 16.5) that has already been completed by the Department (and/or its authorized agent), then the CRT shall determine whether the Contractor was responsible for that emergency remedial work or not. As a result of this determination, the CRT may direct the Contractor to pay the Department for the completed emergency remedial work.

\section{Section 16.7: DEFAULT ON THE CONTRACTOR}

Failure of the Contractor to submit its remedial work schedule within the specified period of time (as expanded in Section 16.5) shall be cause for the Department to complete the remedial work and recover the costs of such from the warranty bond.

Failure of the Contractor to initiate the Conflict Resolution Procedures within the specified period of time (as expanded in Section 16.6) shall be cause for the Department to complete the remedial work and recover the costs of such from the warranty bond.

\footnotetext{
${ }^{32}$ Insert: the number of days for the Contractor to initiate the Conflict Resolution Procedures. This time frame should be minimized to allow the CRT to begin evaluating the conflict as soon as possible so that the responsible party (as identified through the Conflict Resolution Procedures) can perform remedial work to restore the defective portions of the highway to their acceptable and safe conditions as soon as possible. Moreover, this time frame should be same with the time frame required for the Contractor to submit its schedule (as expanded in Section 16.5) for the remedial work. This would enable VDOT to understand the intentions of the Contractor in the sense that whether it is planning to perform the remedial work or it is planning to initiate Conflict Resolution Procedures for the requested remedial work.

${ }^{33}$ Insert: the number of days for the CRT to arrive a decision about the conflict(s) for which the Conflict Resolution Procedures were initiated. This time frame should be minimized to make the CRT reach a final decision as soon as possible so that the responsible party (as identified through the Conflict Resolution Procedures) can perform remedial work to restore the defective portions of the highway to their acceptable and safe conditions as soon as possible.
} 
Failure of the Contractor to perform remedial work within the specified period of time (as expanded in Section 16.5) shall be cause for the Department to complete the remedial work and recover the costs of such from the warranty bond.

Failure of the Contractor to fully comply with the decisions of the Conflict Resolution Team (as expanded in Section 16.6) shall be cause for the Department to complete the remedial work and recover the costs of such from the warranty bond.

Failure of the Contractor or its surety to issue or renew the warranty bond (as expanded in Section 16.2) will be considered as a default and will result in forfeiture of ${ }^{34}$ percent of the face amount of the bond to the Department.

Should the Contractor fail to timely submit any conflict to the CRT, fail to satisfactorily perform any remedial work, or fail to compensate the Department for any emergency remedial work performed by the Department, as determined by the CRT to be the Contractor's responsibility (as expanded in Section 16.6), the Department shall suspend, revoke, or deny the Contractor's certificate of qualification until full and complete payment for the remedial work (and/or emergency remedial work) is made to the Department by the Contractor or its surety. In no case shall the period of suspension, revocation, or denial of the Contractor's certificate of qualification be less than ${ }^{35}$ months.

\section{Section 16.8: EXCLUSIONS AND WAIVERS}

During the warranty period, the Contractor will not be held responsible for defects that are caused by factors unrelated to the Contractor's work. Such external factors which are beyond the control of the Contractor can be listed as 36. Other factors which are not listed here but which may be considered to be beyond the control of the Contractor will be considered by the Department on a case by case basis upon receipt of a written request from the Contractor.

\footnotetext{
${ }^{34}$ Insert: the percentage of the warranty bond which VDOT is willing to receive when declares default on the contractor for such issue.

${ }^{35}$ Insert: the number of months as decided by VDOT to be the minimum length of the period in which the Contractor's certificate of qualification is suspended, revoked, or denied.

${ }^{36}$ Insert: the complete list of the factors which are beyond the control of the contractor and which may cause defects on the asset item for which the warranty clause is developed.
} 


\section{Section 16.9: CONTRACTOR'S OPTION OF MAINTENANCE DURING THE WARRANTY PERIOD}

The intent of the Contract is for the Contractor to improve the ${ }^{37}$ asset item's overall condition rating during the contract term in an effort to provide its long term performance. It is also the intent of the Contract to provide a maintenance-free ${ }^{38}$ asset item during the warranty period. The Contractor may perform certain maintenance activities during the warranty period, but these maintenance activities are limited to the activities approved by the Department. To identify such maintenance activity needs, the Contractor may monitor the highway using nondestructive procedures. The Contractor shall not conduct any coring, milling, or other destructive procedures without prior approval by the Department.

\section{Section 16.10: DEPARTMENT'S RESPONSIBILITIES}

The Department (and/or its authorized agent) will be responsible for performing remedial work to correct the defects that are caused because of the factors that are beyond the control and without the fault or negligence of the Contractor (as expanded in Section 16.8).

The Department (and/or its authorized agent) will be responsible for the incident management and winter weather maintenance activities. These activities can be listed as 39.

The Department (and/or its authorized agent) will be responsible for performing emergency remedial work immediately if the Contractor is unable or refuses to perform such emergency remedial work (as expanded in Section 16.5).

The Department (and/or its authorized agent) will be responsible for monitoring the interstate highway system (that is maintained by the Contractor during the Contract Term) during the warranty period.

\footnotetext{
${ }^{37}$ Insert: the name of the asset item for which the warranty clause is developed

${ }^{38}$ Insert: the name of the asset item for which the warranty clause is developed

${ }^{39}$ Insert: the complete list of the incident management and winter weather maintenance activities that are applicable to the asset item for which the warranty clause is developed.
} 
The Department will be responsible for submitting to the Contractor the comprehensive report containing the results of the warranty compliance evaluations in a timely fashion (as expanded in Section 16.4).

The Department will be responsible for notifying the Contractor in a timely fashion as expanded in Section 16.4) of any remedial or emergency remedial work required to be performed by the Contractor. 


\subsubsection{An Example Warranty Clause for the "Paved Ditches" Asset Item}

This sub-section presents the warranty clause for the "Paved Ditches" asset item which is developed by using the warranty clause template that is presented in the previous sub-section. Thus, the developed warranty clause has the components (as discussed in Section 3.2, Section 3.3, and Section 3.4) that reflect the properties of the "Paved Ditches" asset item. In other words, the blanks within the warranty clause template have been filled in with the words and values which are representing not only the properties of the "Paved Ditches" asset item but also VDOT's expectations with respect to the "Paved Ditches" asset item. This is done to illustrate the process of developing different warranty clauses for different asset items. At certain sections, the blanks within the warranty clause template are filled in by using the values and approaches used in different states that are implementing the warranty concept. These states are Wisconsin, Ohio, Minnesota, and Florida. However, all of the blanks have not been able to be filled in (or filled in with some parameters that were identified in the previous chapter such as "W" and “Z”) due to the M.S. candidate's limited knowledge about VDOT’s expectations in certain issues at the time this warranty clause was developed.

As mentioned before for numerous times, the values used in developing the warranty clause for the "Paved Ditches" asset item just serve the purpose of forming guidelines and hence assisting VDOT in developing its warranty clauses for the performance based road maintenance contracts it will issue.

The warranty clause which is developed for the "Paved Ditches" asset item is presented on the following page. 


\section{ARTICLE XVI \\ WARRANTIES}

\section{WARRANTY FOR THE “PAVED DITCHES” ASSET ITEM}

\section{Section 16.1: GENERAL DESCRIPTION}

This document specifies the requirements for the Contractor to warrant the maintenance work it (the Contractor) has performed for the "Paved Ditches" asset item for a period of Z (Alternative 2) years.

The Contractor shall assume full responsibility for all the associated work specified in this Document for a period of $\underline{Z}$ (Alternative 2) years after the final acceptance of the Contract in accordance with the Section 11.3, including continued responsibility as to any defects discovered by the Department and as to which timely notice was provided within such warranty period until all such pre-existing defects are corrected.

\section{Section 16.2: WARRANTY BOND}

The Contractor shall provide a warranty bond which will be in effect for a minimum of the length of the warranty period which begins upon the final acceptance of the contract in accordance with the Section 11.3. The effective starting date of the warranty bond shall be the date of final acceptance. The warranty bond will be released at the end of the warranty period or after all warranty remedial work has been completed, whichever is latest.

The surety of the bond shall be a surety company authorized to transact business in the State and shall have A.M. Best unit rating not less than "A" throughout the warranty period. If the A.M. Best unit rating of the surety company drops below "A", then the Department will Needs to be determined by VDOT according to its expectations and procedures

The warranty bond(s) will be N Needs to be determined by VDOT according to its

experience with the "Paved Ditches" asset item _. The bonds will ensure the proper and prompt completion of required remedial work, including payments for all labor performed, and all equipment and materials used. 
The warranty bond(s) will be provided in one of the following manners:

1. A single term Z Z (Alternative 2) year warranty bond.

2. A Needs to be determined by VDOT according to its expectations and procedures year renewable, non-cumulative warranty bond for Depends on the first part of this sentence consecutive terms.

Whichever option the Contractor chooses, the Contractor will provide documentation which can act as a proof of $\underline{Z}$ (Alternative 2) year bond commitment before the execution of the contract.

No separate Subcontractor bond is required. However, the bond(s) provided pursuant to this section will cover any work, no matter whether it is performed by the Contractor or any Subcontractor that is employed by the Contractor to perform a part or whole parts of the maintenance work during the contract term.

\section{Section 16.3: WARRANTY COVERAGE AND WARRANTY CRITERION}

Warranty criterion is established by using the parameters that are listed in Table 1.

Table 1: Warranty Criterion

\begin{tabular}{|c|c|c|c|}
\hline Asset & Outcome & $\begin{array}{l}\text { Performance Target } \\
\text { (\% of asset that shall be in } \\
\text { the outcome described } \\
\text { condition) }\end{array}$ & $\begin{array}{l}\text { Condition assessment } \text { acceptance } \\
\text { tolerances and criteria (Service Delivery) }\end{array}$ \\
\hline $\begin{array}{l}\text { Paved } \\
\text { Ditches }\end{array}$ & $\begin{array}{l}\text { Aligned } \\
\text { Structurally sound } \\
\text { Clean }\end{array}$ & $90 \%$ & $\begin{array}{l}\text { - }<1 \text { '” settlement } \\
\text { - no undermining or undercut requiring } \\
\text { action } \\
\text { - }<25 \% \text { spalled } \\
\text { - no obstruction to flow of water that } \\
\text { requires action }\end{array}$ \\
\hline
\end{tabular}




\section{Section 16.4: WARRANTY COMPLIANCE EVALUATIONS}

The Department (and/or its authorized agent) will conduct an inspection at the beginning of the warranty period which shall be completed in $30 \quad$ days. For the remaining years of the warranty period, the Department (and/or its authorized agent) will conduct annual inspections between June 15 and July 15 . The last inspection will be performed by the Department (and/or its authorized agent) just before the completion of the warranty period and shall be completed in 30 days. The methodology of these inspections will be same as the ones' that are conducted within the Evaluation Program that is defined in Section 2.18 and described in Exhibit $\mathbf{G}$ of the Contract.

The Department (and/or its authorized agent) will conduct these inspections at no cost to the Contractor. The Department shall notify the Contractor of the scheduled review. The Contractor or any other interested party may attend the inspections for observation purposes only. Any comments by the Contractor or other interested party may be recorded by the Department. A comprehensive report containing the results of the inspection and the remedial work (as expanded in Section 16.5) required from the Contractor shall be made available to the Contractor within 15 days after the completion of the inspection. The Department (and/or its authorized agent) shall use non-destructive procedures in performing the inspections. If destructive procedures are used by the Department, the Contractor will not be responsible for damages that result from coring, milling or other destructive procedures conducted by the Department.

The Department (and/or its authorized agent) may also conduct special evaluations on a more frequent basis in order to identify the emergency remedial work needs (as expanded in Section 16.5). If any emergency situation is discovered during these special evaluations, the Contractor shall be notified within $\quad 2 \quad$ hours upon the discovery of such situation.

As soon as the identified remedial work is completed (as expanded in Section 16.5), the Department (and/or its authorized agent) shall re-inspect the portions of the highway for which remedial work was required. 


\section{Section 16.5: REMEDIAL WORK}

During the warranty period, if the results of the warranty compliance evaluations reveal that the warranty criterion (as expanded in Section 16.3) is not met, and the Contractor agrees to the validity of the evaluation results, the remedial work, as identified to be necessary through the warranty compliance evaluations (that are expanded in Section 16.4), will be performed by the Contractor at no cost to the Department. The Contractor is free to implement any method in performing the remedial work. The Contractor is also free to choose any material to use in performing the remedial work. At all times the remedial work is performed, the Contractor shall follow a Department- approved traffic control plan.

The Contractor shall notify the Department and submit a written plan for performing the required remedial work within 15 ___ays after being notified by the Department for the remedial work required from it and before starting that remedial work, except in case of emergency remedial work as detailed in this section. The submittal shall only propose the schedule for performing the remedial work, no other information regarding the Contractor's remedial work need to be submitted by the Contractor. The times of the day for performing the remedial work shall be subject to the approval of the Department. The written plan shall be

approved by the Department within $\quad 7 \quad$ days upon the receipt of the written plan. The Contractor shall begin the remedial work upon the approval of its remedial work schedule.

The remedial work shall be performed by the Contractor to improve the asset item's overall condition sufficiently to meet the warranty criterion. The remedial work shall be completed within 30 days following approval of the Contractor's remedial work schedule by the Department. If the remedial work cannot be completed within $30 \quad$ days following approval of the Contractor's remedial work schedule by the Department due to seasonal limitations, the Contractor shall notify the Department in writing and determine a schedule for completion of the remedial work.

If the results of the warranty compliance evaluations reveal that the warranty criterion (as expanded in Section 16.3) is not met, but the Contractor does not agree to the validity of the evaluation results, the Conflict Resolution Procedures (which are expanded in Section 16.6) shall be implemented.

If, in the opinion of the Department, any portion of the highway which is covered by the warranty possesses emergency situations which require immediate attention for the safety of the 
traveling public, the Contractor shall be notified (as expanded in Section 16.4) to perform the emergency remedial work. Such situations which necessitate emergency remedial work can be listed as _. Needs to be determined by VDOT according to its experience with the "Paved Ditches” asset item . If the Contractor cannot perform the required emergency remedial work in 8 hours, the Department may have the work performed, at the Contractor's expense, by Department personnel and/or through a Department procurement. Any work thus performed will not alter the requirements, responsibilities, or obligations of the warranty. If the Contractor refuses to pay for such emergency remedial work depending on the grounds that the emergency situation was caused by factors beyond its control, the Conflict Resolution Procedures (as expanded in Section 16.6) shall be implemented.

If the remedial work performed by the Contractor necessitates the removal of asset items other than the one that is warranted under the Section 16.1 of this Contract, including but not limited to the pavement markings, pavement markers, adjacent lane(s), roadway shoulders, signs, and mile markers, then such asset items shall be removed and replaced at the Contractor's expense.

At the end of the warranty period, the Contractor will be released from further warranty work or responsibility, provided that all previously required remedial work has been completed.

\section{Section 16.6: CONFLICT RESOLUTION PROCEDURES}

A Conflict Resolution Team (CRT), which deals exclusively with the issues related to the warranty, will be established prior to the initiation of the warranty period to resolve any conflicts arising between the Contractor and the Department regarding the warranty requirements. This team will be composed of one representative appointed by the Contractor, one representative appointed by the Department, and an independent party mutually agreed upon by the Contractor and the Department. Decisions of the Conflict Resolution Team will be based on a simple majority vote. The Contractor and the Department acknowledge that use of the Conflict Resolution Procedures is required and the determinations of the Conflict Resolution Team for conflicts arising between them will be binding on both the Contractor and the Department, with no right to appeal by either party, for the purposes of this document. 
All Conflict Resolution Team meetings shall be initiated and paid for by the Contractor. The Department will reimburse the Contractor for all fees associated with meetings only if the Conflict Resolution Team rules substantially in favor of the Contractor, otherwise the Contractor shall be solely responsible for all such costs. The term "substantially" is defined as fifty percent of the issues when entitlement is disputed or fifty percent of the total dollar amount when costs associated with such entitlement are disputed.

The Conflict Resolution Procedures shall be initiated by the Contractor within 15 days after the comprehensive report containing the results of the inspection and the remedial work requested from the Contractor is made available to the Contractor (as expanded in Section 16.4). The CRT will evaluate the dispute. This evaluation may include inspecting the disputed area in the field. The evaluation may also include reviewing the inspection data, obtaining samples, and/or interviewing Department (District or Central Office) or Contractor employees. The CRT will receive the Maintenance Rating Program (MRP) training when it is determined necessary to perform an inspection to resolve the conflict. The CRT's determination(s) will be issued in writing to the Contractor and to the Department within 15 days after the Conflict Resolution Procedures are initiated by the Contractor.

If the Conflict Resolution Procedures are initiated for an emergency remedial work (as expanded in Section 16.5) that has already been completed by the Department (and/or its authorized agent), then the CRT shall determine whether the Contractor was responsible for that emergency remedial work or not. As a result of this determination, the CRT may direct the Contractor to pay the Department for the completed emergency remedial work.

\section{Section 16.7: DEFAULT ON THE CONTRACTOR}

Failure of the Contractor to submit its remedial work schedule within the specified period of time (as expanded in Section 16.5) shall be cause for the Department to complete the remedial work and recover the costs of such from the warranty bond.

Failure of the Contractor to initiate the Conflict Resolution Procedures within the specified period of time (as expanded in Section 16.6) shall be cause for the Department to complete the remedial work and recover the costs of such from the warranty bond. 
Failure of the Contractor to perform remedial work within the specified period of time (as expanded in Section 16.5) shall be cause for the Department to complete the remedial work and recover the costs of such from the warranty bond.

Failure of the Contractor to fully comply with the decisions of the Conflict Resolution Team (as expanded in Section 16.6) shall be cause for the Department to complete the remedial work and recover the costs of such from the warranty bond.

Failure of the Contractor or its surety to issue or renew the warranty bond (as expanded in Section 16.2) will be considered as a default and will result in forfeiture of $\underline{20}$ percent of the face amount of the bond to the Department.

Should the Contractor fail to timely submit any conflict to the CRT, fail to satisfactorily perform any remedial work, or fail to compensate the Department for any emergency remedial work performed by the Department, as determined by the CRT to be the Contractor's responsibility (as expanded in Section 16.6), the Department shall suspend, revoke, or deny the Contractor's certificate of qualification until full and complete payment for the remedial work (and/or emergency remedial work) is made to the Department by the Contractor or its surety. In no case shall the period of suspension, revocation, or denial of the Contractor's certificate of qualification be less than 6 months.

\section{Section 16.8: EXCLUSIONS AND WAIVERS}

During the warranty period, the Contractor will not be held responsible for defects that are caused by factors unrelated to the Contractor's work. Such external factors which are beyond the control of the Contractor can be listed as Extreme weather conditions, Fires, Traffic accidents or similar incidents that result in damage to the paved ditches, The problems introduced during the construction of the highway such as construction defects, Damages that result from destructive inspection procedures conducted by the Department - This list can be expanded or rearranged with the external factors that would cause defects in the "Paved Ditches" asset item as identified by VDOT . Other factors which are not listed here but which may be considered to be beyond the control of the Contractor will be considered by the Department on a case by case basis upon receipt of a written request from the Contractor. 


\section{Section 16.9: CONTRACTOR'S OPTION OF MAINTENANCE DURING THE WARRANTY PERIOD}

The intent of the Contract is for the Contractor to improve the “Paved Ditches” asset item's overall condition rating during the contract term in an effort to provide its long term performance. It is also the intent of the Contract to provide a maintenance-free "Paved Ditches" asset item during the warranty period. The Contractor may perform certain maintenance activities during the warranty period, but these maintenance activities are limited to the activities approved by the Department. To identify such maintenance activity needs, the Contractor may monitor the highway using non-destructive procedures. The Contractor shall not conduct any coring, milling, or other destructive procedures without prior approval by the Department.

\section{Section 16.10: DEPARTMENT'S RESPONSIBILITIES}

The Department (and/or its authorized agent) will be responsible for performing remedial work to correct the defects that are caused because of the factors that are beyond the control and without the fault or negligence of the Contractor (as expanded in Section 16.8).

The Department (and/or its authorized agent) will be responsible for the incident management and winter weather maintenance activities. These activities can be listed as

Needs to be determined by VDOT according to its experience with the "Paved Ditches" asset item .

The Department (and/or its authorized agent) will be responsible for performing emergency remedial work immediately if the Contractor is unable or refuses to perform such emergency remedial work (as expanded in Section 16.5).

The Department (and/or its authorized agent) will be responsible for monitoring the interstate highway system (that is maintained by the Contractor during the Contract Term) during the warranty period.

The Department will be responsible for submitting to the Contractor the comprehensive report containing the results of the warranty compliance evaluations in a timely fashion (as expanded in Section 16.4). 
The Department will be responsible for notifying the Contractor in a timely fashion as expanded in Section 16.4) of any remedial or emergency remedial work required to be performed by the Contractor. 


\section{CHAPTER 5}

\section{PHASE 4- EVALUATION PHASE}

As discussed while presenting the methodology of this research, the warranty clause template developed in the Solution Phase is reflecting the outcomes that are achieved through the subjective analysis of the observations, as performed by the M.S. candidate. Thus, the warranty clause template presented in Chapter $\mathbf{4}$ can be regarded as the first draft that is to be evaluated by the panel of experts. This evaluation process forms the evaluation phase of the research which is presented in this chapter. The final form of the developed warranty clause template, as enhanced after the evaluation phase, is presented in Chapter 6.

\subsection{THE NEED FOR AND THE COMPOSITION OF THE PANEL OF EXPERTS}

Due to the fact that this research has a qualitative nature, the researcher, after observing and analyzing the situations related to the subject matter through an intense literature review, proposes subjective ideas as he believes to be the best solution to the identified problem (Burrell and Morgan 1979). However, as an essential part of the qualitative research, these ideas need to be evaluated by the experts in order to minimize (or at best to completely avoid) the subjectivity which may act as a major drawback present in the achieved solution. Due to the content of this research, these experts needed to be the individuals who are experienced and knowledgeable in the warranty field.

The M.S candidate, therefore, has spent a fair amount of time to identify the members of the panel of experts who are supposed to be professionals that are highly involved in highway construction and maintenance projects and who also have sizeable knowledge in the administration of warranties. The developed warranty clause template needed to have the input of the two most important participants of any highway construction and maintenance project. These participants are the State DOT (as the owner), and the contractor. Especially, given the

different discussions and problems related to the implementation of warranties in the highway construction/maintenance projects as raised by the contracting industry, the contractors' 
opinions about the developed warranty clause template were believed to be invaluable. The other important project participant, i.e. the designer or the architect was not included in this panel, due to the fact that the developed warranty clause template is applicable to the performance based road maintenance projects in which the contractor is also responsible for the design. In addition to these project participants, the input to be obtained form the academic environment was deemed by the M.S candidate as indispensable. For this reason, professors within the academia that have been performing research about the highway warranties since the inception of the concept within the United States were also chosen as the potential members of the panel of experts. And, as the vital member of the panel, a representative of VDOT, who is familiar with the VDOT issued performance based road maintenance contracts for which the warranty clause template is developed, was also included to comment on the specific questions that were directed as a part of this research. For the purposes of confidentiality, the names of these individuals will not be provided throughout this write-up. Nonetheless, in an effort to alleviate the reader in understanding the content and context of the comments received from the panel and in order to clarify the discussions presented within the rest of this chapter, every individual is assigned a code. The list of the assigned codes of the individuals as decided to be the members of the panel of experts and who accepted to be so is provided in Table 5.1. The code of the provider of the feedback which is discussed within a particular section of the text will be italicized and bolded.

Table 5.1: The list of the individuals included in the panel of experts

\begin{tabular}{|c|c|}
\hline Area & Code \\
\hline \hline \multirow{3}{*}{ Academia } & Academic 1 \\
\cline { 2 - 2 } & \\
& Academic 2 \\
\hline \hline \multirow{3}{*}{ State DOT } & $\begin{array}{c}\text { VDOT } \\
\text { Representative }\end{array}$ \\
\hline \hline Contracting & Contractor 1 \\
\cline { 2 - 2 } Industry & Contractor 2 \\
\hline
\end{tabular}




\subsection{THE METHODOLOGY USED IN PERFORMING THE EVALUATION PHASE}

This section presents the means of conducting the Evaluation Phase of this research. After the members of the panel were determined, a document consisting of three sections was sent to the each member. The first section of the document was designed to act as a memorandum discussing very briefly the rationale behind developing warranty clauses for VDOT issued performance based road maintenance contracts, reasons of conducting the evaluation phase, and the approaches used in establishing the warranty criterion and the length of the warranty period present in the developed warranty clause template. The second section of the document contained the warranty clause template (which is a self contained document with the related explanations presented in footnotes) to be evaluated by the panel of experts. The last section of the document contained the general (Part A) and more specific (Part B) questions that were posed to the panel to receive professional feedback which is to be used in enhancing the developed warranty clause template. The document which was sent to the panel is provided in the Appendix $\mathbf{H}$.

The abovementioned methodology of conducting the Evaluation Phase by means of individual communications rather than arranging a panel meeting was chosen particularly due to two reasons. Main reason was the difficulty of bringing various professionals together at a particular time. The second reason was to avoid the potential of the panel members influencing others in a group meeting setting. Thereby, in an effort to receive individual opinions, Evaluation Phase was conducted through individual communications.

\subsection{FEEDBACK OBTAINED FROM THE PANEL OF EXPERTS}

Although not every member of the panel of experts commented on each question posed to them, overall the feedback received from the panel was very detailed and can be said to be invaluable for the prospects of this study. This section provides the responses, opinions and extra comments received from the panel of experts. For this, the focus (i.e. the subject matter) of each question that is posed to the panel is presented in a sub-section and the responses, comments and further discussions gathered for that question are presented underneath that sub-section. 


\subsubsection{Responses to the General Questions}

This sub-section presents the general questions that were directed to the panel of experts and the received responses for those questions.

\subsubsection{Completeness of the Warranty Clause Template}

Overall, the feedback from the panel for the completeness of the warranty clause template was positive. The majority of the members stated that they deemed the warranty clause template as complete. There was one comment received from Academic 1 which suggested that a definite time frame should be given for VDOT to re-inspect the portions of the highway once the remedial work is performed by the contractor. This comment has been taken into consideration and such language is added to the last paragraph within Section 16.4 of the warranty clause template.

\subsubsection{Validity of the Language Used within the Warranty Clause Template}

For this subject matter, majority of the members have stated that they were contented with the legality of the language used within the warranty clause template. Academic 2, on the other hand, has expressed his concern for the usage of the language within some sections of the template. Within his written comment, he has stated that in several cases the language used is somewhat non-conventional. He has also suggested checking this with the VDOT personnel to ensure the language's consistency with the Department's specification format and style. Nonetheless, since the VDOT Representative has deemed the language as legal and appropriate, the M.S. candidate believes that this is not an area of concern at all.

\subsubsection{Risk Allocation}

For this issue, in which the panel was requested to evaluate the warranty clause template for the risk implications on VDOT and on the contractor, Academic 2 clearly stated that the risk allocation is heavily weighed toward the contractor. Nonetheless, he has also affirmed that this is the case for most of the warranty specifications which causes the contractor to struggle in assessing its total risk and which eventually is likely to reflect in high bid prices. Just as in the case of the validity of the language used within the template, the VDOT Representative has 
deemed the risk allocation as fair and as it needs to be for a warranty clause (performance warranty) which is developed for a performance based road maintenance contract.

One of the members of the panel, Contractor 1, has suggested some minor language changes (to be introduced into the warranty clause template) which would decrease the risk imposed upon the contractor and thus which would allocate the risk fairly among VDOT and the contractor. These suggestions will be listed and discussed in detail in Sub-section 5.3.3. The same individual has also stated that if the contractor performs the maintenance work during the contract term as it should do, then the warranty clause imposes no risk on the contractor at all due to the approach by which it defines the length of the warranty period (i.e. using normal deterioration curves). The M.S. candidate believes that particularly this comment shows that the M.S candidate has been successful in his endeavor of the development of a fair warranty clause notion which led to the establishment of Alternative 2 and Alternative 3 as viable alternatives for the length of the warranty period.

\subsubsection{Different Warranty Clause for Each Asset Item}

The concept of developing different warranty clauses with different warranty criterion and different warranty period for each asset item has been acknowledged by all members of the panel of experts. Specifically, one of the contractors (Contractor 1) has stated that although it may require a massive data collection, monitoring, and enforcement effort, with today's technological advancements these efforts can easily be overcome. He has also asserted that due to VDOT's crucial need to economize by refocusing its mission from "hands on maintenance” to managing its assets (which is the case for the VDOT issued performance based road maintenance contracts) taking each asset item into consideration separately is very imperative.

One member of the panel (Academic 1) has emphasized the fact that this concept of developing different warranty clauses for each asset item needs to be implemented carefully. He has furthermore stated that in Wisconsin the same concept is being evaluated by WisDOT. 


\subsubsection{Responses to the Specific Questions}

This sub-section presents the specific questions that were directed to the panel of experts and the received responses for those questions.

\subsubsection{Definition of Defect and Establishment of the Warranty Criterion for each} Asset Item

For this particular issue, the Contractor 1 and the VDOT Representative have approved the approach used in establishing the warranty criterion. The Contractor 1, after going through the memorandum and examining the particular "Paved Ditches" example, has reckoned the approach to be reasonable. The VDOT Representative has noted that, although the approach in defining the warranty criterion is reasonable, it does not necessarily have to be the final version. He has stated that warranty criterion may also be established during the negotiations with the contractor within the Request for Proposal (RFP) process. Academic 2, without commenting on the approach, has underlined the fact that whatsoever approach is used in establishing the warranty criterion, the major challenge to overcome is making the criterion meaningful, measurable, and clearly understandable.

\subsubsection{Evaluation of Alternatives Used in Establishing the Length of the Warranty Period}

This question is the one which brought responses and detailed discussions from every member of the panel. These responses are as follows:

The Academic $\mathbf{1}$ has stated that using Alternative $\mathbf{1}$ for establishing the length of the warranty period is unreasonable given the impossibility of bringing the asset item's overall condition rating up to $100 \%$. He has considered Alternative 2 to be more reasonable given the fact that the value "A" is less than $100 \%$. However in the bottom line, he has deemed Alternative 3 to be the most appealing one given that VDOT selects the length of the warranty period. He has asserted that, Alternative 3 is also reasonable in the sense that VDOT can depend on deterioration curves to perform a back calculation to figure out the value of the overall condition rating required at the end of the contract (for the contractor to be able to meet the warranty criterion throughout the warranty period.) 
The Academic 2 has also judged Alternative 3 to be more viable than the other two. As the main reason for this, he has emphasized that the unavailability of the good data to establish the deterioration curves renders both Alternative 1 and Alternative 2 (both of which heavily depend on the usage of such curves) impractical. He has further noted that, relying on the professional judgment of VDOT personnel, rather than relying on these curves is more preferable.

The VDOT Representative commented that providing a warranty using Alternative 1 to establish the length of the warranty period may result in very costly bid prices for a performance based road maintenance project, making this alternative unfeasible. He has also considered Alternative 2 to be costly. He has deemed Alternative 3 to be the best for roadway assets, especially for the short life cycle assets for which the length of the warranty period can be determined by the judgment of the experienced VDOT personnel.

The Contractor 1 refused the implementation of Alternative 1 stating that an asset can never be as good as new unless it is new. Within the context of his discussion, he has considered Alternative 3 to be the most viable alternative.

The Contractor $\mathbf{2}$ has also deemed Alternative 1 very unreasonable and unrealistic due to the difficulties for a contractor to improve the asset item's overall condition rating up to $100 \%$, making its state as new as just (newly) constructed.

\subsubsection{Approaches in Determining the Value of " $A$ " and the Value of " $W$ "}

Only two members of the panel addressed this question by suggesting possible approaches. Academic 1 has suggested the usage of either actual (previous and similar) data or predictive models. The VDOT Representative stated that the value "A" and "W" needs to be determined by VDOT by considering what level of performance they desire from the asset and how long they can expect that performance to last.

\subsubsection{Defining Emergency Situations}

For this issue, the majority of the panel members has agreed on defining the emergency situation as a situation creating an imminent threat to the public safety. Nonetheless, there have also been some other suggestions brought up by the individuals.

The Academic 1 suggested that, in defining the emergency situations, VDOT should select highway failures and conditions which pose immediate concern for public health, safety, and 
welfare. In addition to this, he has stated that emergencies can also include situations which result in the reduction of the capacity of the roadway system. To him, emergencies are the situations which require the system to be put back in full operation in the shortest time and with minimal disruption to the public.

The VDOT Representative suggested that in defining the emergency situations, VDOT should look for asset item conditions which put the public or the agency in harms way. He underlined the fact that this needs to be determined on an asset by asset and case by case basis.

\subsubsection{Time to Complete Remedial Actions and Emergency Remedial Actions}

The Academic 1 suggested that in establishing the times to complete remedial actions and emergency remedial actions, VDOT should get the input of prospective contractors. He stated that, there should be two or three classes of response times to consider different types of remedial actions and emergency remedial actions that may be required to fix an asset. These classes should be established in balance with the cost to perform the remedial work. He asserted that VDOT should be extremely cautious for this issue in an effort to avoid establishing very long periods for remedial actions which would make the contractor very flexible in performing the remedial actions. In other words, this can make the contractor delay the work to the end of such period where the asset would have incurred damage that cannot be remediable (reversible).

The Contractor 1 has suggested different approaches that can be implemented to determine the time frames required to complete remedial actions and emergency remedial actions. He suggests that rather than establishing specific times for the remedial actions, VDOT should establish a dollar value that needs to be paid by the contractor for the time interval in which the defective asset item (which did not meet the warranty criterion established for it) is non-performing, i.e. not meeting the warranty criterion. This approach of linking the time frame to complete the remedial actions to a specific penalty to be paid by the contractor, in a sense, is a disincentive which would most probably make the contractor complete the remedial actions as soon as possible. For the establishment of the time frame to complete the emergency remedial actions, his approach suggests the determination of a "quickest practicable response" to be made by VDOT. In implementing this approach, VDOT should start with a hypothetical case in which all required personnel, materials, and equipment for the contractor to perform the required emergency remedial actions are immediately available (at "roadside" or at predetermined 
“maintenance/staging depots”). Then, VDOT should evaluate various scenarios and establish a possible list of response times per asset item. Within the context of this approach, VDOT should come up with time frames which are greater than its own crews' expected response times for incident management given the fact that after the completion of the contract term, the contractor's crews would not be readily available (as opposed to the VDOT's crews) in the portions of the highway it had maintained during the contract term.

\subsubsection{Time Frames for Conflict Resolution Procedures}

All of the members of the panel have agreed on the importance and necessity of the presence of Conflict Resolution Procedures during the warranty period.

The VDOT Representative suggested that in establishing the specifics (i.e. procedures, time frames etc...) of Conflict Resolution Procedures, using the same standards stated in the VDOT Road and Bridge Specifications book would be appropriate.

The Contractor 1 emphasized that the time frames for the Conflict Resolution Procedures should be short. He has suggested the initiation of the Conflict Resolution Procedures by the contractor be within five days of receipt of comprehensive report containing the results of the inspection and the remedial work required from the Contractor. He has furthermore suggested that the Conflict Resolution Team should rule within thirty days after the initiation of the Conflict Resolution Procedures.

\subsubsection{Establishing Bond Amount using the "Most Expensive Reasonable Remedy” Approach}

The Academic 1 stated that the process of calculating the cost of the most expensive reasonable remedy requires the input of the construction industry along with the range of possible choices. He has suggested making use of the past experience of VDOT for this issue. The Contractor 1 suggested the cost of the most expensive reasonable remedy be, theoretically, the $100 \%$ of the contract amount. 


\subsubsection{Option of the Contractor to Implement Maintenance Activities During the Warranty Period}

All of the members of the panel that have answered this question were in complete agreement with the concept of giving the contractor the option of implementing maintenance activities during the warranty period. Individuals' comments are as follows:

The Academic 1 emphasized that allowing the contractor to proactively perform maintenance work during the warranty period is a must. He has stated that it is a well established fact in the construction industry that proactive maintenance increases the life of an asset whereas waiting until failure is a costly approach to manage an asset.

The VDOT Representative, by stating that VDOT does not want a contractor to sit by and merely perform maintenance when an asset item has failed, underlined the view of VDOT which calls for the contractor to be proactive so that asset items never or seldom fail.

\subsubsection{Extra Comments and Suggestions made by the Panel of Experts}

In addition to answering the questions posed to them, the members of the panel of experts have also made some suggestions and introduced some extra comments as they deemed necessary to address the issues related to the developed warranty clause template or the concept of developing warranties for VDOT issued performance based road maintenance contracts in general. This sub-section presents these extra comments and suggestions brought up by the panel. The reason for the M.S candidate to include these comments in this chapter is to assist VDOT to benefit from these comments as well as to benefit from the findings of this research.

The Academic 1 emphasized the importance of allocating the risk to the party which is able to better manage and control that risk. He stated that the main purpose of the proposed warranty clause is to decrease the risk imposed upon VDOT. However, in trying to accomplish this, if VDOT cannot identify and quantify the risk and thus allocates too much risk on the contractor, then it will end up paying more for its warranty projects. He has also stated that the cost to administer warranties (i.e. warranty compliance evaluations) needs to be considered. He has suggested the use of a concept so called "lane rental charge" in which the contractor is charged a certain dollar amount for the time interval it creates a traffic disruption (while performing the remedial work). For the issue of exclusions and waivers, he has asserted that even though the exclusions are listed in Section 16.8 of the developed warranty clause template, the 
cause of the non-performance or failure is not clear cut and is therefore likely to be debated. As a conclusion to his feedback, the Academic 1 underlined the fact that developing warranty clauses is an incremental process which begins with a reasonable approach that has the potential of achieving success. With time, the components of the warranty clause (i.e. warranty criterion, length of the warranty period, specifics of the remedial actions etc...) can change with the added experience.

The Academic 2 has stated that establishing answers to the specific questions discussed in Sub-section 5.3.2 is the most important task in accomplishing to develop warranty clauses for VDOT issued performance based road maintenance contracts. He has further suggested that this task needs to be left to the professional judgment of the VDOT personnel.

The VDOT Representative stated that the concept of developing warranty clauses for VDOT issued performance based road maintenance contracts is a very good concept and developed warranties can be considered to be incorporated into the future performance based road maintenance contracts issued by VDOT. He has also added that he is very fond of the fact that such warranties would make the contractor improve the asset items' overall conditions rather than just maintaining them at certain levels.

The Contractor 1 mentioned that while listing the exclusions and waivers in Section 16.8 of the developed warranty clause template, VDOT should include the pre-existing subsurface conditions in addition to the Acts of God. He, furthermore, asserted that trying to address the issue of pre-existing subsurface conditions would really be challenging for VDOT.

The Contractor 2 asserted that VDOT has a right to expect its asset management contracts to solve some of its ongoing maintenance problems and hence most probably VDOT will be using warranty clauses in its road maintenance contracts to solve those problems before long. He has also emphasized that, bonds longer than two years are getting harder to secure. Given the fact that only the largest contractors can obtain such bonds, requiring long warranty periods may result in the absence of smaller contractors and DBEs (Disadvantaged Business Enterprise) from such contracts with warranties. As a comment for the exclusions and waivers section (Section 16.8) within the developed warranty clause template, the Contractor 2 stated that such exclusions and waivers should be stated clearly and hence be very specific because otherwise there can be many conflicts between VDOT and the contractor resulting from the allocation of the defect responsibility to the contractor. 


\subsection{SUGGESTIONS FOR CHANGES IN THE LANGUAGE OF THE DEVELOPED WARRANTY CLAUSE TEMPLATE}

Some members of the panel have suggested some minor changes to be made within the language used in the developed warranty clause template. These suggestions, the discussions of the M.S. candidate related to these suggestions, and the actions taken in the actual warranty clause template (whether the change was introduced to the clause or not) are presented in Table 5.2.

Table 5.2: Language change suggestions made by the panel of experts and the action taken

\begin{tabular}{|c|c|c|}
\hline Language change suggestion & Discussion & Action Taken \\
\hline $\begin{array}{l}\text { Section 16.1- The portion within the } \\
\text { second paragraph which reads as “... } \\
\text { including continued responsibility as to } \\
\text { any defects ...” should be replaced to } \\
\text { read as “... including continued limited } \\
\text { responsibility as defined in the contract } \\
\text { as to defects ...” }\end{array}$ & $\begin{array}{l}\text { This would be a legitimate } \\
\text { modification to explicitly } \\
\text { and more clearly limit the } \\
\text { responsibility of the } \\
\text { contractor to the cases in } \\
\text { which defects are attributable } \\
\text { to the contractor as defined } \\
\text { in other sections of the } \\
\text { clause. }\end{array}$ & $\begin{array}{l}\text { The portion in discussion is } \\
\text { amended as “... including } \\
\text { continued responsibility } \\
\text { (excluding the responsibilities } \\
\text { as set forth in Section } \mathbf{1 6 . 8} \text { and } \\
\text { in Section 16.10) as to } \\
\text { defects ...” The suggested } \\
\text { change is done in this way to } \\
\text { make it more specific to the } \\
\text { warranty clause. }\end{array}$ \\
\hline $\begin{array}{l}\text { Section 16.4- A time frame should be } \\
\text { given for VDOT to re-inspect the work } \\
\text { once the remedial action is performed. }\end{array}$ & $\begin{array}{l}\text { This would be a good } \\
\text { addition to the clause making } \\
\text { the clause more explicit and } \\
\text { specific. }\end{array}$ & $\begin{array}{l}\text { Such language is added to the } \\
\text { end of Section } 16.4 \text {. }\end{array}$ \\
\hline $\begin{array}{l}\text { Section 16.5- The contractor should not } \\
\text { be allowed to select the method that it } \\
\text { wishes to implement in performing the } \\
\text { remedial work. Rather, VDOT should } \\
\text { define the method for the contractor to } \\
\text { implement in performing the remedial } \\
\text { works. }\end{array}$ & $\begin{array}{l}\text { The developed warranty is a } \\
\text { performance warranty } \\
\text { developed for a performance } \\
\text { based contract, the essence } \\
\text { of which is to leave the } \\
\text { contractor free in choosing } \\
\text { its methods and materials } \\
\text { while performing } \\
\text { maintenance. }\end{array}$ & $\begin{array}{l}\text { Suggested change is not } \\
\text { introduced to the clause due to } \\
\text { the stated reason. }\end{array}$ \\
\hline $\begin{array}{l}\text { Section 16.10- The portion in the fourth } \\
\text { paragraph which reads as "The } \\
\text { Department ... will be responsible for } \\
\text { monitoring the interstate highway } \\
\text { system (that ...) during the warranty } \\
\text { period ..." needs to be expressed more } \\
\text { clearly to define what is meant by the } \\
\text { phrase "monitoring the interstate } \\
\text { highway system." }\end{array}$ & $\begin{array}{l}\text { Rewriting the mentioned } \\
\text { phrase in a clear way would } \\
\text { resolve the problem. }\end{array}$ & $\begin{array}{l}\text { The portion is amended as } \\
\text { "The Department ... will be } \\
\text { responsible for monitoring the } \\
\text { interstate highway system } \\
\text { (that ...) to identify the } \\
\text { remedial work and emergency } \\
\text { remedial work needs (as } \\
\text { expanded in Section 16.4) } \\
\text { during the warranty period." }\end{array}$ \\
\hline
\end{tabular}




\subsection{OTHER CHANGES INTRODUCED TO THE WARRANTY CLAUSE TEMPLATE}

During the course of the review of the panel of experts, the M.S. candidate has continued to go through the developed warranty clause template and also continued to perform the literature review of the previously written warranty clauses (by state DOTs) in an effort to evaluate and enhance the warranty clause template that was sent out to the panel. Moreover, after the receipt of the feedbacks from the panel of experts, and after developing another draft of the warranty clause template considering those feedbacks, the M.S candidate has received some important advice and input about the legal language of the template. As a result of these, the M.S. candidate has introduced several alterations to the language of the developed warranty clause template. The M.S. candidate has also identified an entirely new section that needs to be inserted into the developed warranty clause template. The most profound alteration as well as the new section that needs to be inserted into the clause are presented in Table 5.3.

Table 5.3: The changes that need to be introduced to the warranty clause template as identified by the M.S. candidate and through the legal advice

\begin{tabular}{|l|l|}
\hline Before the change & After the change \\
\hline Section 16.6: The term "Conflict & $\begin{array}{l}\text { Section 16.6: That term is replaced with "Warranty Dispute } \\
\text { Resolution Procedures" is used. } \\
\text { Resolution Procedures". This is mainly due to the fact that the } \\
\text { Conflict Resolution Procedures, as worded in the warranty clause } \\
\text { template are quite different from the conflict resolution procedures } \\
\text { commonly used by VDOT in its contracts. Thereby, to make the } \\
\text { procedures peculiar to the warranty clause template (and hence to the } \\
\text { warranty period) as developed in this research, and to avoid possible } \\
\text { confusions that may arise because of the usage of the same terms for } \\
\text { different purposes, the term "Conflict Resolution Procedures" is } \\
\text { decided to be replaced with the term "Warranty Dispute Resolution } \\
\text { Procedures" within the developed warranty clause template. }\end{array}$ \\
\hline $\begin{array}{l}\text { There is not any section within } \\
\text { the clause which is related to the } \\
\text { subcontractors' responsibilities. }\end{array}$ & $\begin{array}{l}\text { Section 16.11 is inserted into the contract. It reads as: "The } \\
\text { Contractor warrants any work which includes the performance of its } \\
\text { Subcontractor. Upon receipt from VDOT of the notice for the } \\
\text { remedial work (and/or emergency remedial work) that is needed for } \\
\text { the maintenance work that was performed by any Subcontractor, the } \\
\text { Contractor shall be responsible for enforcing or performing such } \\
\text { remedial work (and/or emergency remedial work) in accordance with } \\
\text { the Sections written under the Article XVI of the Contract. }\end{array}$ \\
\hline
\end{tabular}




\section{CHAPTER 6}

\section{PHASE 5- ENHANCEMENT PHASE}

This chapter presents the final form of the developed warranty clause template, as enhanced after the evaluation phase. In an effort to reach this final form, the received feedback was analyzed to correct the deficiencies in the solution as identified by the panel of experts. Through this exercise, the solution is enhanced and thus the research is finalized. This final phase is the Enhancement Phase.

\subsection{THE FINAL FORM OF THE WARRANTY CLAUSE TEMPLATE}

The final form of the developed warranty clause template is presented on the following page. 


\section{ARTICLE XVI \\ WARRANTIES}

WARRANTY FOR THE “ ” ASSET ITEM

CONTRACT NO.

\section{Section 16.1: GENERAL DESCRIPTION}

This document specifies the requirements for Contractor to warrant the maintenance work it (Contractor) performed for the “ " 1 asset item for a period of 2 year(s)/month(s) ${ }^{3}$.

Contractor shall assume full responsibility for all work specified in this Document for a period of _ـ_ ${ }^{4}$ year(s)/month(s) after final acceptance of the Contract in accordance with Section 11.3 $\mathbf{3}^{5}$, including continued responsibility (excluding the responsibilities as set forth in Section 16.8 and Section 16.10) as to defects that are identified by the Department and as to which timely notice is provided within such warranty period until all such defects are corrected.

\section{Section 16.2: WARRANTY BOND}

Contractor shall provide a warranty bond for not less than the full warranty period, which commences upon final acceptance of the Contract in accordance with the Section 11.3. The effective starting date of the warranty bond shall be the date of final acceptance. The warranty

\footnotetext{
${ }^{1}$ Insert: the name of the asset item for which the warranty clause is developed.

${ }^{2}$ Insert: the length of the warranty period as identified (for the asset item for which the warranty clause is developed) using either Alternative 1 or Alternative 2 or Alternative 3.

${ }^{3}$ year(s) or month(s), whichever is applicable.

${ }^{4}$ Insert: the length of the warranty period as identified (for the asset item for which the warranty clause is developed) using either Alternative 1 or Alternative 2 or Alternative 3.

${ }^{5}$ Section 11.3 (which is under the Article XI of the current contract) establishes the completion of the Contract Term.
} 
bond will be released at the end of the warranty period or after all warranty remedial work has been completed, whichever is latest.

The surety of the bond shall be a surety company authorized to transact business in the Commonwealth of Virginia and shall have A.M. Best unit rating not less than " $\mathrm{A}$ "6 throughout the warranty period. If the A.M. Best unit rating of the surety company drops below “A”, then the Department shall have the right, which may be exercised at any time thereafter, but not the obligation to 7 .

The warranty bond(s) shall be in an amount not less than 8. The bonds shall ensure the proper and prompt completion of required remedial work, including payments for all labor performed, and all equipment and materials used.

The warranty bond(s) shall be provided in one of the following manners:

1. A single term ${ }^{9}$ year/month ${ }^{10}$ warranty bond.

2. A 11 year/month renewable, non-cumulative warranty bond for 12 consecutive terms.

\footnotetext{
${ }^{6}$ This is the rating that has been required for the performance bond (which only covers the Contract Term) of the current contract.

${ }^{7}$ Insert: a list of all of the steps that need to be taken if the A.M. Best unit rating of the surety company drops below the required rating as set forth in this section.

${ }^{8}$ Insert: the bond amount (for the asset item for which the warranty clause is developed) as established using the "most likely case" scenario.

${ }^{9}$ Insert: the length of the warranty period as identified (for the asset item for which the warranty clause is developed) using either Alternative 1 or Alternative 2 or Alternative 3.

${ }^{10}$ year or month, whichever is applicable.

${ }^{11}$ Insert: the monthly or yearly (whichever is applicable) intervals at which a non-cumulative warranty bond is required by VDOT.

${ }^{12}$ Insert: the number which is calculated by dividing the length of the warranty period as identified (for the asset item for which the warranty clause is developed) using either Alternative 1 or Alternative 2 or Alternative 3 to the monthly or yearly (whichever is applicable) intervals at which a non-cumulative warranty bond is required by VDOT.
} 
Regardless of the option chosen by Contractor, Contractor shall provide documentation evidencing proof of ${ }^{13}$ year/month bond commitment before the execution of the contract.

No separate subcontractor bond is required. However, the bond(s) provided pursuant to this section shall cover all maintenance work, no matter whether such work is performed by Contractor or a subcontractor at any tier that is employed directly or indirectly by Contractor to perform a part or whole parts of the maintenance work during the Contract Term.

\section{SECTION 16.3: WARRANTY COVERAGE AND WARRANTY CRITERION}

Warranty criterion ${ }^{14}$ is established by using the parameters listed in Table $\mathbf{1}^{15}$ below.

\section{Table 1: Warranty Criterion}

\begin{tabular}{|l|l|l|l|}
\hline Asset & Outcome & $\begin{array}{l}\text { Performance Target } \\
\text { (\% of asset that shall } \\
\text { be in the outcome } \\
\text { described condition) }\end{array}$ & $\begin{array}{l}\text { Condition assessment acceptance tolerances and } \\
\text { criteria (Service Delivery) }\end{array}$ \\
\hline & & \\
\hline
\end{tabular}

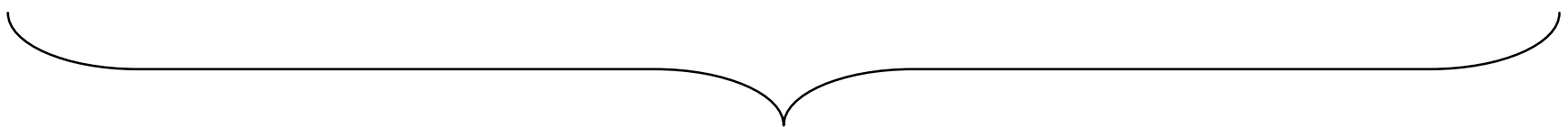

This table needs to be extracted from the Exhibit B of the current contract. The information within this table needs to correspond to the asset item for which the warranty clause is developed.

\footnotetext{
${ }^{13}$ Insert: the length of the warranty period as identified (for the asset item for which the warranty clause is developed) using either Alternative 1 or Alternative 2 or Alternative 3.

${ }^{14}$ Warranty criterion is established using the performance criteria and the performance target for the asset item for which the warranty clause is developed. Warranty criterion for any asset item can be stated as "meeting the performance criteria for at least equal or more than the performance target established for that asset item".

${ }^{15}$ Insert: Table 1 which lists the performance criteria and performance target (for the asset item for which the warranty clause is developed) that are established for the Contract Term within the Exhibit B of the current contract.
} 


\section{Section 16.4: WARRANTY COMPLIANCE EVALUATIONS}

The Department (and/or its authorized agent; referred to collectively hereafter in this Section 16.4 as "Department") will conduct an inspection at the beginning of the warranty period, which inspection shall be completed within 16 days from the warranty commencement date. For the remaining duration of the warranty period, the Department shall have the right, but not the obligation, to conduct additional periodic inspections between the warranty commencement date and the warranty expiration date. Notwithstanding the foregoing, in the event of a multi-year warranty, the Department will conduct at least one annual inspection during each year of the warranty term. The Department will conduct a final inspection within no more than ${ }^{17}$ days of the warranty termination date, which shall be completed within

${ }^{18}$ days of the warranty termination date. The methodology of these inspections will be same as those conducted within the Evaluation Program that is defined in Section $\mathbf{2 . 1 8}{ }^{\mathbf{1 9}}$ and described in Exhibit $\mathbf{G}^{\mathbf{2 0}}$ of the Contract.

The Department will conduct these inspections at no cost to Contractor. The Department shall notify Contractor of the scheduled review. Contractor (and any applicable subcontractor at any tier, material supplier, or surety; referred to collectively hereafter in this Section 16.4 as “Contractor") may attend the inspections for observation purposes only. Any comments by Contractor may be recorded by the Department. A comprehensive report containing the results of the inspection and the remedial work (as expanded in Section 16.5) required from Contractor shall be made available to Contractor within 21 days after the completion of the

\footnotetext{
${ }^{16}$ Insert: the number of days that is allowed for VDOT to complete the initial inspection. This time frame should be minimized to allow the Contractor to start remedial work as soon as possible.

${ }^{17}$ Insert: the number of days that is allowed for VDOT to begin the final inspection. This time frame should be minimized to allow the Contractor to start remedial work as soon as possible.

${ }^{18}$ Insert: the number of days that is allowed for VDOT to complete the final inspection. This time frame should be minimized to allow the Contractor to start remedial work as soon as possible.

${ }^{19}$ Section 2.18 defines the highway maintenance evaluation program that is implemented in the Contract Term in order to assess the work of the contractor during the Contract Term.

${ }^{20}$ Exhibit G describes in detail the highway maintenance evaluation program that is implemented in the Contract Term in order to assess the work of the contractor during the Contract Term.

${ }^{21}$ Insert: the number of days that is allowed for VDOT to prepare and submit the report possessing the results of the inspection. This time frame should be minimized to allow the Contractor to start remedial work as soon as possible.
} 
inspection. The Department will endeavor to use only non-destructive procedures in performing the inspections. However, in the event the Department elects to employ destructive testing procedures, Contractor will not be responsible for damages that result solely therefrom.

The Department may also conduct special inspections on a more frequent basis in order to identify any emergency remedial work needs (as expanded in Section 16.5). If any emergency remedial work is identified during these special inspections, Contractor shall be notified within 22 hours upon the discovery of such required emergency remedial work.

As soon as the identified remedial work is completed (as expanded in Section 16.5), the Department shall begin and, within ${ }^{23}$ days thereafter, complete a re-inspection of the item(s) for which the remedial work was required.

\section{Section 16.5: REMEDIAL WORK}

During the warranty period, if the results of the warranty compliance evaluations reveal that the warranty criterion (as expanded in Section 16.3) is not met, the remedial work, as identified to be necessary through the warranty compliance evaluations (that are expanded in Section 16.4), shall be performed by Contractor at no cost to the Department, subject to Contractor's right to challenge the Department's determination in accordance with Section 16.6 hereof. At all times remedial work is being performed, Contractor shall follow a Departmentapproved traffic control plan.

Contractor shall , prior to commencement of such remedial work, submit a written plan for performing the required remedial work within __ ${ }^{24}$ days after receipt of the Department's notification of required remedial work , except in case of emergency remedial work as detailed in this Section. Contractor's submittal need only to propose the schedule for performing the remedial work; no other information regarding Contractor's remedial work need to be submitted to the Department by Contractor. The times of the day for performing the remedial work shall be subject to the approval of the Department. The written plan shall be

\footnotetext{
${ }^{22}$ Insert: the number of hours that is allowed for VDOT to notify the contractor of the emergency situation. This time frame should be minimized to allow the Contractor to start emergency remedial work as soon as possible.

${ }^{23}$ Insert: the number of days that is required for VDOT to complete the re-inspections.

${ }^{24}$ Insert: the number of days for the Contractor to submit its schedule to perform the required remedial work.
} 
approved by the Department within ${ }^{25}$ days upon the receipt of the written plan. Contractor shall commence the remedial work promptly upon the approval of its remedial work schedule.

The remedial work shall be performed by Contractor to improve the asset item's ${ }^{26}$ overall condition sufficiently to meet the warranty criterion. The remedial work shall be completed within ${ }^{27}$ days following the Department's approval of Contractor's remedial work schedule. If the remedial work cannot be completed within ${ }^{28}$ days following the Department's approval of the Contractor's remedial work schedule due to seasonal limitations, Contractor shall notify the Department in writing and the Department and Contractor shall establish a mutually agreeable schedule for completion of the remedial work.

If Contractor does not agree the Department's reported inspection results, Contractor may initiate the Warranty Dispute Resolution Procedures as set forth in Section 16.6.

If, in the opinion of the Department, any portion of the highway covered by the warranty constitutes an emergency condition requiring immediate attention for the safety of the traveling public, Contractor shall be notified (as expanded in Section 16.4) to perform emergency remedial work. Conditions which necessitate emergency remedial work include, but may not be limited to 29. If Contractor cannot perform the required emergency remedial work within _ـ ${ }^{30}$ hours, the Department may have the work performed, at Contractor's expense, by the Department and/or its authorized agent. Any emergency remedial work performed by the Department and/or its authorized agent will not alter the requirements,

\footnotetext{
${ }^{25}$ Insert: the number of days for VDOT to approve the submitted schedule of the required remedial work. This time frame should be minimized to allow the Contractor to start remedial work as soon as possible.

${ }^{26}$ This is the asset item for which the warranty clause is developed.

${ }^{27}$ Insert: the number of days for the Contractor to complete all of the required remedial work related to the asset item for which the warranty clause is developed. This time frame should be minimized to restore the defective portions of the highway to their acceptable and safe conditions as soon as possible.

${ }^{28}$ Insert: the number of days for the Contractor to complete all of the required remedial work related to the asset item for which the warranty clause is developed.

${ }^{29}$ Insert: the complete list of the occasions that constitute an emergency situation for the asset item for which the warranty clause is developed.

${ }^{30}$ Insert: the number of hours for the Contractor to complete all of the required emergency remedial work related to the asset item for which the warranty clause is developed. This time frame should be minimized to prevent any safety issues that may arise due to these emergency situations.
} 
responsibilities, or obligations of the warranty. If Contractor believes it should not be responsible for the performance and cost of any such emergency remedial work based upon its belief that the emergency condition was caused by factors beyond its control, Contractor may initiate the Warranty Dispute Resolution Procedures as set forth in Section 16.6.

If the remedial work necessitates the removal of asset items other than the one that is warranted under Section 16.1 of this Contract, including, but not limited to, pavement markings, pavement markers, adjacent lane(s), roadway shoulders, signs, and mile markers, then such asset items shall be removed and replaced at Contractor's expense.

At the end of the warranty period, Contractor will be released from further warranty work or responsibility, provided that all previously required remedial work has been satisfactorily completed.

\section{Section 16.6: WARRANTY DISPUTE RESOLUTION PROCEDURES}

A Warranty Dispute Resolution Board (the "Board”) shall be established prior to the initiation of the warranty period to resolve any conflicts arising between Contractor and the Department regarding warranty requirements. The Board shall be composed of one representative appointed by Contractor, one representative appointed by the Department, and an independent party mutually agreed upon by Contractor and the Department. Decisions of the Board will be based on a simple majority vote. Contractor and the Department acknowledge that use of the Warranty Dispute Resolution Procedures is required and the determinations of the Board for conflicts arising between them will be binding on both Contractor and the Department, with no right to appeal by either party.

All Board meetings shall be initiated and paid for by Contractor. The Department will reimburse Contractor for all fees associated with any meeting of the Board only if the Board rules substantially in favor of Contractor; otherwise Contractor shall be solely responsible for all such costs. The term "substantially" is defined as greater than fifty percent of the issues when entitlement is disputed or greater than fifty percent of the total dollar amount when costs associated with such entitlement are disputed, or both. 
The Warranty Dispute Resolution Procedures shall be initiated by Contractor within ${ }^{31}$ days after the comprehensive report containing the results of the inspection and the remedial work required from Contractor is made available to Contractor (as expanded in Section 16.4). The Board shall meet within ___ ${ }^{32}$ days after Contractor's initiation of the Warranty Dispute Resolution Procedures to evaluate the dispute. The Board's evaluation may include inspecting the disputed area in the field. The Board's evaluation may also include reviewing the inspection data, obtaining samples, and/or interviewing Department (District or Central Office) or Contractor employees. The Board shall receive the Maintenance Rating Program (MRP) training when it is determined necessary to perform an inspection to resolve the conflict. The Board's determination(s) shall be issued in writing and shall be provided to Contractor and the Department within 33 days after the Warranty Dispute Resolution Procedures are initiated by Contractor, unless otherwise mutually agreed by Contractor and the Department.

If the Warranty Dispute Resolution Procedures are initiated for an emergency remedial work (as expanded in Section 16.5) that has already been completed by the Department (and/or its authorized agent), then the Board shall determine whether Contractor was responsible for that emergency remedial work. As a result of this determination, the Board may direct Contractor to pay the Department for the completed emergency remedial work.

\footnotetext{
${ }^{31}$ Insert: the number of days for the Contractor to initiate the Warranty Dispute Resolution Procedures. This time frame should be minimized to allow the Board to begin evaluating the conflict as soon as possible so that the responsible party (as identified through the Warranty Dispute Resolution Procedures) can perform remedial work to restore the defective portions of the highway to their acceptable and safe conditions as soon as possible. Moreover, this time frame should be same with the time frame required for the Contractor to submit its schedule (as expanded in Section 16.5) for the remedial work. This would enable VDOT to understand the intentions of the Contractor in the sense that whether it is planning to perform the remedial work or it is planning to initiate Warranty Dispute Resolution Procedures for the requested remedial work.

32 Insert: the number of days (after the initiation of the Warranty Dispute Resolution Procedures by Contractor) for the Board to meet in order to start the evaluation of the dispute. This time frame should be minimized to allow the Board to begin evaluating the conflict as soon as possible so that the responsible party (as identified through the Warranty Dispute Resolution Procedures) can perform remedial work to restore the defective portions of the highway to their acceptable and safe conditions as soon as possible.

${ }^{33}$ Insert: the number of days for the Board to arrive a decision about the conflict(s) for which the Warranty Dispute Resolution Procedures were initiated. This time frame should be minimized to make the Board reach a final decision as soon as possible so that the responsible party (as identified through the Warranty Dispute Resolution Procedures) can perform remedial work to restore the defective portions of the highway to their acceptable and safe conditions as soon as possible.
} 


\section{Section 16.7: DEFAULT ON CONTRACTOR}

Failure of Contractor to submit its remedial work schedule within the specified period of time (as expanded in Section 16.5) shall be cause for the Department to complete the remedial work and recover the costs of such from the warranty bond.

Failure of Contractor to initiate the Warranty Dispute Resolution Procedures within the specified period of time (as expanded in Section 16.6) shall be cause for the Department to complete the remedial work and recover the costs of such from the warranty bond.

Failure of Contractor to perform remedial work within the specified period of time (as expanded in Section 16.5) shall be cause for the Department to complete the remedial work and recover the costs of such from the warranty bond.

Failure of Contractor to fully comply with the decisions of Warranty Dispute Resolution Board (as expanded in Section 16.6) shall be cause for the Department to complete the remedial work and recover the costs of such from the warranty bond.

Failure of Contractor or its surety to issue or renew the warranty bond (as expanded in Section 16.2) will be considered as a default and will result in forfeiture of 34 percent of the face amount of the bond to the Department.

Should Contractor fail to timely submit any conflict to the Warranty Dispute Resolution Board, fail to satisfactorily perform any remedial work, or fail to compensate the Department for any emergency remedial work performed by the Department, as determined by the Board to be Contractor's responsibility (as expanded in Section 16.6), the Department may suspend, revoke, or deny Contractor's certificate of qualification until the remedial work has been satisfactorily performed or full and complete payment for the remedial work (and/or emergency remedial work) is made to the Department by Contractor or its surety. In no case shall the period of suspension, revocation, or denial of Contractor's certificate of qualification be less than 35 months.

\footnotetext{
${ }^{34}$ Insert: the percentage of the warranty bond which VDOT is willing to receive when declares default on the contractor for such issue.

${ }^{35}$ Insert: the number of months as decided by VDOT to be the minimum length of the period in which the Contractor's certificate of qualification is suspended, revoked, or denied.
} 


\section{Section 16.8: EXCLUSIONS AND WAIVERS}

During the warranty period, Contractor will not be held responsible for defects that are caused by factors unrelated to Contractor's work. Factors which are considered to be beyond the control of Contractor are as follows: ${ }^{36}$. Other factors which are not listed here but which may be considered to be beyond the control of Contractor will be considered by the Department on a case by case basis upon receipt of a written request from Contractor.

\section{Section 16.9: CONTRACTOR'S OPTION OF MAINTENANCE DURING THE WARRANTY PERIOD}

The intent of the Contract is for Contractor to improve the 37 asset item's overall condition rating during the Contract Term in an effort to provide its long-term performance. It is also the intent of the Contract to provide a maintenance-free 38 asset item during the warranty period. Contractor may perform certain maintenance activities during the warranty period, but these maintenance activities are limited to the activities approved by the Department. To identify such maintenance activity needs, Contractor may monitor the highway using non-destructive procedures. Contractor shall not conduct any coring, milling, or other destructive procedures without prior approval by the Department.

\section{Section 16.10: DEPARTMENT'S RESPONSIBILITIES}

The Department (and/or its authorized agent) will be responsible for performing remedial work to correct the defects that are caused because of the factors that are beyond the control and without the fault or negligence of Contractor (as expanded in Section 16.8).

\footnotetext{
${ }^{36}$ Insert: the complete list of the factors which are beyond the control of the contractor and which may cause defects on the asset item for which the warranty clause is developed.

${ }^{37}$ Insert: the name of the asset item for which the warranty clause is developed

${ }^{38}$ Insert: the name of the asset item for which the warranty clause is developed
} 
The Department (and/or its authorized agent) will be responsible for the incident management and winter weather maintenance activities. These activities can be listed as 39.

The Department (and/or its authorized agent) will be responsible for performing emergency remedial work immediately if Contractor is unable or refuses to perform such emergency remedial work (as expanded in Section 16.5).

The Department (and/or its authorized agent) will be responsible for monitoring the interstate highway system (that is maintained by Contractor during the Contract Term) to identify the remedial work and emergency remedial work needs (as expanded in Section 16.4) during the warranty period.

The Department will be responsible for submitting to Contractor the comprehensive report containing the results of the warranty compliance evaluations in a timely fashion (as expanded in Section 16.4).

The Department will be responsible for notifying Contractor in a timely fashion (as expanded in Section 16.4) of any remedial or emergency remedial work required to be performed by Contractor.

\section{Section 16.11: SUBCONTRACTOR'S RESPONSIBILITIES}

Contractor warrants any and all work, which includes the performance of its subcontractors at any tier. Upon receipt from VDOT of the notice for the remedial work (and/or emergency remedial work) that is needed for the maintenance work that was performed by a subcontractor at any tier, Contractor shall be responsible for enforcing or performing such remedial work (and/or emergency remedial work) in accordance with the Sections written under Article XVI of the Contract.

\footnotetext{
${ }^{39}$ Insert: the complete list of the incident management and winter weather maintenance activities that are applicable to the asset item for which the warranty clause is developed.
} 


\section{CHAPTER 7}

\section{CONCLUDING REMARKS}

This is the last chapter of this write-up which summarizes the discussions presented up to this point. It recapitulates the problem that is addressed and tried to be solved in this research, summarizes the major findings of this research, lists and briefly discusses the key principles used in developing the warranty clause template, presents the possible contributions made to the body of knowledge by this research and the importance of this study, talks about the advantages of VDOT, introduces some recommendations that could be useful for VDOT in implementing the warranty concept, and finally discusses areas that are related to the subject matter in which possible future research can be performed.

\subsection{SUMMARY}

This research developed a warranty clause template which is proposed to be used in the future performance based road maintenance contracts issued by VDOT. The main rationale behind developing this warranty clause template is to make the prospective contractors implement a maintenance philosophy which would provide improvement in the overall condition of each of the asset items they maintain during the contract term. More importantly, this maintenance approach is also believed to make it possible for those asset items to possess better long term performances. These two concepts, indeed, are the main goals of performance based asset management contracts, one example of which is the contract that was in the scope of this research.

In achieving the abovementioned goal of developing the warranty clause template, the M.S candidate has implemented a research methodology which is not very widely used in the research performed in the field of engineering. This methodology, in scientific terms, was an ideographic methodology which is utilized very commonly in performing the type of the research so called the qualitative research. Being a qualitative research, this research vastly depended on the extensive literature review performed by the M.S. candidate and the invaluable feedback 
received from various professionals who are highly acknowledged in the areas of highway construction and highway construction/maintenance warranties.

Achieving the final form of the warranty clause template was an iterative process. The M.S. candidate developed the template by means of adopting the principles and the language that were used in a number of contracts with warranties and then adapting those to meet the specific needs of the contract that was in the scope of this research. In order to be successful in this endeavor, adopting process called for an extensive literature review and the adapting process required a substantial understanding of the contract that was in the scope of this research. Specifically for the establishment of the length of the warranty period and for the establishment of the warranty criterion for each asset item, the M.S. candidate developed and proposed certain approaches that are peculiar to the contract type that was in the scope of this research. All of the components that should be present in a performance based road maintenance warranty clause were identified by the M.S. candidate and then finally the warranty clause template was developed. After the warranty clause template was developed, it was sent to the panel of experts (members of which were from different entities such as the State DOT, the contracting industry, and the academia) whose feedback was used in an effort to improve the context and the content of the clause for the objective of ensuring the impartiality of this clause. This whole process resulted in the final form of the warranty clause template as presented in the Chapter 6 of this write-up.

\subsection{FINDINGS OF THE RESEARCH}

As underlined numerous times previously, the M.S. candidate has made use of the literature review and thus the adoption and adaptation process frequently as required by the methodology of this research which had a qualitative nature. Nonetheless, the M.S. candidate has also developed certain new approaches and concepts which aided him in establishing the key components of the developed warranty clause template. Apart from the contributions that the developed warranty clause template has made to the body of knowledge (which will be discussed in Section 7.4), these developed new approaches and concepts can be regarded as the specific findings of this research which are used in achieving the sought solution, i.e. the warranty clause 
template for the performance based road maintenance contracts issued by VDOT. These specific findings are listed and discussed briefly in the following paragraphs:

1.) The concept of developing different warranty clause for each asset item: As one of the objectives of this research, the M.S. candidate has tried to make distinctions between the asset items (as far as a warranty clause is concerned) that are covered under the current VDOT performance based road maintenance contract. This endeavor acted as a baseline for him to be able to propose a different warranty clause to be developed for each asset item. This was mainly due to the fact that each asset item is unique and has its own properties defining its lifetime. Each asset item is exposed to different conditions causing it to deteriorate in different amounts when compared to other asset items. Moreover, some asset items have relatively higher importance than others as far as the road users' safeties are concerned. This concept of developing a different warranty clause for each asset item covered under the contract can be regarded as a quite new concept which is justified by the discussions that are presented in Section 3.5 of this write-up. Moreover, this proposed concept has been well received by the panel of experts (as mentioned in Sub-section 5.3.1.4) and thus can be regarded as one of the major findings of this research.

2.) The approach developed for defining defect and establishing the warranty criterion: One of the most important components of the developed warranty clause template is the warranty criterion. In fact, the warranty criterion can be regarded as the key component of the developed warranty clause template since it is the measure against which the contractor is evaluated for its warranty compliance with respect to each asset item. This research has proposed a very straightforward but also a very efficient approach for defining defect and establishing the warranty criterion (as presented in Section 3.2) for each asset item. The approach provides a fair and attainable warranty criterion for each asset item by using the performance criteria and performance targets which are already present in the current VDOT contract and thus which are already agreed upon by the Contractor and VDOT. Due to this fact, developing the warranty criterion for each asset item in the future contracts will require very little effort. Once VDOT establishes the performance target and performance criteria for each asset item to be used during the contract term, developing the warranty criterion for each 
asset item will become a quite simple task which requires just a little amount of language modifications. The warranty criterion established using the approach developed in this research is easily measurable. The most important aspect of the approach developed for establishing the warranty criterion is that it enabled the M.S. candidate to develop a legitimate approach in establishing the length of the warranty period. In other words, the approach used in developing the warranty criterion for any asset item is consistent with the approach used in establishing the length of the warranty period for that asset item. Moreover both approaches greatly serve the main purposes of this research which can be stated as decreasing the risk imposed on VDOT, improving the conditions of the asset items, and providing the long term performances of the asset items that are maintained by the contractor.

3.) The approaches developed for establishing the length of the warranty period: This research has developed three approaches (as described in detail in Section 3.3) that could be used to establish the length of the warranty period for each asset item. As identified in the literature review, there is neither any straightforward way, nor established guidelines to be used in determining the length of the warranty period. It was previously discussed that establishing the length of the warranty period is a crucial task that needs to be undertaken in developing a warranty clause. There are many factors that need to be considered in establishing the length of the warranty period. The most important one is to ensure that the established length is fair for

the contractor and the state DOT. In other words, the warranty period should be long enough for maintenance defects (if any present) to become apparent but not so long that the treatment will deteriorate through the normal use. In developing the approaches to establish the length of the warranty period, this research has tried to address this concept of fairness. Moreover it also tried to develop approaches which would result in the most optimum warranty period as far as the purposes (i.e. reduction of risk on VDOT, improvements in the conditions of the asset items, and long term performances of asset items) of this research are concerned. For these reasons, it can be asserted that the findings of this research in the issue of length of the warranty period are quite valuable. It is important to note that, of the three approaches developed in this research, Alternative 3 (as presented in Sub-section 3.3.3) is the one that has been acknowledged by all of the members of the panel of experts as discussed in Sub-section

\subsubsection{2.}




\subsection{KEY PRINCIPLES USED IN DEVELOPING THE WARRANTY CLAUSE TEMPLATE}

As presented in Chapter 6, this research developed a warranty clause template which contains blanks to be filled in by the related entities as opposed to developing a complete warranty clause. The main reason for the M.S. candidate to refrain from developing a complete warranty clause was the fact that such a complete warranty clause would very less likely be accepted as an end product and thus be implemented by VDOT. This is mainly due to the fact that, although the M.S. candidate has performed a good amount of research to gather information about VDOT's needs and expectations while developing the warranty clause template, such expectations are prone to change as time passes. This, in fact, is very analogous to the situation present in the standard forms of contract. The standard forms of contract prepared by the established entities such as AIA, EJCDC, and FIDIC have been evolving over decades and will continue to do so.

In conclusion, as stated numerous times throughout this write-up, the developed warranty clause template is by no means an end product. Nonetheless, regardless of the words and details that the developed warranty clause template possesses, the main goal in developing such a warranty clause template was to present VDOT an option it can implement to overcome the situations it may face in the absence of warranty clauses within its performance based road maintenance contracts. Thus, rather than elaborating too much on the language, this research has mainly focused on the components that should be present in a warranty clause in an effort to establish some key principles. As opposed to content and context/language which can be changed by VDOT from time to time, such principles should not be altered by any means. These principles that form the basis of the warranty clause template developed in this research are listed and discussed briefly below:

1.) The principle used in establishing the length of the warranty period (Section 16.1): This research has developed three alternatives (as described in detail in Section 3.3) that could be used to establish the length of the warranty period for each asset item. The main principle employed in establishing the length of the warranty period is the utilization of the deterioration curves. All of the three alternatives that are developed for establishing the 
length of the warranty period highly depend on the deterioration curve of the asset item for which the warranty clause is developed. VDOT may either choose the alternative to implement by itself or negotiate with the prospective contractors in deciding on which alternative to implement. VDOT may also develop a completely new alternative to establish the length of the warranty period. Nonetheless, in doing so, it should not ignore the main principle of utilizing the deterioration curves and come up with an arbitrary warranty period which is not supported by scientific fact and figures and thus which is meaningless, unattainable, and unfair. Such principle ensures that the established length is fair for the contractor and the state DOT. Moreover, it ensures that the warranty period is long enough for maintenance defects (if any present) to become apparent but not so long that the treatment will deteriorate through the normal use (as explained in Section 3.3). In other words, the principle of utilizing the deterioration curves for establishing the length of the warranty period results in the most optimum warranty period as far as the purposes (i.e. reduction of risk on VDOT, improvements in the conditions of the asset items, and long term performances of asset items) of this research are concerned.

2.) The principles used in defining the warranty bond (Section 16.2): A project with a warranty requires a warranty bond that would be valid for the warranty period in addition to the performance bond that is valid for the contract term. These two bonds would guarantee the contractor's work not only for the contract term, but also for the warranty period. As a principle, the developed warranty clause template is worded in such a way that it gives certain options to the contractor for furnishing the warranty bond. In other words, warranty clause template's bonding requirements are defined as flexible as possible in an effort to assist the contractors to overcome the burdens of securing warranty bonds (due to the issues presented in Sub-section 2.4.2.6). Another principle used within the warranty clause template is the notion of using “most expensive reasonable remedy to be applied in a most likely case scenario" for establishing the penal value of the warranty bond. One other very important principle which was used in the warranty clause template and which should be followed by VDOT in establishing the requirements for the warranty bonds is the time for the release of the warranty bond by VDOT. This time should not merely be the completion of the warranty period due to the fact that there may be some outstanding remedial works that need to be 
performed after the completion of the warranty period. Thus, in order for VDOT to have the benefits of the warranty bonds until the completion of all of the outstanding remedial works that have been found to be necessary by VDOT, the warranty clause should explicitly state that the time for the release of the warranty bond should be either the end of the warranty period or after all remedial work is completed, whichever is latest. Finally as a last principle, the warranty clause template defines the bonding company's rating as established within the A.M. Best Rating standards as a part of the warranty bonding requirement. In conclusion, in establishing the requirements of the warranty bonds, VDOT should, at a minimum, follow the abovementioned principles to make the requirements as fair, attainable, and clear as possible.

3.) The principle used in the establishment of the warranty criterion (Section 16.3): This research has proposed a very straightforward but also a very efficient approach for establishing the warranty criterion (as presented in Section 3.2) for each asset item. The principle and approach employed in developing the warranty criterion was chosen in such a way to make the warranty criterion fair, measurable and attainable by the contractor. For this, M.S candidate has used the performance criteria and performance targets which are already present in the current VDOT contract and thus which are already agreed upon by the Contractor and VDOT. If deems necessary, VDOT may negotiate the warranty criterion for each asset item with the prospective contractors and twist those criteria. Nonetheless, it would be beneficial for VDOT to follow the approach and principle developed by this research as much as possible to ensure the fairness of the warranty criterion.

4.) The principles used in defining the warranty compliance evaluations (Section 16.4): Warranty clauses should elaborate well enough on the warranty compliance evaluations in an effort to clarify the issues related to these evaluations as much as possible. The principles that were focused on as to be parts of the developed warranty clause template regarding the warranty compliance evaluations are as follows: The time frame for these evaluations should be minimized to allow the contractor to start the remedial work as soon as possible so that the defective portions of the highway are restored to their acceptable and safe conditions as soon as possible. The inspection scheme should be tested and known to be working. The warranty 
clause should explicitly state the need for the visual (windshield) and easy-to-perform (less detailed) inspections which would help VDOT in identifying the repair or replacement needs anytime in between the annual surveys to take care of the emergency and safety situations.

5.) The principles used in defining the remedial actions (Section 16.5): Warranty clauses should elaborate on the extent and content of the remedial actions and the time frame for the remedial actions. In the developed warranty clause template, the contractor is left completely free in implementing the remedial actions as far as the methods and materials it may choose are concerned and also there is not any approval process as far as the nature of the remedial actions are concerned since the contract that is in the scope of this research is a performance based contract. This is a principle that should be kept unchanged by VDOT in the future performance based road maintenance contracts (with warranties) it will issue. As another principle, the time frames for the contractor to complete the remedial actions should be minimized as much as possible in an effort to restore the defective portions of the highway to their acceptable and safe conditions as soon as possible. Another important principle that needs to be considered by VDOT is that the warranty clause should differentiate between the remedial action needs and emergency remedial action needs. The complete list of the occasions that constitute an emergency situation should be developed and then the emergency remedial action requirements (which are to be stricter than the remedial action requirements) need to be spelled out very clearly and specifically within the warranty clause.

6.) The principles used in defining the warranty dispute resolution procedures (Section 16.6): Warranty clauses need to have a section in which solutions for possible disputes that may arise between the entities (the state DOT and the contractor) during the warranty period are presented. The developed warranty clause template states the necessity of a board named as the “Warranty Dispute Resolution Board” which would address such disputes. The warranty clause template defines the composition of such a board and outlines the time frames for the warranty dispute resolution procedures. As a principle, such time frame is required to be minimized so that the responsible party (as identified through the warranty dispute resolution procedures) can perform remedial work to restore the defective portions of the highway to their acceptable and safe conditions as soon as possible. Regardless of the exact board name, 
board composition, and time frame VDOT chooses to implement for the warranty dispute resolution procedures, it should include such elements within Section 16.6 to ensure the completeness of this component of the warranty clause.

7.) The principles used in defining the contractor's default (Section 16.7): Contractor's default during the contract term is elaborated on within the current contract. Nonetheless, if VDOT chooses to incorporate warranty clauses into the contract, the actions to be taken in the case of the contractor's default during the warranty period should also be defined clearly. To accomplish this, the developed warranty clause template presents a list of certain items which can be deemed as defaults on the contractor and the actions to be taken in the case of presence of each item. VDOT may accept this list as is, or change the list. Nonetheless, it should follow the general principles used (including a list of items that can be deemed as defaults and the actions to be taken in the presence of such defaults) within the warranty clause template.

8.) The principles used in establishing the exclusions and waivers (Section 16.8): Warranty clauses certainly need to possess an "Exclusions and Waivers" section to relieve the contractor of meeting the warranty obligations in the cases where some external factors which are beyond the contractor's control are present. Given the unpredictable nature of these factors, the contractor should not be held liable for the defects occurring within the warranty period due to these factors. The main principle that should be used in establishing the "Exclusions and Waivers” section of a warranty clause is that the list of exclusions and waivers should contain all the external factors which may take place either before or after the contractor's maintenance work. Moreover, these exclusions and waivers must be stated very clearly in order to avoid different interpretations that may be possessed by different parties.

9.) The principle used in defining the contractor's option of maintenance during the warranty period (Section 16.9): This research suggests that the main intent of the warranty concept is to make the contractor improve the overall condition rating of each asset item during the contract term in an effort to make each asset item have better long term performance. It is also the main intent of the warranty concept (as proposed by this research) to provide a maintenance-free highway during the warranty period. Depending on this principle, the 
warranty clause template states that the contractor is given the right to perform certain (minimal amount of) maintenance activities during the warranty period. These activities are limited to the activities approved by VDOT. To follow the abovementioned principle, M.S. candidate believes that VDOT should be very selective in deciding on the maintenance work that the contractor is allowed to perform during the warranty period and thus only approve minimal maintenance work as the allowable maintenance work for the warranty period. Such approval process may prevent the contractor from doing any major or capital maintenance work during the warranty period which somehow contradicts the rationale behind the warranty concept (as discussed in detail in Section 3.1) as proposed by this research.

10.) The principles used in defining VDOT's responsibilities (Section 16.10): As soon as the contract term is completed and until the completion of the warranty period, highway asset items are under the responsibility of the contractor. In other words, the contractor is liable in the case of warranty criterion non-compliance and thus needs to perform remedial actions. Nonetheless, the contractor cannot be held responsible to perform certain kinds of maintenance activities (as discussed in Sub-section 3.4.9): Incident management and winter weather maintenance activities. Hence, the developed warranty clause template addresses this principle clearly in the related section (Section 16.10) of the clause. The warranty clause template also clearly defines the day to day activities that should be performed by VDOT such as monitoring the portions of the highway (that is maintained by the contractor during the contract term) to identify the remedial work and emergency remedial work needs, performing remedial work to correct the defects that are caused because of the factors that are beyond the control of the contractor, and performing emergency remedial work immediately if the contractor is unable or refuses to perform such emergency remedial work.

11.) The principles used in defining the subcontractor's responsibilities (Section 16.11): Due to the possibility of conflicts that may arise between the contractor, subcontractor and VDOT, the developed warranty clause template clearly assigns the responsibility of performing or enforcing the required remedial work (for the maintenance work that was performed by any subcontractor) to the contractor. In other words, the clause, as a principle, requires the contractor to resolve the issues of defect apportionment between the contractor and its 
subcontractor(s) on its own. This makes the contractor ultimately responsible for performing the remedial work or having it performed. VDOT should keep this principle in the warranty clause language to avoid some hard-to-resolve issues that may surface in the defect apportionment between the contractor and the subcontractor.

\subsection{CONTRIBUTIONS MADE TO THE BODY OF KNOWLEDGE AND THE IMPORTANCE OF THE STUDY}

As mentioned previously, the developed warranty clause template is proposed to be used in the future VDOT issued performance based road maintenance contracts. The scope of this research, as clearly stated in Sub-section 1.5.2, is limited to VDOT issued contracts. This is mainly due to the fact that in developing the warranty clause template, special consideration was given to VDOT's needs and conditions and, most importantly, expectations from the contract. Nonetheless, some of the principles and approaches (as discussed in Section 7.3) used during the development of the warranty clause template can also be referred to for the development of warranty clauses for the performance based road maintenance contracts issued by the other state DOTs.

Given the fact that the current VDOT-VMS performance based road maintenance contract enacted under the Public Private Transportation Act (PPTA) is the first of its kind issued by VDOT, it has utmost importance. Its successors which will be issued by VDOT as well as other states' agencies are going to use it as a learning document. Thus, VDOT needs to make use of the current VDOT-VMS contract as much as possible. A striking aspect of the current contract is that the contract does not encompass any warranty clauses. Nonetheless, the important issue here is to ensure that VDOT, having the nation's third largest state maintained highway network in its jurisdiction, takes the necessary steps to enhance its future performance based road maintenance contracts.

The research is aspiring to, at least, inform VDOT in the very crucial issue of warranty provisions. The research is aiming to divert VDOT's attention to this issue by presenting the downsides of not having warranty provisions in the performance based road maintenance contracts and also by developing a warranty clause template that can be used to overcome these downsides. After the necessary assessment, if VDOT chooses to incorporate the developed 
warranty clause into its future performance based road maintenance contracts, it will highly benefit from that. The benefits that would be gained after the incorporation of the warranty clause will be as follows:

1.) Developed warranty clause will act as an incentive and make future contractors focus on quality and long term performance improvement which in turn is likely to reduce the life cycle costs of the interstate highway system.

2.) Implementation of the proposed warranty clause will certainly reduce the risk that VDOT will carry in its future contracts as compared to the current contract.

3.) As an expected result of this risk reduction, a significant amount of cost savings is likely to be made by VDOT.

4.) Implementation of the proposed warranty clause can lower the bids of prospective contractors. Knowing that the defects taking place within the warranty periods of previous contracts would be remedied by the previous contractors can make the prospective contractors disregard the costs associated with remedying those defects and make them leave those costs off their bids.

5.) It is true that even without the warranty clauses, in the presence of defects, VDOT can recover the damages it incurs by other means (such as breach of contract lawsuits); but only if it can prove the negligence of the contractor. On the other hand, a warranty clause which is very clear and articulate in the aforementioned issues will relieve VDOT of the burden of proving the negligence of the contractor in the presence of defects.

As VDOT Commissioner Philip Shucet suggested “...maintenance remains a critical item- keeping what we have safe, reliable, and in good condition. In fact the Code of Virginia (\$33.1-23.1) requires that the first allocation be "an amount deemed necessary for maintenance of roads..." In fact, in the current six year program, we have taken $\$ 420$ million from construction to meet maintenance needs...” (Shucet 2003), maintenance of the roadways is of chief importance to VDOT for which vast amount of money is spent. Given this fact, it would be fair to assert that, VDOT should expect to get as much as it can get (in terms of quality, long term performance, and condition improvement of its highway assets) from its privatized 
highway maintenance contracts. And as suggested by this research, incorporation of warranty clauses to these kinds of contracts can be a very important and hence effective step in fulfilling this expectation.

It is important to remind the reader that this research's findings can be tested at earliest in the next performance based road maintenance contract issued by VDOT. In current conditions, it looks like that it will not be earlier than July 2007 (as discussed in Section 1.2). Nonetheless, even if this research's findings are not tested at all, if it can show the community and authorized people that the reasons behind the research, the methodology of the research, and the end product of the research are good enough to be tested, it will have significantly contributed to the body of knowledge.

\subsection{ADVANTAGES OF VDOT}

As presented in Sub-section 2.4.5, warranty concept has both some advantages and disadvantages as deemed by the state DOTs that have experienced implementing warranties in the past. It was furthermore discussed in the same sub-section that even for the same issues like cost, quality, and many others, warranty implementation is perceived differently (as being advantageous or disadvantageous) by different state DOTs.

When VDOT case is examined, it can be stated that advantages of implementing the warranty concept is more likely to outnumber the disadvantages of doing so. The main reason for drawing such a conclusion is that, many of the disadvantages that were listed in Sub-section 2.4.5.2 are not present in VDOT case. Such disadvantages which were mentioned in the abovementioned list but which are not present in VDOT case are as follows:

1.) VDOT will not face the major challenges that were faced by a number of state DOTs in establishing the fair, attainable, meaningful, and measurable warranty criteria. VDOT has already established performance criteria and performance targets (that are already agreed upon by the contractor and VDOT in the current VDOT contract) that is applicable for the contract term. And, as proposed in this research, those performance criteria and performance targets can be used for easily establishing the warranty criteria. 
2.) Presenting attainable warranty criteria to the contractors is likely to keep the contractors' bid prices reasonable. Moreover, using performance warranties and such attainable warranty criteria would alleviate the sureties in providing warranty bonds to the contractors since sureties would know that the contractors are free to choose how to perform their work and moreover they are not required to do something impossible.

3.) VDOT has already established an efficient monitoring program (so called the MRP-Maintenance Rating Program) which is used for the contract term in the current VDOT contract. VDOT can implement the same monitoring program for the warranty period which will enable it to easily measure the contractor's warranty compliance. In other words, VDOT does not need to create a monitoring program from scratch to evaluate warranty compliance. It can easily implement the monitoring program which has already been tested for numerous times and which can be deemed as working. In addition to this, VDOT has the required expertise and thus currently performs yearly extensive inspections to monitor and evaluate the condition of its road network under its Pavement Management System (PMS) and Bridge Management System (BMS). These monitoring systems can also be used for warranty compliance evaluations relieving VDOT of establishing monitoring systems just for its projects with warranties.

4.) VDOT is also not likely to face the disadvantages related to the contractors' inabilities of securing long term warranty bonds. The M.S candidate believes that, if VDOT uses the approaches as proposed in this research to establish the length of the warranty period and requires reasonable amounts of condition improvements (of the asset items) from the contractors, VDOT will most probably end up with warranties of short durations, i.e. six months to one year. Such short warranty periods will not put any burden on the contractors in securing the warranty bonds. This fact removes one of the biggest disadvantages introduced by the warranty concept as discussed in Sub-section 2.4.5.2.

5.) Since the warranty periods will be relatively short, it is less likely for the Equal Single Axle Loads (ESALs) and Average Daily Traffic (ADT) to change during 
the warranty period. This relieves VDOT of preparing and including exclusions related to ESALs and ADT (which may be challenging as presented in Subsection 2.4.5.2) in the warranty clauses and further relieves VDOT of continuously monitoring the highway system for any increases in the ESALs and ADT.

6.) Due to the fact that VDOT performed negotiations as required by the Public Private Transportation Act (PPTA) rather than implementing a low bid procurement in awarding the current contract, it is likely to possess a similar approach in awarding the future performance based road maintenance contracts. This is likely to prevent the drawbacks introduced to the projects with warranties when the low bid award method is used as discussed in Sub-section 2.4.5.2.

7.) Since VDOT uses a total maintenance contract (fence to fence maintenance contract covering all of the asset items present in the roadway) it is to receive all potential benefits of warranties (if VDOT decides to implement warranties for all of the asset items covered under its total maintenance contracts) as opposed to the other state DOTs whose contracts and thus warranties cover only certain portions of their roadways.

8.) VDOT is already familiar with the warranty concept. VDOT has recently awarded projects with warranties. The pavement and some other aspects of the Virginia State Route 288 Project are required to be warranted for 5-20 years (Carpenter et al. 2003.) Moreover, VDOT has also awarded several concrete pavement patching projects with warranties of one year (Long 2003.) These warranties may not be similar to the warranty concept that has been proposed by this research. Nonetheless, they illustrate that VDOT has already taken a large initiative in issuing warranties and thus has gained a certain amount of experience in the administration of warranties. Administration of warranties has been a major challenge that required a learning curve for the state DOTs which have never issued warranties (as discussed in Sub-section 2.4.5.2). Since VDOT has some experience with warranties up to date, this may not be the case for VDOT if it wishes to introduce the warranty concept into its performance based road 
maintenance contracts. Moreover, abovementioned projects show the interest and willingness of VDOT in awarding contracts with warranties.

\subsection{RECOMMENDATIONS FOR VDOT IN INTRODUCING THE WARRANTY CONCEPT INTO ITS PERFORMANCE BASED ROAD MAINTENANCE CONTRACTS}

This section lists a couple of recommendations which VDOT may consider if it wishes to introduce the proposed warranty concept into its future performance based road maintenance contracts. The list below contains a number of suggestions as identified by the M.S. candidate during the stage of the literature review from the experiences of the other state DOTs:

1.) VDOT initially may consider testing the warranty concept in a pilot performance based road maintenance project. This project can be chosen to be a relatively small scale project in order for VDOT to gain experience in administering the warranties. This would furthermore help VDOT get an understanding of the positive and negative consequences of introducing warranties into its performance based road maintenance contracts which may eventually help VDOT change the negative aspects to positive aspects and refine its administration of warranties.

2.) In order to be able to perform comparisons and to better understand the consequences of warranties, VDOT can award two very similar performance based road maintenance projects at the same time; one with warranties and one without warranties. Then VDOT can make comparisons of the important concepts at stake such as the cost and quality by using the data gathered from these very similar two projects. These comparisons may help VDOT in deciding whether to further proceed with warranties or not.

3.) During the negotiation stage, before awarding the contracts with warranties, VDOT may hold meetings with the representatives of the bonding industry and the contracting industry to present that the performance required from the contractors during the warranty period is attainable. As discussed in Sub-section 2.4.3.3, this was an approach used by WisDOT to alleviate the sureties in 
providing warranty bonds to the contractors. These meetings can also ease the concerns of the contractors related to the warranty concept. In conclusion, establishing an efficient communication between the contractors, sureties and VDOT is essential if VDOT wishes to benefit from the warranty concept.

4.) In choosing the value of "A" or "W" (whichever approach VDOT is willing to pursue in establishing the length of the warranty period) as detailed in Sub-section 3.3.2 and Sub-section 3.3.3, VDOT should be reasonable. Otherwise, it may end up receiving very highly priced proposals from the contractors who are trying to compensate their situations for assuming high risks because of very long warranty periods (as discussed in Sub-section 2.4.2.2).

\subsection{POSSIBLE FUTURE RESEARCH AREAS}

This section lists and briefly discusses some possible research that can be conducted as follow up studies to the research presented in this write-up. Not all of the listed areas are directly related to subject matter that was elaborated in this research. Nonetheless, the list contains some possible research subjects that were identified by the M.S. candidate (during the course of performing the current research) as more or less being in the same pathway with this research of developing warranty clauses for performance based road maintenance contracts.

1.) Development of the deterioration models that are required to establish the length of the warranty period: As presented in Section 1.5, this research's main purpose was to develop a comprehensive and complete warranty clause template which is to be presented to VDOT to be assessed, filled in with the required values and expressions, and be incorporated into the future performance based road maintenance contracts it will issue. The main product of this research (i.e. the developed warranty clause) is still a template whose "length of the warranty period" component needs to be filled in with exact figures. As discussed comprehensively in Section 3.3, whichever alternative (Alternative 1, Alternative 2, or Alternative 3) is used, normal deterioration curve of each asset item is required to be able to establish the length of the warranty period for each asset item. Once the normal deterioration curves are obtained, establishing the length of the warranty period for any asset item would be a matter of simple 
graphical calculation. However, currently, such normal deterioration curves are not readily available for every asset item. There has been many research performed up to date about the deterioration models for the "Pavement" asset item but nothing much has been done to figure out the deterioration curves of the other asset items covered under the contract such as the “Paved Ditches” asset item, “Concrete Barriers” asset item, and etc... Due to the fact that this research has developed approaches which call for the establishment of warranty period by using the deterioration models, any research that is elaborating on such deterioration models would be complementary with this research. Although such research would serve to the purpose of taking the results that are achieved in this research to one step further, one should note that such research would require an extensive and long term study. Moreover, it would require a massive data collection (on the highway) and analysis.

2.) The investigation of the possibility of introducing pro-rated warranties into the performance based road maintenance contracts issued by VDOT: As discussed in Sub-section 2.4.2.3, an alternative approach in establishing the warranty criteria is to use a graduated scale throughout the warranty period. In this approach, warranty criteria and parameters are set at a certain value for the first year of the contract and then reduced each year until the termination of the warranty period (Stephens et al. 2002). This approach of reducing the warranty criteria is very similar to a concept called pro-rated warranty which is commonly used in consumer products. Within the context of the pro-rated warranties, the replacement value of the failing product is decreased over time. In other words, if the product fails prior to the expiration of the warranty period, then the amount reimbursed by the manufacturer is based upon the time remaining in the warranty period. Although, the M.S. candidate is not aware of any highway project that is awarded with warranties of graduated scales (or pro-rated warranties), it would be a good research area to investigate the possibility of introducing such warranties into the VDOT issued performance based road maintenance contracts. Such research would require a considerable amount of high-level comparisons to be made between the consumer products and the highway maintenance services to be able to figure out the consequences of introducing the pro-rated warranty concept to performance based road maintenance projects and to be able to arrive a conclusion for the feasibility of doing so. 
3.) The enhancement of the language used in the performance criteria within the current VDOT contract: As one of the committee members for this research and one of the members of the panel of experts have suggested, the language of the performance criteria as used in the current VDOT contract can be interpreted differently by different parties. Table 7.1 presents the performance criteria as extracted from the Exhibit B of the contract for the "Paved Ditches" asset item. As can be seen in the table, the terms "no obstruction to flow of water that requires action” and " $<25 \%$ spalled" are used as the performance criteria for the "Paved Ditches” asset item. The phrase "that requires action" can be interpreted differently by different individuals. Similarly the term “ $<25 \%$ spalled” is subject to different interpretation amongst the parties, i.e. how that area is physically measured, what the unit length/square foot is. These and similar instances can easily be overcome by the inclusion of further definitions to the performance criteria and to the contract in general. Hence, a study which tries to enhance the language used in the performance criteria can be conducted to prevent the possible confusions that such terms can bring about and also to avoid the possible disputes over those terms. This would also ensure the meeting of the minds concept which is the essential element in the formation of any contract.

\section{Table 7.1: Performance Criteria for the "Paved Ditches" asset item as extracted from} the Exhibit B of the current VDOT Contract

\begin{tabular}{|l|l|}
\hline Asset & $\begin{array}{l}\text { Condition assessment acceptance tolerances and criteria (Service } \\
\text { Delivery) }\end{array}$ \\
\hline $\begin{array}{l}\text { Paved } \\
\text { Ditches }\end{array}$ & $\begin{array}{l}\bullet<1 \text { ' settlement } \\
\bullet \text { no undermining or undercut requiring action } \\
\end{array}$ \\
\hline
\end{tabular}

4.) Further enhancements in the VDOT issued performance based road maintenance contracts: This research's scope was limited to the warranty issues as stated in Section 1.5. However, having gone through the contract in a detailed fashion and having made comparisons with other contracts of its kind, the M.S. candidate thinks that the VDOT-VMS Inc. Contract may be enhanced in the area of approval processes, too. Some clauses within the contract contain language that are calling for approval of VMS's work plan of maintenance methodologies and 
emergency response activities by VDOT before VMS can proceed with them. This is a discrepancy with the performance based nature of the contract, because by approving these, VDOT somehow interferes with the processes that the contractor has developed to reach the end products. Moreover, this approval process also relinquishes the whole point of the owner's aim of risk assignment to the contractor, making the VDOT share the liability for possible design deficiencies and problems that may be incurred after the approvals. The M.S. candidate believes that a research regarding this issue can be conducted in the future. This research's findings may help VDOT to enhance its performance based road maintenance contracts furthermore in the subject matter of "delegation of the liability”.

5.) Warranty Survey: If VDOT chooses to introduce the warranty concept into its performance based road maintenance contracts, then its experience during the administration of such warranties certainly needs to be documented to have a lessons learned database. Moreover, the experience of the contractor that undersigned the performance based road maintenance contract with warranties is also indispensable. Given these, it would be a good study to gather these experiences in a meaningful way through the usage of an effective survey. The results of such a survey would help both of the parties to learn from each other's experience as well as from their own experience after the implementation of this new warranty concept for the first time. This, in turn, would enhance the implementation of warranties and help the parties (i.e. VDOT and the contractor) achieve their expectations in a more efficient way. 


\section{BIBLIOGRAPHY}

AASHTO. (1991). "Report on the 1990 European asphalt study tour.” Washington D.C.

AASHTO. (1992). "Report on the 1992 U.S tour of European concrete highways." Washington D.C.

AASHTO Highway Subcommittee on Maintenance. (2002). A guide for methods and procedures in contract maintenance. AASHTO, Washington D.C., August.

“About us.” (2003). < http://www.performanceroads.com/aboutus.htm> (Jun. 6, 2003)

AIA. (1997). "General conditions of the contract for construction." AIA Document A2011997. Washington D.C.

AIA. (1997). "Standard form of architect's services: Design and contract administration." AIA Document B141-1997.Washington D.C.

“A.M. Best Company” (2003) < http://www.ambest.com/> (Nov. 15, 2003)

Anderson, S.D., and Russell, J.S. (2001). "Guidelines for warranty, multi-parameter, and best value contracting.” National Cooperative Highway Research Program Report 451, National Academy Press, Washington D.C.

Associated General Contractors. (2000). "AGC white paper on innovative contracting practices in federal aid highway construction.” Alexandria.

Baker, J.L. (1984). "Use of private contracting in highway maintenance." Innovative Strategies to Improve Urban Transportation Performance. Tennessee, July 23-25, pp 205-210. 
Bartholomew, S.H. (2001). Construction contracting-business and legal principles, Prentice-Hall, London.

Bay Roads Exposed. (2003). “The Bay roads performance based contract at a glance.” The Bay Roads Exposed Conference Poster. New Zealand. pp: 9.

Better Roads. (2001). “Agencies and contractors.” September, pp 26-29.

Botelho, F. (2001). "Performance contracting: The federal perspective." 51st Annual Virginia Transportation Conference, Lexington, October.

Burrell, G., and Morgan, G. (1979). Sociological paradigms and organizational analysis, Heinemann, London.

Caltrans Division of Construction. (1996). “Test and evaluation project 14- Initial report for warranty pilot contract 11-163244.” California Department of Transportation, June.

Carpenter, B., Fekpe, E., and Gopalakrishna, D. (2003). "Performance-based contracting for the highway construction industry-Final report.” Batelle, Columbus, February.

Code of Virginia. (1995). “Public- Private transportation act.”

Coleman, R.P. (1997). Guide to consumer law. The American Bar Association, Random House Inc., New York.

Commonwealth of Virginia. (2001). "Public- Private transportation act of 1995Implementation guidelines.”

Cook, L. (1998). “Shared responsibility, insurance industry perspective.” Symposium on Innovative Contracting. 
Cui, Q., Bayraktar, M.E., Hastak, M., and Minkarah, I. (2003). "Warranty practices on DOT projects in the US.” ISEC-02 Conference. Rome, September $23 r d-24^{\text {th }}$.

Cui, Q., Bayraktar, M.E., Hastak, M., and Minkarah, I. (2003). "Warranty as a real option for DOT projects.” AACE International Transactions. pp 16.1-16.5.

D.C. Department of Public Works. (1996). Standard specifications for highways and structures.

de la Garza, J.M., and Vorster, M. (2002). "VMS and VDOT highway maintenance performance evaluation: Final report for fiscal year 2001.” May.

Dipompo, L., and Robinson, M. (2001). "Performance based contracting in the District of Columbia.” 51st Annual Virginia Transportation Conference, Lexington, October.

Edwards, V.J. (2002). “Performance based contracting workshop course manual.” Federal Publications Seminars, LLC, Falls Church, October.

EJCDC. (1996). "Standard form of agreement between owner and contractor on the basis of a stipulated price.” EJCDC Document No 1910-8.Alexandria.

EJCDC. (1996). “Standard form of agreement between owner and engineer for professional services.” EJCDC Document No 1910-1. Alexandria.

Elmore, L.F., and Crawford, J.T. Jr. (2003). “Defenses in construction defect cases.” The Construction Lawyer. Spring, pp 27-34.

Falls, L.C., Haas, R., McNeil, S., and Tighe, S. (2001). “Asset management and pavement management: Using common elements to maximize overall benefits.” Transportation Research Record 1769. No: 01-2415. 
FAR. (1997). “The Federal acquisition regulation.”

FDOT. (2000). Standard specifications for road and bridge construction.

FDOT. (2000). “Traffic stripes and markings- Performance based.” Section 707. Feb. 16. $<$ http://www.dot.state.fl.us/specificationsoffice/PerformanceBased/D7070000.d03.pdf>

FDOT. (2002). "Contractor guaranteed asphalt pavement.” Section 338. April 15. $<$ http://www.dot.state.fl.us/specificationsoffice/PerformanceBased/D3380000IMP.pdf>

FDOT. "Contractor's warranty period for signal installations." Section 611-5. $<$ http://www.dot.state.fl.us/specificationsoffice/PerformanceBased/Contractor's\%20Wa rranty\%20Period\%20for\%20Signal\%20Installations.pdf>

Federal Trade Commision. (1970). Report on automobile warranties. U.S. Government Printing Office, Washington D.C., February.

Feld, J. (1968). Construction failure. John Wiley \& Sons, Inc., New York.

FHWA. (1994). "Contract administration techniques for quality enhancement study tour.” Washington D.C.

FHWA. (2000). "Briefing: Warranty clauses in federal-aid highway contracts.” Dec. 7.

FHWA. (2001). "Briefing: Special experimental projects No. 14, innovative contracting (SEP-14).” July 25.

FHWA. (2002). "Briefing: FHWA initiatives to encourage quality through innovative contracting practices: Special Experimental Projects No 14 (SEP-14).” July 9. 
FHWA. "Project warranties- Hot mix asphalt concrete pavement." $<$ http://www.ic.usu.edu/search/doc/186.pdf >

FIDIC. (1987). “Conditions of contract for works of civil engineering construction.” 4th Edition.

Focus. (2003). “Pavement warranties: Learning from the European experience.” Jan/Feb 2003. <http://www.tfhrc.gov/focus/jan03/02.htm> (Sep. 10, 2003)

Frost, M., and Lithgow, C.M. (1996). "Improving quality and cutting costs through performance contracts- Australian experience." World Bank Road Management Training Seminar, Washington D.C, December.

Frost, M., and Lithgow, C.M. (1998). "Future trends in performance based contractingLegal and technical perspectives.” IRR Conference. Sydney, May.

Galehouse, L. (1998). “Innovative concepts for preventive maintenance.” Transportation Research Record 1627. No: 98-0719.

Garner, B.A. (2001). Black’s law dictionary. West Publishing, Colorado.

Gill, J., and Johnson, P. (1997). Research methods for managers. SAGE Publications, London.

Graziano, A.M., and Raulin, M.L. (1993). Research methods: A process of inquiry. HarperCollins College Publishers, New York.

Hamilton, W.E. (2001). “Transportation: Road construction warranties.” Fiscal Forum. House Fiscal Agency, March. 
Hancher, D.E. (1994). "Use of warranties in road construction.” NCHRP Synthesis of Highway Practice 195, Transportation Research Board, Washington, D.C.

Hancher, D.E. (1999). “Contracting methods for highway construction.” Transportation Research Board, Washington, D.C., November.

Hardy, P. (2001). “Austroads review of performance contracts: The potential benefits of performance contracts.” Contracting the Future NZIHT Symposium, October.

Hart, C.W.L. (1993). Extraordinary guarantees. American Management Association, New York.

Hastak, M., and Baim, E., J. (2001). "Risk factors affecting management and maintenance cost of urban infrastructure.” Journal of Infrastructure Systems. Volume 7, No 2, June, pp 67-76.

Hays, J.W. (2003). “Construction defect claims against design professionals and contractors.” The Construction Lawyer. Spring, pp 9-14, 44-47.

Hill, G.N., and Hill, K.T. (1995). Real life dictionary of the law. General Publishing, Los Angles.

Hughes, C.S. (1996). "State of the practice of warranty specifications in the United States.” Virginia Transportation Research Council, December.

IEEE/PES Task Force. (1999). “Impact of maintenance strategy on reliability.” Reliability, Risk, and Probability Applications Subcommittee, July.

JLARC. (2001). "Review of VDOT's administration of the interstate asset management Contract.” Commonwealth of Virginia, January. 
Johnson, A.M. (1999). “Use of design/build and warranties in highway construction.” Minnesota Local Research Board, October.

Josephson, P.E., and Hammarlund, Y. (1999). "The causes and costs of defects in construction: A study of seven building projects.” Automation in Construction. 1999-8, pp 681-687.

Kopatich, F., and Canzano, D. (2000) “A lawyer’s view of performance based service contracting.” Contract Law Division. March 24.

Krebs, S.W., Duckert, B., Schwandt, S., Volker, J., Brokaw, T., Shemwell, W., and Waelti, G. (2001). “Asphaltic pavement warranties, five year progress report.” WisDOT, FHWA, WAPA, June.

Leedy, P.D. (1974). Practical research: Planning and design. MacMillan Publishing Co., New York.

Locke, L.F., Silverman, S.J., and Spirduso, W.W. (1989). Proposals that work. SAGE Publications, Newbury Park.

Long, B. (2003). “VDOT’s warranty on concrete pavement patching.” SASHTO Quality Conference. Williamsburg, March 3-6.

McNeill, P. (1985). Research methods. Tavistock Publications, New York.

MDOT (2002). Guidelines for administering warranties on road and bridge construction contracts. Construction and Technology Support Area, November.

MDOT (2002). "Large segment of road-building industry sues to prevent warranties on its work.” MDOT Press Release.

<http://www.michigan.gov/mdot/0,1607,7-151-9620_11057-25342--M_2002_4,00.html> 
MDOT (2002). “Transportation commission adopts pavement warranty policy.” MDOT Press Release.

<http://www.michigan.gov/mdot/0,1607,7-151-9620_11057-31631--M_2002_4,00.html>

“Media resources.” (2003). < http://www.performanceroads.com/mediaresources.htm> (Jun. 6, 2003)

ODOT. (1999). "Implementation of warranted items in state of Ohio highway construction projects."

ODOT. (2000). “Implementation of warranted items on construction projects.” Dec. 31.

ODOT Office of Pavement Engineering. (2001). "Pavement preventive maintenance program guidelines.” May 1.

ODOT. (2002). “Microsurfacing with warranty.” Supplemental Specification 881. Oct. 18. <http://www.dot.state.oh.us/construction/OCA/Specs/SSandPN2002/8811002.pdf>

ODOT. (2003). “Concrete pavement with warranty.” Supplemental Specification 884. <http://www.dot.state.oh.us/construction/OCA/Specs/SSandPN2002/8840403.pdf>

OFPP- Office of Federal Procurement Policy. (1991). “Policy letter 91-2.” Washington D.C, April.

OFPP- Office of Federal Procurement Policy. (1998). “A guide to best practices for performance-based service contracting.” Washington D.C, October.

OFPP- Office of Federal Procurement Policy. (1998). “A report on the performance-based service contracting pilot project.” Washington D.C, May. 
Otto, S., and Ariaratnam, S.T. (1999). “Guidelines for developing performance measures in highway maintenance operations.” Journal of Transportation Engineering. Volume 125, No: 1, January/February, pp 46-54.

Pakkala, P. (2002). Innovative project delivery methods for infrastructure. Finnish Road Enterprise, Helsinki.

Pennsylvania Department of Transportation. (1987). Specifications. Harrisburg, Pennsylvania.

PENREN. (2000). "Request for proposal for the design/build of the metro entrance facility.” Washington D.C., April 10.

PENREN. (2002). "Structure and philosophy of the PENREN preferred contract type." Washington D.C., Jan 25.

PENREN. (2002). "Request for proposal for PENREN roads, grounds- Secure bypass.” Washington D.C., July.

PENREN. "Public release version of the Pentagon renovation wedges 2-5 request for proposal.” Washington D.C.

“Pentagon Renovation Program Acquisition Strategy” (2003)

< http://renovation.pentagon.mil/acquisition.htm> (Feb. 18, 2003)

Peterson, D.E. (1985). "Life cycle cost analysis of pavements.” NCHRP Synthesis of Highway Practice 122. Transportation Research Board, Washington, D.C., pp 23.

Porter, T. (2001). “International trends in procurement models for highway maintenance.” Contracting the Future NZIHT Symposium, October. 
Powell, E., Jr. (2003). “North Carolina DOT’s use of warranties.” SASHTO Quality Conference. Williamsburg, March 3-6.

Prasad, A. (2003). "Florida department of transportation's approach to warranties." SASHTO Quality Conference. Williamsburg, March 3-6.

Ransom, W.H. (1981). Building failures diagnosis and avoidance. J.W. Arrowsmith Ltd, Bristol.

Remenyi, D. (1997). "So you want to be an academic researcher in business and management studies.” European Journal of Information Systems. 190192-6.

Russell, J.S., Hanna A.S., Anderson, S.D., Wiseley, P.W., and Smith, R. J. (1999). “Current use of warranties in highway construction.” Transportation Research Board Annual Meeting.

Sami, N., and McGhee, K.H. (1999). "Condition of the pavement-1998 Interstate and primary highways.” VDOT, Maintenance Division, Richmond.

Sayers, M.W., and Karamihas, S.M. (1998). The little book of profiling. University of Michigan, September.

Schirnack, J. (2001). “A consultant's perspective of highway network asset management practice in England.” Transportation Research Board Meeting. Washington D.C, January.

Schmidt, J. (2003). “VA route 288 and long term warranties.” SASHTO Quality Conference. Williamsburg, March 3-6.

Segal, G.F., Moore, A.T., and McCarthy, S. (2003). “Contracting for road and highway maintenance.” How to guide 21. Reason Foundation, March. 
Sekaran, U. (1984). Research methods for managers: A skill-building approach. John Wiley \& Sons, New York.

Senter, D.A. (2003). “Construction warranties and guarantees.” The construction lawyer. Winter, pp 17-25.

“Services.” (2003). < http://www.performanceroads.com/ourservices_rehabreconst.htm> (Jun. 6, 2003)

Shea, D.M. (2001). "VDOT maintenance program- challenges and opportunities.” 51st Annual Virginia Transportation Conference. Lexington, October.

Shucet, P. (2003). “Virginia’s transportation crisis.” The Vecellio Distinguished Lecture. Virginia Polytechnic Institute and State University, October 10.

Sklar, S.P., Filer, E.L., and Bird, T.M. (2001). "Implied duties of contractors." The Construction Lawyer. Summer, pp 11-21.

Slutzky, L.H. (2003). “Fully understanding and utilizing the call back warranty.” The construction lawyer. Summer, pp 13-16.

SMRP Newsletter. (2000). “Dependability- Performance assessment of a producer and its application in an RCM analysis.” Global Management Science Services, Winter. $<$ http://www.globalmms.com/Publications/>

Stephens, J., Johnson D., Wangsmo, M., and Schillings, P. (1998). “Use of warranties on in-service performance for roadway construction projects.” USDOT, FHWA, August.

Stephens, J. Whelan M., and Johnson, D. (2002). “Use of performance based warranties on roadway construction projects.” USDOT, FHWA, November. 
Stivers, M.L., Smith, K.L., Hoerner, T.E., and Romine, A.R. (1997). “Maintenance QA program implementation manual.” NCHRP 14-12. Transportation Research Board, May.

Sweet, J. (1999). Legal aspects of architecture, engineering and the construction process. Brooks-Cole, Pacific Grove.

Texas Department of Transportation. (1995). Standard specifications for construction and maintenance of highways, streets, and bridges. March 1.

Texas Department of Transportation. (1999). “Contract between state of Texas and VMS maintenance systems, Inc. for improvements of 63,000 miles of total roadway maintenance in Dallas county.” June 10.

Texas State Department of Highways and Public Transportation. (1982). Standard specifications for construction of highways, streets and bridges. September 1.

The World Bank. (2002). "Procurement of performance based management and maintenance of roads.” Washington D.C, February.

Thomas, H.R., Smith, G.R., and Wirsching, S.M. (1995). "Understanding defective specifications.” Journal of Construction Engineering and Management, ASCE, Volume 121 No: 1, March, pp 55-65.

Tomanelli, S.N. (2003). Evaluating and managing performance-based contracts. Federal Publications Seminars, LLC, Falls Church.

Transit New Zealand. (2002). “State highway maintenance contract proforma manual SM032.” New Zealand, March.

Utah T2 Center. (2002). Best practice guide for innovative contracting procedures. 
VDOT. (1996). "Comprehensive agreement for interstate highway asset management services.” December.

VDOT. (1997). Road and bridge specifications. Richmond, January.

VDOT. (2000). “Report on VDOT's comprehensive agreement for interstate asset management services VMS operations for 1999/2000.” VDOT, Maintenance Division, Richmond, December.

VDOT. (2002). "Final report on an action plan for distributed authority to promote effective administration and management of VDOT's contract with VMS, Inc.” Commonwealth of Virginia, August.

VDOT. (2002). Road and bridge specifications. Richmond.

“VMS Inc.” (2003) < http://www.vmsom.com/> (Mar. 16, 2003)

Walizer, M.H., and Wienir, P.L. (1978). Research methods and analysis. Harper \& Row Publishers, Inc., New York.

Wang, Z. (2000). "Formulation and assessment of a customizable procedure for pavement distress index.” PhD thesis, Civil Engineering, The University of Tennessee, Knoxville.

“Warranty Contracting.” (2003).

<http://www.ic.usu.edu/ic_over/warranty/warranty_over.php?heading=11> (Jul. 17, 2003).

Weed, R.M. (1993). “The proof is in the pavement.” Civil Engineering. Volume 63, No:8, August, pp 67-69. 
Wehrt, K. (1999). "Warranties.” Encyclopedia of Law and Economics, Volume I. The History and Methodology of Law and Economics. Cheltenham, Edward Elgar, pp 179199.

Whited, G. (1998). “Quality drivers: State highway agency perspective.” Symposium on Innovative Contracting.

Wilkinson, D. (2000). The researcher's toolkit. RoutledgeFalmer, London.

Wise, J. (2002). “Performance based contracting.” < http://www.gsa.gov >

Zaghloul, S., Saeed, N.A., Jassim, A.A., and Rafi, A.M.. (1998). "End result specifications for warranted asphalt pavements.” TRB No: 1632.

Zietlow, G. (2002). “Cutting costs and improving quality through performance-based road management and maintenance contracts.” University of Birmingham (UK) / Transit New Zealand Senior Road Executive Courses Innovations in Road Management, Birmingham, May. 


\section{APPENDIX A}

\section{EXHIBIT B OF THE VDOT-VMS, INC. CONTRACT}

This appendix presents the Exhibit B of the "Comprehensive Agreement for Interstate Highway Asset Management Services” signed by Virgina Department of Transportation and Virginia Maintenance Services,Inc. in December 1996.

Reference:

VDOT. (1996). “Comprehensive agreement for interstate highway asset management services.” December. 
EXHIBIT B

OUTCOMES AND PERFORMANCE TARGETS 

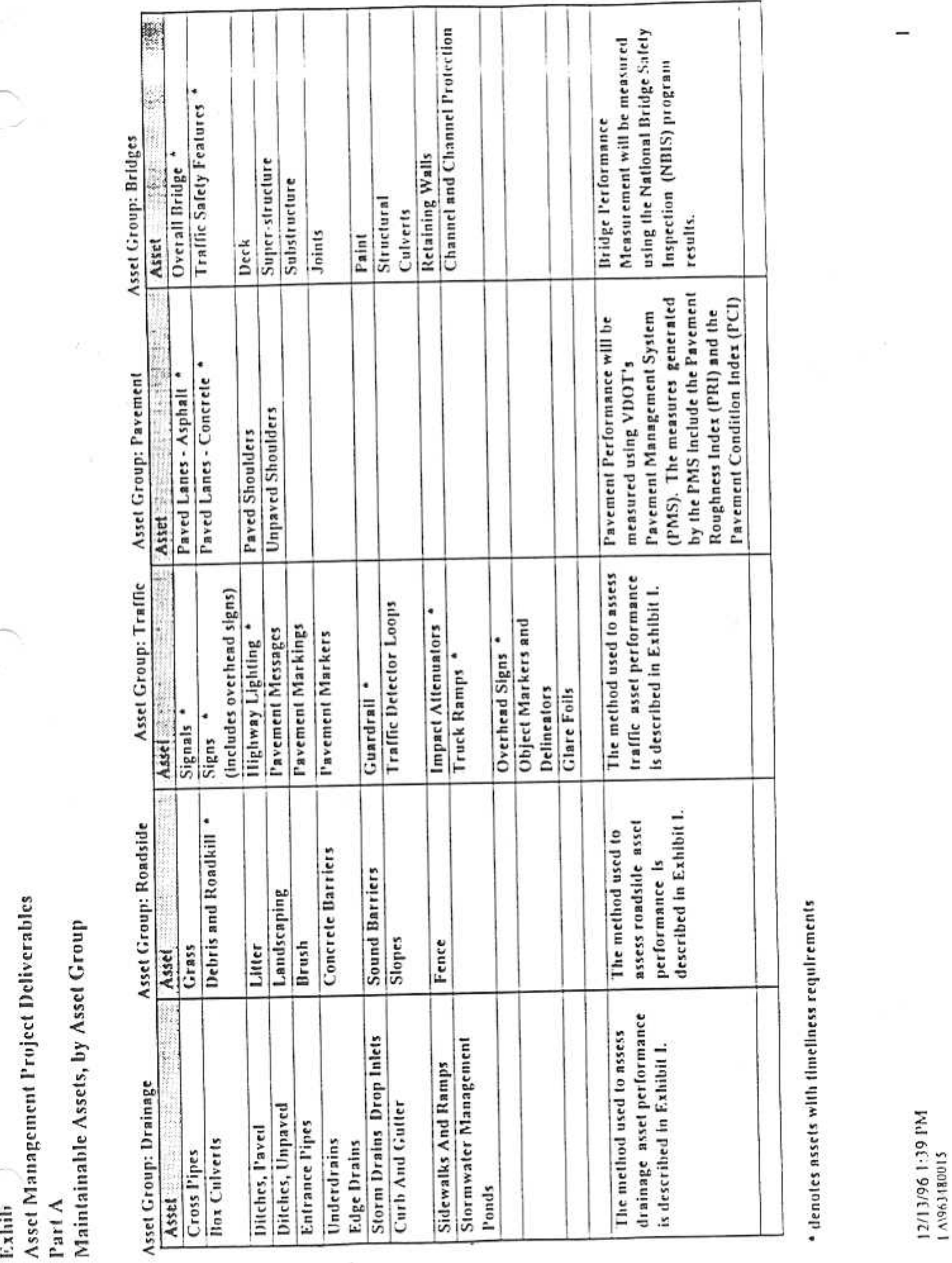


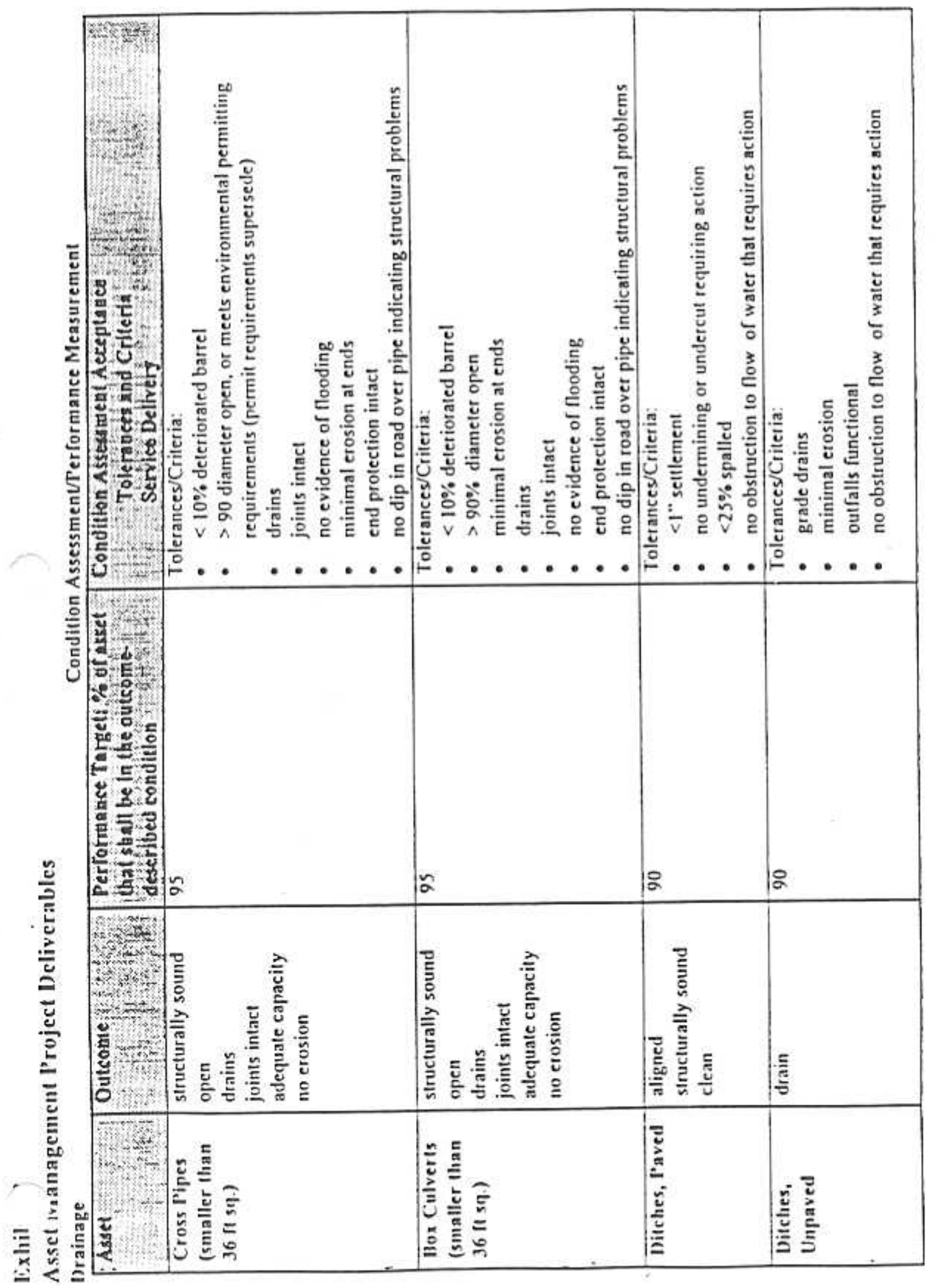

竞 


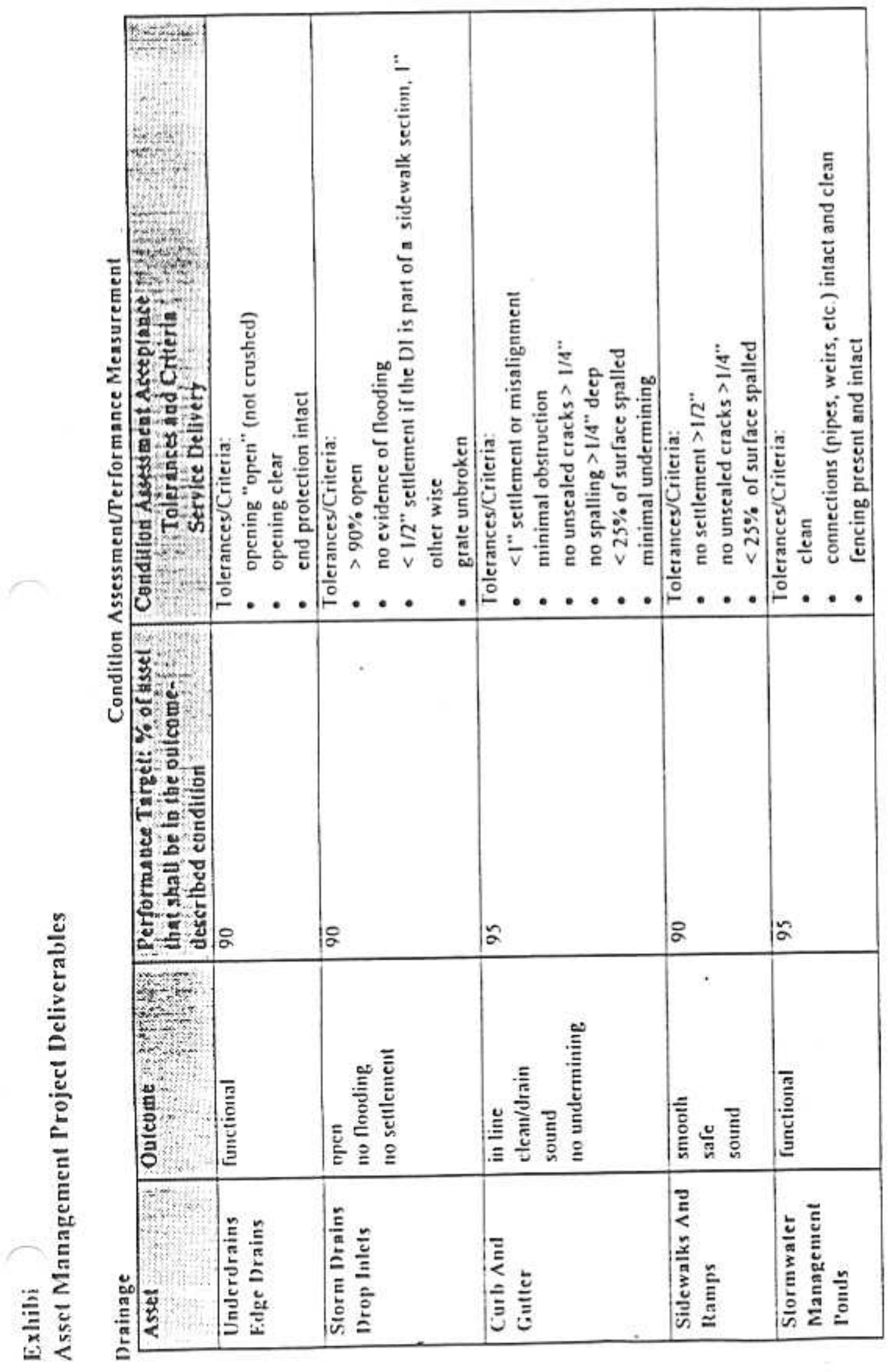

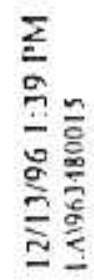




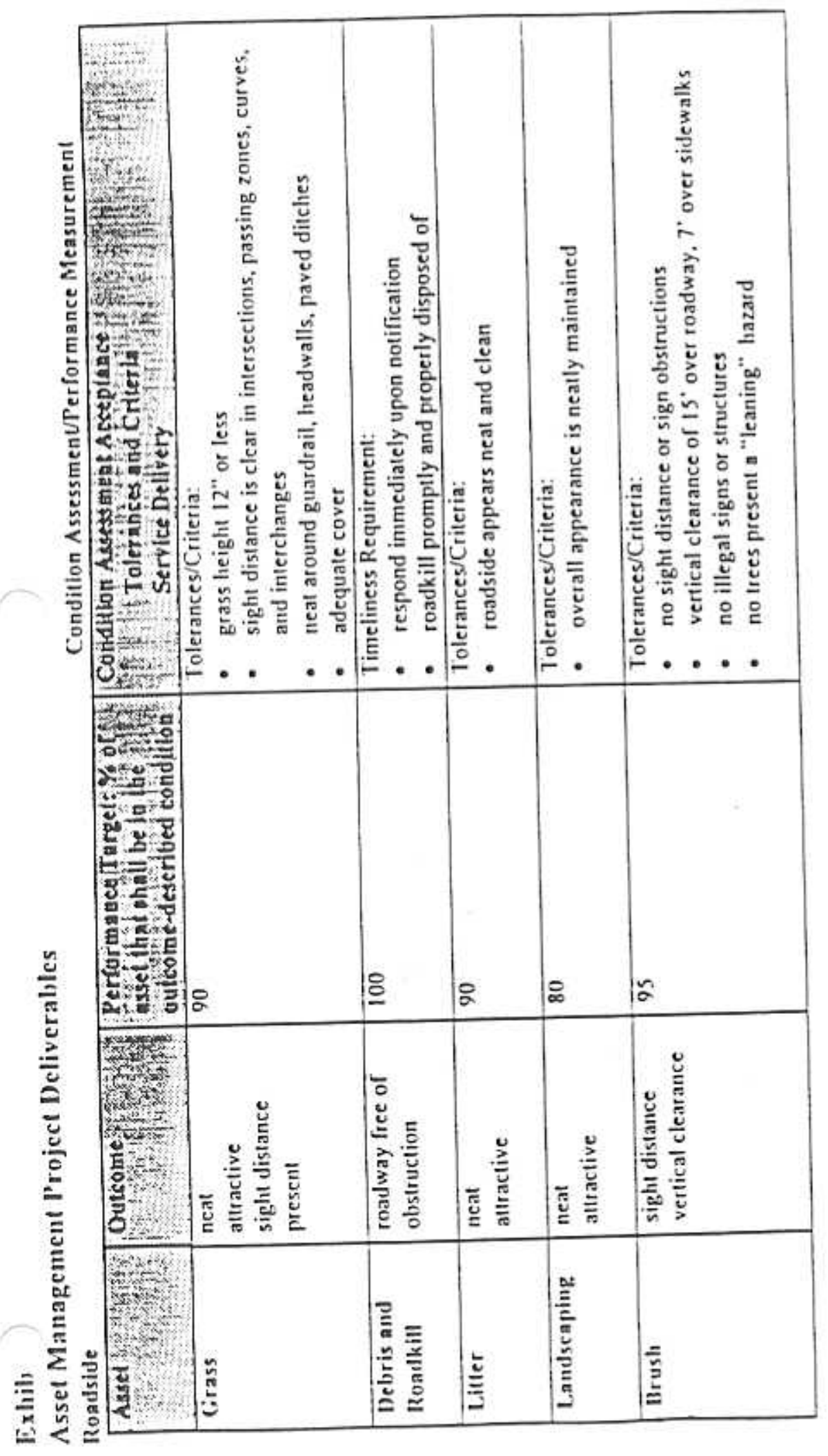

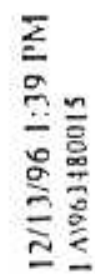




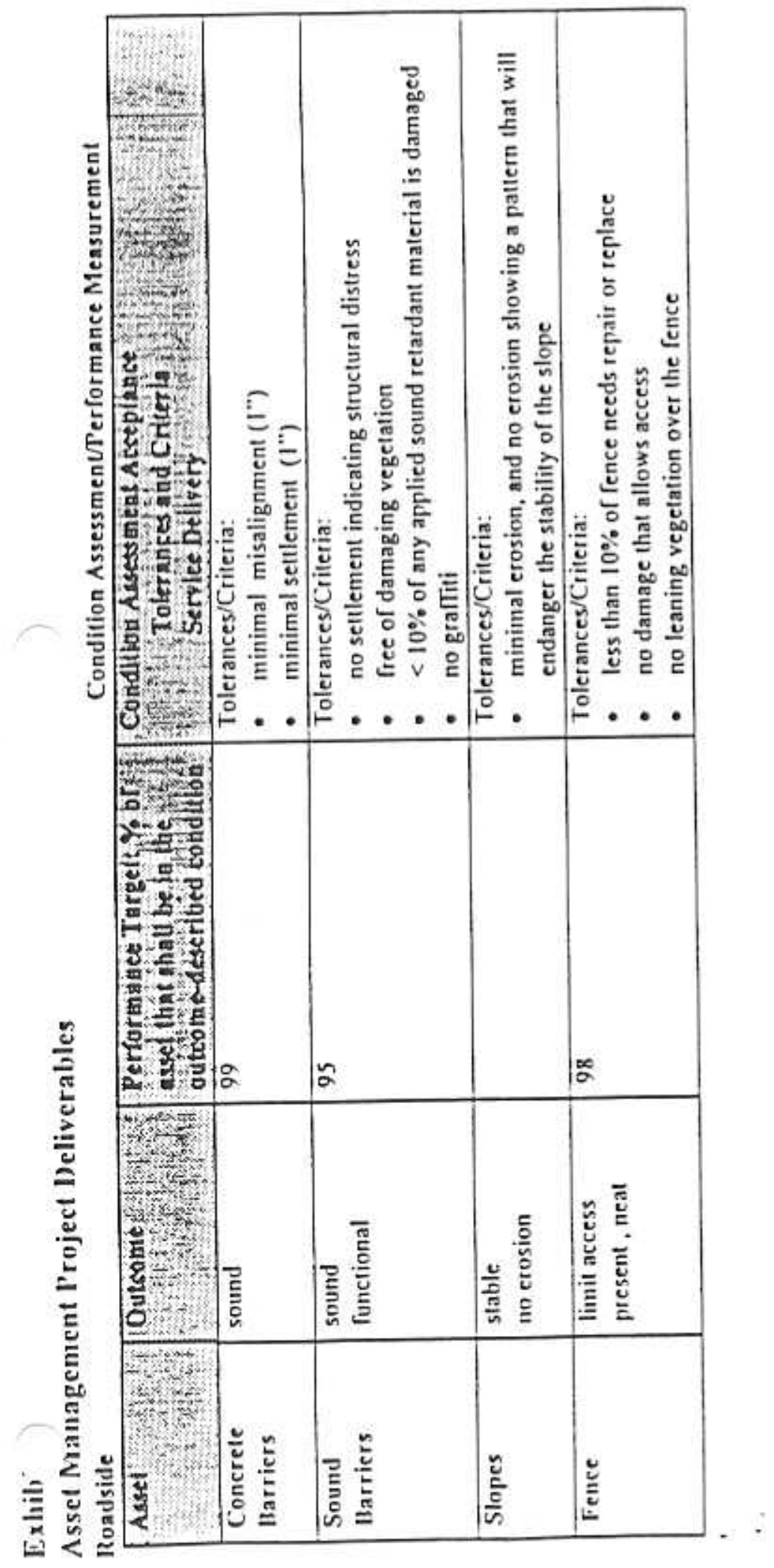

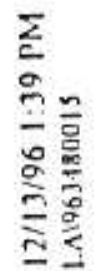




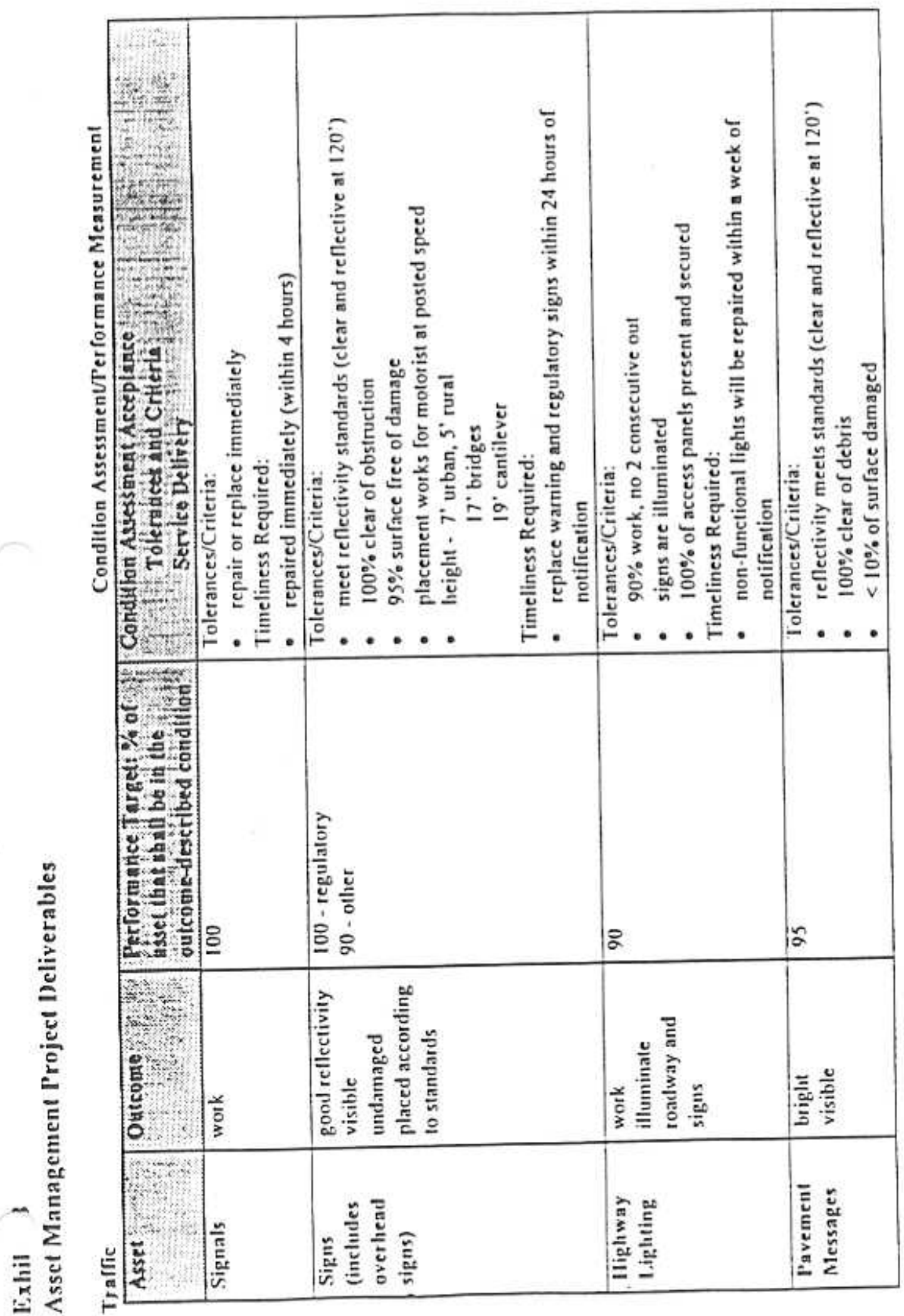

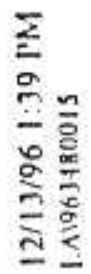




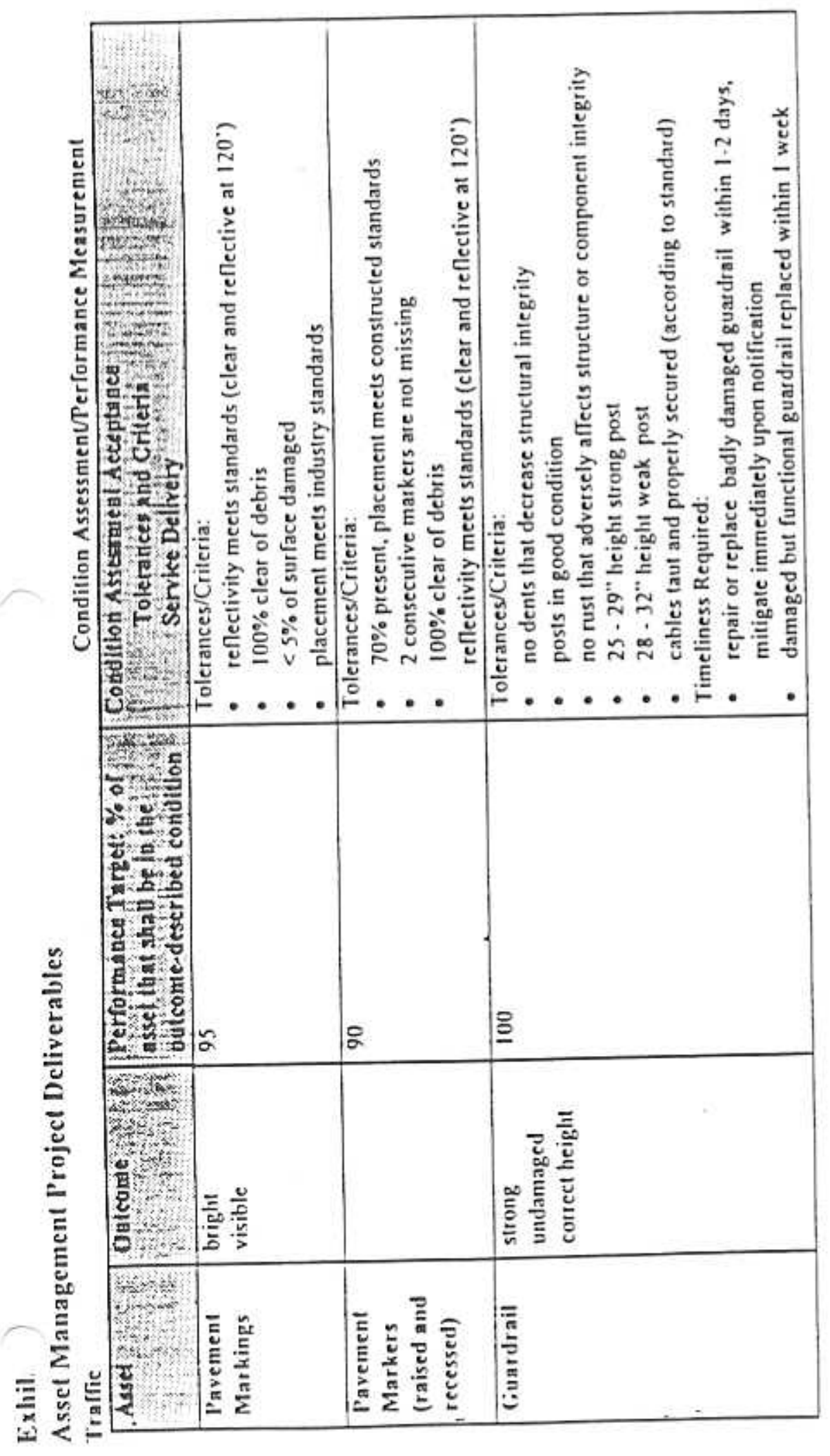

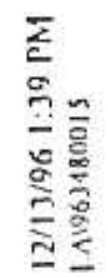




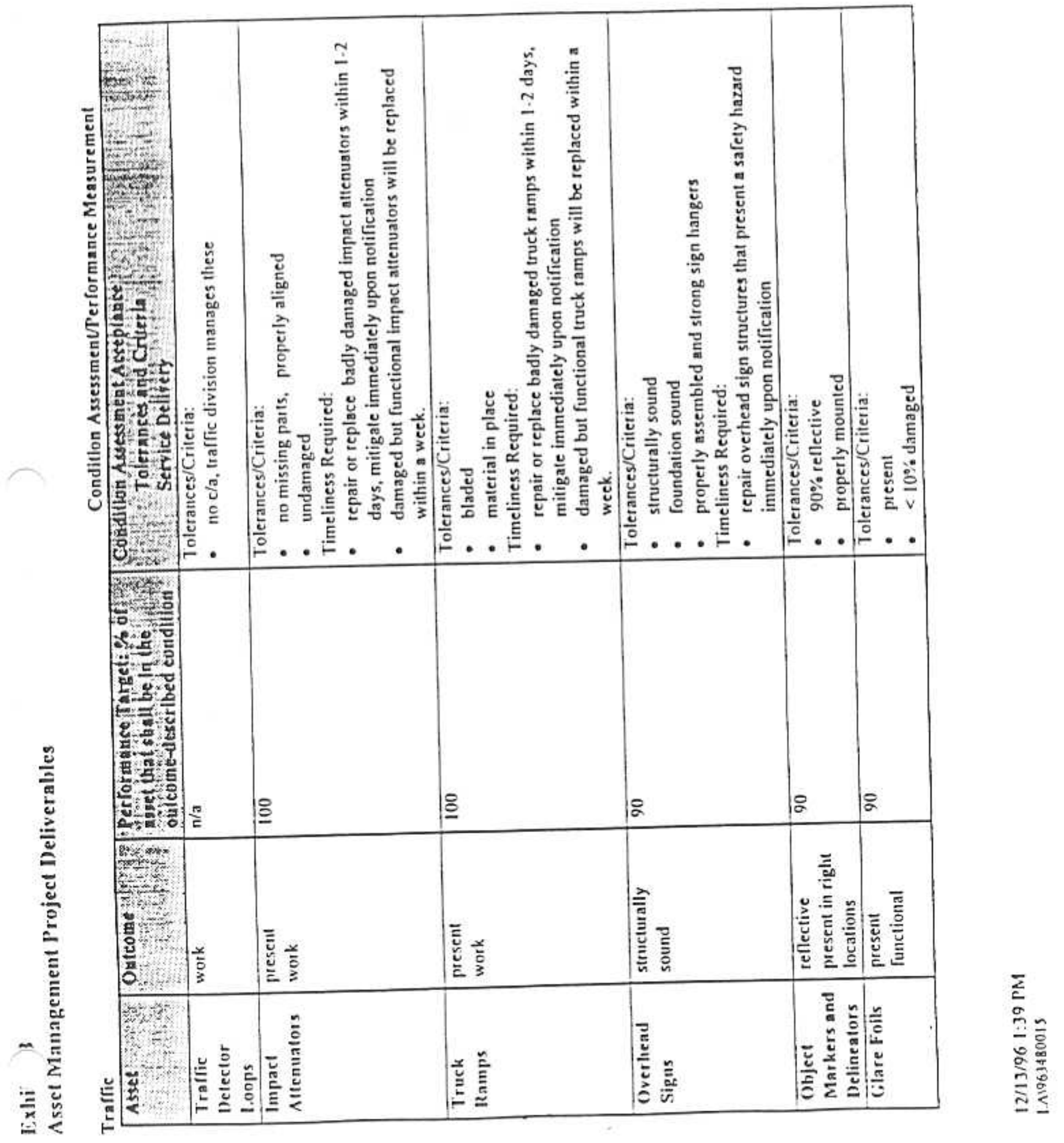




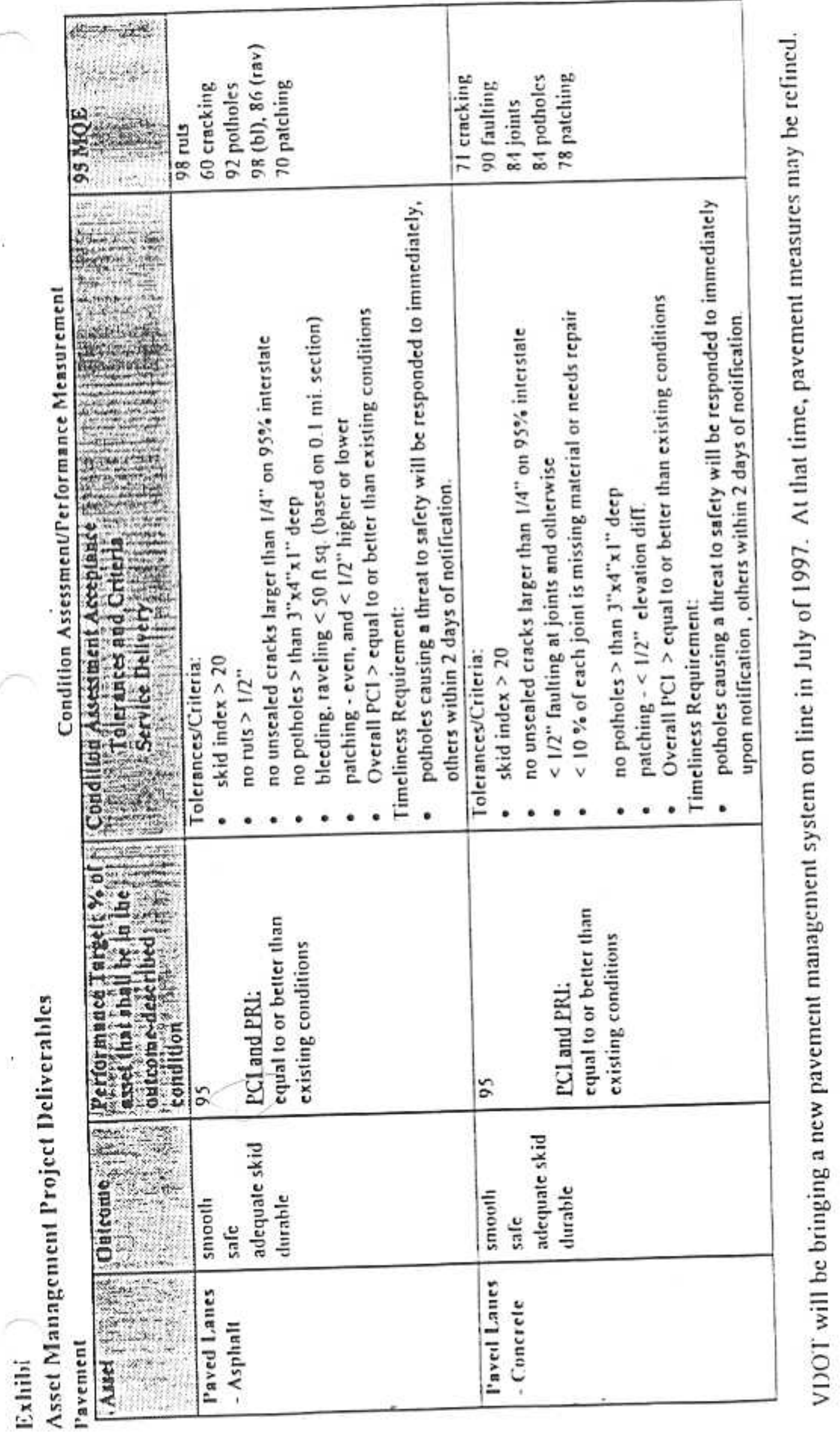

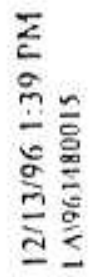




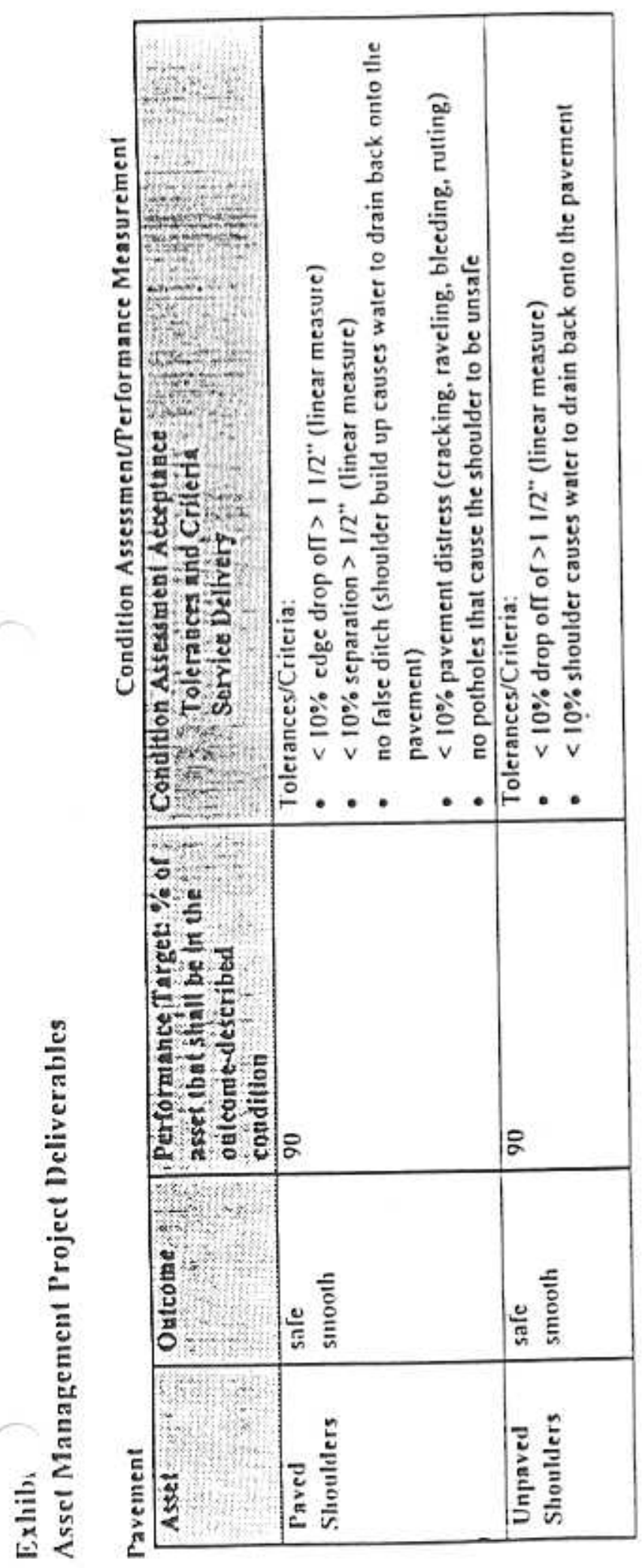




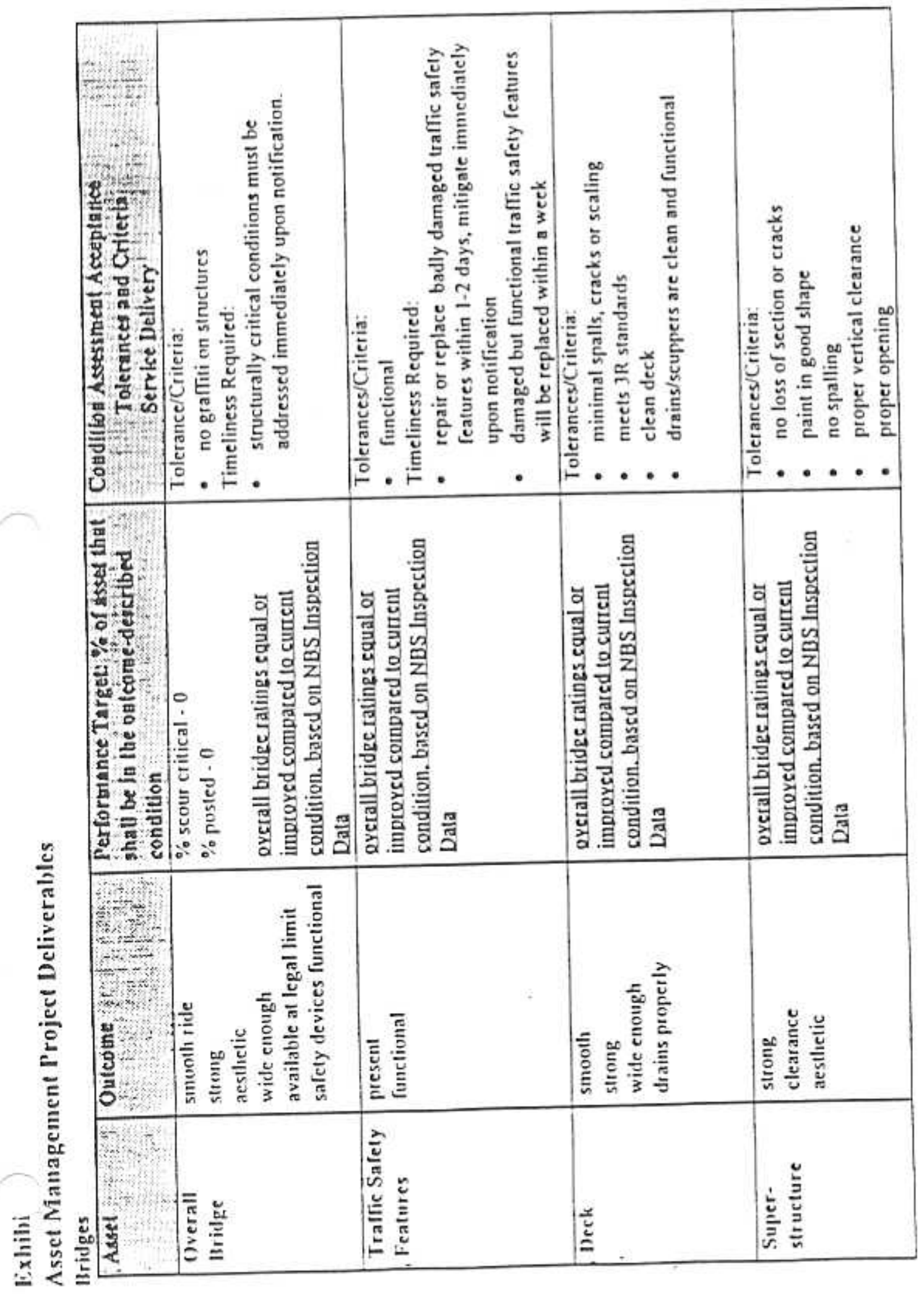

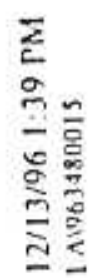




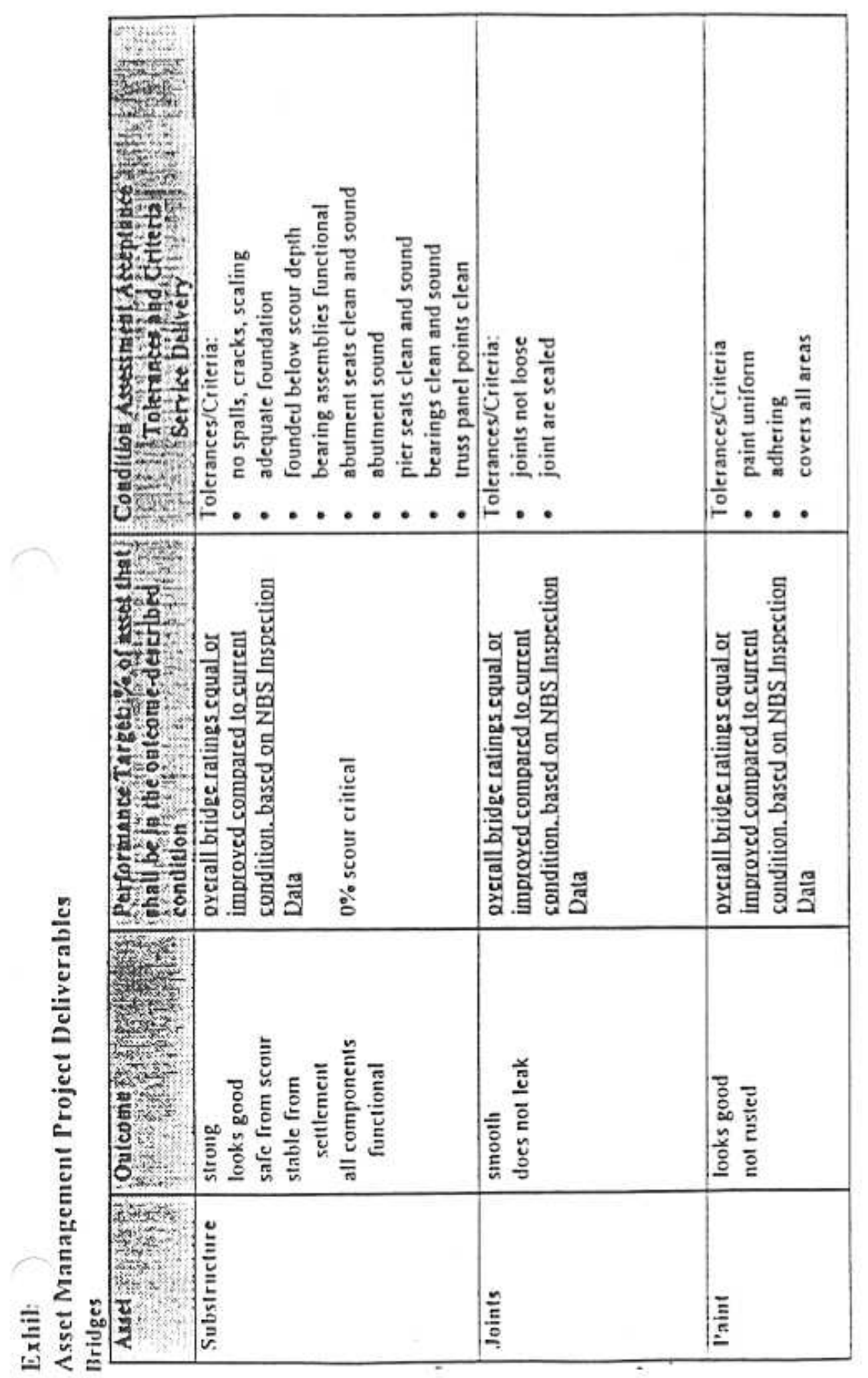

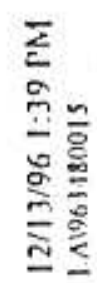




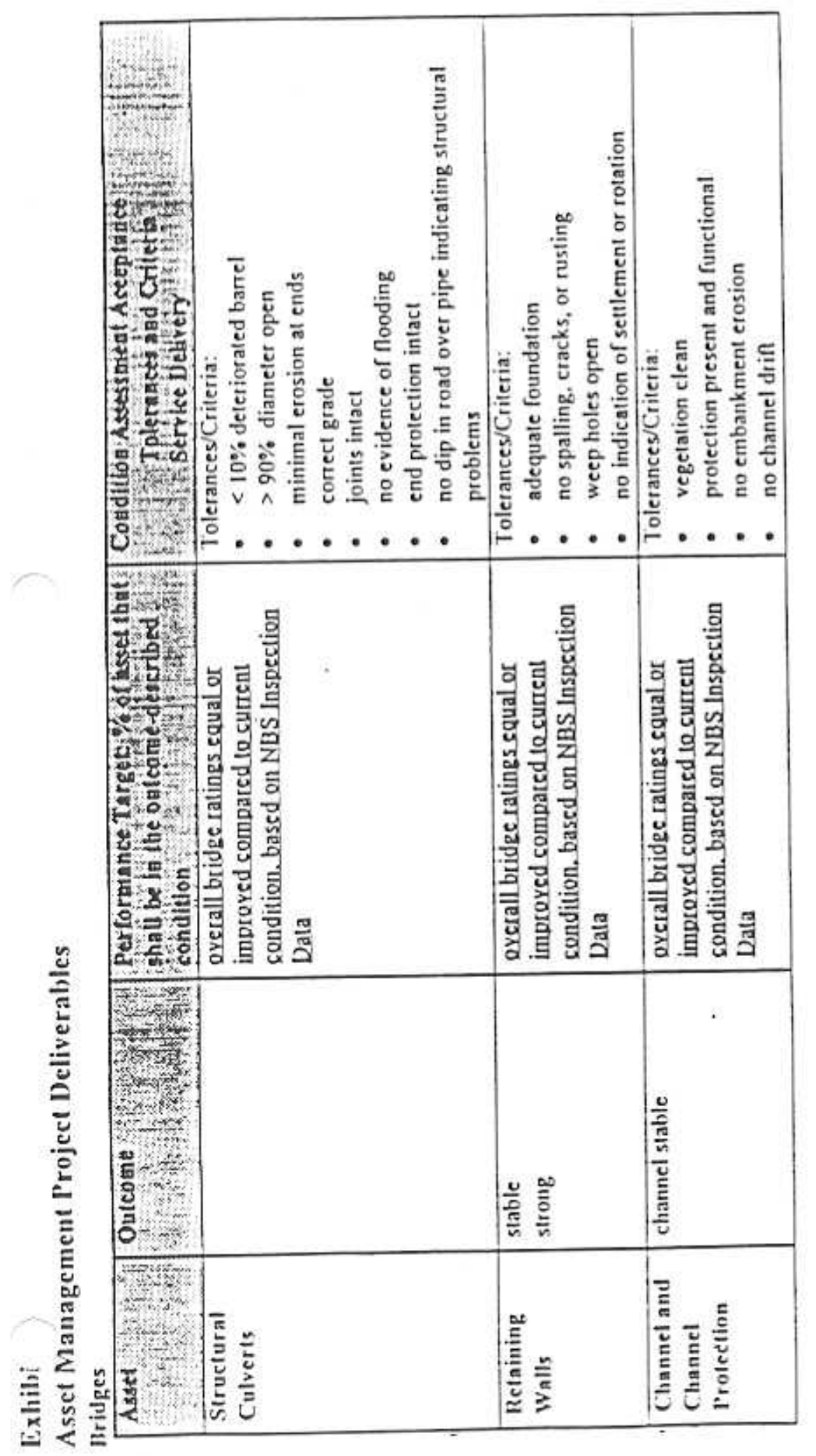

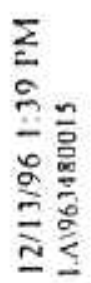




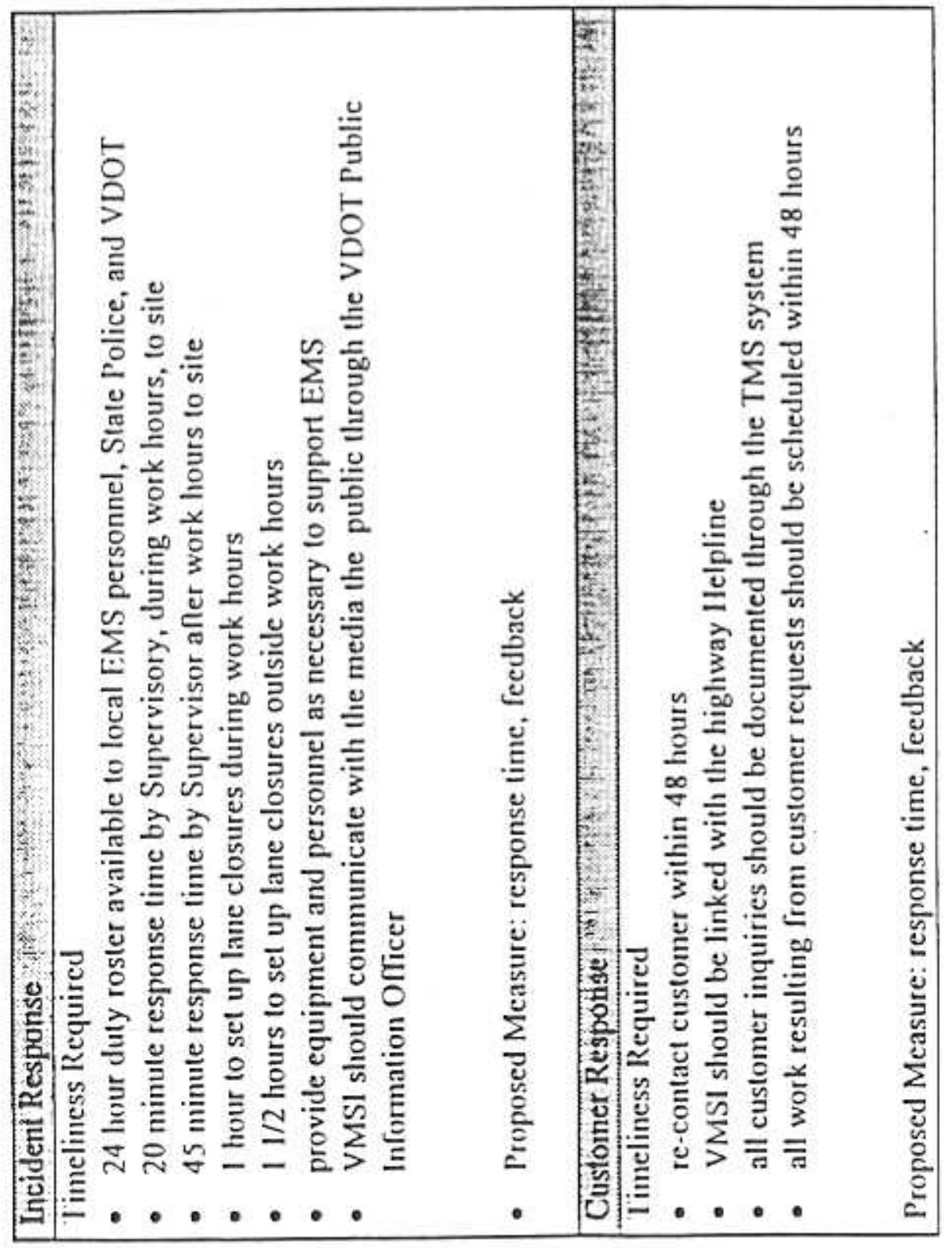

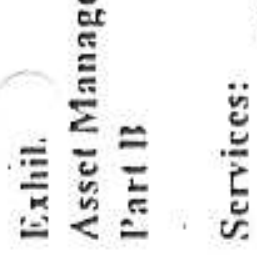




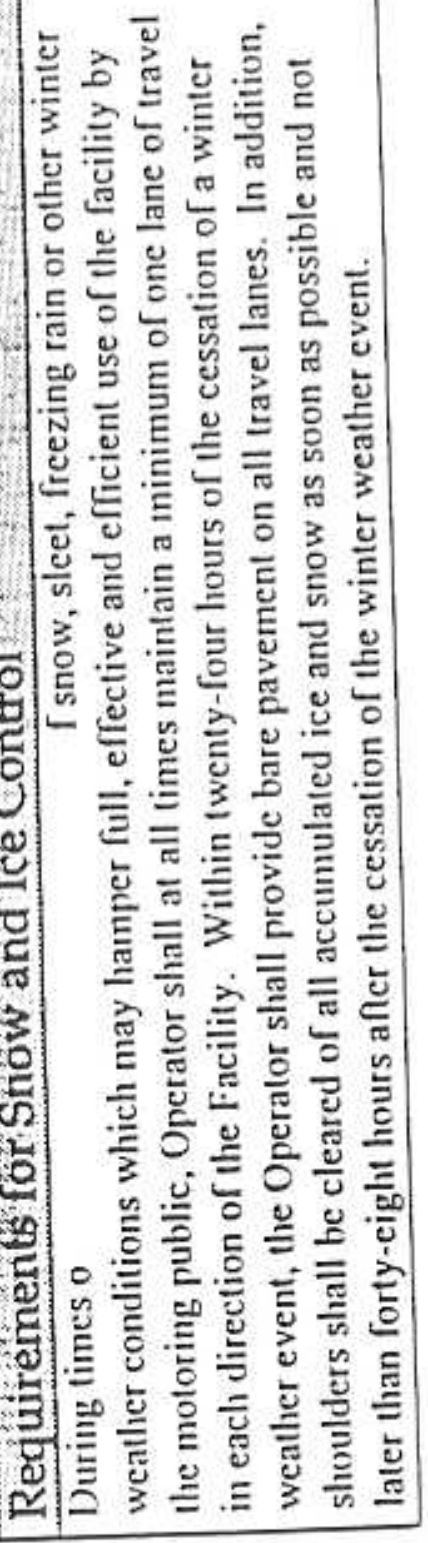




\section{APPENDIX B}

\section{LIST OF ASSET ITEMS}

This appendix presents the list of all asset items to be maintained under the VDOT-VMS, Inc. Contract.

Reference:

VDOT. (1996). "Comprehensive agreement for interstate highway asset management services.” December. 


\begin{tabular}{|c|c|}
\hline Asset Group & Asset Item \\
\hline Shoulders & \begin{tabular}{|l|} 
Shoulders- Hard Surfaced \\
Shoulders- Non-hard Surfaced
\end{tabular} \\
\hline \multirow{7}{*}{ Roadside } & Grass \\
\hline & Landscaping \\
\hline & Brush and Tree Control \\
\hline & Concrete Barrier \\
\hline & Sound Barrier \\
\hline & Slopes \\
\hline & Fence \\
\hline \multirow{9}{*}{ Drainage } & Paved Ditches \\
\hline & Unpaved Ditches \\
\hline & Pipes \\
\hline & Box Culverts \\
\hline & Under/Edge Drains \\
\hline & Storm Drains/Drop Inlets \\
\hline & Curb and Gutter \\
\hline & Sidewalks \\
\hline & Storm Water Management Ponds \\
\hline \multirow{14}{*}{ Traffic } & Signals \\
\hline & Pavement Messages \\
\hline & Pavement Striping \\
\hline & Pavement Makers (raised/recessed) \\
\hline & Delineators/Object Markers \\
\hline & Glare Foils \\
\hline & Regulatory Signs \\
\hline & Other Signs \\
\hline & Luminaries \\
\hline & Guardrail \\
\hline & Impact Attenuators \\
\hline & Truck Ramps \\
\hline & Cross Overs \\
\hline & Rumble Strips \\
\hline
\end{tabular}




\section{APPENDIX C}

\section{WARRANTY CLAUSES USED BY VARIOUS STATE DOTS}

This appendix presents some examples of the warranty clauses used by the Ohio Department of Transportation, Wisconsin Department of Transportation, and Florida Department of Transportation for their road construction and maintenance projects.

References:

FDOT. (2000). “Traffic stripes and markings- Performance based.” Section 707. February 16.

<http://www.dot.state.fl.us/specificationsoffice/PerformanceBased/D7070000.d03.pdf>

FDOT. (2002). “Contractor guaranteed asphalt pavement.” Section 338. April 15. <http://www.dot.state.fl.us/specificationsoffice/PerformanceBased/D3380000IMP.pdf>

FDOT. “Contractor's warranty period for signal installations.” Section 611-5. <http://www.dot.state.fl.us/specificationsoffice/PerformanceBased/Contractor's\%20Warr anty\%20Period\%20for\%20Signal\%20Installations.pdf>

Krebs, S.W., Duckert, B., Schwandt, S., Volker, J., Brokaw, T., Shemwell, W., and Waelti, G. (2001). “Asphaltic pavement warranties, five year progress report.” WisDOT, FHWA, WAPA, June.

ODOT. (2002). “Microsurfacing with warranty.” Supplemental Specification 881. October

18. <http://www.dot.state.oh.us/construction/OCA/Specs/SSandPN2002/8811002.pdf>

ODOT. (2003). “Concrete pavement with warranty.” Supplemental Specification 884. April 18. <http://www.dot.state.oh.us/construction/OCA/Specs/SSandPN2002/8840403.pdf> 
WARRANTY CLAUSES USED BY THE OHIO DEPARTMENT OF TRANSPORTATION 


\title{
STATE OF OHIO \\ DEPARTMENT OF TRANSPORTATION
}

SUPPLEMENTAL SPECIFICATION 884

CONCRETE PAVEMENT WITH WARRANTY

April 18, 2003

\begin{abstract}
884.01 General
884.02 Maintenance Bond

884.03 Warranty Item Coverage

884.04 Concrete Mix Design and Construction

884.05 Annual Review Process

884.06 Remedial Action

884.07 Appeal Process

884.08 Method of Measurement

884.09 Basis of Payment
\end{abstract}

884.01 General. This work shall consist of constructing a Portland cement concrete pavement on a prepared surface in accordance with these specifications and in reasonably close conformity with the lines, grades and typical sections shown on the plans or established by the Engineer. The contractor shall use conventional concrete paving equipment, methods and materials as specified in 451or 452, except as modified by this specification. The Contractor shall warrant the concrete pavement surface for seven years. The Contractor has the option of using Item 451, reinforced Portland cement concrete pavement or Item 452, plain Portland cement concrete under this specification at the thickness specified.

884.02 Maintenance Bond. When the successful Bidder provides the Department with the performance and payment bonds specified in 103.05, the successful Bidder shall also furnish a maintenance bond for seven years in the amount of 40 percent of the price bid for the entire pavement area that is to be warranted.

The Surety that underwrites the maintenance bond is required to have an A.M. Best rating of "A -" or better. The cost of the maintenance bond shall be included in the pay item for the premium for the contract performance bond and the payment bond.

The effective date of the maintenance bond is the date the Department's Form C-85 is issued for the pavement. The issuance of a final C-85 shall occur within 30 days after all of the pavement items, including all safety items, are completed and accepted, and the pavement is open to traffic. The issuance of a partial C-85 shall occur within 30 days after the pavement is completed and accepted, and all safety items are in place to allow the pavement to be safely open to traffic during the winter months from December 1 to April 30. No more than one C-85 will be written each calendar year except with approval of the Director. 
After the final or partial Form C-85 is issued, the Department will notify the Surety. After the Final C-85 is issued, the Department will also establish all final quantities for the project and the project will be finalized using standard procedures. The maintenance bond expires seven years from the issuance of Form C-85.

The Contractor shall maintain the liability insurance specified in 107.12, insuring against Contractor or Contractor authorized operations negligently performed during the warranty period. This insurance shall be in effect throughout the warranty period. A copy of the Certificate of Insurance shall be sent to the District each year.

884.03 Warranty Item Coverage. Warranty items and Remedial Actions are specified in Table A. The warranty applies to all of the concrete pavement (including but not limited to the mainline pavement lanes, shoulders, acceleration/deceleration lanes, collector/distributors and ramps). The warranty does not apply to structural problems below the pavement placed as part of this project, provided the structural problem is not the fault of the Contractor. The Threshold Levels are based on the 0.1 mile $(160 \mathrm{~m})$ Segments described in 884.04.

Meeting the minimum requirements and guidelines of this specification are not to be construed as a warranty, expressed or implied, as to the materials properties and workmanship efforts required to meet the performance criteria set forth in Table $A$.

The design designation in the plan is an indication of the level of traffic expected on this project. Design information, criteria, and calculations are on file in the District office. The warranty requirements of a Section will be waived if the Equivalent 18,000 pound Single Axle Loads (ESALS), calculated using current information and established Department procedures, exceeds the design calculated ESAL's, prorated for the period of years specified in the pay item, by 20 percent or more.

\subsection{Concrete Mix Design and Construction.}

Concrete Mix Design. The concrete mix design used in the concrete pavement shall meet, as a minimum, the requirements of 499, Class $C$ and any other material requirements of 451 and 452. The Contractor may submit a mix design with more cement than specified above. Any request must be proposed in writing to the Engineer. The request shall include historic documentation of compressive and/or flexural strength at 3, 5, 7 and 28 days. The Contractor shall provide certified test data in accordance with 101.03 from a recognized testing laboratory that shows the proposed proportioning will meet a minimum strength requirement of 4000 psi at 28 days of age. A recognized testing laboratory is any laboratory regularly inspected and approved by the Cement and Concrete Reference Laboratory. The proposed mix designs shall be approved by the Director. Any adjustments shall be approved by the Engineer.

Construction. In addition to the maximum joint spacing specified for Item 451 and 452 , the minimum spacing for both types of pavement shall be 12 feet $(3.6 \mathrm{~m})$.

The Contractor may choose to either seal or not seal transverse and longitudinal contraction joints in accordance with Section 451.15. Construct unsealed contraction joints to meet 451.08 (D). The option does not apply to planned expansion joints, joints constructed adjacent to fixed objects, as designated in the plans or required in the Specifications. 
The completed surface shall meet 451.12 , unless the surface tolerance requirements for the Portland cement concrete pavement is modified elsewhere in the contract documents for this project.

The Contractor shall notify the Engineer a minimum of 24 hours prior to start of any concrete paving.

884.05 Annual Review. During the warranty period the Remedial Work will be performed at no cost to the State and will be based on the annual review by the Department. The project shall be divided into 1 mile $(1600 \mathrm{~m})$ Sections. The width of each Section will be the width of a single lane or shoulder. Each Section shall be divided into 0.1 mile $(160 \mathrm{~m})$ Segments.

Each year, between March 1 and April 30, the project will be reviewed by a District Review Team (DRT). The DRT shall notify the Contractor of the scheduled review. The Contractor or any other interested party may attend the annual review, for observation only. Any comments by the Contractor or other interested party will be recorded by the DRT. The DRT will select at least two Segments in each Section to review, but may review the entire section. Within 15 days after the completion of the review, the results will be issued in writing to the Contractor.

The District Deputy Director may waive this yearly review for all or part of the project based on the results of a preliminary review by a member of the DRT. Any such waiver will be in writing to the Contractor.

884.06 Remedial Action. The intent of this contract is for the Contractor to provide a maintenance free pavement. The Contractor may perform routine maintenance during the warranty period, but this routine maintenance is limited to repairs authorized by the Department.

The Contractor's traffic control for performing any work required or allowed by this specification during the warranty period shall be in accordance with current Department policy, the Ohio Manual of Uniform Traffic Control Devices for Streets and Highways, and subject to Department approval of the time the work will be performed. Any major change in Department construction traffic control policy will be considered a changed condition.

Portland cement concrete, joint sealer material, or other materials used for Remedial Action work shall be approved by the Engineer. For Remedial Action work, the Engineer may approve alternatives to the extent or type of specified Remedial Action.

Any pavement markings or raised pavement markers (RPM) removed or obliterated while performing a Remedial Action shall be replaced with pavement markings or RPMs equal to or better than the original products at the Contractor's cost.

All Remedial Actions shall be performed on or before November 15. If an appeal process goes to step 3, the District may revise the date for the completion of the Remedial Action for the appealed item. Prior to performance of a Remedial Action, the Contractor shall submit a Remedial Action plan to the Engineer for approval. This plan shall state when and how the Remedial Action will be done, what material will be used and how traffic will be controlled while the Contractor is performing the Remedial Action. Remedial Action work performed by the Contractor shall be warrantied for 
the remainder of the warranty period.

Emergency work, repairing pavement distresses that are hazardous to the traveling public, will be performed by the Department. If the emergency work is extensive, the Department may authorize the Contractor to do the repairs. The District Construction Engineer (DCE) will determine if the distress is or is not the fault of the Contractor. If the DCE determines the distress is the fault of the Contractor, the cost of this emergency work, no matter who does the emergency work, including traffic control, will be paid by the Contractor. The Contractor is not responsible for pavement damage beyond the Contractor's control (i.e., car fire, oil spill, etc.). The Contractor may appeal the DCE's determination in accordance with 884.07.

884.07 Appeal Process. The Contractor may appeal a finding of the DRT. Any appeal shall be submitted to the DCE, in writing, within 15 days after the written results of the DRT are given to the Contractor.

The DCE will evaluate the Contractor's appeal. This evaluation will include reviewing the disputed area in the field and consulting with the Office of Construction Administration. The evaluation may also include reviewing test data, obtaining samples, or interviewing Department (District or Central Office) or Contractor employees. The DCE's determination will be issued in writing to the Contractor within 45 days after the DCE receives the appeal.

If the Contractor disagrees with the DCE's determination, the Contractor may appeal the determination using step three of the Dispute Resolution and Administrative Claim process.

884.08 Method of Measurement The department will use 451.18 or 452.03 for measurement.

884.09 Basis of Payment. The requirements of 451.18 and 451.19 shall apply. Payment for accepted quantities completed in place will be made at the contract price for:

Item Unit Description

884 Square yard (Square Meter) Portland cement concrete pavement (7 year warranty) 


\begin{tabular}{|c|c|c|}
\hline Distress Type & Threshold Level (per Segment) & Remedial Action \\
\hline $\begin{array}{l}\text { Joint Sealer } \\
\text { (1) (10) }\end{array}$ & $\begin{array}{l}\text { Any pre-formed sealer not in its intended position, } \\
\text { twisted or rolled, missing, not adhering to sides of } \\
\text { joint or exhibiting compression set. } \\
\text { Any hot poured sealer exhibiting adhesive failure } \\
\text { (debonding) or cohesive failure (material splitting) or } \\
\text { both or completely missing material. }\end{array}$ & $\begin{array}{l}\text { Remove, prepare } \\
\text { and replace the } \\
\text { sealant in kind }\end{array}$ \\
\hline & $\begin{array}{l}\text { Any transverse or diagonal cracks in } 452 \text { plain } \\
\text { Portland cement concrete pavement that touch two or } \\
\text { more boundaries of the slab; or that touch one } \\
\text { boundary of the slab and are } 1 / 16 \text { inch ( } 1.5 \mathrm{~mm} \text { ) wide } \\
\text { or wider at any point: } \\
\text { One transverse or diagonal crack per panel } \\
\text { Two or more transverse or diagonal cracks per } \\
\text { panel } \\
\text { Any transverse or diagonal cracks in } 451 \text { reinforced } \\
\text { Portland cement concrete pavement that touch two or } \\
\text { more boundaries of the slab and are open or spalled } \\
\text { at the surface to a width of } 1 / 4 \text { inch (6 mm) over a } \\
\text { distance equal to at least one-half the crack length; or } \\
\text { that touch one boundary of the slab and are at least } \\
4 \text { feet (1.2 m) long and are open or spalled at the } \\
\text { surface to a width of } 1 / 4 \text { inch ( } 6 \text { mm) over a distance } \\
\text { equal to at least one-half the crack length: } \\
\text { One transverse or diagonal crack per panel } \\
\text { Two or more transverse or diagonal cracks per } \\
\text { panel } \\
\text { Any longitudinal cracks: } \\
>15 \text { inches ( } 380 \text { mm) from a longitudinal joint } \\
\leq 15 \text { inches ( } 380 \mathrm{~mm} \text { ) from a longitudinal joint }\end{array}$ & $\begin{array}{l} \\
(5) \\
(6) \\
\\
(6) \\
(7)\end{array}$ \\
\hline $\begin{array}{l}\text { Disintegrated Areas } \\
\text { (3) }\end{array}$ & $\begin{array}{l}\text { Total surface distress greater than one (1) square } \\
\text { foot ( } 0.09 \text { square meters) }\end{array}$ & (8) \\
\hline $\begin{array}{l}\text { Faulting } \\
\text { (4) }\end{array}$ & Any faulting greater than $3 / 16$ inch $(5 \mathrm{~mm})$ & (9) \\
\hline
\end{tabular}


(1) Joint sealer criteria for determining failure will differ depending on whether the transverse joint material (pre-formed elastomeric sealer 705.11) or longitudinal joint material (hot applied sealer, 705.04) is being evaluated.

(2) This distress is defined as any type of cracking (longitudinal, transverse or diagonal) which is visible to the naked eye under dry conditions.

(3) A disintegrated area includes all types of surface disintegration. Surface disintegration is defined as, but not limited to, joint spalling, scaling, high steel mesh (if applicable), and mud or cement balls. For this specification, aggregate popouts are not considered to be surface disintegration.

(4) Differential settlement of one slab in relation to the adjacent slab on either side of a transverse joint or crack. Measured in the wheel path.

(5) Restore load transfer in the wheel tracks or replace concrete slab full depth from transverse joint to transverse joint. Repairs with Item 255, Full Depth Pavement Removal and Rigid Replacement with Type Y-Y joints per Standard Construction Drawings are permitted provided the repair limits are more than 7 feet $(2.1 \mathrm{~m})$ from any transverse joint.

(6) Replace concrete slab full depth from transverse joint to transverse joint. Repairs with Item 255, Full Depth Pavement Removal and Rigid Replacement with Type Y-Y joints per Standard Construction Drawings are permitted provided the repair limits are more than 7 feet $(2.1 \mathrm{~m})$ from any transverse joint.

(7) Rout and seal crack with hot applied joint sealer.

(8) Bonded concrete repair, full depth repair or slab replacement as directed by the Engineer depending on the extent of deterioration.

(9) Repair joints or cracks with Item 255, Full Depth Pavement Removal and Rigid Replacement with Type Y-Y joints per Standard Construction Drawings or, for joints only, subseal in accordance with Supplemental Specifications 812 or 813 and diamond grind full width if necessary.

(10) If transverse and longitudinal contraction joints were not sealed under 884.04 distress type for joint sealer does not apply. 


\section{DEPARTMENT OF TRANSPORTATION}

SUPPLEMENTAL SPECIFICATION 881

MICROSURFACING WITH WARRANTY

October 18, 2002

$\begin{array}{ll}881.01 & \text { General } \\ 881.02 & \text { Maintenance Bond } \\ 881.03 & \text { Warranty Item Coverage } \\ 881.04 & \text { Mix Design and Materials } \\ 881.05 & \text { Annual Review Process } \\ 881.06 & \text { Remedial Action } \\ 881.07 & \text { Appeal Process } \\ 881.08 & \text { Method of Measurement } \\ 881.09 & \text { Basis of Payment }\end{array}$

881.01 General. This work consists of constructing a cold laid polymer modified emulsified asphalt pavement course to fill ruts or provide one or more courses for existing pavements. Warrant the microsurfacing for three years.

881.02 Maintenance Bond. Provide a maintenance bond for a three year period equal to 75 percent of the total amount bid for Item 881 . Furnish this bond at the same time the performance and payment bonds specified in 103.05 are provided.

The Surety that underwrites the maintenance bond is required to have an A.M. Best rating of "A -" or better. The cost of the maintenance bond is included in the pay item for the premium for the contract performance and payment bonds.

The effective date of the maintenance bond is the date the Department's Form C-85 is issued for the pavement. The Department will issue a final C-85 within 30 days after all of the pavement items, including all safety items, are completed and the pavement is open to traffic. The Department will issue a partial C-85 within 30 days after the pavement is completed and accepted, and all safety items are in place to allow the pavement to be safely open to traffic during the winter months from December 1 to April 30. The Department will issue no more than one C-85 each calendar year except with approval of the Director.

After the final or partial Form C-85 is issued, the Department will notify the Surety. After the Final C-85 is issued, the Department will also establish all final quantities for the project and the project will be finalized using standard procedures. The maintenance bond expires 3 years after the issuance of Form C-85.

Maintain the liability insurance specified in 107.12, insuring against Contractor or Contractor authorized operations negligently performed during the warranty period. Provide this insurance throughout the warranty period. 
881.03 Warranty Item Coverage. Meeting the minimum requirements and guidelines of this specification are not to be construed as a warranty, expressed or implied, as to the material properties and workmanship efforts required to meet the performance criteria specified.

Supply all material and labor to perform the Warranty Work at no additional cost to the Department. Perform Warranty Work with material meeting the requirements of 881.04. Certify the component materials and designed mix meet the requirements of 881.04 .

Perform Warranty Work by August 31 of the same year as the review. If an appeal process goes to step 3, the District may revise the date for the completion of the Remedial Action for the appealed item. If any 1000 foot (300 meter) lane segment has repairs or defects greater than 5 percent of the area, resurface with a full lane width of microsurfacing meeting the requirements of 881.04 . Use only microsurfacing for permanent repair and resurfacing areas.

If the Department determines that immediate repairs are necessary, due to a potential hazard to the traveling public, the Department will notify the Contractor and establish a date that all repairs are to be finished.

Perform temporary repairs using material approved by the Engineer. Replace temporary repairs with a permanent repair as soon as weather permits.

Develop a traffic control plan for performing any work required or allowed by this specification during the warranty period in conformance with current Department policy and the Ohio Manual of Uniform Traffic Control Devices for Streets and Highways. The Department will approve when the work is performed. Any major change in Department construction traffic control policy at the time of bid will be considered a changed condition.

881.04 Materials, Mixture, Equipment, and Quality Control. Provide material meeting the requirements of 421.02. Ensure the mixture meets the requirements of 421.03.

Use self-contained, self-propelled, continuous loading units designed for microsurfacing.

Submit a material quality control plan and final mix design to the District Engineer of Tests and Laboratory a minimum of two weeks before the start of production. Submit changes occurring in the mix design during production.

A. Surface Preparation. Prepare surface as specified in 421.08 except the Contractor is responsible for all surface preparation including cleaning, removal of any paint or plastic markings, tack coat and any other work that may effect the performance of microsurfacing.

Seal visible joints and cracks longer than 2 feet $(600 \mathrm{~mm})$ in length as specified in 423.

B. Test Strip. Construct a test strip for the Engineer to evaluate. Construct this test strip 1000 feet $(300 \mathrm{~m})$ long, and include all of the application courses specified. 
Construct the test strip at the same time of day or night the full production will be applied. The Contractor may construct the test strip in 2 days or nights if 881.04D multiple course applications are specified.

The Engineer will evaluate the completed test strip after 24 hours of traffic to determine if the mix design is acceptable. The Contractor may begin full production after the Engineer accepts the test strip.

If the microsurfacing is applied between May 1 and September 30 and If during the construction season the Contractor has constructed a Department approved test strip with the same materials and mix design, the Department will waive the test strip.

C. Single Course Construction. Apply one course of microsurfacing mixture. Construct the course using 421.02 Gradation A aggregate at a minimum rate of 18 pounds per square yard $\left(9.8 \mathrm{~kg} / \mathrm{m}^{2}\right)$ of dry aggregate or 421.02 Gradation B aggregate at a minimum rate of 20 pounds per square yard $\left(11 \mathrm{~kg} / \mathrm{m}^{2}\right)$ of dry aggregate.

D. Multiple Course Construction. Apply a minimum of two courses of microsurfacing mixture. Apply each course separately. Restore the pavement cross section by either rut filling or leveling courses, or a combination of both. Apply this cross section correction to the driving lanes only, before placing the surface course. Apply the surface course to the entire paving pass, which may include the shoulder if specified in the plans. Apply a total combined minimum application rate of 30 pounds per square yard $\left(16.3 \mathrm{~kg} / \mathrm{m}^{2}\right)$ of dry aggregate. The Department may specify, in the plans, a $881.04 \mathrm{C}$ single course microsurfacing on the shoulders.

Rut fill pavement segments greater than 1000 feet (300 meter) in length that have an average rut depth exceeding 0.5 inch $(12 \mathrm{~mm}$ ). Use a microsurfacing mix with 421.02 Gradation B aggregate. Use an approved rut box for each designated wheel track. Construct a clean overlap and straight edges between wheel tracks. Over crown each rutted wheel track to allow for proper traffic consolidation. (For each 1 inch $(25 \mathrm{~mm})$ of applied mix, an additional 0.125 to 0.25 inches ( 3 to $5 \mathrm{~mm}$ ) crown is required for traffic consolidation.)

If leveling courses are used to profile the pavement, use a microsurfacing mix with 421.02 Gradation A or B aggregate.

Construct the final surface course using 421.02 Gradation A aggregate at a minimum application rate of 16 pounds per square yard $\left(9 \mathrm{~kg} / \mathrm{m}^{2}\right)$ of dry aggregate or 421.02 Gradation B at a minimum application rate of 20 pounds per square yard $\left(11 \mathrm{~kg} / \mathrm{m}^{2}\right)$ of dry aggregate.

E. Finished Pavement. Do not allow traffic on the mixture until it has cured sufficiently to prevent pickup by vehicle tires. Ensure the new surface is capable of carrying normal traffic within one hour after application without any damage occurring. Ensure filled ruts are able to sustain traffic within 2 hours after placement. Protect the new surface from potential damage at intersections and driveways.

Ensure the finished surface is free from excessive scratch marks, tears, rippling, and 
other surface irregularities. Ensure the surface area does not contain transverse ripples or longitudinal streaks of 0.2 inch $(5 \mathrm{~mm})$ or more in depth, as measured with a 10 foot (3 meter) straight edge. Ensure the surface area does not exhibit tear marks greater than 0.5 inch $(13 \mathrm{~mm})$ wide and 4 inches $(100 \mathrm{~mm})$ long, or a tear mark greater than 1 inch (25 $\mathrm{mm}$ ) wide and 3 inches $(75 \mathrm{~mm})$ long.

Ensure the longitudinal construction joints and lane edges coincide with the proposed painted lane lines. Construct longitudinal joints with less than a 3 inch $(75 \mathrm{~mm})$ overlap on adjacent passes and no more than 0.25 inch $(6.5 \mathrm{~mm})$ overlap thickness as measured with a 10 foot (3 meter) straight edge. If applicable, place overlapping passes on the uphill side to prevent any ponding of water. Construct neat and uniform transverse joints with no more than a 0.2 inch $(5 \mathrm{~mm})$ difference in elevation across the joint as measured with a 10 foot (3 meter) straight edge. Ensure the edge is neat and uniform with no more than 2 inches $(50 \mathrm{~mm})$ of horizontal variance in any 100 feet (30 meters).

Ensure the restored cross section of the pavement section between any edge line, lane line or center line as measured using a 10 foot (3 meter) straight edge transversely across the pavement does not exceed 0.4 inch $(10 \mathrm{~mm})$, or 0.2 inch $(5 \mathrm{~mm})$ when measured with a 6 foot $(1.8 \mathrm{~m})$ straight edge. The preceding does not apply to any pavement segment that is designed with a quarter crown cross slope or any area of the pavement within 1 foot $(300 \mathrm{~mm})$ of the edge line, lane line or center line. These cross section requirements do not apply to $881.04 \mathrm{C}$ single course microsurfacing.

881.05 Annual Review Process. The District Review Team (DRT) will review the pavement before June 1 each year during the warranty period to determine the performance of the microsurfacing. Repair areas of the pavement that do not meet the Threshold Levels specified in Table A. The District will notify the Contractor in writing of any required Warranty Work.

\subsection{Remedial Actions.}

\begin{tabular}{|l|l|}
\hline \multicolumn{2}{|c|}{ TABLE A - DISTRESS TYPES AND THRESHOLD LEVELS } \\
\hline \multicolumn{1}{|c|}{ Distress Type } & \multicolumn{1}{c|}{ Threshold Level $(6)$} \\
\hline Bleeding / Flushing (1) & 300 square feet $\left(28 \mathrm{~m}^{2}\right)$ \\
\hline Surface Loss $(2)$ & 120 square feet $\left(11 \mathrm{~m}^{2}\right)$ \\
\hline Raveling (3) & 300 square feet $\left(28 \mathrm{~m}^{2}\right)$ \\
\hline Rutting (4)(5) & 0.25 inch $(6.5 \mathrm{~mm})$ continuous in any Segment. \\
\hline
\end{tabular}


Notes:

(1) Excess asphalt binder that creates a shiny, reflective condition that becomes tacky to the touch at higher temperatures.

(2) Loss of surface interlock by traffic wear, debonding, or delamination.

(3) "Moderate" level raveling as defined in the Strategic Highway Research Program (SHRP) "Distress Identification Manual for the Long-Term Pavement Performance Project" (SHRP-P-338).

(4) Measure the wheel path with a 4 foot (1.2 meter) straight edge.

(5) Only applies during the first 120 days after the Form C-85 is issued (see $881.02)$ or after any Warranty work.

(6) Based on 500 foot (150 meter) lane Segment. The beginning of a Segment is the beginning of any distress type.

881.07 Appeal Process. The Contractor may appeal a finding of the DRT. Submit the appeal to the DCE, in writing, within 15 days after the written results of the DRT are received.

The DCE will evaluate the Contractor's appeal. This evaluation will include reviewing the disputed area in the field and consulting with the Office of Construction Administration. The evaluation may also include reviewing test data, obtaining samples, or interviewing Department (District or Central Office) or Contractor employees. The DCE's determination will be issued in writing to the Contractor within 45 days after the DCE receives the appeal.

If in disagreement with the DCE's determination, appeal the determination using Step 3 of the Dispute Resolution and Administrative Claim Process.

881.08 Method of Measurement. The Department will measure microsurfacing with warranty, single course, or microsurfacing with warranty, multiple course by the number of square yards (square meters), completed and accepted in place. The Department will base the width of the pavement course on the width shown on the plans, specified in this specification, or directed by the Engineer. The Department will measure the length along the centerline of each roadway or ramp.

881.09 Basis of Payment. The cost of surface preparation is incidental to Microsurfacing With Warranty.

The Department will not pay for materials, equipment, and labor to make corrections.

The Department will pay for accepted quantities at the contract prices as follows:

Item Unit

881 Square yard (square meter) 881 Square yard (square meter)
Description

Microsurfacing With Warranty, Single Course. Microsurfacing With Warranty, Multiple Course 
WARRANTY CLAUSE USED BY THE WISCONSIN DEPARTMENT OF TRANSPORTATION 


\section{Mainline Asphaltic Pavement, Warranted, Item 90370 Ancillary Asphaltic Pavement, Warranted, Item 90371}

A. Description.

A.1. General. This work consists of the construction and warranty of asphaltic pavement conforming to the lines and grades shown on the plans as directed by the engineer. The contractor will establish the job mix formula, select all materials, and be responsible for the pavement performance and warranty work on the finished pavement for five years following completion of the asphaltic pavement. The provisions of the warranty work apply to all asphaltic mixtures placed under the warranted asphaltic pavement bid items. Sections 401 through 414 of the Standard Specifications are deleted for the warranted asphaltic pavement bid items.

A.2. Mainline Asphaltic Pavement, Warranted. This item consists of all asphaltic pavement placed on both the mainline traveled way and its adjacent mainline shoulders.

A.3. Ancillary Asphaltic Pavement, Warranted. This item consists of all asphaltic pavement, placed on side roads, private and public entrances, ramps, tapers, turn lanes, the new pavement placed within 50 feet $(15 \mathrm{~m})$ of a bridge deck, and other locations not described as Mainline Asphaltic Pavement, Warranted.

B. Warranty. The necessary warranty bond for the asphaltic pavement items will be in effect for the entire five year warranty period beginning when the warranted pavement is completed and open to public traffic. The bonding company must have an A.M. Best rating of "A-" or better and the contractor will provide proof of a five year bond commitment before execution of the contract.

The warranty bond will be $\$$ for the warranted asphaltic pavement. The bond will insure the proper and prompt completion of required warranty work following completion of the pavement, including payments for all labor, equipment, and materials used according to this specification.

For the first year of the warranty bond, the contractor shall provided documentation that the contract bond, which remains in effect for one year beyond the completion of the project, will also include warranty work, as described in Section G. For the remaining four year warranty period, the contractor shall provide documentation that the warranty bond will be provided in one of the following manners:

1. A single term four year warranty bond.

2. A two-year renewable, non-cumulative warranty bond for two consecutive terms.

If the warranted pavement is placed by a subcontractor rather than the contractor, the subcontractor performing the warranted work may provide the warranty bond for the remaining four year warranty period. If a subcontractor does provide the bond, it shall be a dual obligee bond, naming the contractor and the Wisconsin Department of Transportation as obligees. The subcontractor warranty bond will be one of the following:

1. A single term four year warranty bond.

2. A two-year renewable, non-cumulative warranty bond for two consecutive terms.

Failure of the contractor, sub-contractor or its surety to issue or renew the warranty bond will be considered a default and will result in forfeiture of $20 \%$ of the face amount of the bond to the Department.

All warranty work will be as prescribed in Section G. At the end of the warranty period, the contractor will be relieved of the responsibility to perform further warranty work, provided all previous 
warranty work has been completed.

C. Quality Control and Documentation. Prior to construction, the contractor will provide the engineer with a Quality Control Plan. The Quality Control Plan shall outline the contractor's material and construction control processes. At a minimum the plan shall include each of the following:

1. A list of the quality control tests that will be used to control the material and construction quality.

2. The quality control sampling, testing and documentation frequencies.

3. The asphaltic pavement job mix formulas (JMF) planned for the project, and the method used to develop the JMF.

4. A list of project materials.

5. The names of the two Conflict Resolution Team members that will represent the contractor, and a proposed third party member.

The engineer will provide the contractor the two names of the Conflict Resolution Team members that will represent the Department, and a response to the third party member proposed by the contractor, within ten days after receiving the Quality Control Plan. If the engineer disagrees with the third party member proposed by the contractor, the engineer will provide an alternate proposal and initiate discussion with the contractor to determine a mutually agreed upon member.

At the completion of the project, the contractor shall provide documentation of the project to the engineer. This documentation shall consist of all quality control test results performed to control materials and construction; and any changes made to typical widths and depths of subgrade, subbase, base, and surface.

D. Conflict Resolution Team. The Conflict Resolution Team will have the final authority to make decisions if a conflict occurs. The team will resolve disputes by a majority vote. The team will consist of two contractor representatives, two Department (District \& Central Office) representatives, and a third party mutually agreed upon by both the Department and the contractor. The cost of the third party will be equally shared between the Department and the contractor. The team members will be identified in writing prior to the start of paving. The team will receive the Department Pavement Surface Distress Survey Training, when it is determined necessary to make a distress survey of the pavement to resolve a dispute.

E. Pavement Distress Surveys, Evaluations, and Contractor Monitoring.

E.1. Pavement Distress Surveys. The Department's Bureau of Highway Construction will conduct a pavement distress survey of the warranted mainline asphaltic pavement during the first year following construction. For the remaining years of the warranty period, the Bureau will conduct distress surveys of the mainline pavement according to the normal surveying cycle of the Bureau, between April 15 and May 15; or if requested by the contractor or district. The Bureau's surveying cycle is dependent on the location of the highway and the highway classification. The Department's Pavement Surface Distress Survey Manual will be used to determine and measure the different types of distress.

The pavement distress surveys will be conducted by dividing the highway system into nominal onemile sections. Two one-tenth mile segments in each mile will be evaluated for pavement distress. One of the segments evaluated will be between 0.3 and 0.4 miles from the start of the section. The second one-tenth mile segment will be selected randomly by the Department. If areas other than the surveyed segments are suspected of meeting or exceeding a threshold level, the Department will divide the entire mainline project pavement into 0.1 mile segments and conduct a distress survey in any, or all, segment(s). The distress survey results will be made available to the district, central office, contractor, and FHWA within 14 days after completion of the survey. Pavement distress threshold criterion are listed in Section F.

If any of the threshold level criterion are met and the contractor agrees to the validity of the pavement distress survey results, the contractor will remedy the distress. Remedial work shall be determined according to Section G. If any of the threshold level criterion are met and the contractor does not agree to the validity 
of the pavement distress survey results, written notification of the dispute will be made to the engineer by June 15. The Conflict Resolution Team will resolve the dispute.

E.2. Ancillary Pavement Evaluation, Fifth Year. In the fifth year of the warranty period, and in the interim years if requested by the contractor or district, a department and a contractor representative will, together, review and evaluate the project's Ancillary Asphaltic Pavement, Warranted. The pavement will be evaluated for performance in regards to its intended purpose.

If both the department representative and the contractor representative agree on the pavement's performance and necessary remedial work, the contractor will remedy the distress. If the two evaluators are not in agreement on the need for or type of remedial work, the Conflict Resolution Team will resolve the dispute. If any of the conditions described in the footnotes of the table in Section F are met, the contractor will be relieved of performing the remedial action for the described pavement distress.

E.3. Contractor Monitoring. During the warranty period, the contractor may monitor the pavement using nondestructive procedures. Coring, milling or other destructive procedures may not be performed by the contractor, without approval of the engineer.

F. Table of Distress Types, Threshold Levels, and Remedial Action. The Department will include each of the distress types listed below in the mainline pavement survey. The table lists the remedial action required for each distress type when the corresponding threshold level criterion is met.

\section{DISTRESS TYPE}

Alligator Cracking**

Block Cracking

Edge Raveling

Flushing

Longitudinal Cracking (shoulder line cracking is excluded from the segment measurements),

Longitudinal

Distortion

\section{THRESHOLD LEVELS}

$\geq 1 \%$ of the area in a segment.

$\geq 1 \%$ of the area in a segment.

$\geq 10 \%$ of the segment length.

$\geq 20 \%$ of the segment length.

$>1000$ linear feet for cracks which average greater than $1 / 2$ inch in width

$>1000$ linear feet with $25 \%$ of the linear feet having band cracking or dislodgement.

$\geq 1 \%$ of the segment length.

\section{REMEDIAL ACTION}

Remove and replace distressed layer(s). The removal area shall be equal to $150 \%$ of the distressed surface to a depth not to exceed the warranted pavement.

Remove and replace distressed layer(s). The removal area shall be equal to $110 \%$ of the distressed surface to a depth not to exceed the warranted pavement.

Remove and replace distressed layer(s). The removal area shall be equal to $110 \%$ of the distressed surface to a depth not to exceed the warranted pavement.

Remove and replace distressed surface mixture full depth.

Rout and seal all cracks with nubber crack filling material, or agreed upon equal.

If over 1000 feet, remove pavement and replace for the affected depth. If less than or equal to 1000 feet, place a patch 2 feet in width and 2 feet longer than the crack length, for the affected depth or agreed upon equal.

Remove and replace distressed layer(s). The removal area shall be equal to $110 \%$ of the distressed surface to a depth not to exceed the warranted pavement. 


$\begin{array}{ll}\text { Rutting * } & \geq 0.25 \text { inches in depth, } \\ & <0.5 \text { inches in depth. } \\ & \geq 0.5 \text { inches in depth. } \\ & \geq \text { Slight (for segregation, a } \\ \text { Surface Raveling } & \text { more segregated areas per } \\ & \text { segment. A segregated } \\ & \text { area is } 30 \text { square feet or } \\ & \text { more in size). } \\ & \text { When the warranted } \\ & \text { asphaltic pavement is } \\ & \text { constructed over a } \\ \text { gransverse } & \text { material, base course } \\ \text { Cracking*** cracks per } & \text { segment which have a } \\ & \text { average open width } \\ & \text { greater than } 1 / 2 \text { inch. } \\ & \text { When the warranted } \\ & \text { asphaltic pavement is } \\ & \text { constructed over concrete } \\ \text { pavement, }>50 \text { cracks per } & \text { segment which have an } \\ \text { average open width } \\ \text { greater than } 1 / 2 \text { inch. }\end{array}$

$>25$ cracks per segment with $25 \%$ of the linear feet of cracking baving band cracking or dislodgement.

$\begin{array}{ll}\text { Transverse Distortion } & \begin{array}{l}\geq 1 \% \text { of the segment } \\ \text { length. }\end{array} \\ \text { Patching **, *** } & \begin{array}{l}\geq 150 \text { lincar feet of } \\ \text { patching per segment } \\ \text { (excluding longitudinal } \\ \text { cracking remedial action). }\end{array}\end{array}$

Potholes, slippage areas and other disintegrated areas.

Any presence of this type of distress.
Remove ruts by milling surface with fine-tooth mill, overlaying, or micro surfacing.

Remove and replace surface layer.

Apply a chip seal coat or partial depth repair.

Rout and seal all cracks with a rubberized crack filler, or approved equal.

Rout and seal all cracks with a rubberized crack filler, or approved equal.

Remove and replace distressed layer(s) to a depth not to exceed the warranted pavement.

Remove and replace distressed layer(s). The removal area shall be equal to $110 \%$ of the distressed surface to a depth not to exceed the warranted pavement.

Remove and replace the surface layer or place a minimum $1-1 / 4^{\prime \prime}$ overlay.
Remove and replace the distressed area(s). The removal area will be equal to $150 \%$ of the distressed area to a depth not to exceed the warranted pavement.

* $\quad$ Rutting depth and length will be initially identified using standard WisDOT procedures. If rutting depth meets the threshold criterion, the final rut depth and length will be established by a method mutually agreed upon by the contractor and the Department.

The rutting threshold level is waived when the accumulated ESAL's are $50 \%$ or more above the projected fifth year accumulated ESAL's. The contractor will only be responsible for mixture and placement problems.

** When the warranted asphaltic pavement is constructed over a granular base course material, the 
contractor will be relieved of the responsibility for remedial action for Alligator Cracking if the area in question is of proper thickness (not thinner than 0.5 inches from plan thickness) and the average recovered penetration of the surface course asphalt cement is above 30 and one (or more) of the following are true:

1. the base is plan thickness minus 2.0 inches or thinner, or

2. the subgrade density is less than $90 \%$ of optimum, or

3. the actual accumulated ESAL's are $50 \%$ or more above the projected fifth year accumulated ESAL's.

*** When the warranted asphaltic pavement is constructed over concrete pavement, the contractor will be relieved of the responsibility for remedial action for Transverse Cracking and Patching of the pavement if the area in question is of proper thickness (not thinner than plan thickness minus 0.5 inches) and the concrete pavement below the warranted pavement has experienced a blow up, joint disintegration, or similar failure.

G. Warranty Work. The contractor shall perform Warranty Work, during the five year warranty period, at no additional cost to the Department. Warranty work consists of remedial work, elective/preventive maintenance, and the required fourth year crack routing and sealing. The contractor shall maintain insurance, for performing warranty work, as specified in Section 107.26 of the Standard Specifications throughout the five year warranty period.

During warranty work operations, traffic control will be as specified in Section 643 of the Standard Specifications and all will conform to Part 6 of the Wisconsin Manual on Uniform Traffic Control Devices. The contractor will document all warranty work performed and annually provide this information to the Pavement Performance Section of the Department's Bureau of Highway Construction.

If warranty work necessitates a corrective action to the pavement markings, adjacent lane(s), or shoulders, that additional corrective action will be the responsibility of the contractor.

The contractor will not be held responsible for distresses which are caused by factors beyond the control of the contractor. Emergency repairs of these distresses will be the responsibility of the Department.

G.1. Remedial Work. Remedial work will be based on the results of the mainline pavement distress surveys or the ancillary pavement evaluation. Remedial work shall be performed in the same calendar year that the pavement distresses were recorded. Remedial work to be performed and materials to be used will be the joint decision of the contractor and the engineer. The contractor will not be responsible for damages that result from coring, milling or other destructive procedures conducted by the Department.

For mainline asphaltic pavement segments that meet the distress threshold level criterion of the table in Section F, the contractor shall perform the remedial work prescribed in the remedial action column of the table. The remedial work shall be performed in all segments of the project where a threshold level is met. The remedial work shall be applied to the entire segment(s) and the adjacent lanes and asphaltic shoulders.

For distressed ancillary asphaltic pavement and distressed mainline shoulders not adjacent to distressed mainline pavement the contractor shall perform remedial work as mutually determined by the contractor and the engineer.

If, at anytime during the warranty period, 30 percent or more of the project segments require or have received remedial action, then the entire project will receive remedial action as mutually determined by the contractor and the engineer.

The contractor will have the first option to perform the remedial work. If, in the opinion of the engineer, the problem requires immediate attention for the safety of the traveling public, and the contractor cannot perform the remedial work within eight hours, the engineer may have the remedial work done by other forces and at the contractor's expense. Remedial work performed by other forces will not alter the 
requirements, responsibilities, or obligations of the warranty.

G.2. Elective/Preventive Maintenance. Elective/preventive maintenance will be a contractor option. Elective/preventive maintenance to be performed and materials to be used will be coordinated jointly by the contractor and the engineer.

G.3. Required Fourth Year Crack Routing and Sealing. During the fourth year of pavement service, the contractor shall route and seal the cracks of the mainline and ancillary pavement which extend through the full depth of the surface course with a rubberized crack filler or approved equal material.

H. Method of Measurement. The warranted asphaltic pavement bid items will be measured by the ton, based on the quantity of mixture placed, completed, and accepted. The contractor will present certified records of shipment for the quantities placed under this special provision.

The Department will measure Mainline Asphaltic Pavement, Warranted, as specified above up to a maximum of $105 \%$ of the plan quantity.

The Department will measure Ancillary Asphaltic Pavement, Warranted, as specified above up to a maximum of $105 \%$ of the plan quantity, or the quantity mutually agreed to by the contractor and engineer.

I. Basis of Payment. Mainline Asphaltic Pavement, Warranted; and Ancillary Mainline Asphaltic Pavement, Warranted, as measured above, will be paid for at the contract unit price, that price will be full compensation for furnishing, preparing, hauling, mixing and placing all materials, including asphaltic materials; for compacting mixtures; for preparation of foundation, unless otherwise provided; for the warranty bond(s), and warranty work; for the Quality Control Plan, and required documentation; for traffic control; and for all labor, tools, equipment and incidentals necessary to complete the work. 
WARRANTY CLAUSES USED BY THE FLORIDA DEPARTMENT OF TRANSPORTATION 


\section{CONTRACTOR GUARANTEED ASPHALT PAVEMENT. (REV 4-15-02)}

PAGE 317. The following new Section is inserted after Section 337.

\section{SECTION 338 CONTRACTOR GUARANTEED ASPHALT PAVEMENT}

\section{8-1 Description.}

Construct a Contractor Guaranteed Asphalt Pavement (CGAP) consisting of Asphalt Concrete Structural Course and Asphalt Concrete Friction Course. CGAP requirements will not apply to Asphalt Base or Miscellaneous Asphalt.

Assume responsibility for the quality control, production, placement, compaction, testing and inspection of all CGAP asphalt mixtures. Furnish a copy of all required mix designs to the Engineer at least 14 days prior to any paving work. Assume responsibility for all mix designs, with the exception of FC-5. The Department will provide the mix design for FC-5 mixes.

The requirements of Sections 330, 334 and 337 of the Standard Specifications, as amended, will apply to CGAP, with the following exceptions:

deleted.

1. All split sample and same sample verification sampling and testing requirements are

2. All independent sample verification sampling and testing shall be conducted as specified, but is for informational purposes only. The minimum frequency for independent sample verification sampling and testing is increased to $1 / 4000$ tons [1/4000 metric tons].

3. All resolution sampling and testing requirements are deleted.

4. All quality control sampling and testing shall be conducted as specified, but are for process control purposes only. Calculate pay factors for informational purposes only. Any specific actions required due to either individual QC test results or low pay factors shall be taken as specified.

The requirements of 9-2.2.4 shall not apply, regardless of where such requirement is contained in the Contract Documents, and any such references are superseded by the requirements of this Special Provision.

The Responsible Party (as defined in 338-2) shall assume maintenance responsibility for all the associated work specified in this section for a period of five years after final acceptance of the Contract in accordance with 5-11, including continued responsibility as to any deficiencies discovered by the Department and as to which notice was provided to the Responsible Party within such 5-year guarantee period until all such pre-existing deficiencies are resolved.

\section{8-2 Responsible Party.}

Prior to any CGAP being placed on the project, the Contractor shall designate a Responsible Party for the CGAP. The Responsible Party shall be either the Contractor or the Department approved subcontractor performing the CGAP work. If the Responsible Party is the subcontractor, the subcontractor shall be a pre-qualified contractor with the Department in the category of asphalt, and such designation must be made to the Department by the Contractor and the proposed subcontractor must execute and deliver to the Department a form, as provided by the Department, whereby the subcontractor assumes all responsibility as the Responsible Party for the CGAP and the 5-year guarantee period as specified in this section, prior to or concurrently with Contractor's request to sublet any CGAP work. Failure to timely designate the Responsible Party shall result in the Contractor being the Responsible Party unless otherwise agreed to in writing by the Department. 
Upon final acceptance of the Contract in accordance with 5-11, the Contractor's responsibility for maintenance of all the work or facilities within the project limits of the Contract will terminate in accordance with 5-11; with the sole exception that the obligations set forth in this section for CGAP shall continue thereafter to be the responsibility of the Responsible Party as otherwise provided in this section.

\section{8-3 Quality Control and Documentation.}

Prior to CGAP construction, the Responsible Party will provide the Engineer with a Quality Control Plan for CGAP. The Quality Control Plan shall outline the Responsible Party's material and construction control processes. At a minimum the Plan shall include each of the following:

1. A list of the quality control tests that will be used to control the material and construction quality.

2. The quality control sampling, testing, corrective actions and documentation frequencies as required by Sections 334 and 337.

3. The asphalt mix design(s) planned for the project. (During production, any changes in the design mix shall also be submitted.)

4. Certification of the materials being used in the project.

At the completion of the project, the Responsible Party shall provide documentation of the CGAP to the Engineer. This documentation shall consist of all quality control test results performed to control materials and construction; and any changes made to the pavement dimensions and/or pavement structure. Final payment will be withheld until satisfactory documentation is provided.

\section{8-4 Pavement Evaluation and Remedial Work.}

The Department's Flexible Pavement Condition Survey Program will be used as a basis for determining the extent and the magnitude of the pavement distresses occurring on the project. The Department will conduct a LOT-by-LOT pavement condition survey (PCS) of the pavement following the final acceptance of the project, and at intermediate times as determined necessary by the Engineer. The final survey will be conducted, no later than 45 calendar days, before the end of guarantee period.

All surveys will be conducted at no cost to the Responsible Party. The Responsible Party will be advised of the survey schedule prior to the survey taking place. The results of the survey, intermediate or final, shall be made available to both the Engineer and the Responsible Party within 15 calendar days after completion of the survey.

If the survey findings, intermediate or final, are to be disputed by the Responsible Party, provide written notification to the Engineer within 30 calendar days of the date of receipt of the survey.

For evaluation purposes, the project will be subdivided into LOTs of one-tenth (0.1) mile [0.2 $\mathrm{km}]$ per lane.

During the guarantee period, the Responsible Party may monitor the project using nondestructive procedures. The Responsible Party shall not conduct any coring, milling or other destructive procedures without prior approval by the Engineer.

338-4.1 Distress Indicators: The Department will use the following pavement distress indicators and methods of measurement of distress to evaluate the CGAP:

a. Rut Depth - As determined by the Department's High Speed Profiler in accordance with the Flexible Pavement Condition Survey Handbook.

b. Rideability - As determined by the Department's High Speed Profiler in accordance with the Flexible Pavement Condition Survey Handbook. The Department will test the quality of the pavement smoothness for final acceptance by laser profiler as specified in 330-13.6.

c. Raveling, Delamination, Potholes, Slippage Areas, and other disintegrated areas - As determined in accordance with the Flexible Pavement Condition Survey Handbook.

d. Cracking - As determined manually in accordance with the Flexible Pavement

Condition Survey Handbook. 
338-4.2 Threshold Values and Remedial Work: Threshold values and associated remedial work for the CMAP are specified in Table 338-1.

\begin{tabular}{|c|c|c|c|}
\hline \multicolumn{4}{|c|}{$\begin{array}{c}\text { TABLE 338-1 } \\
\text { CONDITION SURVEY }\end{array}$} \\
\hline Type of Distress & Type of Survey & $\begin{array}{l}\text { Threshold Level for } \\
\text { Each LOT (0.1 Mile) } \\
\text { per lane }\end{array}$ & Remedial Work \\
\hline \multirow[t]{2}{*}{ Rutting } & \multirow[t]{2}{*}{ Any Survey } & Depth $>0.30 "$ & $\begin{array}{l}\text { Remove and replace the distressed } \\
\text { LOT(s) to the full distressed depth } \\
\text { and full lane width. }\end{array}$ \\
\hline & & Depth $<=0.30 "$ & None required \\
\hline Rideability & Any Survey & $\mathrm{RN}<3.69$ & $\begin{array}{l}\text { Remove and replace the distressed } \\
\text { LOT(s) to the full distressed area(s) } \\
\text { and full lane width }\end{array}$ \\
\hline Cracking & Any Survey & $\begin{array}{l}\text { Cracking }>1 / 8 \text { " (Class } \\
\text { 1B), accumulative } \\
\text { cracking length }>50 \text {, }\end{array}$ & $\begin{array}{l}\text { Remove and replace the distressed } \\
\text { LOT(s) to the full distressed depth } \\
\text { and full lane width. }\end{array}$ \\
\hline \multirow[t]{2}{*}{$\begin{array}{l}\text { Raveling, } \\
\text { delamination and } \\
\text { other } \\
\text { disintegrated } \\
\text { areas affecting } \\
\text { the friction } \\
\text { course }\end{array}$} & $\begin{array}{l}\text { Intermediate } \\
\text { Survey }\end{array}$ & $\begin{array}{l}\text { Underlying layer } \\
\text { exposed, individual } \\
\text { length }>10\end{array}$ & $\begin{array}{l}\text { Remove and replace the distressed } \\
\text { area(s) to the full distressed depth } \\
\text { and full lane width or temporarily } \\
\text { patch the distressed area(s). } \\
\text { Patch the distressed area(s) and } \\
\text { remove and replace the distressed } \\
\text { area(s) to the full distressed depth } \\
\text { and full lane width prior to the final } \\
\text { survey. }\end{array}$ \\
\hline & Final Survey & $\begin{array}{l}\text { Observation by } \\
\text { Engineer: }\end{array}$ & $\begin{array}{l}\text { Remove and replace the distressed } \\
\text { area(s) and extend 50' at both ends } \\
\text { from the distressed area across the } \\
\text { full lane width. }\end{array}$ \\
\hline $\begin{array}{l}\text { Pot holes, } \\
\text { slippage area(s), } \\
\text { segregated } \\
\text { area(s) and other } \\
\text { disintegrated } \\
\text { areas. }\end{array}$ & Any Survey & $\begin{array}{l}\text { Observation by } \\
\text { Engineer }\end{array}$ & $\begin{array}{l}\text { Remove and replace the distressed } \\
\text { area(s) to } 150 \% \text { of the area(s) or } \\
\text { temporarily patch the distressed } \\
\text { area(s) and remove and replace the } \\
\text { distressed area(s) to } 150 \% \text { of the } \\
\text { area(s) prior to the final survey. }\end{array}$ \\
\hline
\end{tabular}

Remark: (1) The Ride Number (RN) established by the laser profiler will express the ride quality of the pavement of a LOT being tested.

(2) For any two deficient LOTs not separated by 3 passing LOTs, the repair work shall cover the entire length of the deficient LOTs (including the passing LOTs). 
(3) If the area of cracking, patching or raveling within a LOT exceeds $60 \%$ of the LOT area, the total LOT shall be corrected by approved methods.

(4) The longitudinal construction joint at the lane line will not be considered as cracking during the survey.

(5) The rideability of the pavement shall be determined in accordance with the requirements of 330-13.6 (Acceptance Testing for Pavement Smoothness by Laser Profiler) and all deficiencies shall be corrected prior to the final acceptance of the project.

If a measured distress value indicates remedial action is required per Table 338-1, the Responsible Party shall begin remedial work within 45 calendar days of notification by the Department or a ruling of the Disputes Review Board. The Disputes Review Board will determine the allowable duration for the completion of the remedial work.

In the event remedial action is necessary and forensic information is required to determine the source of the distress, the Department may core or trench the pavement. The Responsible Party will not be responsible for damages to the pavement as a result of any forensic activities conducted by the Department.

The Responsible Party has the first option to perform all remedial work that is determined by the Department to be his responsibility. If, in the opinion of the Engineer, the problem poses an immediate danger to the traveling public and the Responsible Party cannot begin remedial work within 72 hours of written notification, the Engineer has the authority to have the remedial work performed by other forces. The Responsible Party is responsible for all incurred costs of the work performed by other forces should the problem (remedial work) be determined to be it's responsibility. Remedial work performed by other forces does not alter any of the requirements, responsibilities or obligations of the Responsible Party.

The Responsible Party shall complete all remedial work to the satisfaction of the Engineer. Any disputes regarding the adequacy of the remedial work will be resolved by the Disputes Review Board. Approval of remedial work does not relieve the Responsible Party from continuing responsibility under the provisions of this specification.

Notify the Engineer in writing prior to beginning any remedial work. Meet the requirements of the Department's Standard Specifications for Road and Bridge Construction when performing any remedial work.

Perform all remedial works at no cost to the Department. If remedial work necessitates a corrective action to the pavement markings, adjacent lane(s), or roadway shoulders, perform these corrective actions using similar products at no additional cost to the Department.

\section{8-5 Disputes Resolution.}

The project Disputes Review Board will be utilized to resolve any and all disputes that may arise involving administration and enforcement of this Specification. If there is no project specific Disputes Review Board, the current Regional Disputes Review Board for the project area shall have jurisdiction. The Responsible Party, as designated in 338-2, and the Department acknowledge that use of the Disputes Review Board is required and the determinations of the Disputes Review Board for disputes arising out of this CGAP Specification will be binding on both the Responsible Party and the Department, with no right of appeal by either party.

Any and all Disputes Review Board meetings after final acceptance of the Contract in accordance with 5-11 shall be requested and paid for by the Responsible Party. The Department will reimburse the Responsible Party for all fees associated with meetings only if the Disputes Review Board rules substantially in favor of the Responsible Party, otherwise the Responsible Party shall be solely responsible for all such costs. 


\title{
TRAFFIC STRIPES AND MARKINGS - PERFORMANCE BASED. (REV 2-16-00)
}

PAGE 775. The following new Section is added after Section 706:

\author{
SECTION 707 \\ TRAFFIC STRIPES AND MARKINGS \\ PERFORMANCE BASED
}

\section{7-1 Description.}

The work under this Section consists of the application of Traffic Stripes and Markings in accordance with the details shown on the plans, and maintaining and warranting these Traffic Stripes and Markings for a minimum period of five years. The warranty period will begin on the date provided in writing by the Engineer that all striping and markings meet initial acceptance criteria. The Engineer will release the Contractor from further warranty work and responsibility at the end of the warranty period in accordance with 5-11, provided all deficiencies have been corrected and the work accepted by the Engineer.

\section{7-2 Materials.}

707-2.1 General: These materials shall produce an adherent, retroreflective pavement marking system capable of resisting deformation by traffic. Manufacturers will have the option of formulating the material according to their own specifications. However, the requirements specified herein and the performance requirements of this Section will apply for the original application and duration of the warranty period regardless of the type of formulation used. All of the products designated in this Specification shall meet the classification of non-hazardous waste as defined by 40 CFR 261.24 when tested in accordance with EPA Method 1311, Toxicity Characteristics Leaching Procedures (TCLP). The material, upon preparation and installation, shall not exude fumes which are toxic, or detrimental to persons or property.

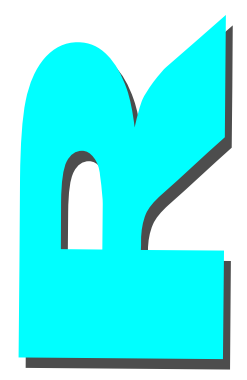

\section{7-2.2 Composition.}

The composition will be determined by the pavement marking manufacturer and shall comply with the requirements of this Section.

The material used shall contain no lead or Resource Conservation and Recovery Act (RCRA) materials, in accordance to EPA Method 3050 and 6010.

707-2.3 Physical Requirements.

707-2.3.1 Set to Bear Traffic Time: Set to Bear Traffic Time is the maximum elapsed time allowed to meet the following condition: After driving over the line in a simulated passing maneuver, with a passenger car at a speed of 25 to $35 \mathrm{mph}$ [ 40 to $56 \mathrm{~km} / \mathrm{h}$ ], there shall be no visual deposition of the striping material to the pavement surface when viewed from a distance of 50 feet [15 $\mathrm{m}$ ].

When applied at the temperatures and thickness specified by the pavement marking manufacturer and this Section, the material shall set to bear traffic in less than two minutes.

707-2.3.2 Color: The white pavement marking material shall be pure white and free from any tint. When tested in accordance with ASTM D 4960, the material shall show no deviations from magnesium oxide color standard greater than the following:

\begin{tabular}{|l|l|l|}
\hline Scale Definition & Magnesium Oxide Standard & Sample \\
\hline RD & $100 \%$ & $75.0 \%$ minimum \\
\hline
\end{tabular}




\begin{tabular}{|l|l|l|}
\hline \multicolumn{2}{|c|}{ Reflectance } \\
\hline Red-Green & 0 & -5 to +5 \\
\hline Yellow-Blue & 0 & -10 to +10 \\
\hline
\end{tabular}

criteria:

The color of the yellow pavement marking material shall meet the following

Initial daytime reflectance (y)......43\% minimum

Initial chromaticity shall fall within the area bordered by the following

coordinates:

\begin{tabular}{|l|l|l|l|l|}
\hline $\mathrm{X}$ & & & & \\
$\mathrm{Y}$ & 0.455 & 0.510 & 0.472 & 0.530 \\
\hline
\end{tabular}

Intermittent and final chromaticity shall fall within the area bordered by the

following coordinates:

\begin{tabular}{|l|l|l|l|l|}
\hline $\mathrm{X}$ & 0.435 & 0.510 & 0.449 & 0.530 \\
\hline $\mathrm{Y}$ & 0.429 & 0.485 & 0.377 & 0.456 \\
\hline
\end{tabular}

\section{7-3 Tolerances in Dimensions and Alignment.}

707-3.1 Dimensions:

707-3.1.1 Longitudinal Lines: Apply traffic stripes with the dimensions shown in the Roadway and Traffic Design Standards, Index No. 17346.

The Contractor may allow the length of the 10 foot [3 m] segment for skip stripe, and the 30 -foot [ $9 \mathrm{~m}$ ] gap between segments to each vary \pm 1 foot $[300 \mathrm{~mm}]$, but must then ensure overtolerance and under-tolerance lengths approximately compensate.

707-3.1.2 Transverse Markings, Gore Markings, Arrows, and Messages: When the specified width of the marking cannot be made with a single pass and multiple passes are required, the Contractor may allow the width of the line to vary by \pm 1 inch $[25 \mathrm{~mm}]$.

707-3.2 Alignment: On tangents, and on curves up to one degree, ensure the alignment of the stripe does not deviate from the string line by more than 1 inch [25 $\mathrm{mm}$ ]. Do not allow the alignment to deviate more than 2 inches [50 $\mathrm{mm}$ ] on curves exceeding one degree. In addition, ensure the outer edge of the edge strip falls uniformly at no less than 2 inches [50 $\mathrm{mm}$ ] or more than 4 inches [100 $\mathrm{mm}$ ] from the edge of pavement, and has no noticeable breaks or deviations in alignment or width. Longitudinal lines shall be offset at least 2 inches $[50 \mathrm{~mm}]$ from construction joints on concrete pavement.

\section{7-4 Acceptance Criteria.}

707-4.1 Measurement Zone: A measurement zone is defined as each 1 mile [kilometer] section or an entire stripe or marking, whichever is less. A measurement zone is deficient when $10 \%$ of the stripes or markings fall below the minimum of any of the specification requirements. The stripes and markings shall meet the following requirements:

707-4.2 Thickness: Edge lines, gore island, diagonal stripe markings, bike lane symbols and messages shall have a thickness of 0.100 inch [2.5 mm] maximum, after application of the glass spheres, when measured above the pavement surface at the edge of the stripe or marking. Lane lines, center lines, transverse markings (except edge lines) and stripes and markings within traffic wearing areas (such as 
dotted turning guide lines) shall have a thickness of 0.150 inch [4.0 mm] maximum, when measured above the pavement surface at the edge of the stripe or marking.

707-4.3 Retroreflectivity: The initial retroreflectivity of white traffic stripes and markings shall be not less than $250 \mathrm{mcd} / \mathrm{lx}-\mathrm{m} 2$. The initial retroreflectivity of yellow traffic stripes and marking shall not be less than $175 \mathrm{mcd} / \mathrm{lx}-\mathrm{m} 2$. Intermittent and final retroreflectivity of white and yellow pavement marking shall not be less than $125 \mathrm{mcd} / \mathrm{lx}-\mathrm{m} 2$. Intermittent and final retroreflectivity requirements will not apply to transverse lines, messages, bike lane symbols and bike longitudinal lines.

707-4.4 Color: The pavement markings shall meet the color requirements of 707-2.3.2.

\section{7-5 Correction of Deficiencies.}

707-5.1 Notice of Deficiencies: Upon notification of a deficiency during initial application or during the warranty period, the Contractor shall correct the deficiency by removal and reapplication of the deficient 1 mile [kilometer] LOT. When the Engineer determines that it is necessary to remove a deficiency, use a method that will not damage the pavement and which will eliminate the marking pattern regardless of weather and light conditions. During the warranty period, deficiencies shall be corrected within 30 days of notification, using the original type material, unless an equal or better material is submitted to and approved by the Department. If the Contractor fails to correct the deficiencies within the 30 days specified above or fails to meet the requirement of the initial testing and certification, the Engineer has the authority to have the deficiencies corrected by any other lawful means, including requiring the surety to correct the deficiencies. The Contractor shall be responsible for the cost of such corrective work. All work and materials required for correction of deficiencies shall be at no cost to the Department.

707-5.2 Exclusion of Deficiencies: If it is found that any one of the following factors applies to the deficiency under consideration, the warranty does not apply to that deficiency:

a. Determination that AADT (Average Annual Daily Traffic) has increased by $25 \%$ or more over the AADT identified in the Contract for a specific road section.

b. Determination that deficiency was due to failure of the pavement surface.

c. Determination that deficiency was due to work done on the roadway by a third party.

\section{7-6 Lane Use Fees.}

It is the desire of the Department to provide durable traffic stripes and markings that minimizes the disruption of traffic. Therefore, should it be necessary for the Contractor to block or close traffic lanes during the warranty period including moving operations, the Contractor will be assessed a "lane use" fee. There will be no lane use fees prior to the warranty period beginning. The lane use fee will be calculated in the following manner.

$\$ 100.00$ per lane mile [ $\$ 62.00$ per lane kilometer] (of blocked or closed roadway), per 10,000 AADT for the roadway (as identified in the Contract) per calendar day.

\section{NON SI EXAMPLE}

A four lane highway with 20,000 AADT, 6 miles in length, would result in a lane use fee of $\$ 4800(\$ 100 \times 4$ lanes x 6 miles x 2 AADT) if all four lanes were blocked or closed at any time during a calendar day. If two lanes of the four lane highway are blocked or closed at any time, the lane use fee would be $\$ 2400$ ( $\$ 100 \times 2$ lanes x 6 miles x 2AADT).

\section{SI EXAMPLE}

A four lane highway with 20,000 AADT, 6 kilometers in length would result in a lane use fee of $\$ 2976$ (\$62 x 4 lanes x 6 kilometers x 2 AADT) if all four lanes were blocked or closed at any time during a calendar day. If two lanes of the four lane highway are blocked or closed at any time, the lane use fee would be $\$ 1488$ ( $\$ 62$ x 2 lanes x 6 kilometers x 2AADT). 


\section{7-7 Certification, Testing Methods and Frequency.}

707-7.1 General: The Contractor is required to provide the Department with testing results and certifications that the markings meet the requirements of 707-2, 707-3, 707-4, and 707-7. The certification of materials for 707-2.1, 707-2.2 and 707-2.3 shall be provided prior to the placement of any materials. The test results shall be certified as meeting the specification requirements by a registered Professional Engineer. The Department may perform spot checks of the stripes and markings. In the event of disputed retroreflectivity or color readings, the 30 meter retroreflectivity or color instrument of the Department shall be deemed decisive.

707-7.2 Initial Testing and Certification: The reflectance and chromaticity shall comply with the initial reflectance and chromaticity requirements of 707-2. Within 90 days after beginning of the Contract time the testing and certification results for each roadway section shall be provided to the Department. Printed documents shall be provided for the initial and warranty periods and will include: route, county, direction, retroreflectivity, dimensional measurements, color, material type, pavement surface, and date of measurement.

707-7.3 Warranty Testing and Certification: The stripes and markings shall be measured annually with a Department approved 30 meter mobile retroreflectometer, and tested and inspected for compliance with specification requirements. The chromaticity shall comply with the intermittent and final chromaticity requirements of 707-2. Each year, within 30 days of the anniversary of acceptance of the stripes and markings, testing and certification results shall be provided to the Department.

707-7.4 Dimensions: The width shall be checked using a ruler to measure the width of the stripe at the beginning, middle and end of each 1 mile [kilometer] LOT. The width for the LOT shall be the average of all measurements taken within the 1 mile [kilometer] LOT. The thickness of markings placed shall be measured using a Starrett No. 270 Taper Gage. Thickness measurements with the Taper Gage are obtained by placing a straight edge lengthwise across the pavement marking and sliding the gage underneath the straight edge until contact is made. Thickness checks shall be made at the beginning, middle and end of each 1 mile [kilometer] LOT. The thickness for the LOT shall be the average of all measurements taken within the 1 mile [kilometer] LOT. The dimension testing will only be required for initial application and for correction of deficiencies.

707-7.5 Retroreflectivity: Stripes and markings shall be evaluated with a Department approved 30 meter mobile retroreflectometer. Retroreflectivity shall be measured per the written instructions of the mobile retroreflectometer manufacturer. Readings shall be accumulated into 0.1 mile [kilometer] zones. The retroreflectivity for the LOT shall be the average of the ten 0.1 mile [kilometer] zones taken with the 1 mile [kilometer] LOT.

707-7.6 Color: For intermittent and final tests, color measurements shall be made after a visual inspection identifies a measurement zone of suspected non-performing color. The daytime reflectance and chromaticity shall be measured with a BYK Gardner Handy Colorimeter or equivalent in accordance with ASTM E 1347. The instrument shall be set to read $\mathrm{x}, \mathrm{y}$, and Y coordinates with 45 degree/ 0 degree bidirectional geometry, observer angle of 2 degree, and illuminant C. Color measurements shall be made at the beginning, middle and end of each 1 mile [kilometer] LOT. The color measurements for LOT shall be the average of all measurements taken with the 1 mile [kilometer] LOT.

\section{7-8 Contract Duration.}

The minimum warranty period for this Contract will be five years. Longer warranty periods (maximum 8 years) in yearly increments bid by Contractors will be considered with award of the Contract being considered in the following manner:

1. Total Bid Price/Years of Warranty Period $=$ Weighted Price

2. Award will be made based on the lowest weighted price. 


\section{1-5 Contractor's Warranty Period for Signal Installations.}

611-5.1 General Requirements: After satisfactory completion of all field tests in accordance with 611-4 and as a condition precedent to final acceptance of all work under the Contract in accordance with 5-11, provide a Warranty/Maintenance Bond for the repair or replacement of any defective components of the signal installations which shall be in effect for a 90 day period after final acceptance in accordance with 5-11. Include the costs of the bond in the costs of other bid items.

In addition to satisfying the provisions of Section 287.0935, Florida Statutes, the bonding company is required to have a A.M. Best rating of " $\mathrm{A}$ " or better. If the bonding company drops below the "A" rating during the 90 day Warranty/Maintenance Bond period, provide a new Warranty/Maintenance Bond for the balance of the 90 day period from a bonding company with an " $A$ " or better rating. In such event, all costs of the premium for the new Maintenance Bond will be at the Contractor's expense.

The Warranty/Maintenance Bond shall be written and issued in the amount of the total sums bid for all electrical or electronic equipment furnished and installed as part of any traffic signal installation or system of traffic control devices.

At the end of the 90 day warranty period, the Contractor will be released by the Engineer from further warranty work and responsibility, provided all previous warranty work and remedial work, if any, has been completed satisfactorily.

611-5.2 Contractor's Responsibilities: During the warranty period, the Contractor is responsible for the following:

(a) Repair or replacement of equipment that fails to function properly due to defective materials or workmanship.

(b) Upon notification by the Engineer of a malfunction, restore the equipment to proper operating condition within 12 hours after notification by the Engineer.

If the Contractor fails to restore the equipment to proper operating condition within 12 hours after notification, the Engineer has the authority to have the remedial work performed by other forces. The Contractor is responsible for all incurred costs of the work performed by other forces. Remedial work performed by other forces does not alter any of the requirements, responsibilities or obligations of this warranty.

(c) In the event that the equipment does not function or malfunctions due to defective materials or workmanship, the Contractor is liable for any impairment to the safety of pedestrian and vehicular traffic resulting from such malfunction.

611-5.3 Department's Responsibilities: During the warranty period, the Department is responsible for the following:

(a) Electrical energy costs which are paid for by the local maintaining agency.

equipment.

(b) All adjustments, such as timing, necessary for the normal operations of

(c) Documentation of the individuals involved and the time of Contractor notification upon failure or malfunction of equipment.

(d) Repair or replacement of any part of the installation damaged as a result of natural causes or those resulting from vehicular or pedestrian traffic not associated with Contractor activities. 


\section{APPENDIX D}

WARRANTY SURVEY PERFORMED IN MONTANA

This appendix presents the table summarizing the responses received from the contractors for the survey perfomed by the Montana State University. 


\begin{tabular}{|c|c|c|c|c|c|c|}
\hline \multirow{3}{*}{\begin{tabular}{|l|}
\multicolumn{1}{|c|}{ Information Requested } \\
Past experience with warranty \\
contracts in highway construction
\end{tabular}} & \multicolumn{6}{|c|}{ Percentage of the Responses (out of 23 respondents) } \\
\hline & Extensive & Some & Little & \multicolumn{3}{|c|}{ None } \\
\hline & 0 & 17 & 22 & \multicolumn{3}{|c|}{61} \\
\hline \multirow{2}{*}{$\begin{array}{l}\text { Aware of the concept of using } \\
\text { warranties on in-service } \\
\text { performance for roadway } \\
\text { construction projects }\end{array}$} & \multicolumn{2}{|c|}{ Yes } & \multicolumn{2}{|c|}{ No } & \multicolumn{2}{|c|}{ No Answer } \\
\hline & \multicolumn{2}{|c|}{70} & \multicolumn{2}{|c|}{30} & \multicolumn{2}{|c|}{0} \\
\hline \multirow{2}{*}{$\begin{array}{l}\text { Appropriate type of specifications } \\
\text { for roadway construction work }\end{array}$} & Methods & "Materials & Both & Warranty & \multicolumn{2}{|c|}{ Other } \\
\hline & 17 & 39 & 13 & 13 & \multicolumn{2}{|c|}{8} \\
\hline \multirow{2}{*}{$\begin{array}{l}\text { Type of construction activities } \\
\text { appropriate for in-service warranty } \\
\text { contracts (first choice) }\end{array}$} & Crack seal & Chip seal & Overlay & Reconstruction & \multicolumn{2}{|c|}{ Other } \\
\hline & 9 & 9 & 0 & 39 & \multicolumn{2}{|c|}{43} \\
\hline \multirow{2}{*}{$\begin{array}{l}\text { Type of roadway appropriate for a } \\
\text { demonstrating warranty project }\end{array}$} & Interstate & Primary & Secondary & Local & \multicolumn{2}{|c|}{ Other } \\
\hline & 35 & 9 & 22 & 17 & \multicolumn{2}{|c|}{17} \\
\hline \multirow[t]{2}{*}{ Payment terms } & \multicolumn{2}{|c|}{ 100\% at completion } & \multicolumn{2}{|c|}{ 90\% at completion } & \multicolumn{2}{|c|}{ Other } \\
\hline & \multicolumn{2}{|c|}{78} & \multicolumn{2}{|c|}{9} & \multicolumn{2}{|c|}{13} \\
\hline \multirow{2}{*}{$\begin{array}{l}\text { Bonus payments for extraordinary } \\
\text { performance }\end{array}$} & \multicolumn{2}{|c|}{ Yes } & \multicolumn{2}{|c|}{ No } & \multicolumn{2}{|c|}{ No answer } \\
\hline & 7 & & & & 13 & \\
\hline Measures appropriate to evaluate & Cracking & Rutting & Roughness/ ride & Skid resistance & Appearance & Other \\
\hline in-service performance & 21 & 25 & 26 & 7 & 11 & 10 \\
\hline Would consider bidding on a & $\bar{Y}$ & & & & No an & \\
\hline warranty contract & 6 & & & & 17 & \\
\hline Pre-qualification is an appropriate & $\bar{Y}$ & & & & No an & \\
\hline projects & 6 & & & & 9 & \\
\hline Award warranty project to the & $\bar{Y}$ & & & & No an & \\
\hline $\begin{array}{l}\text { program of work } \\
\text { progration approved }\end{array}$ & 6 & & & & 13 & \\
\hline Use of in-service warranties will & $\bar{Y}$ & & & & No an & \\
\hline $\begin{array}{l}\text { have a positive effect on the } \\
\text { quality of the job done }\end{array}$ & 4 & & & & 9 & \\
\hline Use of warranty contracts will & $\bar{Y}$ & & & & No an & \\
\hline $\begin{array}{l}\text { result in improved relationships } \\
\text { between MDT and the contractor }\end{array}$ & 3 & & & & 13 & \\
\hline
\end{tabular}

Source: Stephens et al. 1998, pp 55 


\section{APPENDIX E}

WARRANTY PRACTICES USED IN THE EUROPEAN COUNTRIES

This appendix presents the table summarizing the common highway warranty practices used in the European countries. 


\begin{tabular}{|c|c|c|c|c|c|}
\hline Country & Basis of Award & Structural Design & QA/QC & Warranty Period & Bonding \\
\hline Austria & $\begin{array}{l}\text { Open bid for standard projects; closed bid to } \\
\text { prequalified bidders for special projects }\end{array}$ & State approved & Contractor & $\begin{array}{l}\text { Asphalt concrete: } 2-5 \text { years } \\
\text { Concrete Pavement: } 5 \text { years }\end{array}$ & $\begin{array}{l}\text { Warranty bond deducted from final } \\
\text { invoice and paid to contractor within } 30 \\
\text { days of end of the warranty period }\end{array}$ \\
\hline Denmark & Lowest life cycle costs & State & Contractor & 5 years & Retain $5 \%$ of the contract amount \\
\hline France & Low bid & Contractor & Contractor & $5-10$ years & NA \\
\hline Germany & Low bid with consideration given for alternates & $\begin{array}{l}\text { Contractor (within state } \\
\text { established limits) }\end{array}$ & $\begin{array}{l}\text { QA: State QC: } \\
\text { Contractor }\end{array}$ & $\begin{array}{l}\text { Highways: } 4 \text { years } \\
\text { Bridges and earthwork: } 5 \text { years }\end{array}$ & $5 \%$ of contract retained \\
\hline Norway & $\begin{array}{l}\text { Best or lowest bid, allows for some innovation } \\
\text { and alternates, considers quality and future } \\
\text { maintenance costs }\end{array}$ & State approved & Contractor & 3 years & $\begin{array}{l}\text { Surety of } 15 \% \text { of contract during } \\
\text { construction required, drops to } 3 \% \text { after } \\
\text { one year, } 2 \% \text { after two years, and } 1 \% \\
\text { after three years }\end{array}$ \\
\hline Sweden & Low bid & Joint & Contractor & \begin{tabular}{|l|} 
Roadways: 2 years \\
Pavements: 3 years $\quad$ Bridges: \\
5 years
\end{tabular} & $5 \%$ surety required \\
\hline |United Kingdom & Low bid & State approved & State & $\begin{array}{l}\text { Contractor required to provide } \\
\text { maintenance for one year, United } \\
\text { Kingdom is looking into } \\
\text { expanding their warranty } \\
\text { program }\end{array}$ & $1.5 \%$ contract retained \\
\hline
\end{tabular}

Sources: Stephens et al. 1998, pp 22 and Johnson 1999,pp 6 


\section{APPENDIX F}

\section{DEFECTS LIABILITY CLAUSES USED IN VARIOUS PERFORMANCE BASED ROAD MAINTENANCE CONTRACTS}

This appendix presents the warranty clauses used in the performance based road maintenance contracts written by the World Bank and the Transit New Zealand.

\section{References:}

The World Bank. (2002). "Procurement of performance based management and maintenance of roads.” Washington D.C, February.

Transit New Zealand. (2002). "State highway maintenance contract proforma manual SM032.” New Zealand, March. 
41. Defect

Liability
41.1 The Contractor warrants that the Works and Services or any part thereof shall be free from defects in the design, engineering, materials and workmanship of the Works and Services executed.

41.2 The Defect Liability Period shall be eighteen (18) months from the date of Completion of the Contract (or any part thereof) or twelve (12) months from the date of Operational Acceptance of the Works and Services (or any part thereof), whichever occurs first, unless specified otherwise in the SCC.

If during the Defect Liability Period any defect should be found in the design, engineering, materials and workmanship of the Works and Services executed by the Contractor, the Contractor shall promptly, in consultation and agreement with the Employer regarding appropriate remedying of the defects, and at its cost, repair, replace or otherwise make good (as the Contractor shall, at its discretion, determine) such defect as well as any damage to the Road caused by such defect. The Contractor shall not be responsible for the repair, replacement or making good of any defect or of any damage to the Road arising out of or resulting from improper operation or maintenance of the Road by the Employer after taking over.

41.3 The Contractor's obligations under this GCC Clause 41 shall not apply to

(a) any materials that are supplied by the Employer, are normally consumed in operation, or have a normal life shorter than the Defect Liability Period stated herein;

(b) any designs, specifications or other data designed, supplied or specified by or on behalf of the Employer or any matters for 
which the Contractor has disclaimed responsibility herein;

(c) any other materials supplied or any other work executed by or on behalf of the Employer, except for the work executed by the Employer under GCC Sub-Clause 41.6.

41.4 The Employer shall give the Contractor a notice stating the nature of any such defect together with all available evidence thereof, promptly following the discovery thereof. The Employer shall afford all reasonable opportunity for the Contractor to inspect any such defect.

41.5 The Employer shall afford the Contractor all necessary access to the Facilities and the Site to enable the Contractor to perform its obligations under this GCC Clause 41.

The Contractor may remove from the Site any Plant and Equipment or any part of the Facilities that are defective if the nature of the defect, and/or any damage to the Facilities caused by the defect, is such that repairs cannot be expeditiously carried out at the Site.

41.6 If the Contractor fails to commence the work necessary to remedy such defect or any damage to the Road caused by such defect within a reasonable time (which shall in no event be considered to be less than fifteen (15) days), the Employer may, following notice to the Contractor, proceed to do such work, and the reasonable costs incurred by the Employer in connection therewith shall be paid to the Employer by the Contractor or may be deducted by the Employer from any monies due the Contractor or claimed under the Performance Security.

41.7 If the Road or any part thereof cannot be used by reason of such defect and/or making good of such defect, the Defect Liability Period of the Road or such part, as the case may be, shall be extended by a period equal to the period during which the Road or 
such part cannot be used because of any of the aforesaid reasons.

41.8 Except as provided in GCC Clauses 40 and 41, the Contractor shall be under no liability whatsoever and howsoever arising, and whether under the Contract or at law, in respect of defects in the Road or any part thereof, the Plant and Equipment, design or engineering or work executed that appear after Completion of the Works and Services, except where such defects are the result of the gross negligence, fraud, criminal or willful action of the Contractor. 


\subsubsection{Maintenance Responsibility}

The presence of other contractors does not relieve the Contractor of its obligations to maintain the Assets according to the Contract Documents, unless the presence of other contractors directly affects the Services.

The Contractor is required to manage all activities within the Limit of Works to the extent that it is necessary to ensure the safe and efficient movement of traffic at all times, and that the quality of the Assets are not compromised by the activity or inactivity of others. The Contractor will not be responsible for maintenance of:

a) those Assets included within the limits of a capital works contract being undertaken within the Limit of Works under another contract between the date of possession of site and the date of practical completion of those other contracts.

b) any assets which have been upgraded as a capital work under other contracts and, for the time being, are the maintenance responsibility of another contractor between the date of practical completion and the end of the defects liability period of those other contracts.

A joint inspection, conducted by the Superintendent and the Contractor on practical completion of other contracts, will identify any particular maintenance or omission responsibilities of the other contractor that may exist at the date of practical completion. The Contractor will be responsible for ongoing day to day and periodic maintenance to any assets that lie within the limit of works of other contracts between the date of practical completion and the end of the defects liability period of those other contracts.

A joint inspection, conducted by the Superintendent and the Contractor at the end of the defects liability of other contracts, will identify any particular maintenance or omission responsibilities of the other contractor that may exist at the end of the defects liability period. The Contractor will not resume responsibility for the Assets in question until the identified reasonable responsibilities of the other contractor are discharged, but only to the extent that such responsibilities have not been discharged. 


\section{APPENDIX G}

\section{FAR WARRANTY CLAUSE USED IN THE PENREN PROJECT}

This appendix presents the warranty clauses (as extracted from the Federal Acquisition Regulation-FAR) used in the performance based Wedge 2-5 Renovation and the performance based Metro Entrance Facility projects that are the two important components of the Pentagon Renovation (PENREN) Project.

Reference:

FAR. (1997). “The Federal acquisition regulation.” 


\subsection{6-21 Warranty of Construction}

As prescribed in 46.710(e)(1), the contracting officer may insert a clause substantially as follows in solicitations and contracts when a fixed-price construction contract (see 46.705(c)) is contemplated, and the use of a warranty clause has been approved under agency procedures: Warranty of Construction (Mar 1994)

(a) In addition to any other warranties in this contract, the Contractor warrants, except as provided in paragraph (i) of this clause, that work performed under this contract conforms to the contract requirements and is free of any defect in equipment, material, or design furnished, or workmanship performed by the Contractor or any subcontractor or supplier at any tier.

(b) This warranty shall continue for a period of 1 year from the date of final acceptance of the work. If the Government takes possession of any part of the work before final acceptance, this warranty shall continue for a period of 1 year from the date the Government takes possession.

(c) The Contractor shall remedy at the Contractor's expense any failure to conform, or any defect. In addition, the Contractor shall remedy at the Contractor's expense any damage to Governmentowned or controlled real or personal property, when that damage is the result of--

(1) The Contractor's failure to conform to contract requirements; or

(2) Any defect of equipment, material, workmanship, or design furnished.

(d) The Contractor shall restore any work damaged in fulfilling the terms and conditions of this clause. The Contractor's warranty with respect to work repaired or replaced will run for 1 year from the date of repair or replacement.

(e) The Contracting Officer shall notify the Contractor, in writing, within a reasonable time after the discovery of any failure, defect, or damage.

(f) If the Contractor fails to remedy any failure, defect, or damage within a reasonable time after receipt of notice, the Government shall have the right to replace, repair, or otherwise remedy the failure, defect, or damage at the Contractor's expense.

(g) With respect to all warranties, express or implied, from subcontractors, manufacturers, or suppliers for work performed and materials furnished under this contract, the Contractor shall--

(1) Obtain all warranties that would be given in normal commercial practice;

(2) Require all warranties to be executed, in writing, for the benefit of the Government, if directed by the Contracting Officer; and 
(3) Enforce all warranties for the benefit of the Government, if directed by the Contracting Officer. (h) In the event the Contractor's warranty under paragraph (b) of this clause has expired, the Government may bring suit at its expense to enforce a subcontractor's, manufacturer's, or supplier's warranty.

(i) Unless a defect is caused by the negligence of the Contractor or subcontractor or supplier at any tier, the Contractor shall not be liable for the repair of any defects of material or design furnished by the Government nor for the repair of any damage that results from any defect in Governmentfurnished material or design.

(j) This warranty shall not limit the Government's rights under the Inspection and Acceptance clause of this contract with respect to latent defects, gross mistakes, or fraud.

\section{(End of clause)}

Alternate I (Apr 1984). If the Government specifies in the contract the use of any equipment by "brand name and model," the contracting officer may add a paragraph substantially the same as the following paragraph $(\mathrm{k})$ to the basic clause:

(k) Defects in design or manufacture of equipment specified by the Government on a "brand name and model" basis, shall not be included in this warranty. In this event, the Contractor shall require any subcontractors, manufacturers, or suppliers thereof to execute their warranties, in writing, directly to the Government. 


\section{APPENDIX H}

\section{THE DOCUMENT SENT TO THE PANEL OF EXPERTS}

This appendix presents the complete document that was sent to the Panel of Experts for their review. 


\section{MEMORANDUM}

To the Panel of Experts:

Attached, you will find the developed warranty clause template which will be proposed to be incorporated into the "Comprehensive Agreement for Interstate Highway Asset Management Services”, which is a performance based highway maintenance contract issued by the Virginia Department of Transportation (VDOT).

This template is prepared mainly by using the literature related to the warranty concept (NCHRP Project 10-49, AIA Contract Documents, EJCDC Contract Documents, FIDIC Contract Documents, World Bank Contract Documents, Transit New Zealand Contract Documents).

More specifically, certain language and approaches that are used in the warranty clauses that are prepared by Ohio Department of Transportation (ODOT), Michigan Department of Transportation (MDOT), Wisconsin Department of Transportation (WisDOT), Florida Department of Transportation (FDOT), and Minnesota Department of Transportation (MnDOT) have been made use of extensively. On the other hand, for the establishment of the warranty criterion and the length of the warranty period, certain approaches as developed by the M.S. candidate have been implemented. The fact that the contract in the scope of this research is a performance based total maintenance contract (different in nature from the contracts for which warranties are developed by the abovementioned states) necessitated such different approaches to be developed.

As mentioned above, the contract in the scope of this research is a performance based highway maintenance contract. A contractor performing work under this contract is responsible for the maintenance of $\mathbf{3 2}$ highway asset items (such as the pavement, paved ditches, luminaries, pipes, sidewalk, box culverts, fence, concrete barriers and etc...) within a certain portion of Virginia's interstate highway system. The current contract ${ }^{1}$ establishes certain performance criteria for each asset item and requires the contractor to meet the performance targets which are, also, established for each asset item.

In very general terms, this research is aiming to improve the contractibility of VDOT in the future performance based highway maintenance contracts it will issue.

\footnotetext{
${ }^{1}$ The term "current contract", whenever used within this text, means the VDOT-VMS Inc. Contract. However, this research uses the VDOT-VMS Inc. Contract for only the purposes of presenting the current contract's terms and conditions, establishing the baseline for the problem definition of this research, and addressing some general issues about the contract. Hence, the discussions presented in this text are for any arbitrary and prospective contractor and do not have any implications on the current contractor, VMS Inc.
} 
More specifically, this research is aiming to develop a warranty clause template (which then can be used by VDOT in developing complete and comprehensive warranty clauses for each asset item) which will provide the following:

1) Decrease the amount of risk imposed upon VDOT

2) Make the contractor improve the asset items' overall condition throughout the contract term rather than just maintaining them to barely meet the performance targets specified in the contract. This, in fact, is the essence of the asset management concept as defined by Falls et al as " $a$ systematic process of maintaining, upgrading, and operating physical assets costeffectively. In the broadest sense, the assets of a transportation agency include physical infrastructure such as pavements, bridges...” (Falls et al 2001). This also ensures the long term performance of the asset items.

It is important to note that, the M.S. candidate proposes that different warranty clauses need to be developed for each asset item covered under the terms of the current contract. This is mainly due to the fact that each asset item is unique and has its own properties defining its lifetime. Each asset item is exposed to different conditions causing it to deteriorate in different amounts when compared to other asset items. Moreover, some asset items have relatively higher importance than others as far as the road users’ safeties are concerned.

Due to the fact that this research has a qualitative nature in which the researcher, after observing and analyzing the situations related to the subject matter through an intense literature review, proposes subjective ideas as he believes to be the best solution to the identified problem (Burrell and Morgan 1979). However, at the current phase of this research, the proposed solution (i.e. the developed warranty clause template) needs to be evaluated by the experts in the warranty arena.

In the following attachment, first the approaches used in establishing the warranty criterion and the length of the warranty period are concisely discussed. Then the developed warranty clause template (which is a self contained document with the related explanations presented in footnotes) is presented to be evaluated by you. Finally, some questions are posed to the Panel to receive professional feedback which will be used in enhancing the developed warranty clause template. 


\section{1) Approach Used in Defining Defect and Developing Warranty Criterion for} Each Asset Item

For the current contract, defect for each asset item can be characterized in terms of the performance criteria and performance target (which are presented in the Exhibit B of the current contract) established for that asset item. For example by examining the Exhibit B, for the "Paved Ditches" asset item, the defect can be defined as "meeting the performance criteria for less than $90 \%$ of the total amount of paved ditches present in the interstate system maintained by the contractor". Vice versa, same statement can be made as "not meeting the performance criteria for more than 10\% (100\% minus 90\%) of the total amount of paved ditches present in the interstate system maintained by the contractor". It can be noticed that the first part of this statement (presented in italics format) is established using the performance criteria and the second part (presented in bold format) is established using the performance target defined in the Exhibit B of the current contract.

Thus, the broadest definition of defect for the "Paved Ditches” asset item is "(a) having less than 1 inch of settlement or (b) having no undermining or undercut that requires action or (c) having less than $25 \%$ of the area spalled or (d) having no obstruction to flow of water that requires action or (e) any combination of (a), (b), (c) and (d); for less than $90 \%$ of the total amount of paved ditches present in the interstate system maintained by the contractor". These statements are made using the "Paved Ditches” row of the table that is present in the Exhibit B of the VDOT- VMS contract. This row as extracted from the Exhibit B is provided in Table 1.

Table 1: Performance Criteria and Performance Target for the "Paved Ditches" asset item as extracted from the Exhibit B of the VDOT-VMS Contract

\begin{tabular}{|c|c|c|c|}
\hline Asset & Outcome & $\begin{array}{l}\text { Performance Target } \\
\text { (\% of asset that shall } \\
\text { be in the outcome } \\
\text { described condition) }\end{array}$ & $\begin{array}{l}\text { Condition assessment acceptance tolerances and } \\
\text { criteria (Service Delivery) }\end{array}$ \\
\hline $\begin{array}{l}\text { Paved } \\
\text { Ditches }\end{array}$ & $\begin{array}{l}\text { Aligned } \\
\text { Structurally sound } \\
\text { Clean }\end{array}$ & $90 \%$ & $\begin{array}{l}\text { - }<1 \text { '’ settlement } \\
\text { - no undermining or undercut requiring action } \\
\text { - }<25 \% \text { spalled } \\
\text { - no obstruction to flow of water that requires action }\end{array}$ \\
\hline
\end{tabular}


It is important to note that the discussion presented above is applicable for the duration of the contract term. In other words, in preparing the contract, VDOT established the performance criteria and performance targets (both of which are used in the definition of the defect for each asset item) for the contract term. However, if VDOT perceives "meeting certain performance criteria for less than a pre-defined target for (or similarly, not meeting certain performance criteria for more than a certain percentage of) an asset item" as a defect for the contract term, same definition of defect can be applicable after the contract term too. To state it more clearly, the performance criteria and targets are established with the long time experience of VDOT, and hence, an asset item, perceived to be defective during the contract term (by using performance criteria and performance targets) when maintenance work is being performed may well be perceived to be defective after the completion of the contract term if it possesses the criteria and overall condition rating that make it defective. Therefore, there is not point in generating two different definitions of defect; one for the contract term, and one for the warranty period, for exactly the same asset item. With all these in hand, it can confidently be asserted that the definition of defect which will be used in developing the warranty criterion can be the same as the definition of defect that is applicable over the contract term. Furthermore, it can also confidently be stated that this definition of the defect for each asset item as used for the contract term simply depends on $\mathbf{2}$ variables that are established in the current contract: Performance criteria and performance target.

Given all of the above discussions, the warranty criterion for the "Paved Ditches" asset item can be established as "meeting the performance criteria for at least equal or more than $90 \%$ of the total amount of paved ditches present in the interstate system maintained by the contractor”. Using the previous example, the warranty criterion (in its broadest sense) for the "Paved Ditches” asset item can be stated as “(a) having less than 1 inch of settlement and (b) having no undermining or undercut that requires action and (c) having less than 25\% of the area spalled and (d) having no obstruction to flow of water that requires action; for at least equal or more than $90 \%$ of the total amount of paved ditches present in the interstate system maintained by the contractor”. 


\section{2) Approaches Used in Establishing the Length of the Warranty Period}

Alternative 1: In this alternative, the normal deterioration curve of the asset item for which the length of the warranty period is to be established is used to identify the time necessary for that asset item to deteriorate from its new state to the state where it is said to be defective. Such a curve should reflect the situation in which the asset item deteriorates from normal daily usage without being maintained. Moreover, this curve should be plotted for only normal daily conditions in which there are not any extreme events such as very severe weather and/or very heavy traffic. Figure 1 illustrates the normal deterioration curve for the "Paved Ditches" asset item. The term "new state" means the state in which the "Paved Ditches" asset item is in its best possible condition, i.e. newly (just) constructed. This implies that the overall condition rating for the "Paved Ditches" asset item is $\mathbf{1 0 0 \%}$, meaning that all of the paved ditches present in the interstate system maintained by the contractor are meeting the performance criteria. Secondly, the "defective state" for the "Paved Ditches" asset item presented in the graph is exactly the state for which "Paved Ditches" asset item was defined to be defective in the previous section. In other words, the defective state that is illustrated in the graph is the state in which the pre-established performance criteria are not met for the performance target (as defined in the previous section). Thus, this defective state for the "Paved Ditches" asset item is presented in terms of the performance target established in the current VDOT-VMS contract.

As discussed above, this curve reflects the situation in which no maintenance activity is performed (which, in fact, is similar to the case for the warranty period in which the contractor is allowed to implement minimal maintenance activities as expanded in the warranty clause template Section 16.9). It would be fair to assert that an asset item, which is well maintained during the contract term, should reach to its best possible condition (i.e. its new state) by the completion of the contract term. And it would also be fair to state that; upon the completion of the contract, and thus with the beginning of the warranty period, same well maintained asset item would begin to deteriorate in accordance with its normal deterioration curve (deteriorate with the rate that is plotted in its normal deterioration curve) and thus would reach to its defective stage at the time that is specified in its normal deterioration curve. And given all of these conditions, it would be fair to assert that; this time, in which the well maintained asset reaches to its defective stage, marks the end of the warranty period. Note that 
this time is represented as " $\mathbf{X}$ " in Figure 1. In conclusion, the warranty period may be established as "the period starting with the completion of the contract term and ending with the time which reflects the defective state of the asset item in the normal deterioration curve of that asset item”.

Alternative 2: The above proposed alternative of establishing the warranty duration has a major drawback when examined thoroughly within the highway maintenance concept. As presented above, Alternative 1 assumes and requires that at the end of the warranty period, as the maintenance activities are terminated, the asset item's overall condition rating should be $\mathbf{1 0 0 \%}$. This implies that the maintenance activities performed during the contract term should be in such a way that, they should improve the asset item's overall condition to the maximum extent possible. This means that the asset item should be brought up to its new state, making it as new as newly (just) constructed. However, expecting the contractor to improve the asset item's overall condition to the maximum extent possible to reach an overall condition rating of $\mathbf{1 0 0 \%}$ is both unreasonable and unrealistic given the nature of the highway maintenance projects. To resolve this issue, the length of the warranty period, which was established previously, should be reconsidered. The warranty period can be re-established using a different portion of the normal deterioration curve. Alternative 2 determines the length of the warranty period by using a normal deterioration curve in which the initial overall condition rating of the asset is assumed to be at a certain level above ("A") of the performance target (but below 100\%). This alternative is presented in Figure 1.

Alternative 3: Alternative 3, calls for the establishment of the warranty period without defining any intermediate value like " $A$ " that helps to calculate the length of the warranty period. This alternative proposes that the length of the warranty period should be determined by the state agency, VDOT, according to its expectations with regards to the performance of the highway and its assets. For this, VDOT needs to set the time period in which it would not be willing to maintain the asset item or to pay for the maintenance of the asset item, after the completion of the contract term. This time period, in fact, constitutes the warranty period it wishes to implement. Then, to ensure that this established length is reasonable, back calculation should be made to identify the value of the overall condition rating required at the end of the contract term for the contractor to be able to meet the warranty criteria all through this established warranty period as illustrated in Figure 2. 


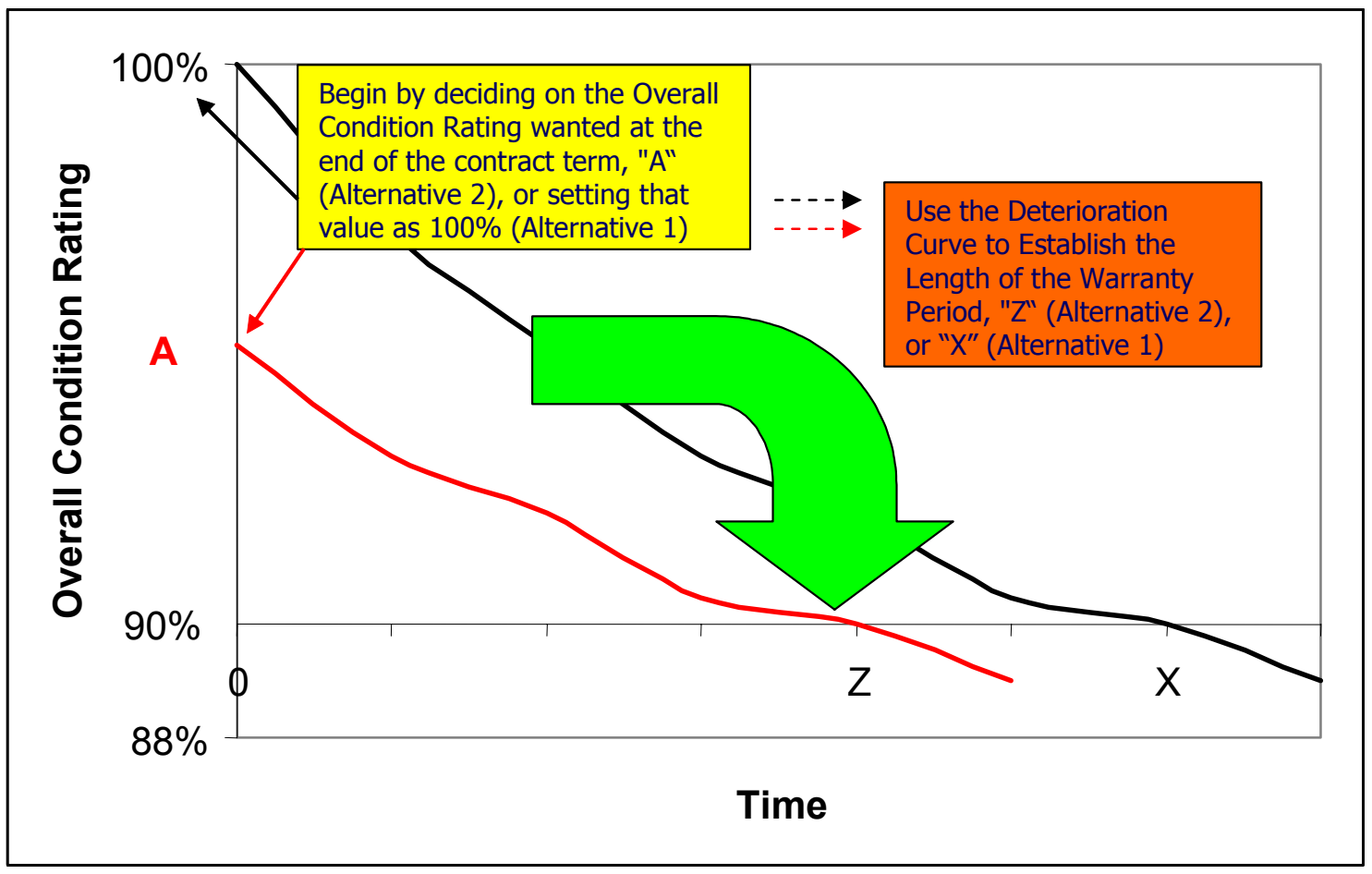

Figure 1: Establishing the length of the warranty period using Alternative 1 or Alternative 2

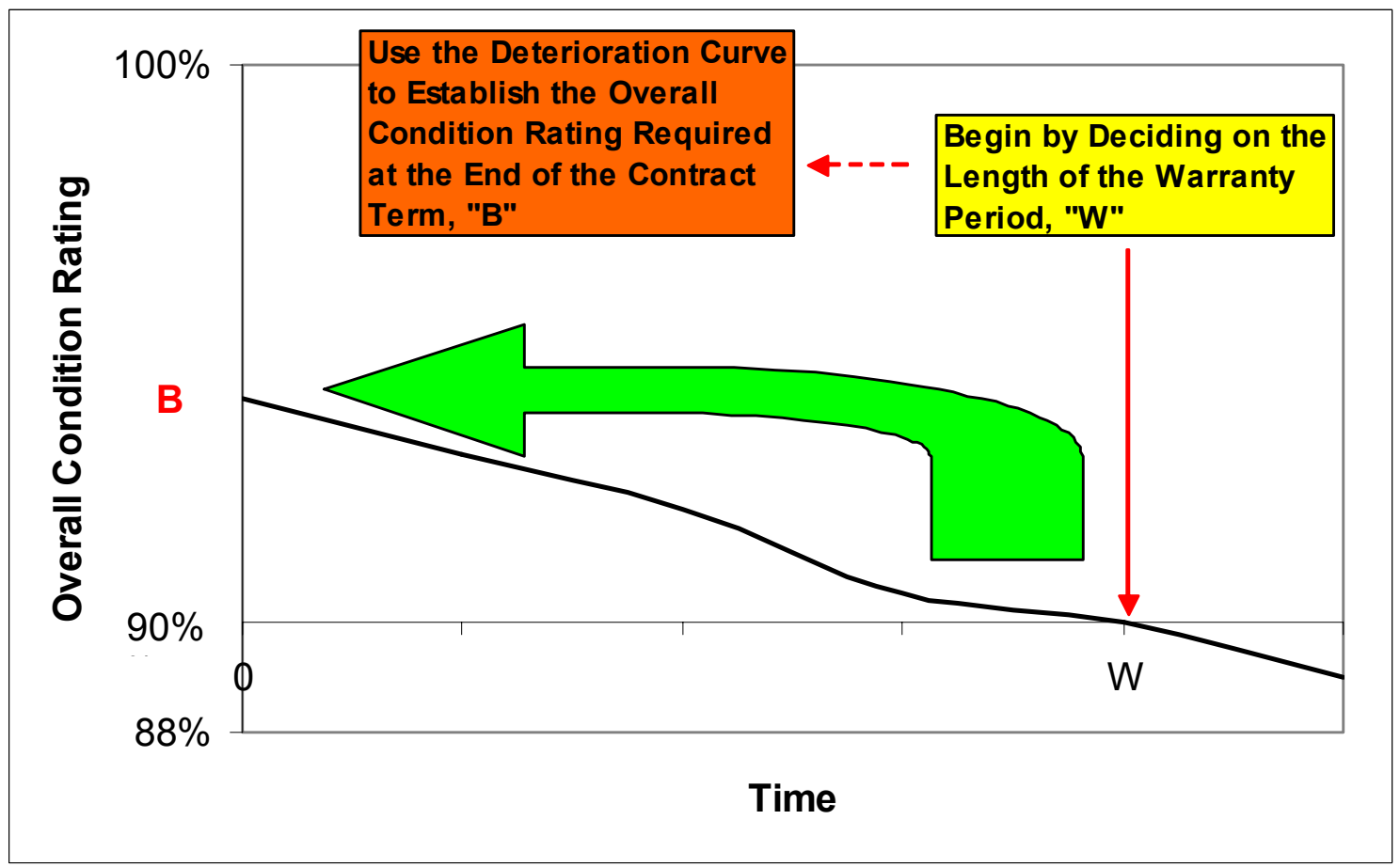

Figure 2: Establishing the length of the warranty period using Alternative 3 


\section{ARTICLE XVI \\ WARRANTIES}

WARRANTY FOR THE “

” ASSET ITEM

\section{Section 16.1: GENERAL DESCRIPTION}

This document specifies the requirements for the Contractor to warrant the maintenance work it (the Contractor) has performed for the " "1 asset item for a period of

\footnotetext{
${ }^{2}$ year(s)/month(s) ${ }^{3}$.
}

The Contractor shall assume full responsibility for all the associated work specified in this Document for a period of ${ }^{4}$ year(s)/month(s) after the final acceptance of the Contract in accordance with the Section $\mathbf{1 1 . 3 ^ { 5 }}$, including continued responsibility as to any defects discovered by the Department and as to which timely notice was provided within such warranty period until all such pre-existing defects are corrected.

\section{Section 16.2: WARRANTY BOND}

The Contractor shall provide a warranty bond which will be in effect for a minimum of the length of the warranty period which begins upon the final acceptance of the contract in accordance with the Section 11.3. The effective starting date of the warranty bond shall be the date of final acceptance. The warranty bond will be released at the end of the warranty period or after all warranty remedial work has been completed, whichever is latest.

\footnotetext{
${ }^{1}$ Insert: the name of the asset item for which the warranty clause is developed.

${ }^{2}$ Insert: the length of the warranty period as identified (for the asset item for which the warranty clause is developed) using either Alternative 1 or Alternative 2 or Alternative 3.

${ }^{3}$ year(s) or month(s), whichever is applicable.

${ }^{4}$ Insert: the length of the warranty period as identified (for the asset item for which the warranty clause is developed) using either Alternative 1 or Alternative 2 or Alternative 3.

${ }^{5}$ Section 11.3 (which is under the Article XI of the current contract) establishes the completion of the Contract Term.
} 
The surety of the bond shall be a surety company authorized to transact business in the State and shall have A.M. Best unit rating not less than " $A$ "6 throughout the warranty period. If the A.M. Best unit rating of the surety company drops below "A", then the Department will 7 .

The warranty bond(s) will be $\_{ }^{8}$. The bonds will ensure the proper and prompt completion of required remedial work, including payments for all labor performed, and all equipment and materials used.

The warranty bond(s) will be provided in one of the following manners:

1. A single term ${ }^{9}$ year/month ${ }^{10}$ warranty bond.

2. A ${ }^{11}$ year/month renewable, non-cumulative warranty bond for consecutive terms.

Whichever option the Contractor chooses, the Contractor will provide documentation which can act as a proof of $\_$_ ${ }^{13}$ year/month bond commitment before the execution of the contract.

\footnotetext{
${ }^{6}$ This is the rating that has been required for the performance bond (which only covers the Contract Term) of the current contract.

${ }^{7}$ Insert: a list of all of the steps that need to be taken if the A.M. Best unit rating of the surety company drops below the required rating as set forth in this section.

${ }^{8}$ Insert: the bond amount (for the asset item for which the warranty clause is developed) as established using the "most likely case" scenario.

${ }^{9}$ Insert: the length of the warranty period as identified (for the asset item for which the warranty clause is developed) using either Alternative 1 or Alternative 2 or Alternative 3.

${ }^{10}$ year or month, whichever is applicable.

${ }^{11}$ Insert: the monthly or yearly (whichever is applicable) intervals at which a non-cumulative warranty bond is required by VDOT.

${ }^{12}$ Insert: the number which is calculated by dividing the length of the warranty period as identified (for the asset item for which the warranty clause is developed) using either Alternative 1 or Alternative 2 or Alternative 3 to the monthly or yearly (whichever is applicable) intervals at which a non-cumulative warranty bond is required by VDOT.

${ }^{13}$ Insert: the length of the warranty period as identified (for the asset item for which the warranty clause is developed) using either Alternative 1 or Alternative 2 or Alternative 3.
} 
No separate sub-contractor bond is required. However, the bond(s) provided pursuant to this section will cover any work, no matter whether it is performed by the Contractor or any subcontractor that is employed by the Contractor to perform a part or whole parts of the maintenance work during the contract term.

\section{Section 16.3: WARRANTY COVERAGE AND WARRANTY CRITERION}

Warranty criterion ${ }^{14}$ is established by using the parameters that are listed in Table $1^{15}$.

Table 1: Warranty Criterion

\begin{tabular}{|l|l|l|l|}
\hline Asset & Outcome & $\begin{array}{l}\text { Performance Target } \\
\text { (\% of asset that shall } \\
\text { be in the outcome } \\
\text { described condition) }\end{array}$ & $\begin{array}{l}\text { Condition assessment acceptance tolerances and } \\
\text { criteria (Service Delivery) }\end{array}$ \\
\hline & & \\
\hline
\end{tabular}

$\Upsilon^{\prime}$

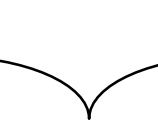

This table needs to be extracted from the Exhibit B of the current contract. The information within this table needs to correspond to the asset item for which the warranty clause is developed.

\section{Section 16.4: WARRANTY COMPLIANCE EVALUATIONS}

The Department (and/or its authorized agent) will conduct an inspection at the beginning of the warranty period which shall be completed in ${ }^{16}$ days. For the remaining years of the

\footnotetext{
${ }^{14}$ Warranty criterion is established using the performance criteria and the performance target for the asset item for which the warranty clause is developed. Warranty criterion for any asset item can be stated as "meeting the performance criteria for at least equal or more than the performance target established for that asset item".

${ }^{15}$ Insert: Table 1 which lists the performance criteria and performance target (for the asset item for which the warranty clause is developed) that are established for the Contract Term within the Exhibit B of the current contract.

${ }^{16}$ Insert: the number of days that is allowed for VDOT to complete the initial inspection. This time frame should be minimized to allow the Contractor to start remedial work as soon as possible.
} 
warranty period, the Department (and/or its authorized agent) will conduct annual inspections between ___ ${ }^{17}$ and ___ ${ }^{18} .{ }^{19}$ The last inspection will be performed by the Department (and/or its authorized agent) just before the completion of the warranty period and shall be completed in ${ }^{20}$ days. The methodology of these inspections will be same as the ones' that are conducted within the Evaluation Program that is defined in Section $\mathbf{2 . 1 8}{ }^{\mathbf{2 1}}$ and described in Exhibit $\mathbf{G}^{22}$ of the Contract.

The Department (and/or its authorized agent) will conduct these inspections at no cost to the Contractor. The Department shall notify the Contractor of the scheduled review. The Contractor or any other interested party may attend the inspections for observation purposes only. Any comments by the Contractor or other interested party may be recorded by the Department. A comprehensive report containing the results of the inspection and the remedial work (as expanded in Section 16.5) required from the Contractor shall be made available to the Contractor within ${ }^{23}$ days after the completion of the inspection. The Department (and/or its authorized agent) shall use non-destructive procedures in performing the inspections. If destructive procedures are used by the Department, the Contractor will not be responsible for damages that result from coring, milling or other destructive procedures conducted by the Department.

The Department (and/or its authorized agent) may also conduct special evaluations on a more frequent basis in order to identify the emergency remedial work needs (as expanded in

\footnotetext{
${ }^{17}$ Insert: the beginning date of the annual inspections.

${ }^{18}$ Insert: the completion date of the annual inspections.

${ }^{19}$ This time frame should be minimized to allow the Contractor to start remedial work as soon as possible. If the warranty period is less than 1 year for the asset item for which the warranty clause is developed, then this sentence needs to be removed from the clause.

${ }^{20}$ Insert: the number of days that is allowed for VDOT to complete the final inspection. This time frame should be minimized to allow the Contractor to start remedial work as soon as possible.
}

${ }^{21}$ Section 2.18 defines the highway maintenance evaluation program that is implemented in the Contract Term in order to assess the work of the contractor during the Contract Term.

${ }^{22}$ Exhibit G describes in detail the highway maintenance evaluation program that is implemented in the Contract Term in order to assess the work of the contractor during the Contract Term.

${ }^{23}$ Insert: the number of days that is allowed for VDOT to prepare and submit the report possessing the results of the inspection. This time frame should be minimized to allow the Contractor to start remedial work as soon as possible. 
Section 16.5). If any emergency situation is discovered during these special evaluations, the Contractor shall be notified within ${ }^{24}$ hours upon the discovery of such situation.

As soon as the identified remedial work is completed (as expanded in Section 16.5), the Department (and/or its authorized agent) shall re-inspect the portions of the highway for which remedial work was required.

\section{Section 16.5: REMEDIAL WORK}

During the warranty period, if the results of the warranty compliance evaluations reveal that the warranty criterion (as expanded in Section 16.3) is not met, and the Contractor agrees to the validity of the evaluation results, the remedial work, as identified to be necessary through the warranty compliance evaluations (that are expanded in Section 16.4), will be performed by the Contractor at no cost to the Department. The Contractor is free to implement any method in performing the remedial work. The Contractor is also free to choose any material to use in performing the remedial work. At all times the remedial work is performed, the Contractor shall follow a Department- approved traffic control plan.

The Contractor shall notify the Department and submit a written plan for performing the required remedial work within ___ ${ }^{25}$ days after being notified by the Department for the remedial work required from it and before starting that remedial work, except in case of emergency remedial work as detailed in this section. The submittal shall only propose the schedule for performing the remedial work, no other information regarding the Contractor's remedial work need to be submitted by the Contractor. The times of the day for performing the remedial work shall be subject to the approval of the Department. The written plan shall be approved by the Department within ___ ${ }^{26}$ days upon the receipt of the written plan. The Contractor shall begin the remedial work upon the approval of its remedial work schedule.

\footnotetext{
${ }^{24}$ Insert: the number of hours that is allowed for VDOT to notify the contractor of the emergency situation. This time frame should be minimized to allow the Contractor to start emergency remedial work as soon as possible.

${ }^{25}$ Insert: the number of days for the Contractor to submit its schedule to perform the required remedial work.

${ }^{26}$ Insert: the number of days for VDOT to approve the submitted schedule of the required remedial work. This time frame should be minimized to allow the Contractor to start remedial work as soon as possible.
} 
The remedial work shall be performed by the Contractor to improve the asset item's ${ }^{27}$ overall condition sufficiently to meet the warranty criterion. The remedial work shall be completed within ${ }^{28}$ days following approval of the Contractor's remedial work schedule by the Department. If the remedial work can not be completed within ${ }^{29}$ days following approval of the Contractor's remedial work schedule by the Department due to seasonal limitations, the Contractor shall notify the Department in writing and determine a schedule for completion of the remedial work.

If the results of the warranty compliance evaluations reveal that the warranty criterion (as expanded in Section 16.3) is not met, but the Contractor does not agree to the validity of the evaluation results, the Conflict Resolution Procedures (which are expanded in Section 16.6) shall be implemented.

If, in the opinion of the Department, any portion of the highway which is covered by the warranty possesses emergency situations which require immediate attention for the safety of the traveling public, the Contractor shall be notified (as expanded in Section 16.4) to perform the emergency remedial work. Such situations which necessitate emergency remedial work can be listed as ${ }^{30}$. If the Contractor can not perform the required emergency remedial work in 31 hours, the Department may have the work performed, at the Contractor's expense, by Department personnel and/or through a Department procurement. Any work thus performed will not alter the requirements, responsibilities, or obligations of the warranty. If the Contractor refuses to pay for such emergency remedial work depending on the grounds that the emergency situation was caused by factors beyond its control, the Conflict Resolution Procedures (as expanded in Section 16.6) shall be implemented.

\footnotetext{
${ }^{27}$ This is the asset item for which the warranty clause is developed.

${ }^{28}$ Insert: the number of days for the Contractor to complete all of the required remedial work related to the asset item for which the warranty clause is developed. This time frame should be minimized to restore the defective portions of the highway to their acceptable and safe conditions as soon as possible.

${ }^{29}$ Insert: the number of days for the Contractor to complete all of the required remedial work related to the asset item for which the warranty clause is developed.

${ }^{30}$ Insert: the complete list of the occasions that constitute an emergency situation for the asset item for which the warranty clause is developed.

${ }^{31}$ Insert: the number of hours for the Contractor to complete all of the required emergency remedial work related to the asset item for which the warranty clause is developed. This time frame should be minimized to prevent any safety issues that may arise due to these emergency situations.
} 
If the remedial work performed by the Contractor necessitates the removal of asset items other than the one that is warranted under the Section $\mathbf{1 6 . 1}$ of this Contract, including but not limited to the pavement markings, pavement markers, adjacent lane(s), roadway shoulders, signs, and mile markers, then such asset items shall be removed and replaced at the Contractor's expense.

At the end of the warranty period, the Contractor will be released from further warranty work or responsibility, provided that all previously required remedial work has been completed.

\section{Section 16.6: CONFLICT RESOLUTION PROCEDURES}

A Conflict Resolution Team (CRT), which deals exclusively with the issues related to the warranty, will be established prior to the initiation of the warranty period to resolve any conflicts arising between the Contractor and the Department regarding the warranty requirements. This team will be composed of one representative appointed by the Contractor, one representative appointed by the Department, and an independent party mutually agreed upon by the Contractor and the Department. Decisions of the Conflict Resolution Team will be based on a simple majority vote. The Contractor and the Department acknowledge that use of the Conflict Resolution Procedures is required and the determinations of the Conflict Resolution Team for conflicts arising between them will be binding on both the Contractor and the Department, with no right to appeal by either party, for the purposes of this document.

All Conflict Resolution Team meetings shall be initiated and paid for by the Contractor. The Department will reimburse the Contractor for all fees associated with meetings only if the Conflict Resolution Team rules substantially in favor of the Contractor, otherwise the Contractor shall be solely responsible for all such costs. The term "substantially" is defined as fifty percent of the issues when entitlement is disputed or fifty percent of the total dollar amount when costs associated with such entitlement are disputed. 
The Conflict Resolution Procedures shall be initiated by the Contractor within 32 days after the comprehensive report containing the results of the inspection and the remedial work requested from the Contractor is made available to the Contractor (as expanded in Section 16.4). The CRT will evaluate the dispute. This evaluation may include inspecting the disputed area in the field. The evaluation may also include reviewing the inspection data, obtaining samples, and/or interviewing Department (District or Central Office) or Contractor employees. The CRT will receive the Maintenance Rating Program (MRP) training when it is determined necessary to perform an inspection to resolve the conflict. The CRT's determination(s) will be issued in writing to the Contractor and to the Department within 33 days after the Conflict Resolution Procedures are initiated by the Contractor.

If the Conflict Resolution Procedures are initiated for an emergency remedial work (as expanded in Section 16.5) that has already been completed by the Department (and/or its authorized agent), then the CRT shall determine whether the Contractor was responsible for that emergency remedial work or not. As a result of this determination, the CRT may direct the Contractor to pay the Department for the completed emergency remedial work.

\section{Section 16.7: DEFAULT ON THE CONTRACTOR}

Failure of the Contractor to submit its remedial work schedule within the specified period of time (as expanded in Section 16.5) shall be cause for the Department to complete the remedial work and recover the costs of such from the warranty bond.

\footnotetext{
${ }^{32}$ Insert: the number of days for the Contractor to initiate the Conflict Resolution Procedures. This time frame should be minimized to allow the CRT to begin evaluating the conflict as soon as possible so that the responsible party (as identified through the Conflict Resolution Procedures) can perform remedial work to restore the defective portions of the highway to their acceptable and safe conditions as soon as possible. Moreover, this time frame should be same with the time frame required for the Contractor to submit its schedule (as expanded in Section 16.5) for the remedial work. This would enable VDOT to understand the intentions of the Contractor in the sense that whether it is planning to perform the remedial work or it is planning to initiate Conflict Resolution Procedures for the requested remedial work.

${ }^{33}$ Insert: the number of days for the CRT to arrive a decision about the conflict(s) for which the Conflict Resolution Procedures were initiated. This time frame should be minimized to make the CRT reach a final decision as soon as possible so that the responsible party (as identified through the Conflict Resolution Procedures) can perform remedial work to restore the defective portions of the highway to their acceptable and safe conditions as soon as possible.
} 
Failure of the Contractor to initiate the Conflict Resolution Procedures within the specified period of time (as expanded in Section 16.6) shall be cause for the Department to complete the remedial work and recover the costs of such from the warranty bond.

Failure of the Contractor to perform remedial work within the specified period of time (as expanded in Section 16.5) shall be cause for the Department to complete the remedial work and recover the costs of such from the warranty bond.

Failure of the Contractor to fully comply with the decisions of the Conflict Resolution Team (as expanded in Section 16.6) shall be cause for the Department to complete the remedial work and recover the costs of such from the warranty bond.

Failure of the Contractor or its surety to issue or renew the warranty bond (as expanded in Section 16.2) will be considered as a default and will result in forfeiture of $\_$_ ${ }^{34}$ percent of the face amount of the bond to the Department.

Should the Contractor fail to timely submit any conflict to the CRT, fail to satisfactorily perform any remedial work, or fail to compensate the Department for any emergency remedial work performed by the Department, as determined by the CRT to be the Contractor's responsibility (as expanded in Section 16.6), the Department shall suspend, revoke, or deny the Contractor's certificate of qualification until full and complete payment for the remedial work (and/or emergency remedial work) is made to the Department by the Contractor or its surety. In no case shall the period of suspension, revocation, or denial of the Contractor's certificate of qualification be less than ${ }^{35}$ months.

\section{Section 16.8: EXCLUSIONS AND WAIVERS}

During the warranty period, the Contractor will not be held responsible for defects that are caused by factors unrelated to the Contractor's work. Such external factors which are beyond the control of the Contractor can be listed as 36. Other factors which are not listed

\footnotetext{
${ }^{34}$ Insert: the percentage of the warranty bond which VDOT is willing to receive when declares default on the contractor for such issue.

${ }^{35}$ Insert: the number of months as decided by VDOT to be the minimum length of the period in which the Contractor's certificate of qualification is suspended, revoked, or denied.

${ }^{36}$ Insert: the complete list of the factors which are beyond the control of the contractor and which may cause defects on the asset item for which the warranty clause is developed.
} 
here but which may be considered to be beyond the control of the Contractor will be considered by the Department on a case by case basis upon receipt of a written request from the Contractor.

\section{Section 16.9: CONTRACTOR'S OPTION OF MAINTENANCE DURING THE WARRANTY PERIOD}

The intent of the Contract is for the Contractor to improve the ${ }^{37}$ asset item's overall condition rating during the contract term in an effort to provide its long term performance. It is also the intent of the Contract to provide a maintenance-free ${ }^{38}$ asset item during the warranty period. The Contractor may perform certain maintenance activities during the warranty period, but these maintenance activities are limited to the activities approved by the Department. To identify such maintenance activity needs, the Contractor may monitor the highway using nondestructive procedures. The Contractor shall not conduct any coring, milling, or other destructive procedures without prior approval by the Department.

\section{Section 16.10: DEPARTMENT'S RESPONSIBILITIES}

The Department (and/or its authorized agent) will be responsible for performing remedial work to correct the defects that are caused because of the factors that are beyond the control and without the fault or negligence of the Contractor (as expanded in Section 16.8).

The Department (and/or its authorized agent) will be responsible for the incident management and winter weather maintenance activities. These activities can be listed as 39 .

The Department (and/or its authorized agent) will be responsible for performing emergency remedial work immediately if the Contractor is unable or refuses to perform such emergency remedial work (as expanded in Section 16.5).

\footnotetext{
${ }^{37}$ Insert: the name of the asset item for which the warranty clause is developed

${ }^{38}$ Insert: the name of the asset item for which the warranty clause is developed

${ }^{39}$ Insert: the complete list of the incident management and winter weather maintenance activities that are applicable to the asset item for which the warranty clause is developed.
} 
The Department (and/or its authorized agent) will be responsible for monitoring the interstate highway system (that is maintained by the Contractor during the Contract Term) during the warranty period.

The Department will be responsible for submitting to the Contractor the comprehensive report containing the results of the warranty compliance evaluations in a timely fashion (as expanded in Section 16.4).

The Department will be responsible for notifying the Contractor in a timely fashion as expanded in Section 16.4) of any remedial or emergency remedial work required to be performed by the Contractor. 


\section{Evaluation Questions for the Requested Feedback}

\section{A. General Questions}

1. Could you evaluate the warranty clause template for completeness? Is it missing any component that should be present in a warranty clause developed specifically for highway maintenance projects?

2. Could you comment on the language used in the clause? Is it valid as far as the US legal system is concerned? Would that language be acceptable as far as any US Court's point of view is concerned?

3. Could you evaluate the clause as far as the risk allocation is concerned?

4. Do you think that the idea of developing different warranty clause for each asset item is ideal given the conditions of the performance based highway maintenance contract?

\section{B. Specific Questions}

1. Is the definition of defect and warranty criterion established for each asset item reasonable?

2. Could you evaluate the applicability of each alternative (Alternative 1, Alternative 2, and Alternative 3) that is developed for establishing the length of the warranty period? Which alternative would you suggest to be more viable?

3. Would you suggest any approach to VDOT in determining the value of "A" (as shown in Figure 1) and the value of "W" (as shown in Figure 2)?

4. How should VDOT proceed in defining the emergency situations that need emergency remedial actions for each asset item (Section 16.5, footnote 30)?

5. How should VDOT proceed in establishing the required time for the contractor to complete the required remedial and emergency remedial actions (Section 16.5, footnote $\mathbf{2 8}$ and footnote $\mathbf{3 1}$ )?

6. How should VDOT proceed in establishing the time frames for the Conflict Resolution Procedures (Section 16.6, footnote 32 and footnote 33)?

7. How should VDOT proceed in calculating the most expensive reasonable remedy in order to establish the bond amount (Section 16.2, footnote 8)?

8. Should the contractor be given the option of implementing certain (and minimal) maintenance activities during the warranty period (Section 16.9)? 


\section{VITA}

\section{MEHMET EGEMEN OZBEK}

Mehmet Egemen Ozbek was born on September 26, 1980 in Ankara, Turkey, as the younger child of Tulay and Ahmet Ozbek. He received his B.S. degree in Civil Engineering after completing his studies in Middle East Technical University (METU), Turkey, in February 2002. In August 2002, he joined the Vecellio Construction Engineering and Management Program (VCEMP) in Virginia Polytechnic Institute and State University to pursue a M.S. degree in Civil Engineering. During his studies, he has been the research assistant for a project directed by Dr. Jesus M. de la Garza. He received the degree of Master of Science in Civil Engineering in May 2004. He is planning to continue his studies in the $\mathrm{PhD}$ program within the Vecellio Construction Engineering and Management Program (VCEMP) in Virginia Polytechnic Institute and State University.

His e-mail addresses: meozbek@vt.edu, egemenozbek@yahoo.com 